The Care Sport Connector in the Netherlands 

The Care Sport Connector in the Netherlands 


\section{Thesis committee}

\section{Promotor}

Prof. Dr M.A. Koelen

Professor of Health and Society

Wageningen University \& Research

\section{Co-promotors}

Dr M.A.E. Wagemakers

Associate professor, Health and Society

Wageningen University \& Research

Dr G.R.M. Molleman

Research Manager of the Academic Collaborative Centre AMPHI

Radboud University Medical Centre, Nijmegen

\section{Other members}

Prof. Dr E.J.M. Feskens, Wageningen University \& Research

Dr J. Harting, Amsterdam Medical Centre / University of Amsterdam

Dr M.T.W. Leurs, Ministry of Health, Welfare and Sport, The Hague

Dr ir. H.J.J. van der Poel, Mulier Institute, Utrecht

This research was conducted under the auspices of the Wageningen School of Social Sciences (WASS). 


\title{
The Care Sport Connector in the
}

\author{
Netherlands
}

\author{
Karlijn Leenaars
}

\section{Thesis}

submitted in fulfilment of the requirements for the degree of doctor at Wageningen University

by the authority of the Rector Magnificus,

Prof. Dr A.P.J. Mol,

in the presence of the

Thesis Committee appointed by the Academic Board

to be defended in public

on Friday 22 September 2017

at 11 a.m. in the Aula. 
Karlijn Leenaars

The Care Sport Connector in the Netherlands, 266 pages.

PhD thesis, Wageningen University, Wageningen, the Netherlands (2017) With references, with summaries in English and Dutch

ISBN: 978-94-6343-610-6

DOI: $10.18174 / 417923$ 


\section{Table of Contents}

$\begin{array}{lll}\text { Chapter Page } & \text { Pag } & \end{array}$

1. General introduction $\quad 7$

2. Connecting Primary Care, Sport, and Physical Activity: A longitudinal multiple case study design to evaluate the role of Care Sport Connectors in connecting primary care, sport, and physical activity, and residents' participation

3. Facilitators and barriers in the collaboration between the primary care and the sport sector in order to promote physical activity: A systematic literature review

4. The role of the Care Sport Connector in the Netherlands

6. The connection between the primary care and the physical activity sector: professionals' perceptions

7. The operational context of care sport connectors in the Netherlands

8. Exploring the impact of the Care Sport Connector in the Netherlands

9. General discussion

Summary

Samenvatting

Dankwoord

About the author 


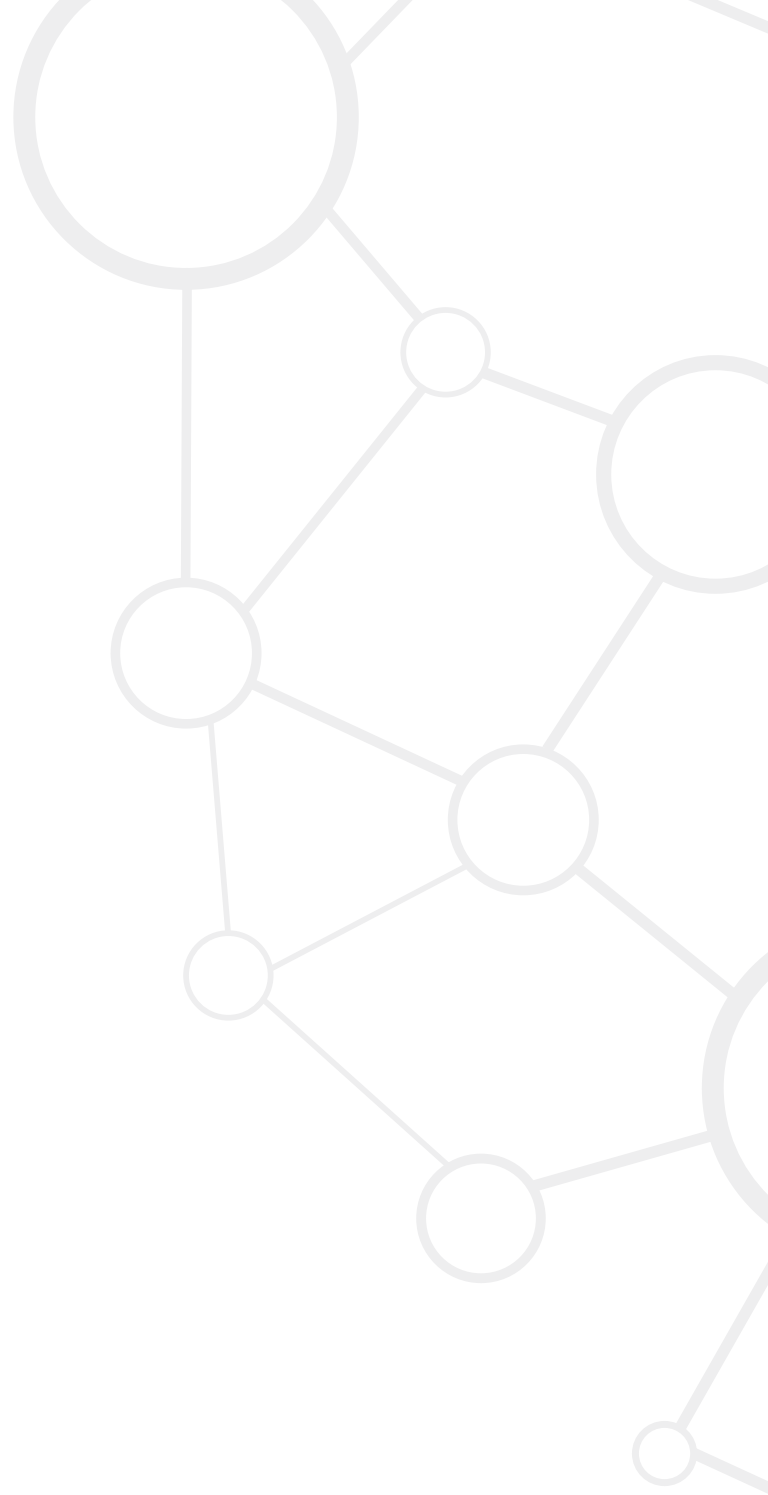




\title{
Chapter 1
}

\author{
General introduction
}




\section{Background}

In the Netherlands, $25 \%$ of the population are diagnosed with a chronic disease, like respiratory diseases, musculoskeletal disorders, cardiovascular disease, and diabetes [1]. The expectation is that this number will increase in the next 20 years because of the growth and ageing of the Dutch population [1-2]. The increase in chronic diseases is alarming given that chronic diseases are highly preventable [3]. A significant reduction in the percentage of the population contracting one or more chronic diseases is possible by tackling and preventing physical inactivity, which is the fourth leading independent risk factor for death caused by non-communicable chronic diseases [4]. Different reviews have shown the importance of engaging in regular physical activity (PA) to reduce the incidence of chronic diseases, like cardiovascular diseases, diabetes, and osteoporosis, and to attenuate or reverse the disease process in patients with these chronic diseases [5]. Regular PA thus contributes to the primary and secondary prevention of several chronic diseases, and therefore the promotion of PA among primary care patients seems to be an important health promotion strategy. In the last few years, the promotion of PA among primary care patients has been one of the core strategies of Dutch policy. In the Netherlands, about $40 \%$ of Dutch adults and $50 \%$ of people with a chronic disease do not meet the Dutch recommendation about being moderately physically active for 30 minutes at least five days per week [6]. To stimulate PA, in 2012 the Dutch Ministry of Health, Welfare, and Sport introduced Neighbourhood Sport Coaches (NSCs) (in Dutch Buurtsportcoach), ascribing to them a broker role [7]. These coaches are $40 \%$ funded by the state and $60 \%$ funded by the municipality or other local organisations. Some of these coaches, so-called Care Sport Connectors (CSCs), are employed specifically to connect the primary care sector (all care that is directly accessible to the patient, i.e. GP, physiotherapist, dietician) and the PA sector (covers all PA services in the neighbourhood, i.e. sports clubs, fitness centres, PA lessons at community centres, and walking groups) in order to guide primary care patients towards local PA facilities. This latest strategy is the topic of this thesis.

This chapter first addresses the topic of PA promotion and introduces a brief overview of the policy developments and strategies employed to address physical inactivity among the population in the Netherlands. The strategy concerning CSCs is highlighted. Secondly, the problem description, main objectives, and research questions are presented. The chapter ends with a general outline of this thesis.

\section{PA promotion}

Regular PA contributes to the primary and secondary prevention of several chronic diseases and is recognised as one of the main determinates of health because of its numerous benefits for the musculoskeletal, cardiovascular, metabolic, endocrine, psychological, and immune systems [8-9]. Therefore, over the past few years, interest in promoting PA has increased - more specifically as part of strategies to reduce risks for non-communicable diseases, including overweight and obesity [10].

In the promotion of PA, the importance of strategies targeting both individual and environmental factors is recognised [11-12]. This is particularly so because programmes that focus on the individual have had limited success in promoting long-term adherence to PA [13], and the motivation to be physically active can be hindered by environmental obstacles, like a lack of green spaces, transportation systems designed for cars as opposed to pedestrians or cyclists, lack of suitable PA activities, and sedentary jobs [12]. Creating a more 
supportive environment for activity holds promise for improving population-wide PA and enables the long-term success of programmes targeting individuals [12]. Therefore, a social ecological model - which emphasises the environmental and policy context of behaviour while incorporating social and physiological influences - is necessary for the promotion of PA [13-15]. Box 1.1 provides more information on this social ecological model for health promotion.

Box 1.1 Social ecological model for health promotion

An ecological perspective pays direct attention to both behaviour and its individual and environmental determinants [15]. McLeroy et al. [15] developed an ecological model for health promotion. In this model, behaviour is viewed as being determined by the following:

- Intrapersonal factors: characteristics of the individual

- Interpersonal processes and primary groups: formal and informal social networks and social support systems

- Institutional factors: social institutions with organisational characteristics, and formal rules and regulations for operations

- Community factors: relationships among organisations, institutions, and informal networks

- $\quad$ Public policy: local, state, and national laws and policies.

The importance of an ecological model for health promotion is that it divides the social environment into analytic levels that can be used to focus attention on different levels and types of social influences in order to develop more comprehensive and appropriate interventions [15-16]. Ecological models of PA often include variables at the following levels of influence: intrapersonal (biological, psychological), interpersonal/cultural, organisational, and policy [14].

To create a supportive environment for PA, collaboration and interaction are required among policymakers from several different sectors, like landscape, health, and sports, each tackling the PA goal for different reasons but with the same agenda to make the population or population subgroup more active [11]. As Kickbusch [17-18] argues, policies that address different determinants are considered the most promising. Therefore, policy integration which involves the interrelation of the content (e.g. policy goals, policy instruments) of policies from several sectors [19] seems to be necessary for the promotion of PA [11, 20]especially because an integrated PA policy gives support, coherence, and visibility at the political level, and it makes it possible for relevant stakeholders to assign roles and responsibilities [21]. There are different degrees of policy integration. Box 1.2 provides an overview of these different degrees. 
Box 1.2 Different degrees of policy integration

Kickbush's [18] typology of policy integration distinguishes three intellectual policy waves, ranging from a one-directional, health-centred approach, involving policy integration in the implementation stage (IA), to a multi-directional model that involves policy integration in decision making and development processes (HiAP) [22].

- Intersectoral action (IA): efforts by the health sector to work collaboratively with other sectors of society to achieve improved health outcomes

- Healthy public policy: is characterised by an explicit concern for health and equity in all areas of policy and by accountability for health impact

- Health in all policies (HiAP): a horizontal, complementary policy-related strategy with a high potential for contributing to population health. The core of HiAP is to examine health determinants that can be influenced to improve health but are mainly controlled by policies of sectors other than health.

\section{PA promotion in the Netherlands}

In the 1970s, the Dutch government recognised a need to adopt a PA policy, which is still in place today. In this policy, the promotion of PA among the population and utilising PA to address health, upbringing, and welfare problems have always been a concern. However, over the years, a shift in vision can be identified. From the 1970s to the 1990s, PA was mostly seen as a social right of the population, whereas from the 1990s onwards the promotion of PA has been seen as a necessary precondition to exploit the positive effects of sports, like health improvement and social integration [23]. This section reflects on the developments in Dutch PA promotion policy.

After the Dutch government acknowledged that it had a role in the field of sport, its policy in the 1970s focused on the promotion of PA among the population with the aim of ensuring that everyone could participate in sport. The government had the task of eliminating existing barriers. Policy was therefore focused on the improvement of the quality of the PA sector and on the alignment and organisation of the policy around that sector [23]. In the 1980s, PA participation was a less urgent concern, and policy was focused mostly on improving the quality of the PA sector and tackling problems like the lack of volunteers and the lack of support for top sport [23].

In the 1990s, exploiting the positive effects of PA for society became the focus of policy. To utilise the opportunities provided by PA, stakeholders and other policy fields needed to recognise the opportunities that sport had to offer - like PA as a scientific field; the use of PA for the improvement of health, wellbeing, and employment; and the exploitation of the benefits of top sport for the economic sector - and support them [24]. Therefore, the coordination and alignment of the PA sector was the focus of the first integral PA policy in 1996. In the late 1990s, the number of physically inactive people, people who were overweight, obese, or had a chronic disease, and an increase in healthcare costs became an issue [23], and therefore exploiting the positive effects of PA on the improvement of health and PA participation currently hold a central role in Dutch PA policy [25-29].

Although from the late 1990s to date Dutch PA policy has focused on the promotion of PA as a way to exploit the positive effects of PA, over time differences can be distinguished in the focus and target groups of the PA promotion policy, as reflected in the PA promotion programmes implemented between 1999 and now (Table 1.1). The first three programmes implemented - Breedtesport Impuls, Buurt, Onderwijs, Sport impuls, and Programma 
Meedoen - focused mostly on strengthening the sports sector and stimulating PA among youth. These programmes were intended to enlarge the sports offering in neighbourhoods and strengthen sports clubs. The programmes implemented thereafter - Impuls Brede scholen, Sport en Cultuur, Impuls Nationaal Actie Plan Sport en Bewegen, Beweegkuur, and Sport en Bewegen in de Buurt - focused more on the promotion of PA and on intersectoral collaboration, whereby collaboration was sought with other sectors like health and education. In addition, some programmes were intended specifically for PA promotion among specific groups who could benefit from PA. For example, the Beweegkuur programme was intended to stimulate PA among primary care patients, aiming to improve the health of this target group. As part of the programme, networks among primary care, welfare, and PA professionals were organised to implement it. However, for economic reasons the programme was discontinued [30].

A reason for the shift in focus in PA promotion programmes is that the Dutch government wanted to exploit the benefits of PA for society as a whole [26]. Therefore, in 2005 a second integral PA policy was implemented, focusing on three issues: participation, exercise, and performing [26]. The first two topics focused on the use of PA as a means to stimulate the participation of residents in community activities and to promote the health of the population by tackling physical inactivity. The third topic focused on exploiting the potential that top sport has to offer. To date, policy is still based on these three issues. Although PA was always mentioned in Dutch public health policy, from 2005 onwards, PA promotion has been mentioned as a priority of this public health policy. Nowadays, PA promotion programmes are included in public health policy as a strategy to stimulate residents' health [28-29].

These developments are also visible in the latest programme Sport en bewegen in de buurt, which is part of both Dutch PA policy and public health policy, in which PA promotion and intersectoral collaboration are the main pillars. This programme intends to create a sporty society in which the whole population has the opportunity to opt for an active and healthy lifestyle [7]. Removing barriers that hinder people from becoming physically active and collaboration between different sectors are the principles of the programme. Whereas the predecessor of this programme, Impuls Brede scholen, Sport en Cultuur, focused only on youth and sought collaboration with education, the Sport en Bewegen in de Buurt programme focuses on the whole population, and collaboration is sought with education, welfare, healthcare, business, and child care [7]. 
Table 1.1 PA programmes implemented in the Netherlands from 1999

\begin{tabular}{|c|c|c|}
\hline Programme & Year & Aim and target group \\
\hline $\begin{array}{l}\text { Breedtesportimpuls (BSI) } \\
\text { Grassrootsport Impulse }\end{array}$ & $\begin{array}{l}1999- \\
2009\end{array}$ & $\begin{array}{l}\text { Supporting municipalities to develop and implement (if possible with } \\
\text { other sectors) activities to strengthen recreational sports in } \\
\text { municipalities }\end{array}$ \\
\hline $\begin{array}{l}\text { Buurt, Onderwijs, Sport } \\
\text { impuls (BSO) } \\
\text { Community, Education, Sports } \\
\text { Impulse }\end{array}$ & $\begin{array}{l}2005- \\
2011\end{array}$ & $\begin{array}{l}\text { Supporting municipalities in their approach to address inequalities in } \\
\text { youth ( } 4-19 \text { year) of health, wellness, education, upbringing, sports, } \\
\text { and nuisance }\end{array}$ \\
\hline $\begin{array}{l}\text { Programma Meedoen } \\
\text { Programme Participation }\end{array}$ & $\begin{array}{l}2006- \\
2010\end{array}$ & $\begin{array}{l}\text { Nine sports federations, } 11 \text { municipalities, and their sports clubs } \\
\text { worked together to stimulate sport and PA among youngsters in } \\
\text { disadvantaged neighbourhoods }\end{array}$ \\
\hline $\begin{array}{l}\text { Impuls Brede scholen, Sport } \\
\text { en Cultuur } \\
\text { Impulse Community Schools, } \\
\text { Sports, and Culture }\end{array}$ & $\begin{array}{l}2008- \\
2012\end{array}$ & $\begin{array}{l}\text { Funding for municipalities to appoint new sports employees (in Dutch } \\
\text { Combinatiefunctionaris) who are employed to enlarge the sports } \\
\text { offering at schools, to strengthen sports clubs, to stimulate the daily } \\
\text { sports offering at and around schools, and to stimulate youth to } \\
\text { become familiar with the practice of art }\end{array}$ \\
\hline $\begin{array}{l}\text { Impuls National Actie Plan } \\
\text { Sport en Bewegen } \\
\text { National Action Plan Sport } \\
\text { and Exercise }\end{array}$ & $\begin{array}{l}2008- \\
2012\end{array}$ & $\begin{array}{l}\text { Providing funding for the development of new effective programmes } \\
\text { to stimulate PA and consequently decrease the number of inactive and } \\
\text { overweight people, and to prevent the development of chronic } \\
\text { diseases }\end{array}$ \\
\hline $\begin{array}{l}\text { Beweegkuur } \\
\text { Exercise Therapy }\end{array}$ & $\begin{array}{l}2009- \\
2012\end{array}$ & $\begin{array}{l}\text { A lifestyle intervention tailored to the individual needs of patients, } \\
\text { focusing on a change in physical activity behaviour and dietary } \\
\text { behaviour to support the prevention and treatment of type } 2 \text { diabetes } \\
\text { mellitus; this intervention was implemented in the primary care } \\
\text { setting }\end{array}$ \\
\hline \multirow[t]{2}{*}{$\begin{array}{l}\text { Sport en Bewegen in de } \\
\text { Buurt } \\
\text { Sport and exercise in the } \\
\text { neighbourhood }\end{array}$} & $\begin{array}{l}\text { 2012- } \\
\text { to } \\
\text { date }\end{array}$ & $\begin{array}{l}\text { Availability of suitable and safe sport and PA activities for every citizen } \\
\text { in the neighbourhood. The programme consists of two measures: } \\
\text { - Neighbourhood Sport Coaches (NSC): funding for municipalities to } \\
\text { employ NSCs, who are employed to organise new PA activities, } \\
\text { strengthen sports clubs, and connect the PA sector with other } \\
\text { sectors like education, welfare, childcare, healthcare, and } \\
\text { business }\end{array}$ \\
\hline & & $\begin{array}{l}\text { CSC: specifically employed to connect the primary care } \\
\text { and the PA sector to guide primary care patients towards } \\
\text { local PA facilities } \\
\text { - Sport Impuls: funding for sports clubs to enlarge the sport and PA } \\
\text { offering in the neighbourhood }\end{array}$ \\
\hline
\end{tabular}




\section{Organisations involved in Dutch PA promotion policy}

In the Netherlands, several national organisations are involved in Dutch PA promotion policy. The largest national organisations are NOC*NSF, Knowledge Centre Sport (in Dutch Kenniscentrum Sport), Association for Sport and Municipalities (in Dutch Vereniging Sport en Gemeenten (VSG)), and the Dutch organisation for health research and health care innovation (ZonMw). These organisations develop and implement activities to promote PA or have a supporting and executive role in the implementation of the government's national PA policy. In addition, ZonMw facilitates research in the field of PA promotion. Below, we briefly describe these organisations.

\section{NOC*NSF}

NOC*NSF emerged in 1993 from a merger between the Dutch Olympic Committee (NOC) and the Dutch Sports Federation (NSF). The ambition of NOC*NSF is to increase PA participation in the Netherlands to $75 \%$ [31]. NOC*NSF supports national sports federations and stimulates collaboration between them to create the best possible sports conditions so that everyone can participate in sport. In addition, NOC*NSF is responsible for the Dutch Olympic and Paralympic team [31]. An example of a PA promotion programme implemented by NOC*NSF is the National Sports Week, which aims to stimulate the population to engage in PA in sports clubs.

\section{Knowledge Centre Sport}

Knowledge Centre Sport emerged in 2016 from a merger between the Dutch Institute for Sport and Exercise (in Dutch Nederlands Instituut voor Sport en Bewegen (NISB)) and Unlimited Sports (in Dutch Onbeperkt Sportief). Knowledge Centre Sport is tasked by the Dutch Ministry of Health, Welfare, and Sport to support the implementation of practical and scientific knowledge in the field of sport and exercise [32]. This is a change in focus. NISB, commissioned in 1999 by the Dutch Ministry of Health, Welfare, and Sport, was in fact responsible for the organisation of activities aimed at grassroots sports and for supporting municipalities and sports organisations with their grassroots sports policy [33]. In that period, NISB coordinated and supported the implementation of PA promotion programmes as part of Dutch PA policy - for example, Nationaal Actieplan Sport en Bewegen and the Beweegkuur programme.

\section{Association for Sport and Municipalities (VSG)}

VSG, founded in 1949, was originally called National Contact Board (In Dutch De landelijke Contactraad). Its mission is to support municipalities with the development and implementation of their PA policy and to support municipalities with their issues concerning sports accommodation [34]. VSG fulfils a role as intermediary for municipalities with the national government and sports federations. It fulfils this role by, for example, organising network meetings and conferences for policymakers.

\section{ZonMw}

The Netherlands has no significant tradition of research in the field of sport and physical education. In the 1990s, for the first time, long-term research programmes were conducted [35]. In the period 2004-2014, the Sport, health, and exercise research programme was executed by ZonMw, commissioned by the Dutch Ministry of Health, Welfare, and Sports. This programme was intended to strengthen the sport research infrastructure, to generate 
knowledge about positive and negative aspects of sport and exercise, and to stimulate the embedding of this knowledge [36]. Currently, the research programme Sport is being carried out by ZonMw, commissioned by the Dutch Ministry of Health, Welfare, and Sport. This programme aims to strengthen scientific research in the field of sport and build sustainable knowledge for policy and practice. Research is focused on the three issues, participation, exercise, and performing, as part of current Dutch PA policy [36].

\section{Current policy}

With regard to the current policy programme Sport en Bewegen in the Buurt, NOC*NSF, Knowledge Centre Sport, and Association for Sport and Municipalities have been assigned a role in its implementation. Their role is to support municipalities, sports clubs, PA professionals, and NSCs with the implementation of the programme. They organise meetings for relevant programme stakeholders in order to stimulate knowledge transfer, they implement an education programme for NSCs, and they support the implementation of scientific knowledge in practice. ZonMw facilitates with their current research programme Sport research in the field of PA promotion. The study described in this thesis is funded by this research programme.

\section{The Care Sport Connector}

Current PA policy in the Netherlands is aimed at connecting the PA sector with other sectors to promote PA among the population. As part of the latest PA promotion programme, Sport en Bewegen in de Buurt, NSCs were introduced to connect the PA sector with other sectors. This function is $40 \%$ funded by the government, with the remaining $60 \%$ funded by the municipality or other local organisations. Some of these coaches, so-called Care Sport Connectors (CSCs) and the topic of this thesis, are employed specifically to connect the primary care sector and the PA sector with the aim of guiding primary care patients towards local sports facilities. The defined outcome of CSCs is an increased number of primary care patients participating in local PA facilities and being physically active in their neighbourhood. The general idea is that CSCs facilitate the connection between the primary care and the PA sector; professionals in these sectors collaborate; these professionals implement lifestyle interventions; the lifestyle interventions reach certain target groups; these target groups become self-managing regarding their PA; target groups become more physically active in their neighbourhood; and health outcomes improve. The CSC concept fits well with a social ecological approach because, through CSCs, different determinants on different levels intrapersonal, community, institutional, and policy - can be targeted to stimulate PA among the target group.

\section{Intersectoral collaboration and the broker role}

The aim of the CSC is to stimulate intersectoral collaboration between the primary care and the PA sector. Intersectoral collaboration is defined as people and organisations from multiple sectors working together for a common purpose [37]. Intersectoral collaboration between the healthcare sector and other societal sectors is expected to have the potential to bring about changes in at least two directions. Firstly, it should lead to the improvement of health determinants and thereby improve the health of individuals and populations. Secondly, it is expected to increase awareness of the health implications of policy decisions and organisational practice within and among these different sectors [38]. Although 
intersectoral collaboration seems promising it is also challenging, because it means working in a new area or setting, with new people with different backgrounds, interests, and perspectives [39-40].

A broker role seems to offer the promise of improving intersectoral collaboration [41-42]. Brokers facilitate the flow of information between stakeholders who are hindered from communicating by some gap or barrier [42]. The broker role finds its origin in Burt's structural holes theory [43]. According to Burt [43], brokers are said to reach across a structural hole. A structural hole manifests itself between two actors that are not connected [43]. Brokers provide benefits for a network based on the idea that unconnected actors are sources of unique information that can be used by the broker to facilitate access to information and resources, facilitate knowledge transfer, and coordinate effort across the network (Burt, 1992). Brokers are expected to connect useful ideas, generate innovative ideas, and increase understanding and co-operation between different sectors [41-42]. A review by Long et al. [42] showed that the broker role is studied in a wide range of settings and contexts, from the hospital setting to engineering projects, but not yet in the primary care and the PA sector. Also, it appeared that most studies evaluated actors' positions within their network, measured with parameters like betweenness centrality (i.e. calculated by considering the extent to which an individual's position in the network lies between the positions of other individuals), network density (i.e. overall level of connectedness among organisations in the network), and the opportunities and constraints for brokerage behaviour that those positions gave in terms of team performance, innovation, and knowledge integration [42]. So, most studies concerning brokers focus on a broker's position and its impact on a network performance measured by quantitative outcomes. However, as brokers may play a significant role in establishing intersectoral collaboration, it is also important to explore the work, significance, and challenges of brokers in various settings [44-45] - for example, the primary care and the PA setting. The CSC case enables us to explore the broker role in connecting the primary care and the PA sector in order to stimulate PA.

\section{Importance of an evaluation of CSCs' impact}

It is necessary to have an insight into CSCs' role as a broker in connecting the primary care and the PA sector for several reasons. Firstly, the CSC function is new and unique, and therefore the latest Dutch policy and its accountability need to be evaluated. Secondly, intersectoral collaboration between the primary care and the PA sector is challenging, hence an insight into CSCs' role and impact seem to be relevant to further improve this connection. Thirdly, because the role and impact of a broker in establishing intersectoral collaboration in the field of primary care and the PA setting is not often studied, a deeper insight can help us to advance health promotion theory and practice. This is further explained below.

In relation to the first point, the strategy of establishing a broker role to connect both sectors and guide primary care patients towards PA facilities is new and unique in the Netherlands. In 2013, 90\% of Dutch municipalities had appointed NSCs. However, the NSCs' job description, required competences, and impact, and how they could be embedded in their context, were not clear. At that time, a blueprint for NSC funding was deliberately not presented, allowing municipalities to deploy NSCs in line with local needs and contexts. It is therefore accepted that NSCs and CSCs will operate differently because of their different backgrounds and contexts. Scientific research is needed to explore CSCs' role and their 
impact to study whether an initiative like the CSC is a suitable policy strategy to promote PA and overcome the challenges surrounding the connection between the primary care and the PA sector. In addition, an insight into conditions that facilitate or hinder CSCs in their work to connect both sectors is useful to further improve policy concerning CSC funding and the connection between both sectors.

In relation to the second point, previous studies on collaboration between the primary care and the PA sector, and on initiatives for PA promotion in primary care settings, showed that connecting the primary care and the PA sector is challenging for various reasons. A first reason is that the differences between both sectors, such as culture (professional organisation versus voluntary organisation) and different shared interests (programme interest versus increasing member numbers) can hinder collaboration between the primary care and the PA sector [46-47]. A second reason is that factors related to the primary care and the PA sector can hinder the referral of primary care patients towards local PA facilities. Health professionals consider their lack of time, their formal education, competing priorities, and their perception of patients' lack of motivation to be physically active as factors that negatively influence PA promotion [48-50]. In addition, the lack of suitable PA activities for the target group is seen as a factor relating to the PA sector that could hinder the referral of primary care patients [51]. An insight into impacts mediated by a broker role on improving collaboration between both sectors and into processes that contribute to the connection between both sectors seems relevant to further improve the connection between the primary care and the PA sector.

And, finally, in relation to the third point, as far as can be ascertained, to date there have been no in-depth studies about a broker role that reveal the specific competencies that go with the role, the impact of the role on connecting the primary care and the PA sector, and the impact on residents' health. Therefore, scientific research to explore CSCs' role, their impact, conditions that facilitate or hinder CSCs, and processes that contribute to the connection between both sectors helps us to formulate lessons that can be learned to advance health promotion theory and practice.

\section{Aim of the thesis}

CSCs are employed to connect the primary care and the PA sector in order to stimulate PA among primary care patients. This function is new in the Netherlands and seems a promising way to stimulate intersectoral collaboration between both sectors. The CSC case enables us to explore the role and impact of a broker in stimulating intersectoral collaboration, and therefore four research questions are formulated:

1. What processes contribute to the connection between the primary care and the PA sector?

2. What conditions at national and local level facilitate or hinder CSCs in connecting the primary care and the PA sector?

3. What impacts are mediated by CSCs, and what are the perceived societal benefits for the municipality, neighbourhood, and local residents?

4. What lessons can be learned to advance health promotion theory and practice?

This thesis employed a multiple case study design in which 15 CSCs from nine municipalities spread over the Netherlands were followed in their work from 2014 to the end of 2016. In 
line with a multiple case-study design [52] in which different data collection methods were used (literature review, interview, focus group, document analysis, and questionnaires), perspectives of different stakeholders (policymakers, professionals, CSCs) in the connection between both sectors on different levels (policy, and community) were taken into account. Including different perspectives and using a mixed-methods approach enabled us to provide a comprehensive insight into the connection established by CSCs. In addition, cross-case synthesis helped us to draw general conclusions concerning the connection between the primary care and the PA sector when different cases share some similarities [52].

As CSCs have the task of connecting the primary care and the PA sector and stimulating PA among the target group, another study - not part of this thesis - is being carried out as well, with the aim of exploring CSCs' impact on promoting PA among the target group. The focus is on the type of lifestyle programmes conducted by CSCs or professionals within the connection between the primary care and the PA sector, and possible changes in health and PA behaviour among the lifestyle programme participants. In addition, the study will reveal facilitators of, and barriers to, the implementation of appropriate lifestyle programmes.

\section{General outline of this thesis}

This thesis explores CSCs' role and their impact in connecting the primary care and the PA sector on the basis of the four research questions. Chapter 2 provides more detailed information on the design of, and the methods used in, this study. Chapters 3 to 6 provide an insight into the processes that contribute to the connection between the primary care and the PA sector (Q1). To study these processes, different kinds of studies were conducted. Chapter $\mathbf{3}$ presents the results of a systematic literature review on collaborative initiatives between the primary care and the PA sector to stimulate PA. In addition, facilitators and barriers in these collaborative initiatives were identified. In Chapter 4, the CSC role as perceived by CSCs themselves is outlined. The way CSCs establish a connection between the primary care and the PA sector and perceived barriers to, and facilitators of, this connection are also discussed. Chapter $\mathbf{5}$ discusses the CSC role as a broker as it develops over time. Professionals' perceptions of the CSC role and the connection between the primary care and the PA sector are addressed in Chapter 6. To study the conditions at national and local level that facilitate or hinder CSCs in connecting the primary care and the PA sector (Q2), the operational context was studied. For this study, a theoretical framework was developed, based on a literature search, interviews with experts, and a workshop. The CSCs' operational context is discussed in Chapter 7. Finally, in Chapter 8, CSCs' impact on connecting the primary care and the PA sector and the perceived societal benefits for the municipality, neighbourhood, and local residents are presented (Q3). The studies discussed in Chapters 36 also contribute to an insight into conditions that facilitate or hinder CSCs in connecting the primary care and the PA sector (Q2) and into impacts mediated by CSCs and their benefits (Q3). In Chapter 9, we synthesise the results of the separate studies and formulate lessons for health promotion theory and practice (Q4). Figure 1.1 provides an overview of the research questions linked to the chapters of this thesis. 


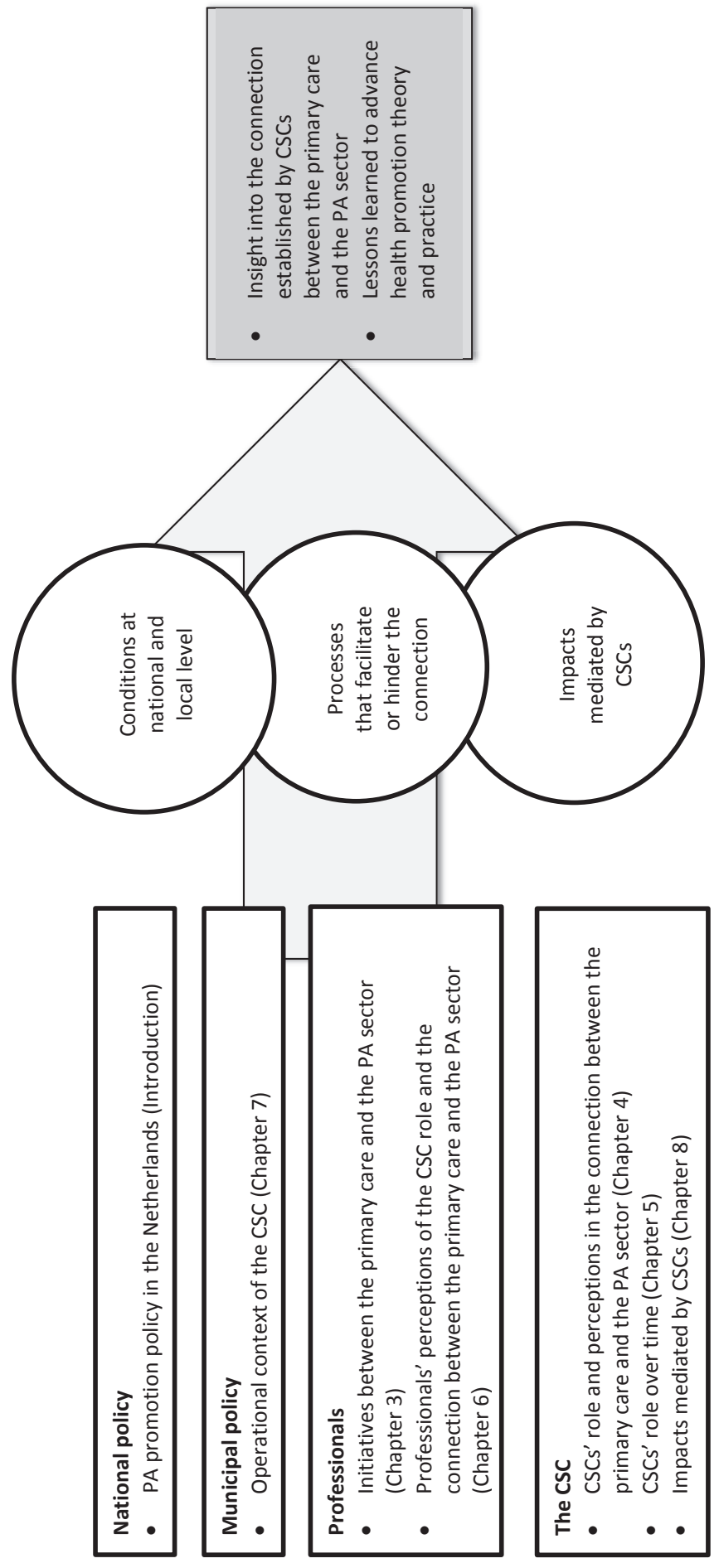

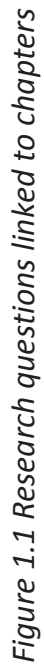




\section{References}

1. Heijmans, M, Spreeuwenberg P, Rijken M. Ontwikkeling in de zorg voor chronisch zieken. Utrecht: NIVEL; 2010.

2. Blokstra A, Verschuren WMM, Baan CA, Boshuizen HC, Feenstra TL, Hoogenveen RT, Picavet HSJ, Wijga AH. Vergrijzing en toekomstige ziektelast. Prognose chronische ziektenprevalentie 2005-2025. Bilthoven: RIVM; 2007.

3. Epping-Jordan JE, Galea G, Tukuitonga C, Beaglehole R. Preventing chronic diseases: taking stepwise action. Lancet 2005, 5:366(9497):1667-71

4. Matheson GO, Klugl M, Dvorak J, Engebretsen L, Meeuwisse WH, Schwellnus M et al. Responsibility of sport and exercise medicine in preventing and managing chronic disease: applying our knowledge and skill is overdue. British Journal of Sports Medicine 2011, 45:1272-1282

5. Warburton DE, Nicol CW, Bredin SS. Health benefits of physical activity: the evidence. Canada Medical Association Journal 2006,174, 801-809.

6. Hildebrandt VH, Chorus AMJ, Stubbe JH. Trend report on physical activity and health 2010/2011. Leiden: TNO; 2013.

7. Ministerie van Volksgezondheid, Welzijn en Sport. Programma Sport en Bewegen in de Buurt. Den Haag, Ministerie VWS; 2011.

8. Balady GJ, Berra KA, Golding LA, Gordon NF, Mahler DA, Myers JN et al. ACSM's Guidelines for Exercise Testing and Prescription. 6th ed. United States of America: Lippincott Williams \& Wilkins; 2000.

9. U.S. Department of Health and Human Services. Physical activity and Health: A Report of the Surgeon General. Atlanta: U.S. Department of Health and Human Services, Centers for Disease Control and Prevention, National Centre for Chronic Disease Prevention and Health Promotion; 1996.

10. Daugbjerg SB, Kahlmeier S, Racioppi F, Martin-Diener E,Martin B, Oja P, Bull F. Promotion of Physical Activity in the European Region: Content Analysis of 27 National Policy Documents Journal of Physical Activity and Health 2009, 6, 805-817

11. Woods CB, and Mutrie N. Putting Physical Activity on the Policy Agenda. Quest 2012, 64:2, 92-104.

12. King AC, and Sallis JF. Why and how to improve physical activity promotion: Lessons from behavioral science and related fields. Preventive Medicine 2009, 49, 286-288.

13. Mutrie N, and Woods CB. How can we get people to become more active? A problem waiting to be solved. 2003. In McKenna J, and Riddoch C. (Eds.) Perspectives on Health and Exercise (1st ed., pp. 129-152). Basingstoke, Uk: Palgrave Macmillan.

14. Sallis JF, Cervero RB, Ascher W, Henderson KA, Kraft MK, Kerr J. An ecological approach to creating active living communities. Annual Reviews Public Health 2006, 27:297-322. Doi: 0.1146/annurev.publhealth.27.021405.102100

15. McLeroy KR, Bibeau D, Steckler A, Glanz K. An Ecological Perspective on Health Promotion Programs. Health Education and Behaviour 1988. doi:10.1177/109019818801500401.

16. Sallis J, Owen N, and Fisher EB. Ecological models of health behavior. 2008. In Glanz, K, Rimer BK, and Viswanath K. Health Behavior and Health Education. Theory, Research and Practice (4th ed.), San Francisco, CA: Jossey-Bass.

17. Kickbusch I. Adelaide revisited: from healthy public policy to health in all policies. Health Promotion International 2008,23,1-4. 
18. Kickbusch I. Health in all policies: the evolution of horizontal health governance. In Kickbusch I., Buckett K. (eds), Implementing Health in all Policies. Adelaide 2010, 1st edition. Department of Health, Government of South Australia, Adelaide, Australia, pp. 11-24.

19. Shannon MA, and Schmidt CH. Theoretical approaches to understanding intersectoral policy integration, 2002. in: I. Tikkanen, P. Glu" ck \& H. Pajuoja (Eds) Cross-Sectoral Policy Impacts on Forests, EFI Proceedings No. 46 (Joensuu, European Forest Institute).

20. Bull F, Bellew B, Schoppe S, and Bauman A. Developments in national physical activity policy: An international review and recommendations towards better practice. Journal of Science and Medicine in Sport 2004, 7(1),S93-S104.

21. World Health Organization. Review of physical activity promotion policy development and legislation in European Union Member States (Rep. No. 10). Copenhagen: World Health Organization; 2010.

22. Peters DTJM. Policy networks across portfolio boundaries: An analysis of integrated public health policy in Dutch municipalities. Amsterdam: University of Amsterdam; 2016.

23. Breedveld $K$, van der Poel $H$, de Jong $M$, Collard D. Beleidsdoorlichting Sport, Hoofdrapport. 's Hertogenbosch: Mulier Instituut; 2011.

24. Ministerie van Volksgezondheid, Welzijn en Sport. Wat sport beweegt. Contouren en speerpunten voor het sportbeleid van de rijksoverheid. Rijswijk: Ministerie VWS; 1996.

25. Ministerie van Volksgezondheid, Welzijn en Sport. Sport, bewegen en gezondheid. DenHaag, Ministerie VWS; 2001.

26. Ministerie van Volksgezondheid, Welzijn en Sport. Tijd voor sport, bewegen, meedoen, presteren. Den Haag, Ministerie VWS; 2005.

27. Ministerie van Volksgezondheid, Welzijn en Sport. De kracht van sport. Den-Haag, Ministerie VWS; 2007.

28. Ministerie van Volksgezondheid, Welzijn en Sport. Kiezen voor gezond leven. Den-Haag, Ministerie VWS, 2007.

29. Ministerie van Volksgezondheid, Welzijn en Sport. Gezondheid dichtbij. Den-Haag, Ministerie VWS, 2011.

30. Ministerie van Volksgezondheid, Welzijn en Sport. Kamerbrief: stoppen-metrokenprogramma en beweegkuur. Den Haag, Ministerie VWS; 2011.

31. NOC*NSF. About us. Retrieved from: www.nocnsf.nl. Last accessed: 21-04-2017.

32. Kenniscentrum sport. About us. Retrieved from: www.kenniscentrumsport.nl. Last accessed: 21-04-2017.

33. Ministerie van Volksgezondheid, Welzijn en Sport. Kamerbrief sportbeleid, oprichting NISB. Den-Haag: Ministerie VWS;1999.

34. Vereniging Sport en Gemeenten. About us. Retrieved from: www.sportengemeenten.nl. Last accessed: 21-04-2017.

35. Breedveld K, Molleman G, Smits F, Reijgersberg N. Kennisagenda Sport 2011 - 2016. 's Hertogenbosch: Mulier Insituut. Den-Haag: Bureau Maat; 2010.

36. ZonMw. About us. Retrieved from. www.zonmw.nl. Last accessed: 21-04-2017.

37. Roussos ST, Fawcett SB: A review of collaborative partnerships as a strategy for improving community health. In: Annual Review of Public Health 2000:(12)369-402.

38. Green L, Daniel M, Novick L. Partnerships and coalitions for community-based research. Public health reports 2001, 116(SUPPL. 1):20-31.

39. Koelen MA, Vaandrager $L$, and Wagemakers A. The healthy alliances (HALL) framework: Prerequisites for success. Family Practice 2012, 29 (SUPPL.1), 132-138. 
40. Lasker RD, Weiss ES, Miller R: Partnership Synergy: A Practical Framework for Studying and Strengthening the Collaborative Advantage. The Milbank quarterly 2001, 79(2):179205.

41. Harting J, Kunst AE, Kwan A, and Stronks K. A 'health broker' role as a catalyst of change to promote health: An experiment in deprived Dutch neighbourhoods. Health Promotion International 2011, 26, 65-81.

42. Long JC, Cunningham FC, and Braithwaite J. Bridges, brokers and boundary spanners in collaborative networks: a systematic review. BMC Health Services Research 2013, 13(1).

43. Burt RS. Structural Holes: The Social Structure of Competition. Cambridge MA: Harvard University Press; 1992.

44. Williams P. The competent boundary spanner. Public administration 2002, 80(1), $103-$ 124.

45. Kousgaard MB, Kjær Joensen AS, and Thorsen T. The challenges of boundary spanners in supporting inter-organizational collaboration in primary care - a qualitative study of general practitioners in a new role. BMC Public Health 2015,16,17.

46. Casey M, Payne W, Brown S. and Eime R. Engaging community sport and recreation organisations in population health interventions: Factors affecting the formation, implementation, and institutionalisation of partnerships efforts. Annals of Leisure Research 2009,12,129-147.

47. Den Hartog F, Wagemakers A, Vaandrager L, van Dijk M, and Koelen MA. Alliances in the Dutch Beweegkuur lifestyle intervention. Health Education Journal 2014, 73, 576-587.

48. Huijg JM, van der Zouwe N, Crone MR, Verheijden MW, Middelkoop BJC, Gebhardt WA. Factors influencing the introduction of physical activity interventions in primary health care: a qualitative study. International Journal of Behavioral Medicine 2015, 22(3), 404414.

49. Hébert ET, Caughy MO, and Shuval K. Primary care providers' perceptions of physical activity counselling in a clinical setting: A systematic review. British Journal of Sports Medicine 2012, 46, 625-631.

50. Leemrijse C, de Bakker D, Ooms L, and Veenhof C. Collaboration of general practitioners and exercise providers in promotion of physical activity a written survey among general practitioners. BMC Family Practice 2015, 16(1), 96. doi:10.1186/s12875-015-0316-8

51. Ooms L, Veenhof C, Schipper-van Veldhoven N, et al. Sporting programs for inactive population groups: factors influencing implementation in the organized sports setting. BMC Sports Science Medicine and Rehabilitation 2015;7:12. doi:10.1186/s13102-0150007-8

52. Yin RK. Case Study Research. Design and Methods. 3rd ed. London: SAGE publications; 2003. 


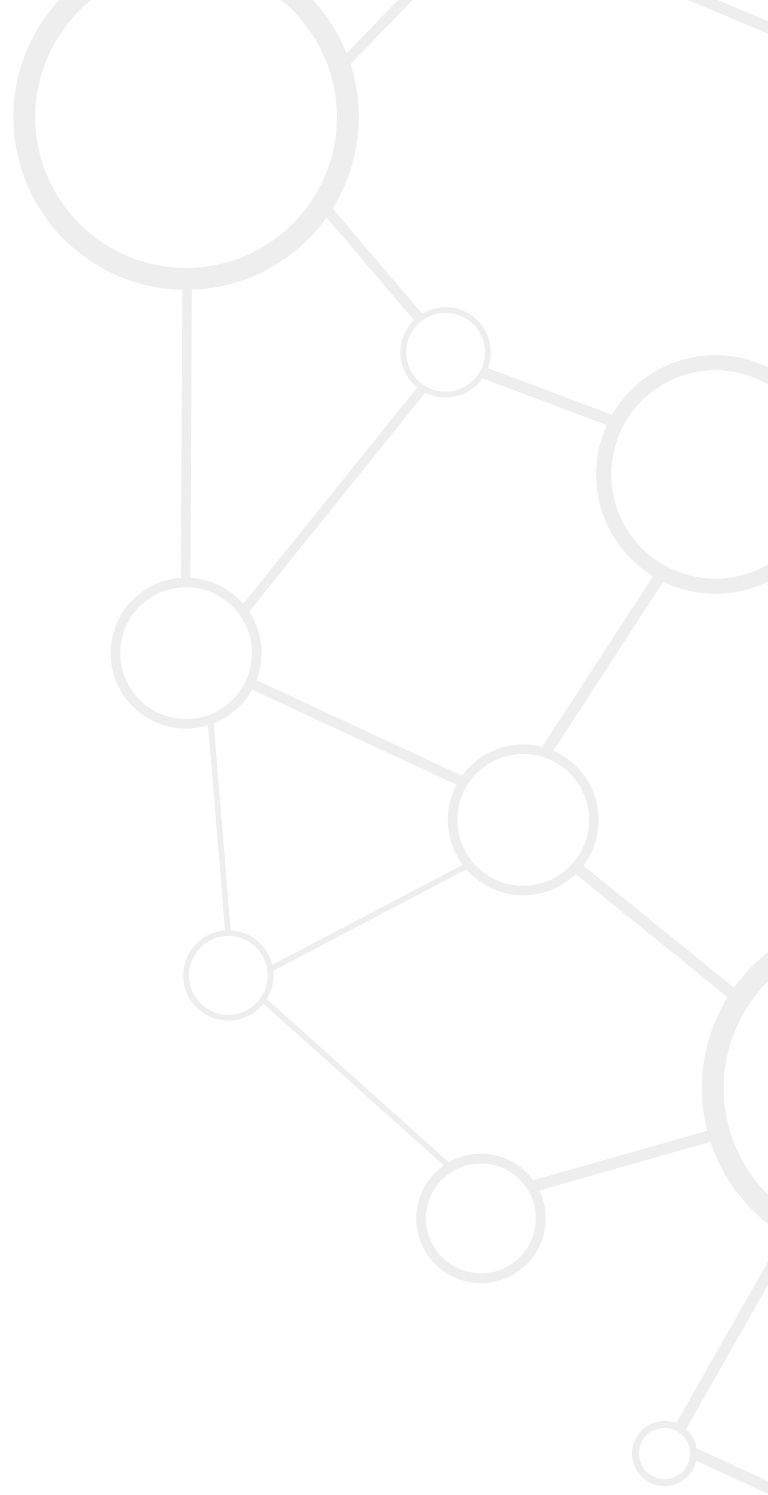




\section{Chapter 2}

Connecting Primary Care, Sport, and Physical Activity: A longitudinal multiple case study design to evaluate the role of Care Sport Connectors in connecting primary care, sport, and physical activity, and residents' participation.

\section{Published as:}

Smit E, Leenaars KEF, Wagemakers MAE, Molleman GRM, Koelen MA, van der Velden J. Evaluation of the role of Care Sport Connectors in connecting primary care, sport, and physical activity, and residents' participation in the Netherlands: study protocol for a longitudinal multiple case study design. BMC Public Health, 2015. 


\begin{abstract}
Background

The number of people with one or more chronic diseases is increasing, but this trend could be reduced by tackling and preventing physical inactivity. Therefore, in 2012, the Dutch Ministry of Health, Welfare, and Sport introduced Care Sport Connectors (CSCs), to whom a broker role has been ascribed. The defined outcome of CSCs role is an increased number of residents participating in local sports facilities and being physically active in their own neighbourhood. To realize this, primary healthcare and sports professionals need to collaborate, and local sports facilities and neighbourhoods need to offer accessible physical activities for people in the locality, including people with one or more chronic diseases or at increased risk of chronic disease(s). Adequate scientific research is needed to assess CSCs' impact on: 1) connecting primary care, sport, and physical activity and 2) increasing the number of residents who engage in physical activity to promote their health.
\end{abstract}

\title{
Methods and design
}

To study the role and the impact of CSCs, a longitudinal multiple case study will be conducted, in nine municipalities spread over the Netherlands, from 2014 until 2017. A mixed methodology will be used to perform action research and process evaluation. Study I focuses on the expected alliances for health and the preconditions that facilitate or hinder CSCs in the formation of these alliances. The study population will consist of intermediary target groups and a literature review, interviews, focus groups, and document analysis will be undertaken. Study II will concentrate on lifestyle program participants to identify health and physical activity behavior changes. For this purpose, interviews, literature studies, a Delphi study, fitness tests, and questionnaires will be used.

\section{Discussion}

Linking and integrating results gained by multiple methods, at different levels, will provide a validated assessment of CSCs' impact on connecting the healthcare and sports sectors. This will reveal changes in residents' physical activity behavior, and also the circumstances under which this will happen. The assessment in combination with general lessons learned from the different case studies will make it possible to determine whether CSCs are able to fulfill the policy aspiration and whether it would be beneficial to extend this function. 


\section{Background}

Physical activity is recognized as one of the main determinants of health because of its numerous benefits for the musculoskeletal, cardiovascular, metabolic, endocrine, psychological and immune systems [1, 2]. In the Netherlands, $32 \%$ of the total population is diagnosed with one or more chronic diseases, and this figure is expected to increase to $40 \%$ by 2030 [3]. Only slightly more than $50 \%$ of this group is meeting the Dutch Healthy Physical Activity Guideline [4]: 30 minutes of moderate physical activity at least five days a week. A significant reduction in the percentage of the population contracting one or more chronic diseases is possible by tackling and preventing physical inactivity, which is the fourth leading independent risk factor for death caused by non-communicable chronic disease [5]. Increasing physical activity is a challenge because of different and interrelated determinants that contribute to lifestyle behaviors at multiple levels such as the individual, the social, the environmental, and the policy level [6]. Therefore, an ecological approach is most appropriate to address physical activity behavior [7]. In order to develop activities to promote health, it is necessary that different actors, both within and outside the health sector, collaborate with one another [8-10]. This intersectoral collaboration often takes place in the form of alliances or networks. Through intersectoral collaboration, talents, resources, relations, and approaches to influencing determinants of health can be linked and shared to work very much more effectively, efficiently, and sustainably than one sector would achieve alone [8-12]. Despite the fact that intersectoral collaboration is more effective and efficient to reach health goals, it is quite difficult to build effective and sustainable partnerships [12-14]. The fact that each actor and sector has different backgrounds, interests, perspectives, cultures, and knowledge domains makes collaboration challenging $[12,14]$ and not always successful 15 - 16]. A Dutch study demonstrated that building alliances between the care sector and the sports sector to initiate and implement the BeweegKuur, a combined lifestyle intervention, was hampered because each sector had different cultures and different target groups [17]. Another difficulty, revealed by this study on the BeweegKuur and in other studies, is that residents' participation in the interventions is hard to realize [17-20]. Moreover, it is challenging to motivate people, especially people with health problems, to participate in physical activities [3, 21], although, based on a literature review [22], there is evidence that primary care-based physical activity interventions are effective in reaching physically inactive adults. Another barrier faced by lifestyle interventions aiming to transfer patients from healthcare to local physical activity facilities is that transferal levels often lag behind desired levels [17-19]. Transferal of patients is limited because, amongst other things, patients prefer to stick in the known and secure environment of the healthcare sport facilities instead of participating in unknown or untried local facilities [19, 23]. The above indicates that both participation and transferal rates are much lower than expected; this might mean that patients are not sufficiently prepared for the responsibilities of self-management [23]. Selfmanagement refers to the ability of a person to cope with a disease or the possible risk factors, and to the personal skills to maintain or improve health and wellness [24]. Apparently, patients need to be better equipped to manage their own physical activity behavior during and after an intervention. For patients to become more confident and motivated to be physically active, they probably need the support of a healthcare professional [25-26]. A previous study indicates that better results are achieved when professionals personally direct patients to local sports facilities [19]. However, the major 
time investment by health care professionals that this requires is impossible for the majority of them [27].

To address the described challenges, to improve collaboration between sectors, and to increase patients' participation and self-management, a broker role seems to be promising. Previous studies have revealed that a broker role improves collaboration between multiple sectors [28-29]. A broker with the task of connecting the healthcare and sports sectors, is in the position to support professionals in developing and implementing activities that stimulate patients to participate and transfer to local sports facilities, because they have contacts with both sectors 27]. Therefore, in 2012, the Dutch Ministry of Health, Welfare, and Sport introduced Neighborhood Sports Coaches (Buurtsportcoaches), to whom a broker role has been ascribed. This function is $40 \%$ funded by the state, with the remaining $60 \%$ funded by the municipality or other local organizations. Several Neighborhood Sport Coaches focus specifically on the connection between primary care, sport, and physical activity, the so-called Care Sport Connectors (CSCs). The defined outcome of the CSC role is an increased number of residents participating in local sports facilities and being physically active in their own neighbourhood. To realize this, local sports facilities and neighbourhoods need to offer accessible physical activities for people in the neighbourhood, including people with one or more chronic diseases or at increased risk of chronic disease(s)[30]. The general idea is that CSCs facilitate the connection between the care, sport, and physical activity sectors; professionals in these sectors collaborate; these professionals implement lifestyle interventions; the lifestyle interventions reach certain target groups; these target groups will become self-manageable regarding their physical activity; target groups will become more physically active in their neighborhood; and health outcomes will improve.

The introduction of the CSC concept is new and unique. However, there is no clear job description with required competencies or a clear idea of how CSCs can be embedded in their context. As far as can be ascertained, to date there have been no in-depth studies about a health broker role that reveal the specific competencies that go with the role, the impact of the role on connecting different sectors, and on residents' health. It is accepted that CSCs will operate in different ways because of their different backgrounds and different contexts. Adequate scientific research is needed to assess CSCs' impact on: 1) connecting primary care, sport, and physical activity and 2) promoting the health of primary care patients. This research project consists of two studies to get insight into the impact of the CSC function and into opportunities and lessons to advance health promotion theory and practice in the Netherlands.

Study I focuses on the intermediary target groups: CSCs and professionals in primary care, sport, and physical activity who implement lifestyle programs. CSCs are expected to form health alliances by connecting professionals from different sectors and to achieve and sustain collaboration in these alliances. Consequently, the following research questions will be examined:

SI.1. What are the processes that contribute to the connection between primary care, sport and physical activity, and what is the role of the CSC in forming these alliances?

SI.2. What are the conditions at national and local level that facilitate or hinder CSCs in connecting primary care, sport, and physical activity?

SI.3. Which impacts are mediated by CSCs, and what are the perceived societal benefits for the municipality, neighborhood, and local residents? 
Study II concentrates on health and physical activity behavior changes of primary care patients who participate in lifestyle programs. Center of attention is the target group: adults from the neighborhood who participate in lifestyle programs organized by professionals from the alliances of Study I. The following research questions will be addressed:

SII.1. Which lifestyle programs are implemented, and which target groups are reached?

SII.2. What strategies are effective in increasing participation, self-management and transferal of primary care patients, and which preconditions are essential to accomplish these?

SII.3. What is the effect in terms of physical activity behavior and maintenance, selfmanagement, quality of life, experienced health, and health gains?

\section{Theoretical framework}

To frame this study and the research questions, it is necessary to get insight into the context in which CSCs work and how behavior change may take place within this context. Therefore, the theoretical framework is based on the Expanded Chronic Care Model (ECCM) [23] and the Theory of Triadic Influence (TTI) [30]. This framework will be used to position the function of a CSC and individual behavior changes from a holistic perspective.

\section{The Expanded Chronic Care Model}

The ECCM [24] is a combination of the Chronic Care Model [32] and the principles of the Ottawa Charter [33] (see Figure 2.1). Wagner et al. [32] proposed a re-design of the health system in response to the increasing number of patients with a chronic disease. Until then, the health system was focused on the treatment of communicable diseases. The Chronic Care Model shows how to provide appropriate care for patients with a chronic disease. It is characterized by the productive interactions and relationships between health professionals and patients [24, 32]. Patients have to become more responsible for their own health, and professionals have to adopt a proactive, supporting role to encourage patients' health competencies [32,34]. This is necessary because most of the unhealthy determinants influencing health reside outside the health sector [35]. Therefore, Barr et al. [24] added the principles of the Ottawa Charter to the Chronic Care Model in the ECCM. This created a focus on health promotion to construct supportive environments for citizens, thereby making them able to make better choices regarding their health in everyday life [33].

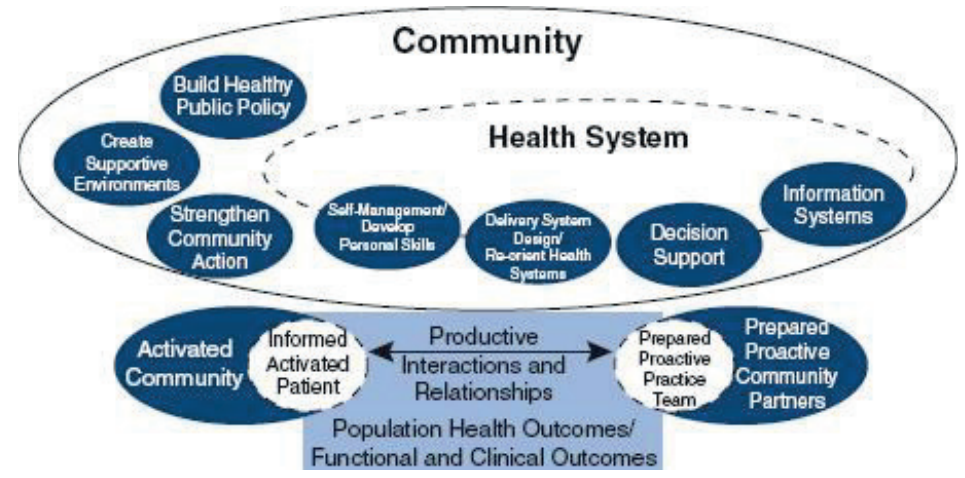

Figure 2.1 Expanded Chronic Care Model [24] 
The ECCM complies with the multidisciplinary approach by combining population health promotion and the prevention and management of chronic disease [24]. The focus is broader than only persons with a disease; everyone and the whole community is addressed to live healthily [24, 36]. Health becomes central instead of illness [37] because of the interaction between the healthcare sector and other sectors in the community, such as transport, education, and sport. The ECCM visualizes the different stakeholders, actors and components involved in the connection between healthcare and health promotion. It gives insight into the broader health system wherein CSCs have to work and which components could be used to arrange the connection between healthcare, sport and physical activity.

\section{Theory of Triadic Influence}

TTI $[31,38]$ proposes that behaviours are most immediately controlled by decisions or intentions (see Figure 2.2). These decisions and intentions to perform behaviours result from an individual's attitude towards behaviour, social normative beliefs, and self-efficacy behavioural control [31]. It is a comprehensive theory, in which other theories with a focus on different aspects of the whole have been brought together [39]. Variables are organized along two dimensions: levels of causation and streams of influence, structured in a logical $3 \mathrm{x}$ 3 framework [39].

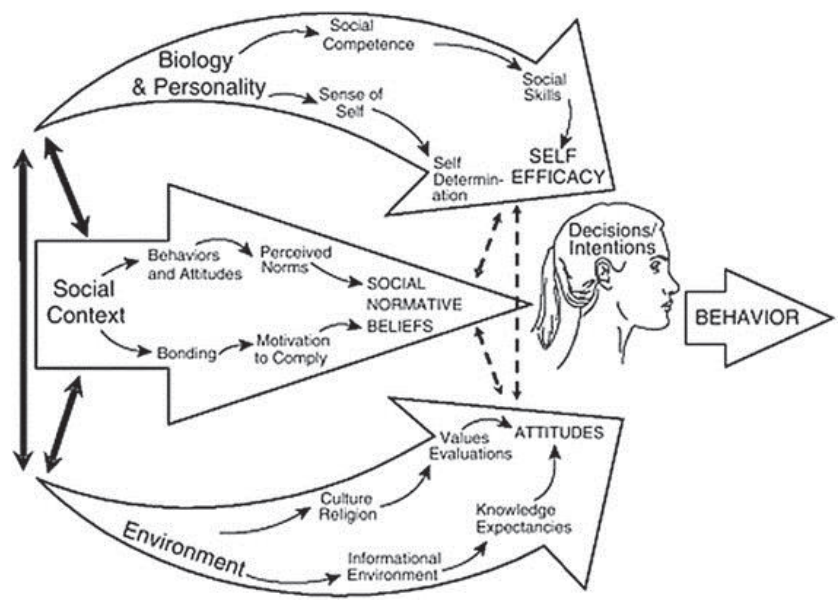

Figure 2.2 Theory of Triadic Influences [31, 38]

The TTI arranges variables by different levels of causation, wherein individual control decreases with a higher level: 1 ) proximal or immediate causes have direct effects on behavior, 2) distal or predisposing causes are mediated through other variables, and 3) some causes are underlying or ultimate causes that are broad and relatively stable [31]. These levels act through the proposed streams of influence, resulting in intentions and behaviors: 1) intra-personal influences that contribute to a person's self-efficacy, 2) interpersonal social influences that contribute to social normative beliefs, and 3) cultural-environmental influences that contribute to attitudes $[31,39]$. To elucidate how CSCs directly or indirectly influence residents' physical activity behavior and to assess the impacts of CSCs, the TTI will 
be used. CSCs' indirect influence stems from the initiated connection with other relevant stakeholders to connect primary care, sport, and physical activity and the preconditions arranged by national, regional, and local organizations to facilitate the work of CSCs (Study I). This will lead to changes in work structures, policies, and physical activity facilities and is shown and explained by TTI through the more distal causes and cultural and environmental influences. CSCs' direct influence takes place through direct contact with the target group to arrange and perform lifestyle interventions (Study II). In the TTI, contact with the CSC is a proximal cause that will lead to changes in intra-personal, interpersonal, cultural, and environmental influences.

\section{Study design}

To study the role and the impact of the CSC, a longitudinal multiple case study will be conducted in nine municipalities spread over the Netherlands, from 2014 until the end of 2016. A mixed methodology will be used to perform action research and process evaluation. Table 2.1 provides an overview of the data collection methods and the planning of this study.

Action research provides direct feedback about the results to the CSCs and stakeholders, thus helping them to decide how to continue [40]. This is made possible by the use of tools which facilitate a learning process for CSCs and stakeholders in order to instigate change to improve practice [41]. Process evaluation will be used to monitor and document program implementation and can aid in elucidating the relation between specific program elements and program outcomes [42].

A mixed methodology is suitable for an appropriate multiple case study and action research design [43-44]. Therefore, data will be collected through interviews, focus groups, document analysis, questionnaires, literature study, and a health-related fitness battery. These methods will be used in multiple rounds over three years to reveal changes over time. The fitness battery will be applied in a one group pre-test/post-test design, with a baseline measurement and two post-tests.

\section{Study population}

Nine municipalities, spread over the Netherlands, were selected through convenience sampling based on project partners' contacts. Inclusion criteria were: 1) the municipality has appointed a CSC for the next four years (until 2017) with the task of connecting primary care, sport, and physical activity and 2) the CSC's target group is comprised of adults. The particular CSC was selected in consultation with the representative civil servant in each municipality; the total number of CSCs in the study is 14 . This is approximately $15 \%$ of the CSCs employed to connect primary care and sport for adults in the Netherlands [45]. Each research question has additional participants such as professionals in the alliances of CSCs, national policymakers, and experts in the field of health, sports, and physical activity policy, residents, healthcare professionals, sports professionals, and participants in lifestyle interventions. These are explained in the description of each research question; an overview is shown in Table 2.2. 


\section{Study I}

Study I focuses on the expected alliances for health and the preconditions which facilitate or hinder CSCs in forming these alliances. The study population will consist of intermediary target groups, such as CSCs, professionals in primary care, professionals in sport and physical activity who implement lifestyle programs, policymakers, and staff members of supporting organizations.

\section{SI.1: Connecting primary care, sport and physical activity, and the role of the CSC}

To assess CSCs' impact on participants' environmental stream, CSCs' role in forming alliances between primary care, sport, and physical activity will be studied, and factors that contribute to the collaboration in these alliances will be identified. Therefore, Koelen et al.'s [12] HALL framework will be used. The HALL framework identifies three clusters of factors that either hinder or facilitate the success of alliances: 1 ) institutional factors: the circumstances or incentives rooted in the institutional and economic environment of organizations that participate in the alliances, 2) personal factors of participants in the alliance, for example attitudes and beliefs, self-efficacy, social identity, and personal relationships, and 3) factors relating to the organization of the alliance, for example a flexible timeframe, roles and responsibilities, communication structure, management, shared mission, building on capacities, visibility [12].

\section{Methods and participants}

Literature review

To our knowledge, there is no review available with a focus on intersectoral collaboration between the primary care and the sports sector in order to promote physical activity. Therefore, a review will be conducted with the aim of: 1) documenting and describing collaboration initiatives between the primary care and sports sectors in order to promote physical activity and 2) identifying barriers and facilitators in these collaboration initiatives between the primary care and the sports sector.

Interviews

To study the processes that contribute to the connection between primary care, sport, and physical activity and conditions that facilitate or hinder CSCs in their work, every six months, for three years, a semi-structured interview will be held with the 14 CSCs, in total 84 interviews. The topics will be based on the HALL framework and will relate to the level and functioning of the collaboration in the alliances, the role of CSCs, and preconditions for CSCs' work.

Focus groups

To study the processes that contribute to the connection between primary care, sport, and physical activity, every year, for three years, a focus group will be held with the 14 CSCs and the professionals in their alliances. In total, 42 focus groups will be held. These focus groups will concentrate on the level and functioning of collaboration in the alliances.

Tools

In the interviews with the CSCs and the focus groups, we will use existing and validated tools that assess collaboration and at the same time facilitate discussion. These tools generate directly actionable knowledge. To study the processes that contribute to the connection 
between primary care, sport, and physical activity, Zaalmink et al.'s [46] Network Analysis Tool, Wagemakers et al.'s [47] Coordinated Action Checklist, Zaalmink et al.'s [46] Timeline Method, and Frey et al.'s [48] Levels of Collaboration Survey will be used.

Network Analysis Tool

The Network Analysis Tool [46] gives insight into a network's involvement in a specific initiative. Roles of different contributors will be explored to become aware of their position in the network, thereby making it possible to get an overview of the network. This will lead to actionable knowledge because the CSC can decide whether the existing network has potential to grow and build further. This analysis reveals novel suggestions to bring the initiative one step further.

Coordinated Action Checklist

Coordinated action is the collaboration of two or more sectors to accomplish an outcome. The Coordinated Action Checklist [47] can be used for the facilitation and evaluation of community health partnerships with different contexts and levels, phase of the program, and participants. It evaluates collaboration for diverse dimensions, such as suitability of partners, task dimension, relation dimension, growth dimension, and visibility dimension. Results will be visualized to give insight into strengths and possible improvements, thereby encouraging feedback and discussion.

Timeline Method

The Timeline Method [46] sorts out important events and influences inside and outside the network. It gives insight into these events and influences from each participant's point of view in a certain time frame. This encourages discussion and evaluation to facilitate the collaboration in a positive manner.

Levels of Collaboration Survey

The Levels of Collaboration Survey [48] gives insight into different stages of collaboration with a description of the networking, cooperation, coordination, coalition, and collaboration stages. The stage of collaboration at a given time will be represented by a score on the scale. To measure changes over time, scores will be compared over time.

\section{SI.2: Conditions at national and local level that facilitate or hinder CSCs}

CSCs work in different municipalities and therefore the contexts in which they work will differ. This will lead to differences in the way CSCs operate in forming alliances and to differences in the way local residents' environmental stream and their physical activity behaviour will be influenced. For that reason, the conditions in national and local policy and the public health capacity of the municipalities will be assessed to identify the context in which each CSC works. Also, CSCs' experiences with the preconditions for their work will be addressed during the interviews to identify facilitators and barriers.

Methods and participants

Document analysis

To get insight into national and local policy regarding public health and CSCs, a document analysis will be performed every year. National policy and the local policy of each municipality will be analyzed with the use of a checklist based on Rütten et al.'s ADEPT model [49]. ADEPT, which stands for Analysis of Determinants of Policy Impact, aims to explain and influence policy development and policy impact implementation under four 
headings: goals, obligations, resources, and opportunities. The ADEPT model is useful to elucidate the role of policy processes in health promotion output and outcome. In addition, it is useful to identify necessary conditions in policy for a broker role such as the CSC.

Interviews

To assess the local-level conditions in which CSCs are working, policymakers from the nine municipalities will be interviewed. The local public health capacity mapping checklist, based on the frameworks of Meyer et al. [50] and Aluttis et al. [51-52], the tools of Aluttis et al. [53] and Bagley and Lin [54], and interviews with experts, will be used during the interview to identify the context in which CSCs are working and the contextual changes over a period of time. This will make it possible to compare the capacity of the participating municipalities.

Tools

Local public health capacity mapping checklist

This checklist consists of five dimensions to map the public health capacity of a municipality. These dimensions - policy characteristics, organizational structure, resources, programs and partnerships, and municipal context - are operationalized on the basis of the tools of Allutis et al. [53] and Bagley \& Lin [54]. Quantitative operationalizations will be interrogated with a questionnaire prior to the interview wherein the qualitative operationalizations will be addressed. This will give the opportunity to clarify ambiguities in the questionnaire with the policymakers.

\section{SI.3: Mediated impacts and perceived societal benefits}

Physical inactivity is an enormous risk factor for non-communicable diseases, which are currently creating an economic burden due to the increased prevalence of physical inactivity. Because the policy concerning CSCs - to connect primary care, sport, and physical activity and to prevent inactivity - is new and unique, it is necessary to evaluate the perceived benefits for the municipality, its residents, and professionals in the primary care and sports sectors.

\section{Methods and participants}

Focus groups

To assess the impact of CSCS and the perceived societal benefits for the municipality, in total 14 focus groups with the CSCs, their alliances, and residents will be held at the end of the project. The aim of these groups is to identify the kind of programs conducted, the perceived results of these programs, and the perceived impact for professionals in the primary care and sports sectors, the neighbourhood, and its residents. The effect arena [54] will be used to structure these focus groups.

Tools

Effect arena

The effect arena [55] structures the dialogue about an intervention's investments and societal benefits as perceived by stakeholders. This is made possible by the completion of the following steps; problem analysis, determination of zero alternative, determination of project alternatives, identification of costs and effects, quantification and monetization of 
effects. It gives insight into and the possibility to examine the added value of an intervention; this is the first step towards a societal costs-benefits analysis.

\section{Data analysis Study I}

The interviews and focus groups will be audio-taped and transcribed (intelligent verbatim style). The data analysis will be based on Creswell's [56] six steps for qualitative data analysis. So, after the transcripts of the interviews and the focus groups are read, they will be coded and analysed using software for qualitative analysis (Atlas.ti, version 7.0). Both topdown and bottom-up coding will be used to analyse the interviews and focus groups. The top-down coding will use with predefined codes based on factors mentioned in the TTI and the HALL framework. The bottom-up coding (free coding) will trace general themes that emerge in the interviews and focus groups. In this way, relevant topics devised in advance of the study design and relevant topics from practice will be fully mapped. The codes will be clustered into themes. These themes will make it possible to interrelate and interpret the data [56].

The data gathered in the cases will be used to describe each case and build explanations on the CSC role in connecting primary care, sport, and physical activity [44]. In addition, we will make use of cross-case synthesis. This cross-case synthesis treats each individual case study as a separate study [44]. Word tables will be used to display the data from the individual cases according to the different frameworks presented in the theoretical framework. These word tables will also be used to analyse whether different groups of cases appear to share some similarities and deserve to be considered instances of the same type of general case [44]. Similar results in this study's different cases will make it possible to draw general conclusions - for example, factors that hinder or facilitate the connection between primary care, sport, and physical activity. 


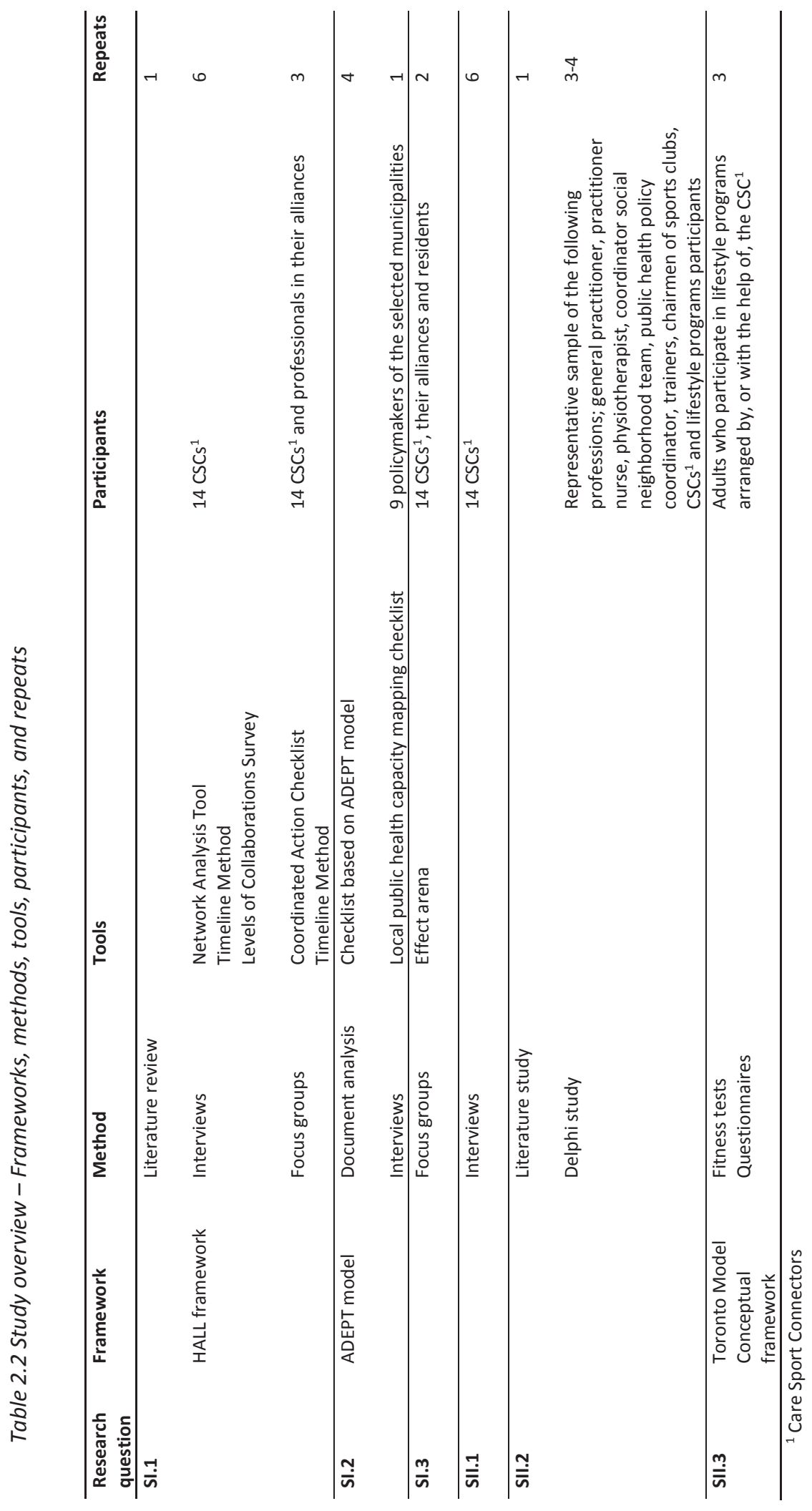




\section{Study II}

Study II will concentrate on lifestyle programs participants to identify health and physical activity behavior changes. In addition, the study will reveal facilitators for, and barriers to, the implementation of appropriate lifestyle programs.

\section{SII.1: Lifestyle programs and target groups}

Lifestyle interventions aim to improve people's health on themes such as smoking cessation, reduction of alcohol abuse, health dietary improvement, increased physical activity, or a combination of these themes. This study focuses on physical activity programs, and perhaps also programs in which other themes are also targeted.

Physical activity is defined as bodily movement produced by the contraction of skeletal muscle that increases energy expenditure above the basal level [57]. It can be classified in several ways, such as purpose, intensity, and type. The Dutch Healthy Physical Activity Guideline, which is 30 minutes of moderate physical activity at least five days a week, takes duration, frequency, and intensity into account [4]. Other elements that are crucial to stay physically active in the long term, revealed in previous studies, are cost, trainer qualifications, environment, and point in time $[18,19,23,58]$. These elements are relevant to describe in a monitor report, and, additionally, relevant elements described in Wolfenstetter's conceptual framework [59] will be monitored to create input for a societal costs-benefits analysis.

\section{Methods and participants}

Interviews

Interviews will be conducted with the CSC to retrieve information about all the lifestyle programs arranged by, or with the help of, the CSC. During the interview, a table with characteristics of the lifestyle programs will be filled in to get insight into the type of programs and their target groups. These interviews will be held every six months with the 14 CSCs, in conjunction with the interviews of for research question SI.1.

\section{SII.2: Strategies and preconditions to increase participation, self-management and transferal of primary care patients}

As mentioned before, principles such as participation, transferal of patients from healthcare to local physical activity facilities, and enhancing self-management are essential but hard to realize in lifestyle programs. This part of the study will focus on these principles to improve the implementability of lifestyle programs.

\section{Methods and participants}

Literature study

To gain input for a Delphi study, a literature study will be conducted to get insight into: 1) the different levels of participation and the experiences with community participation in lifestyle interventions, 2) indicators of self-management for individuals with, or at risk of, chronic disease, 3 ) experiences with the transferal of patients from healthcare to local physical activity facilities in the Netherlands, and 4) views and experiences of individuals with, or at risk of, chronic disease on behavior change techniques used to enhance physical activity adherence during, and the maintenance after, a program. In addition, the review of 
research question SI.1 will be used to get insight into facilitators and barriers for intersectoral collaboration between the healthcare and sports sectors.

Delphi study

A Delphi study will be carried out to identify strategies to increase participation, selfmanagement, and transferal of patients. The ultimate aim is that this knowledge will contribute to the development of appropriate lifestyle interventions and their implementation. In order to get a comprehensive insight into the barriers and challenges to these different strategies, professionals representing different sectors will be involved in the Delphi study. From each of the following professions, a representative sample of Dutch professionals will be included by random sampling: general practitioner, practitioner nurse, physiotherapist, coordinator of the social neighborhood team, public health policy coordinator, trainers, chairman of a sports club, and CSCs. Additionally, participants of lifestyle programs will be included: 10 potential participants, 10 dropouts, and 10 participants who have completed a lifestyle program.

The first round of the Delphi study will consist of an open-ended questionnaire to discover viewpoints of each profession and participants in relation to physical activity, lifestyle programs, and intersectoral collaboration for the transferal of patients, self-management, and participation. This will reveal opportunities and barriers for the implementation of certain programs, and these will be the input for the statements in round 2 . The statements in round 2 will be scored on a 7-point Likert scale by each professional and participant in order to determine which tasks will be recognized as their responsibility to ensure a better implementation of lifestyle programs and the intersectoral collaboration between the health and sports sectors for the transferal of patients. In the third and optional fourth round, there needs to be consensus about the possibilities within each profession and the necessities for each profession. The statements on which consensus is reached will be used to compose a checklist for CSCs to develop and implement lifestyle programs.

\section{SII.3: Effect in terms of physical activity behavior and maintenance, self-management, quality of life, experienced health, and health gains}

The defined outcome of the CSC role is an increased number of residents participating in local sports facilities and being physically active in their own neighbourhood, for which it is necessary that people have the possibility to maintain their physical activities. This goal is proposed because of the increase in non-communicable diseases partly caused by inactivity. It is necessary to know whether the lifestyle interventions arranged by, or with the help of, CSCs influence physical activity behaviors and consequently improve people's health. Therefore, this part of the study will take the effects of lifestyle interventions into account. The complex relationship between physical activity, fitness, and health is described by Bouchard and Shephard in the Toronto Model [60]. A basic level of fitness is required for overall health in all individuals, the so-called health-related fitness, defined as 'an ability to perform daily activities with vigor' and a lower risk of developing non-communicable diseases. Health-related fitness is divided into five components: morphological, muscular strength and endurance, motor, cardio-respiratory fitness, and metabolic fitness. Physical activity influences health-related fitness directly and consequently has an impact on an individual's health. The components of health-related fitness are measurable and will form the basis of the fitness test. 
However, the concept of health is broader than the measurable components of healthrelated fitness. Huber et al. [61] introduced the dynamic definition of health as 'Health as the ability to adapt and to self-manage, in the face of social, physical and emotional challenges'. In 2013, they operationalized the concept into the measurable dimensions of body functions, mental functions and perceptions, spiritual dimension, quality of life, social participation, and daily functioning. This conceptual framework will be used in the current study to decide which topics are relevant to include, in relation to physical activity and health, for a questionnaire to assess the impact on health.

\section{Methods and participants}

In a one-group pretest /post design, lifestyle programs participants will perform a fitness test and fill in a questionnaire to assess their maintenance of physical activity and health gains. This will take place at the start of the lifestyle program (TO), at the end of the lifestyle program (T1), and one year after the start of the lifestyle program (T2).

\section{Fitness test}

The fitness test includes all components of health-related fitness by measuring blood pressure, heart rate, height, weight, percentage fat, waist circumference, flexibility of the hamstring, shoulders and back, arm and leg strength and endurance, dynamic balance, blood glucose, cholesterol, and cardio-respiratory endurance. To ensure that it is safe for them to participate in the fitness test, potential participants must first pass the Par-q questionnaire. Questionnaire The questionnaire will retrieve information about physical activity behavior, sedentary behavior, stages of changes, experienced health, self-management, motivation, selfefficacy, experienced health gains, knowledge, goals, and healthcare use.

\section{Sample size calculation}

The study population of the one-group pretest/ post-test will consists of adults who start a lifestyle program arranged by, or with the help of, the CSC in one of the nine municipalities. Inclusion will be determined by convenience sampling. The sample size calculation is based on alpha $=0.05$ and power $=0.80$ and assumes additionally:

- The primary outcome measure is maintenance of physical activity behavior after a lifestyle program, by participating in a local sports or exercise activity. Pilot data from the BeweegKuur revealed that $10-30 \%$, depending on the context, of the participants continue participating in local sports facilities after the lifestyle program [S.P.J Kremers, Personal Communication, November 2012]. The expected value for this study is $40 \%$ because of the introduction of the CSC, although $20 \%$ is set as the criterion for this sample size calculation.

- Some of the effects will be explainable by differences in support, lifestyle programs, and context in each neighborhood. There are no data available from the BeweegKuur about the intra-class correlation coefficient (ICC). An ICC of 0.15 is assumed, based on research into common values and similar interventions [62-65].

The required number of participants is 414 , which will lead to 258 independent observations due to a design effect of 1.6. On the assumption of a drop-out rate of $10 \%$ during the lifestyle program [66], $10 \%$ at T1, and $20 \%$ at T2 [67], a baseline sample of 640 participants is required. 


\section{Data analysis Study II}

The first round of the Delphi study will be analyzed via content analysis. Similar answers will be combined into themes with the use of Atlas.ti 7.0, and each theme will be used to generate statements. The statements, scored on a 7-point Likert scale, in the subsequent rounds will be analyzed with the help of the SPSS program. Measures of central tendency and level of dispersion will be used. Agreement is reached if $80 \%$ of respondents' responses fall within two categories on a 7-point Likert scale.

The quantitative data gathered via the fitness tests and questionnaires will be analyzed using the SPSS program. Multivariate techniques make it possible to test whether there is a relation between dependent variables such as physical activity behavior or motivation and independent variables such as gender, age, and nationality. Longitudinal data analysis will be used to study the individual development of the outcome variables and to determine whether there is a relationship with the individual development of other variables. 


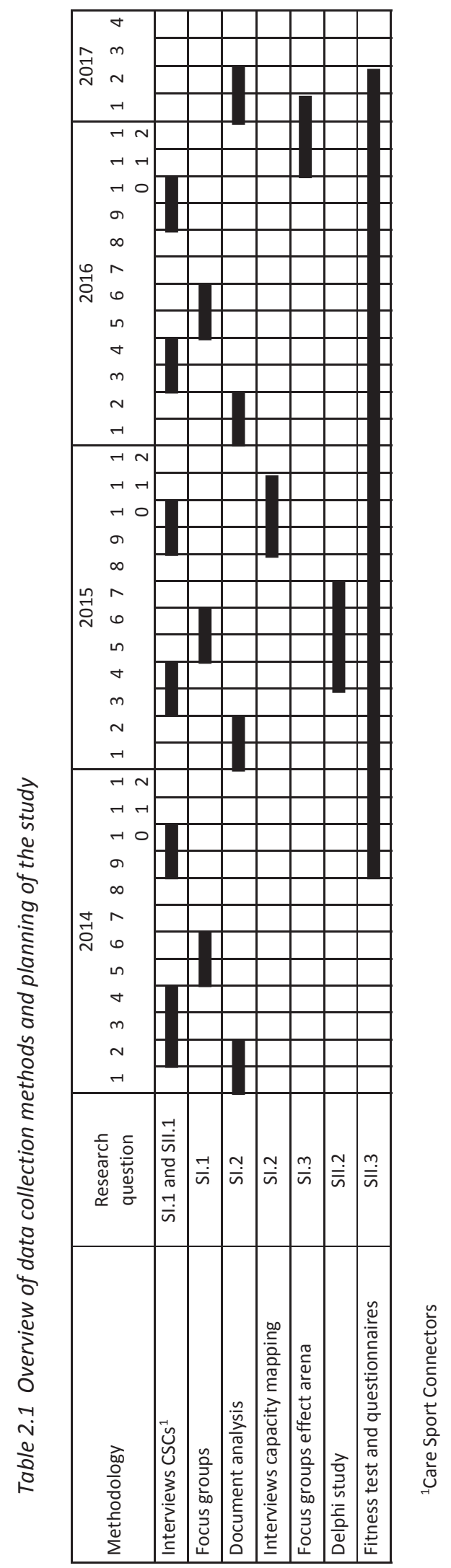




\section{Discussion}

This study is designed to provide information about the implementation of the CSC function in nine municipalities, spread over the Netherlands. Through a mixed methods design, it will be possible to examine whether CSCs can achieve their objectives: 1 ) to connect primary care, sport and physical activity and 2) to increase the number of physically active residents. Besides this, the study will reveal whether a broker role contributes to improved intersectoral collaboration, increased participation by residents, transferal of patients from healthcare to physical activity facilities, and self-management. Facilitators and barriers that are brought to light will be transformed into practical tools for CSCs and recommendations for supportive organizations to advance health promotion theory and practice in the Netherlands.

\section{Relevance}

The number of people with one or more chronic diseases is increasing, and this trend could be reduced by tackling and preventing physical inactivity. A healthier population will benefit society at large through, for example, enhanced wellbeing, a decrease in healthcare costs, and higher work productivity [68]. The CSC function is implemented under national and local policy in order to reverse this trend, and this study will reveal whether CSCs are able to fulfill these policy aspiration.

The novelty of the CSC function means that there is no clear job description with required competencies. Therefore, it is not yet clear for what CSCs can and should be held accountable. By the use of qualitative and quantitative methods in multiple cases, it is possible to get insight into results achieved, opportunities, and realistic expectations. In addition, this study will generate actionable knowledge with stakeholders to improve practice immediately. Process evaluation makes it possible to get insight into developments achieved because of the implementation of this actionable knowledge. Accurate actionable knowledge is very helpful for a new, developing function, especially because of the expanding number of Neighborhood Sport Coaches in the Netherlands. At the start of this study in 2012, 3.2\% of the 1850 FTE for Neighborhood Sport Coaches were employed as CSCs for adults in the Netherlands [69]. An in-depth study over 18 municipalities revealed that, in 2014, 12\% of the surveyed Neighborhood Sport Coaches focused on connecting primary care and sport [70].

\section{Strengths and limitations}

The study design is optimized for internal and external validity because action research, process evaluation, and the one-group pretest/post design are combined. The principle of triangulation is continuously applied to optimize the reliability of this study, using multiple methods, multiple sources, and multiple cases [71-72]. Internal validity is enhanced by triangulation of methods and resources, whereby results will be checked with other stakeholders. In addition, other verification techniques will be used, such as expert consultation and loop learning $[43,73]$. External validity is enhanced by studying multiple cases. Case studies take place in real-life settings and provide insight into the why and how in practice. Similar results in different cases will make it possible to draw general conclusions. This will result in formulated preconditions and prerequisites for CSCs rather than the general effect of CSCs. Because of differences in contexts in the multiple cases and the absence of a control case without a CSC, the latter is not possible. 
In this study, a one-group pretest /post design will be used to measure physical activity maintenance and health gains. This design is appropriate to follow patients and residents who participate in activities and interventions, organized by, or with the help of, the 14 CSCS in this study, over an extended period. Individual-level results obtained from the one-group pretest/post design will be linked with results at the intervention, the environment and the policy level in order to be able to explain why changes in physical activity behavior and health have taken place, or not. For this study, a randomized controlled trial design is not appropriate, because it is impossible to arrange suitable control groups in real-life settings that resemble the contexts of the cases in our study. The context is different in each case and is exposed to continual change over time because of the action of the CSC, but probably also because of other stakeholders and events outside the control of the study [74]. Linking and integrating results gained by multiple methods at different levels will result in a validated assessment of the impact of CSCs on connecting the healthcare and sports sectors, changes in residents' physical activity behavior will be ascertained and the circumstances in which this will happen will be established [75]. The assessment, in combination with general lessons learned from the different case studies, will make it possible to determine whether CSCs are able to fulfill the policy aspiration and whether it would be beneficial to extend this function over more municipalities.

\section{Ethics approval}

This study has been approved by the Medical Ethical Review Committee: CMO Regio Arnhem-Nijmegen (filenumber 2013-492). 


\section{References}

1. Balady GJ, Berra KA, Golding LA, Gordon NF, Mahler DA, Myers JN et al. ACSM's Guidelines for Exercise Testing and Prescription. 6th ed. United States of America: Lippincott Williams \& Wilkins; 2000.

2. U.S. Department of Health and Human Services. Physical activity and Health: A Report of the Surgeon General. Atlanta: U.S. Department of Health and Human Services, Centers for Disease Control and Prevention, National Centre for Chronic Disease Prevention and Health Promotion; 1996.

3. Hoeymans N, van Loon J, Achterberg P, van den Berg M, Harbers M, den Hertog F et al. Volksgezondheid Toekomst Verkenning 2014. Bilthoven: RIVM; 2014.

4. Kemper HCG, Ooijendijk WTM, Stiggelbout M. Consensus over de Nederlandse norm voor gezond bewegen. TSG 2000;78(3):180-3.

5. Matheson GO, KlugI M, Dvorak J, Engebretsen L, Meeuwisse WH, Schwellnus M et al. Responsibility of sport and exercise medicine in preventing and managing chronic disease: applying our knowledge and skill is overdue. British Journal of Sports Medicine 2011. doi:10.1136/bjsports-2011-090328.

6. Bauman AE, Reis RS, Sallis JF, Wells JC, Loos RJF, Martin BW. Correlates of physical activity: why are some people physically active and others not? Lancet 2012. doi: 10.1016/S0140-6736(12)60735-1.

7. McLeroy KR, Bibeau D, Steckler A, Glanz K. An Ecological Perspective on Health Promotion Programs. Health Education and Behaviour 1988.

8. Butterfoss FD, Goodman RM, Wandersman A. Community coalitions for prevention and health promotion. Health Education Research 1993. doi:10.1093/her/8.3.315.

9. Green L, Daniel M, Novick L. Partnerships and Coalitions for Community-Based Research. Public Health Reports 2001;116 Suppl 1:20-31.

10. Koelen MA, Vaandrager $L$, Wagemakers $A$. What is needed for coordinated action for health? Family practice 2008;25 Suppl 1:i25-31.

11. World Health Organization. Action plan for the global strategy for the prevention and control of noncommunicable diseases. World Health Organization; 2008. Retrieved from: http://whqlibdoc.who.int/publications/2009/9789241597418_eng.pdf?ua=1. Accessed 19 March 2015.

12. Koelen MA, Vaandrager L, Wagemakers A. The healthy alliances (HALL) framework: prerequisites for success. Family practice 2012, 29 Suppl 1:i132-i8.

13. Lasker RD, Weiss ES, Miller R. Partnership Synergy: A Practical Framework for Studying and Strengthening the Collaborative Advantage. Milbank Q 2001. doi:10.1111/14680009.00203.

14. Cheadle A, Beery W, Wagner E, Fawcett S, Green L, Moss D et al. Conference report: community based health promotion--state of the art and recommendations for the future. Am J Preventive Medicine 1997, 13(4):240-3.

15. Lasker RD, Weiss ES, Miller R. Partnership synergy: a practical framework for studying and strengthening the collaborative advantage. Milbank Q 2001, 79(2):179-205.

16. Kreuter MW, Lezin NA, Young LA. Evaluating community-based collaborative mechanisms: implications for practitioners. Health Promotion Practice 2000;1(1):49-63.

17. den Hartog F, Wagemakers A, Vaandrager L, van Dijk M, Koelen MA. Alliances in the Dutch BeweegKuur lifestyle intervention. Health Education Journal 2014, 73, 576-587.

18. Denge PJt. Gezondheidsmakelaar als vliegwiel; Een evaluatieonderzoek 658 naar het project Gezondheidsmakelaars in Nijmegen. Nijmegen: Gemeente Nijmegen; 2012. 
19. den Hartog F, Wagemakers A, Vaandrager L, Koelen M. 'Een gedeelde passie voor gezonder leven' Evaluatieonderzoek naar netwerken rondom de beweegkuur en gecombineerde leefstijl interventies. Wageningen: Wageningen University; 2012.

20. Harting J, Assema P. Community-projecten in Nederland: de eeuwige belofte? Rotterdam: Optima Grafische Communicatie; 2007.

21. Marcus BH, Forsyth L. Motivating people to be physically active. Champaign: Human Kinetics; 2003.

22. Eakin EG, Glasgow RE, Riley KM. Review of primary care-based physical activity intervention studies. Family Practice 2000, 49(2):158-68.

23. Meijer S, Hesselink A, Martens M. Leefstijlbeïnvloeding in de eerstelijn. Verkenning naar de ervaringen van zorgverleners. RIVM briefrapport 255022001/2012. Bilthoven: RIVM; 2012.

24. Barr VJ, Robinson S, Marin-Link B, Underhill L, Dotts A, Ravensdale D et al. The expanded Chronic Care Model: an integration of concepts and strategies from population health promotion and the Chronic Care Model. Hospital Quarterly 2003;7(1):73-82.

25. Pearson ML, Mattke S, Shaw R, Ridgely MS, Wiseman SH. Patient Self-Management Support Programs: An Evaluation. Rockville, MD: Agency for Healthcare Research and Quality; 2007.

26. CBO. Zorgmodule Zelfmanagement 1.0. Utrecht: CBO; 2014.

27. van Dijk M, Wigger S. Van zorg naar sport en bewegen: Interviews met zorgverleners en sportaanbieders over de doorstroom van BeweegKuur-deelnemers vanuit de eerstelijns gezondheidszorg naar het lokale sport- en beweegaanbod. 2012. Retrieved from: http://www.beweegkuur.nl/documenten-2013/van-zorg-naar-sport.-interviews-metzorgverlenersen-beweegaanbieders.pdf. Accessed 15 Nov 2013.

28. van der Linden J, van der Grinten M, Gramberg P,van Aarsen E. Effecten van de inzet van combinatiefuncties in het onderwijs. Utrecht: Oberon; 2012.

29. Harting J, Kunst AE, Kwan A, Stronks K. A 'health broker' role as a catalyst of change to promote health: an experiment in deprived Dutch neighbourhoods. Health Promotion International 2011, 26(1):65-81.

30. Ministerie van Volksgezondheid, Welzijn en Sport. Programma Sport en Bewegen in de Buurt. Den Haag, Ministerie VWS; 2011.

31. Flay BR, Snyder F, Petraitis J. The theory of triadic influence. In: DiClemente RJ, Crosby RA, Kegler MC, editors. Emerging theories in health promotion practice and research. 2nd ed. San Francisco: Jossey-Bass; 2009.

32. Wagner EH, Austin BT, Korff MV. Organizing Care for Patients with Chronic Illness. Milbank Q 1996, 74(4):511-44.

33. World Health Organization. The Ottawa Charter for Health Promotion. Copenhagen: World Health Organisation; 1986.

34. Raad voor de Volksgezondheid en Zorg. Perspectief op gezondheid 20/20. Den Haag: Raad voor de Volksgezondheid en Zorg; 2010.

35. Evans R, Barer M, Marmor T. Why are some people healthy and others not? The determinants of Health of Populations. New York: Walter de Gruyter; 1994.

36. Laroche HH, Davis MM, Forman J, Palmisano G, Reisinger HS, Tannas C et al. Children's Roles in Parents' Diabetes Self-Management. American Journal of Preventive Medicine. 2009; doi:10.1016/j.amepre.2009.08.003.

37. Huijben MEM. Het Chronic Care Model in Nederland. Den Haag: Raad voor de Volksgezondheid en Zorg; 2011. 
38. Flay BR, Petraitis J. The Theory of Triadic Influences. A new theory of health behavior with implications for preventive interventions. Advance in Medical Sociology 1994;4:1944.

39. Snyder FJ, Flay BR. Brief Introduction to the Theory of Triadic Influence. Purdue and Oregon State University; 2012.

40. Koelen $\mathrm{M}$, vd Ban AW. Health education and health promotion. Wageningen: Wageningen Academic Publishers; 2004.

41. Whitehead D, Taket A, Smith P. Action research in health promotion. Health Educucation Journal 2003; doi:10.1177/001789690306200102.

42. Saunders RP, Evans MH, Joshi P. Developing a Process-Evaluation Plan for Assessing Health Promotion Program Implementation: A How-To Guide. Health Promotion Practice 2005, 6:134.

43. Wagemakers A. Community health promotion. Facilitating and evaluating coordinated action to create supportive social environments. Wageningen: Wageningen University; 2010.

44. Yin RK. Case Study Research. Design and Methods. 3rd ed. London: SAGE publications; 2003.

45. de Jong M, van Lindert C, van de Poel H. Voortgangsrapportage Monitor, Sport en Bewegen in de Buurt, 2013. Utrecht: Mulier Instituut; 2013.

46. Zaalmink W, Wielinga E, Bergevoet R, Geerling-Eiff F, Holster $H$, Hoogerwerf L et al. Networks with free actors. Wageningen: Wageningen University; 2008.

47. Wagemakers A, Koelen MA, Lezwijn J, Vaandrager L. Coordinated action checklist: 734 a tool for partnerships to facilitate and evaluate community health promotion. Global Health Promotion 2010, 17(3):17-28.

48. Frey BB, Lohmeier JH, Lee SW, Tollefson N. Measuring collaboration among grand partners. American Journal of Evaluation 2006, 27:383-92.

49. Rütten A, Gelius P, Abu-Omar K. Policy development and implementation in health promotion - from theory to practice: the ADEPT model. Health Promotion International 2011. doi:10.1093/heapro/daq080.

50. Meyer AM, Davis M, Mays GP. Defining organizational capacity for public health services and systems research. JPHMP. 2012;18(6):535-44.

51. Aluttis CA, Chiotan C, Michelsen M, Costongs $C$, Brand $H$, on behalf of the public health consortium. Review of Public Health Capacity in the EU. Luxembourg: European Commission Directorate General for Health and Consumers; 2013.

52. Aluttis C, Van den Broucke S, Chiotan C, Costongs C, Michelsen K, Brand H. Public health and health promotion capacity at national and regional level: a review of conceptual frameworks. Journal of Public Health Research 2014, 3(1).

53. Aluttis C, Van den Broucke S, Chiotan C, Costongs C, Michelsen K, Brand H. Review of Public Health Capacity in the EU: Supplement to the final report. Luxembourg: European Commission

Directorate General for Health and Consumers; 2013.

54. Bagley $\mathrm{P}$, Lin V. The development and pilot testing of a rapid assessment tool to improve local public health system capacity in Australia. BMC Public Health 2009;9(1):413.

55. SEV. Effectenarena. SEV. 2013. Retrieved from: http://www.effectenarena.nl/. Accessed 31 Oct 2013.

56. Creswell JW. Research design: Qualitative, quantitative, and mixed methods approaches. United 
States of America: Sage; 2013.

57. Caspersen CJ, Powell KE, Christenson G. Physical Activity, Exercise, and Physical Fitness: Definitions and Distinctions for Health-Related Research. Public Health Reports 1985, 100(2):126-31.

58. Helmink JHM, Boekel LCV, Sluis MEvd, Kremers SPJ. Lange termijn evaluatie onder deelnemers aan de BeweegKuur. Rapportage van de resultaten van een follow-up meting bij deelnemers.

Maastricht: Maastricht University; 2011.

59. Wolfenstetter SB. Conceptual framework for standard economic evaluation of physical activity programs in primary prevention. Prevention science : the official journal of the Society for Prevention Research 2011, 12(4):435-51.

60. Bouchard C, Shephard RJ. Physical activity fitness and health: the model and key concepts. In: Bouchard C, Shephard RJ, Stephens T, editors. Physical activity fitness and health: International proceedings and consensus statement. Champaign, IL: Human Kinetics; 1999, 77-88.

61. Huber M, Vliet Mv, Giezenberg M, Knottnerus A. Towards a Conceptual Framework relating to 'Health as the ability to adapt and to self manage'. Operationalisering Gezondheidsconcept. Driebergen: Louis Bolk Instituut; 2013.

62. Hox JJ. Multilevel analysis. Techniques and applications. New Jersey: Lawrence Erlbaum Associates; 2002.

63. Reinehr T, Hoffmeister U, Mann R, Goldapp C, Westenhofer J, Egmond-Froehlich A et al. Medical care of overweight children under real-life conditions: the German BZgA observation study. International Journal of Obesity 2009, 33(4):418-23.

64. Mendis S, Johnston SC, Fan W, Oladapo O, Cameron A, Faramawi MF. Cardiovascular risk management and its impact on hypertension control in primary care in low-resource settings: a cluster-randomized trial. Bulletin of the World Health Organization 2010, 88:412-9.

65. Spybrook J, Raudenbush SW, Liu X, Congdon R, Martínez A. Optimal Design for Longitudinal and Multilevel Research: Documentation for the "Optimal Design" Software. 2008. Retrieved from: http://people.cehd.tamu.edu/ okwok/epsy652R/OD/od-manual20080312-v176.pdf. Accessed 13 Nov 2014.

66. van Berg S. Gezond in de buurt in beweging. Een project naar aanleiding van het 10 -jarig bestaan van 'Gezond in de buurt'. Eindhoven: GGD Brabant-Zuidoost; 2010.

67. Baker PRA, Soares FDP, Weightman AL, Foster C. Community wide interventions for increasing physical activity. Cochrane Database of Systematic Reviews 2011. DOI: 10.1002/14651858.CD008366.pub3.

68. Hildebrandt VH, Bernaards CM, Stubbe JH. Trendrapport Bewegen en Gezondheid 2010/2011. Leiden: TNO; 2013.

69. van den Heuvel A, Heijkoop C, de Jong M. Samenvatting monitor Impuls brede scholen, sport en cultuur 2013 (over 2012). Den Haag: BMC; 2013.

70. Pulles I, Leijenhorst M, Reijgersberg N, Hilhorst J, van Lindert C. Verdiepingsonderzoek buurtsportcoaches 2014: verbreding en structurele samenwerking. Verdiepingsonderzoek naar processen en ervaren opbrengsten van de inzet van buurtsportcoaches op lokaal niveau. Utrecht: Mulier Instituut, Kennispraktijk; 2014.

71. Koelen M, Vaandrager L, Colomer $\mathrm{C}$. Health promotion research: dilemmas and challenges. Journal of epidemiology and community health 2001, 55(4):257-62. 
72. Cohen DJ, Crabtree BF. Evaluative criteria for qualitative research in health care: controversies and recommendations. Ann Fam Med. 2008, 6(4):331-9.

73. Argyris C. Single-Loop and Double-Loop Models in Research on Decision Making. Administrative Science Quarterly 1976;21(3):363-75. doi:10.2307/2391848.

74. Hawe P, Shiell A, Riley T. Complex interventions: how "out of control" can a randomised controlled trial be? BMJ 2004; doi: http://dx.doi.org/10.1136/bmj.328.7455.1561.

75. Sadler-Smith E. Learning and development for managers: Perspectives from research and practice. 1st 809 ed. Oxford: Blackwell Publishing; 2009. 


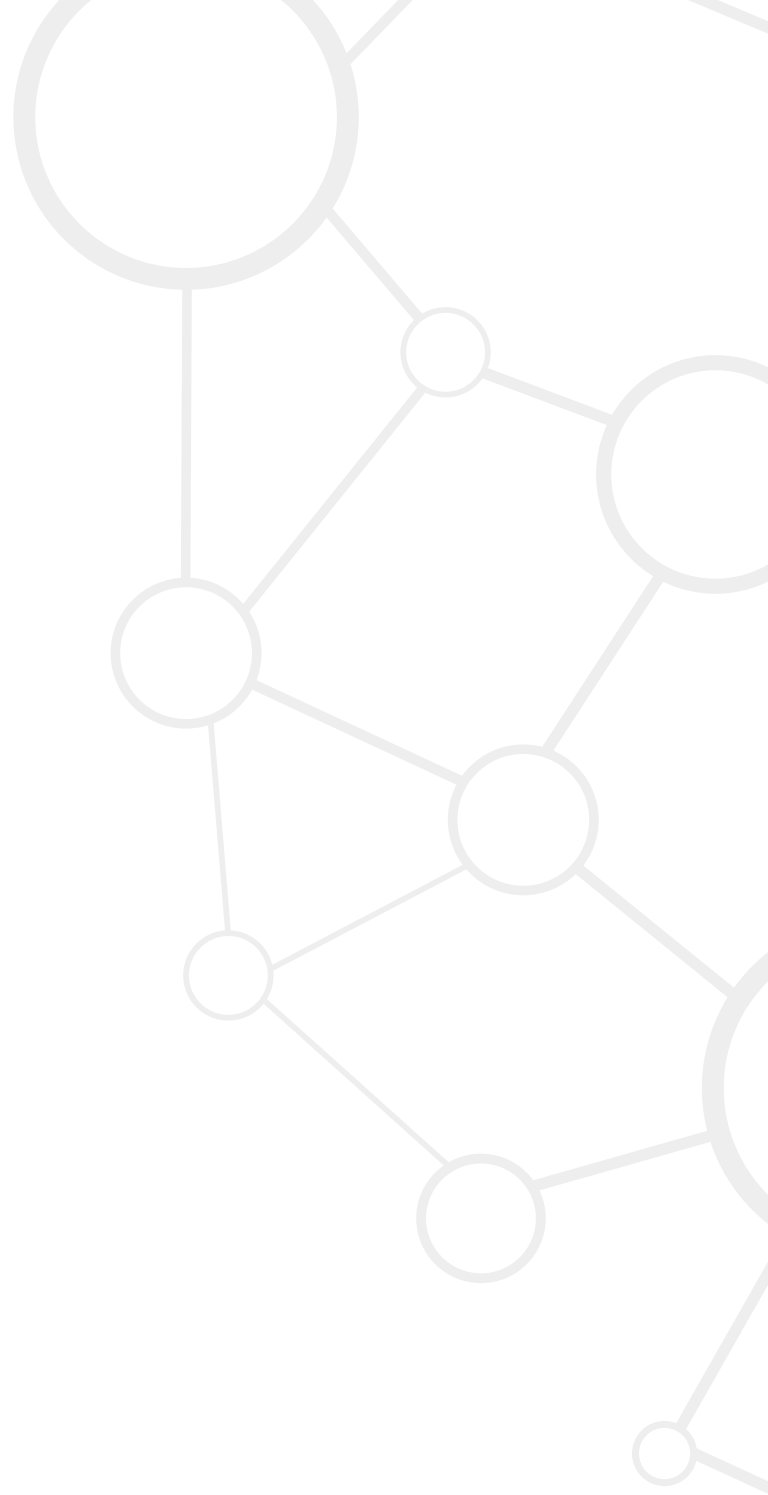




\section{Chapter 3}

Facilitators and barriers in the collaboration between the primary care and the sport sector in order to promote physical activity: A systematic literature review

\section{Published as:}

Leenaars KEF, Smit E, Wagemakers A, Molleman GRM, Koelen MA. Facilitators and barriers in the collaboration between the primary care and the sport sector in order to promote physical activity: A systematic literature review. Preventive Medicine, 2015. 


\begin{abstract}
Introduction

The aim of this review was to identify collaborative initiatives between the primary care and the sport sector in order to promote physical activity (PA), and barriers and facilitators in these initiatives.

\section{Method}

Pubmed, SportDiscus, Web of Science, and SOCindex were systematically searched for publications published between 2000 and June 2014. Publications reporting on collaboration between the primary care and the sport sector to promote PA were included. Publications reporting on non-empirical data were excluded, except for study protocols.
\end{abstract}

\title{
Results
}

The search process yielded 1352 publications. After selection, 40 publications were included. Twenty-eight different initiatives were divided into four forms of collaboration, and two approaches to promote PA were distinguished with different kinds of facilitators and barriers. In the referral of patients, sport professionals' lack of medical knowledge, and health professionals' lack of time, were seen as barriers. In networks to organize activities to promote PA among the community, different shared interests and different cultures were seen as barriers.

\section{Conclusion}

This review showed that performance of intersectoral collaboration and the collaboration between both sectors are still unexplored. This review provides a first step towards an insight into collaboration and factors that facilitate or hinder collaboration between these sectors. 


\section{Introduction}

To address public health challenges like the increasing number of people with chronic diseases, there is a need to join forces both within the healthcare sector and between the health and other societal sectors, especially because no organisation has the resources, access, and trust relationships to address the wide range of community determinants of public health problems [1-4]. Therefore, intersectoral collaboration - defined as people and organisations from multiple sectors working together for a common purpose - has become an increasingly popular health promotion strategy [5]. Intersectoral collaboration between the healthcare and other societal sectors is expected to have the potential to bring about changes in at least two directions. Firstly, it should lead to the improvement of health determinants and thereby the health of individuals and populations. Secondly, it is expected to increase awareness of the health implications of policy decisions and organisational practice within and among these different sectors [2].

Intersectoral collaboration is challenging because it means working in a new area or setting, with new people with different backgrounds, interests, and perspectives $[1,4,6]$. A health broker seems to offer the promise of improving intersectoral collaboration [7]. In 2012, the Dutch Ministry of Health, Welfare, and Sport introduced neighbourhood sport coaches (in Dutch Buurtsportcoach) - to whom a broker role has been ascribed - to stimulate physical activity (PA) and connect the sport sector with other sectors. The sport sector covers all PA services in the neighbourhood, i.e. sport clubs, fitness centres, PA lessons at community centres. Some of these coaches, the so-called Care Sport Connectors (CSCs), are employed specifically to connect the primary care and the sport sector in order to guide primary care patients towards local sport facilities.

Recent years several studies about PA promotion have been conducted in the primary care setting. Reviews provided an overview of the effect of PA or PA promotion on health outcomes [8-11], the effectiveness of PA promotion based in primary care [12-17], and the perceptions of primary care providers on PA promotion $[18,19]$. In addition, reviews considering intersectoral collaboration in the field of health promotion provided an overview of the effectiveness of partnerships for improving community health $[5,20]$. However, no review specifically addresses intersectoral collaboration between the primary care and the sport sector. Research indicates differences between both sectors that influence collaboration, such as culture, target groups, and way of working [21, 22]. However, an overview of barriers to, and facilitators of, this intersectoral collaboration between the primary care and the sport sector is - to our knowledge - not available. CSCs may find it useful to have an overview of initiatives and barriers and facilitators in collaborations between the primary care and the sport sector so that they can facilitate collaboration between these sectors and guide primary care patients towards local sport facilities. Therefore, the aim of this paper is to: 1) document and describe collaborative initiatives between the primary care and the sport sector to promote PA, and 2) identify barriers and facilitators in these collaborative initiatives. 


\section{Method}

\section{Search strategy}

To search for literature on collaboration initiatives between the primary care and the sport sector, a literature search was conducted in Pubmed, SportDiscus, Web of Science, and SOCindex. These databases were systematically searched for original research published in English, Dutch, or German between January 2000 and June 2014. These databases were selected to cover medical and health-related literature from Pubmed and sport-related literature from SportDiscus. Web of Science and SOCindex were searched to cover more general literature about the topic of this review. The time span (2000-2014) was chosen to assess recent evidence on collaboration between the primary care and the sport sector, in particular because intersectoral collaboration has become popular as a health promotion strategy since the start of the 21th century [5].

The search strategy combined the concepts: 1) collaboration, 2) primary care, 3) sport sector, and 4) promote PA. Each of these concepts is operationalised in more detail below. The complete search strategy is shown in table 3.1.

\section{Collaboration}

Because of the variety in strategies for, and definitions of, collaboration, Himmelman's [23] categorisation of collaboration and synonyms for (intersectoral) collaboration were used to operationalise the concept 'collaboration'. 'Broker' was added because of its promising role in facilitating intersectoral collaboration.

\section{Primary care}

Primary care was operationalised by using synonyms for primary care. Actors representing the primary care sector were added as search terms, as also health/lifestyle in combination with intervention/programme, because primary care professionals are often involved in the implementation of these programmes or interventions.

\section{Sport sector}

The sport sector was operationalised with synonyms for sport and combined with actors representing the sport sector.

\section{Promote PA}

Promote PA was operationalised with synonyms for the concept 'promote' and combined with synonyms for the concept 'physical activity'.

The Boolean operators 'OR' and 'AND' were used to separate synonyms and link the concept and the different search term groups. 
Table 3.1 Search strategy for the present review

\begin{tabular}{ll}
\hline Concepts & Search \\
\hline Collaboration & $\begin{array}{l}\text { (collaborat* OR network* OR coordinat* OR cooperat* OR intersector* OR inter- } \\
\text { sector* OR partnership* OR allianc* OR multisector* OR multi-sector* OR broker*) }\end{array}$ \\
\hline Primary care & $\begin{array}{l}\text { ("primary care" OR "public health" OR "health sector" OR "general pract*" OR GP OR } \\
\text { physician OR dietician OR physiotherapist OR "family pract*" OR "health professional*” } \\
\text { OR "health intervention*" OR "health program*" OR "lifestyle program*" OR "lifestyle } \\
\text { intervention*") }\end{array}$ \\
\hline Sport sector & $\begin{array}{l}\text { ((sport OR sports OR physical activity or exercise) AND (sector OR club* OR } \\
\text { organi?ation* OR professional* OR facility OR facilities OR provider* OR organized OR } \\
\text { non-organized OR counsellor* OR service*)) }\end{array}$ \\
\hline $\begin{array}{l}\text { Promote } \\
\text { physical } \\
\text { activity }\end{array}$ & $\begin{array}{l}\text { ((promot* OR improv* OR stimulat* OR increas*) AND ("physical activity" OR sport OR } \\
\text { sports OR exercise OR "active lifestyle")) }\end{array}$ \\
\hline Other & $\begin{array}{l}\text { AND Language=(English OR Dutch OR German) AND Document Type= NOT(review OR } \\
\text { editorial OR conference abstracts OR book OR theoretical arguments) AND }\end{array}$ \\
& NOT(developing countries) \\
\hline
\end{tabular}

\section{Study selection}

In the first selection phase, titles and abstracts of the identified publications were reviewed by the first author (KL). A random selection of $11 \%$ of all titles and abstracts was reviewed by a second reviewer (AW), resulting in $89.2 \%$ agreement between the two reviewers. In the second phase, full texts of potentially relevant publications were independently reviewed by two reviewers ( $K L$ and $\mathrm{AW}$ or ES). Any disagreements were resolved by discussion to reach consensus between the reviewers, or by consulting a third reviewer (AW or ES). For included publications, backward citations (reference lists) and forward citations (via Pubmed and Google Scholar) were checked for additional relevant publications.

Publications were included when: they contained empirical data (1) on collaboration between primary care and the sport sector in order to promote PA and (2) were written in English, Dutch, or German and published between 2000 and June 2014.

1. Books, reviews, theoretical arguments, editorials, conference abstracts were excluded. However, study protocols were included, because they report on existing plans for collaboration initiatives.

2. Publications reporting on collaboration in just one of the sectors were excluded. For example, publications reporting on PA counselling by a GP without sport-sector involvement were excluded. Publications about collaboration between primary care and sport that did not aim to promote PA were also excluded - for example, publications reporting on collaborative initiatives to prevent injuries.

Studies originating in developing countries were excluded since there might be social, cultural, and organisational differences from Western countries and therefore these studies would not be suitable for this review. 


\section{Data analysis}

After the study selection, the full texts of the included studies were examined by two independent researches ( $K L$ and $A W$ ) to analyse the collaborative initiative between primary care and sport (type of collaboration, partners, target group, structure or programme after referral, aim) and to identify barriers and facilitators in these initiatives.

\section{Assessment of study quality}

The quality of included publications reporting on barriers and facilitators in the collaboration between the primary care and the sport sector were assessed independently by three researchers (KL, AW, ES) on the basis of Boulton et al.'s [24] criteria, as shown in table 3.2. These criteria focus on aspects for good practices in sampling, data collection, and analysis in qualitative studies and are therefore suitable for the assessment of study quality. In total, 18 plusses could be assigned. Studies with fewer than 7 plusses were considered as low quality, studies with 7-12 plusses as medium quality, and studies with 13 or more plusses as high quality. 


\section{Table 3.2 Quality assessment of qualitative studies}

\section{Introduction}

1. Is the aim of the study clear?

(i.e. clearly formulated at the beginning and consistent with the way data were collected and analysed)

2. Is a qualitative approach appropriate to the aim? (i.e. aim conceived in terms of investigating 'what' or 'how')

\section{Sample and generalisability}

3. Are the criteria for selecting the sample clearly described? (i.e. exclusion and inclusion criteria specified)

4. Is the method of recruitment clear? (i.e. an account of from where, by whom, and how those potentially included in the sample were contacted)

5. Are the characteristics of the sample adequately described? (i.e. age, gender, ethnicity, social class, and other relevant demographic characteristics)

6. Is the final sample adequate and appropriate? (I. e. large and diverse enough for the aims of the study to be fulfilled)

Methods of data collection

7. Is the fieldwork adequately described? (i.e. an account of where data were collected, by whom, in what context)

8. Are methods of data collection adequately described? (i.e. an account of the ways the data were elicited, and the type and range of questions)

9. Are the data collected systematically? (i.e. evidence of consistent use of interview guide or rationale for ceasing questioning)

10. Are the data collected sensitively? (i. e. evidence of flexible approach, responsiveness to participants' agendas, follow-up questions, and adequate time given)

11. Are careful records of data kept? (i.e. audio/video recordings and fieldnotes which can be independently inspected)

\section{Data analysis}

12. Are the data analysis processes adequately described? (i.e. an account of how data were processed and interpreted; of how concepts, themes, or categories were developed)

13. Is evidence provided in support of the analysis? (i.e. excerpts from original data, summaries of examples, or numerical data presented as evidence for interpretation made)

14. Is sufficient original material presented? (i.e. original material not just a token illustration)

15. Is there evidence that supporting material is representative? (i. e. excerpts are named or numbered and sources given)

16. Is there evidence of efforts to establish validity? (i.e. evidence that accounts of the phenomenon reflect it accurately)

17. Is there evidence of efforts to establish reliability? (i.e. evidence that accounts of the phenomenon are consistent over time or between researchers)

\section{Discussion}

18. Is the study set in a broader context? (i.e. compared with other studies in terms of methods, findings, or implications; related to a wider literature and body of knowledge)

Source: based on Boulton et al. [24] 


\section{Results}

\section{Search results}

After the removal of duplicates, the search process yielded 1352 potentially relevant publications. During the first selection phase, 1221 publications were excluded because they did not meet the inclusion criteria. Full texts of 131 publications were assessed, leading to the inclusion of 25 publications. Fifteen additional publications were included via forward and backward citation tracking. The final sample consists of 40 original publications describing a collaborative initiative between the primary care and the sport sector in order to promote PA. Figure 3.1 is a flow chart representation of the literature selection process.

\subsection{Flow chart of the literature selection process}

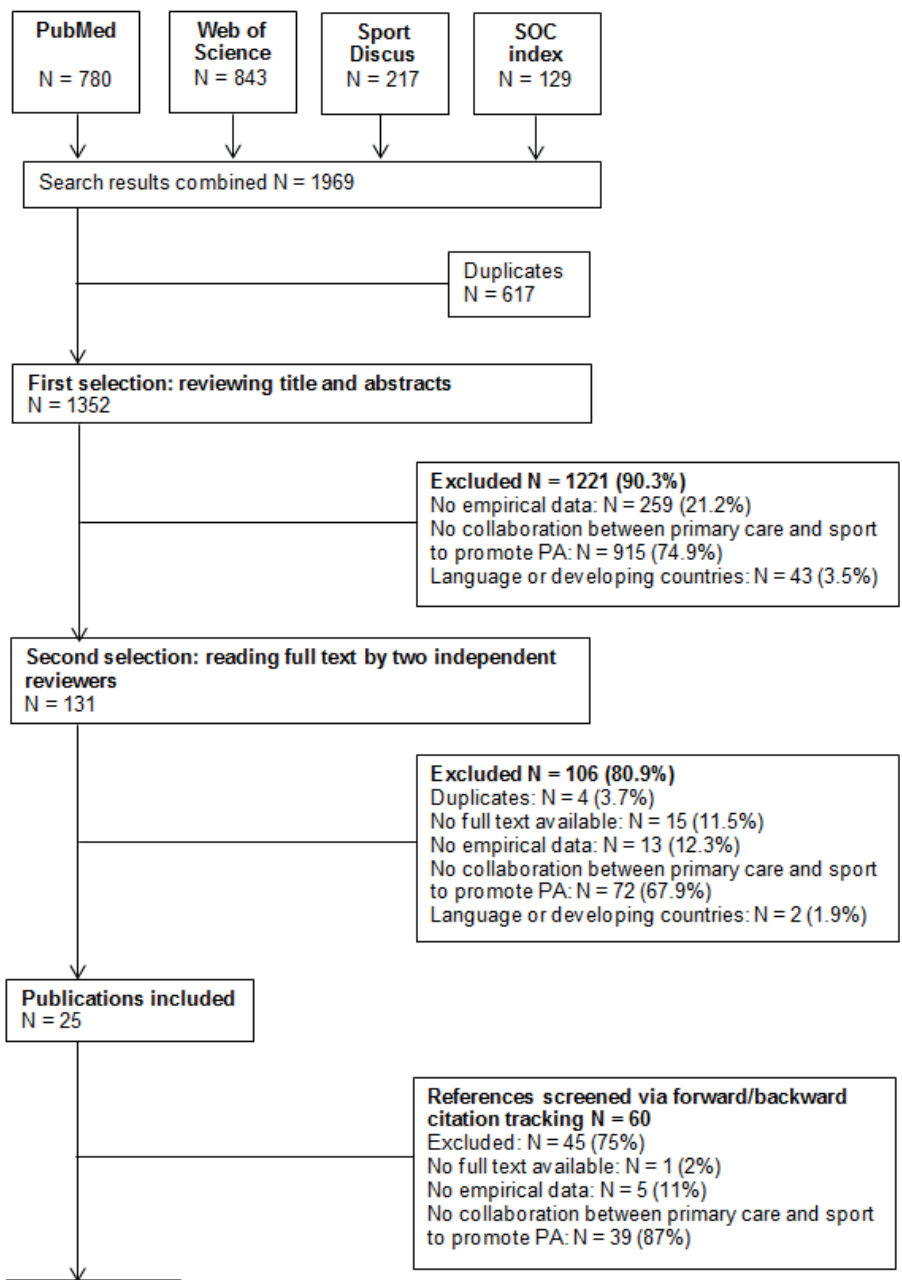

Final inclusion $\mathrm{N}=40$ 


\section{Characteristics of included studies}

Of the 40 studies included in this review, 9 were conducted in Canada and 8 in the USA. Nineteen studies were performed in Europe, of which 12 in the UK, 5 in the Netherlands, 1 in Sweden, and 1 in Germany. Three studies were conducted in Australia and 1 in Colombia. Four studies in this review are study protocols, 14 used quantitative methods, 14, qualitative methods, and eight, mixed methods to study the collaborative initiative. Ten studies aimed to study the effect of the collaborative initiative on participants' PA behaviour, eight aimed to study the experiences of professionals involved in the initiative, seven aimed to study network structures and functions, four evaluated both process and effects of the initiative, four studied participants' experiences, and three did not mention their aim.

\section{Collaborative initiatives between the primary care and the sport sector}

Of the 40 studies included in this review, 20 publications reported on 20 different initiatives between the primary care and the sport sector. The other 20 publications reported on eight different initiatives: the BeweegKuur programme $(n=4), \operatorname{PAC}(n=4)$, VicHealth $(n=2)$, collaboration between a Community Health Centre and a YWCA $(n=2), \operatorname{SESPAN}(n=2), C N-$ Diabetes $(n=2), \operatorname{PARS}(n=2)$, and NERS $(n=2)$.

These 28 initiatives can be divided into four different forms of collaboration between the two sectors. Thirteen initiatives used a referral scheme, ten organised a network among different community partners with representatives of the primary care and the sport sector, four consisted of a multidisciplinary primary care team with a connection to the sport sector, and two developed a partnership between a community health centre and a sport facility. One initiative, the BeweegKuur programme, had two different forms of collaboration. Helmink et al. [25, 26] and Berendsen et al. [27] reported on the multidisciplinary primary care team carrying out the BeweegKuur programme and were allocated to that group. Den Hartog et al. [22] reported on regional and local BeweegKuur alliances and therefore this publication was allocated to the network group.

Although all these four forms of collaborative initiatives aim to promote PA, two different settings and approaches can be distinguished: a primary care setting in which collaboration was set up to refer and guide specifically primary care patients, and a community setting in which collaboration was set up to organize PA activities more in general. In the primary care setting, , primary care patients were referred to sport facilities through referral schemes, a partnership between a health centre and a sport facility, or a multidisciplinary primary care team. In the community setting, activities to promote PA were organized by a community network of primary care and sport professionals. Appendix 3.1 provides a complete overview of all 28 collaborative initiatives.

\section{Collaborative initiatives to refer primary care patients to sport facilities}

Referral schemes

Nine of the 13 referral schemes were implemented in the United Kingdom, two in Canada, one in the Netherlands, and one in Sweden. In all these initiatives, primary care professionals made the referral. In four initiatives, a GP made the referral [28-31], and, in one initiative, a physiotherapist made the referral [32]. Four initiatives used referral cards to refer patients to a local leisure centre or sport and recreation organisations [28, 30, 31, 33]. In two initiatives, a leisure centre staff member contacted the patient after referral [29, 34], and in three other initiatives patients were contacted by a member of the initiative [35-37]. Six initiatives did not explicitly mention the method of referral. 
The programme after referral differed in the initiatives. In nine initiatives, patients were given an exercise programme at the sport facility [28, 30, 33-35, 38-41]. One of these initiatives used a standardised exercise support protocol [34]. In four initiatives, prescribed PA could be either self-monitored, organised activities, or a consultation with a sport advisor for referral to exercise groups or information [31, 36, 37, 42], and in one initiative patients received a subsidised leisure pass [29]. One initiative did not mention the programme after referral [32].

The focus in all 13 referral schemes was on promoting PA among sedentary patients or patients who could benefit from PA. Four initiatives had a more specific focus: to effect a change in lifestyle, or to achieve 30 minutes of moderate PA at least five days per week, [28, $36,37,41]$. All 13 referral schemes referred primary care patients, but five initiatives had a more specific target group: patients from deprived neighbourhoods or patients with risk factors for certain diseases, like cardiovascular disease, diabetes, anxiety, or depression [32, $34,36,40,41]$.

\section{Multidisciplinary primary care team with a connection to the sport sector}

Four initiatives consisted of a multidisciplinary primary care team with a connection to the sport sector. Two multidisciplinary primary care teams were organised in Canada, one in the Netherlands, and one in Germany.

Three initiatives consisted of a multidisciplinary care team carrying out the programme, establishing links with local sport facilities or referring patients to these local sport facilities [25-27, 43-45]. These multidisciplinary care teams consisted always of a GP, a physiotherapist, and a dietician. These three initiatives targeted specific groups: patients with diabetes [43,45], primary care patients [25-27], and residents aged 60 years or older who were not in need of care and were living independently [44].

The other initiative integrated a PA counsellor in the primary care team [46-49]. Patients received intensive autonomy-supportive counselling over a three-month period by the PA counsellor.

Partnership between a community health centre and a sport facility

Two initiatives, both in the USA, organised a formal partnership between a community health centre and a local sport facility, with the aim of improving access to an exercise programme for low-income patients [50-52]. In these initiatives, patients received free membership of the YMCA after referral by community health centre professionals.

\section{Collaborative initiatives to promote PA among the community}

Network among community partners including the primary care and the sport sector Ten initiatives organised a network for the organisation of activities to promote PA among the community. Four of these networks were organised in the USA. The other networks were organised in Canada ( $n=1)$, Australia $(n=2)$, United Kingdom $(n=1)$, the Netherlands $(n=1)$, and Colombia $(n=1)$. All these 10 networks consisted of different community-based, non-profit, and public organisations [21, 22, 53-62].

The 10 initiatives aimed to promote PA among different target groups. Three had a more specific aim: two initiatives aimed to make it easier for people to be active in their daily routines and to make healthy choices more available $[53,55]$, and one initiative aimed to reduce cardio-vascular disease (CVD) risk factors among Hispanics [54]. Nine networks targeted the whole community, and four of these networks had a more specific target group in the community: Hispanics [54], low-income groups [21, 56], children [59], primary care 
patients [22], and older adults [57, 58].

\section{Facilitators and barriers in the collaboration between the primary care and the sport sector}

Of the 40 publications included in this review, 13 reported facilitators and/or barriers in 12 different collaborative initiatives. Seven studies in these publications were assessed as high quality and six studies as medium quality (Appendix A.2).

Seven publications reported on barriers and/or facilitators specific to the collaboration between the primary care and the sport sector: four reported on facilitators/barriers in the referral of primary care patients to local sport facilities [28, 31, 32, 52], and three reported on facilitators/barriers in the promotion of PA through a community network $[21,22,56]$. The other six publications reported on barriers and/or facilitators not specific to the collaboration between the primary care and the sport sector but to intersectoral collaboration in general $[43,53,57,59,60,62]$. Table 3.3 gives an overview of facilitators and barriers in the different forms of collaboration and approaches, and Appendix 3.2 provides a complete overview of facilitators and barriers in the collaborative initiatives.

\section{Facilitators and barriers in collaborative initiatives to refer primary care patients to sport} facilities

Facilitators for the referral of primary care patients to local sport facilities were reported in two publications on a referral scheme $[28,31]$ and in one publication on a partnership between a health centre and a sport facility [52]. Trinh et al. [31] and Cashman et al.[52] reported that collaboration provided physicians with a better understanding and awareness of the services and support available to their patients. The referral scheme also laid the groundwork for a relationship between physicians and sport organisations. Foley et al. [28] and Cashman et al.[52] reported that the referral process provided a welfarist and commercial benefit for leisure. Both publications reported funding [28] or remuneration [31] as a priority or a key influence on ongoing implementation.

Barriers to the referral of primary care patients to local sport facilities were reported in three publications on a referral scheme $[28,31,32]$ and in one publication on a partnership between a health centre and sport facility [52]. Three publications identified lack of communication as a barrier in the collaboration [28, 31, 52]. Physicians mentioned the lack of feedback from the sport or leisure professionals on their patients' progress. Another barrier was leisure or sport professionals' limited medical knowledge [28, 32]. Therefore, physicians and physiotherapists were 'unsure' and 'apprehensive' of the PA programme for the patients and 'uncomfortable' with the leisure or fitness professionals. Also, physicians' and physiotherapists' lack of time was identified as a barrier that caused problems for physicians to implement the interventions. Barriers to the partnership between the health centre and sport facility resulted mostly from the success of the partnership. The high number of patient referrals led to overcrowding, which resulted in reducing the number of referred patients who could use the facility. 


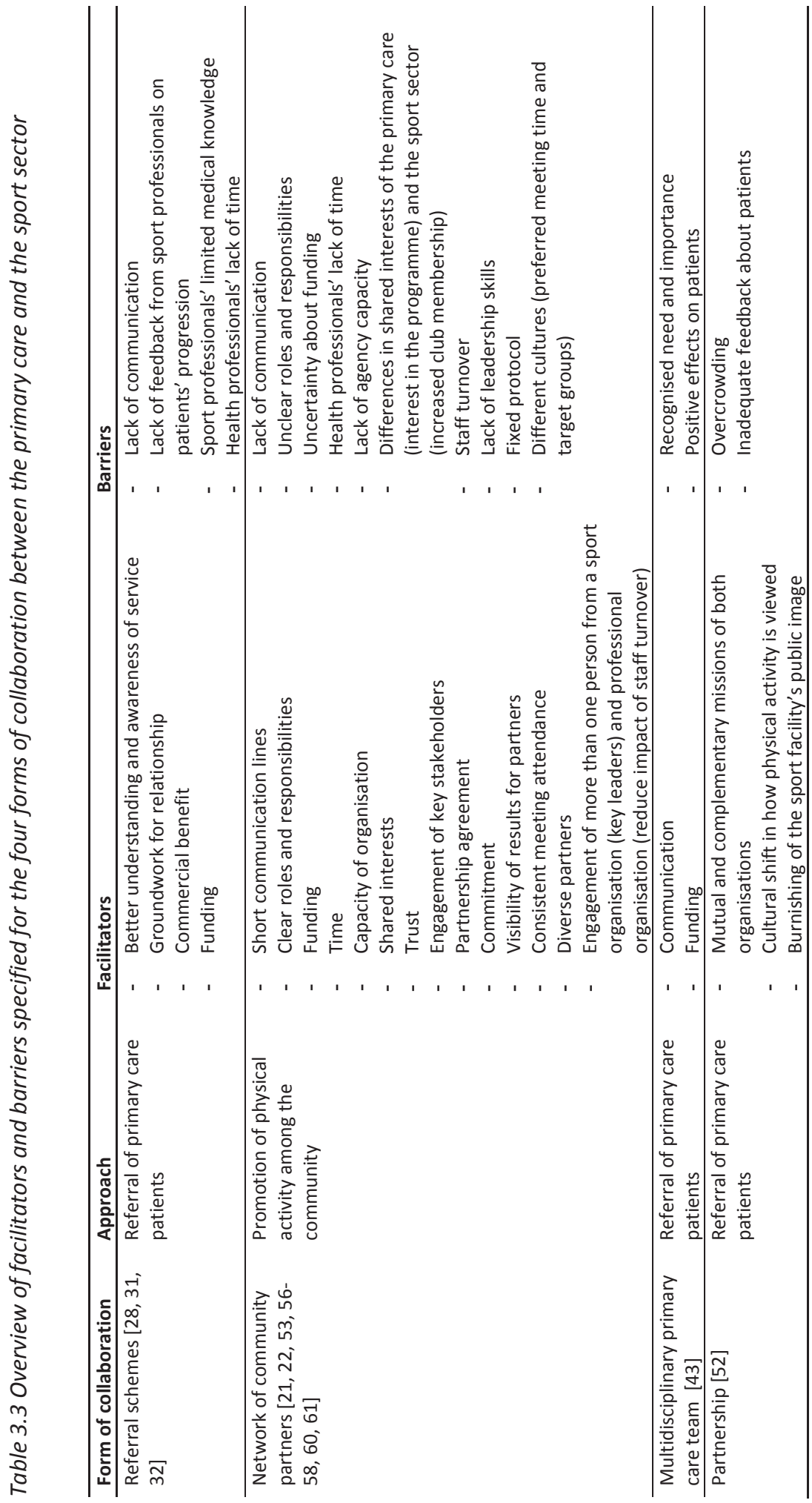




\section{Facilitators and barriers in collaborative initiatives to organize activities to promote PA} among the community

Three publications reported on facilitators/barriers in the promotion of PA through a community network with representatives of the primary care and the sport sector [21, 22, 56]. Trust and shared interests among members [56], having enough time to develop trust among members [22], funding [56], formalisation of the partnership agreement [21], and the engagement of key stakeholders [21] were seen as facilitating factors for partnership formation. Short communication lines and communicating roles and responsibilities [22, 56], the organisation's capacity to participate and develop programmes, the organisation's commitment, engagement of more than one person from a sport organisation (key leaders that influence the strategic direction of the sports club), professional organisation (reduce the impact of staff turnover), and visibility of results for the partners $[22,56]$ were seen as facilitating factors for the partnership function.

The barriers identified in publications on networks among different community partners to promote PA were mainly the inverse of the facilitators mentioned above. So, a lack of communication, unclear roles and responsibilities, staff turnover in professional organisations [56], lack of agency capacity [56], lack of leadership [56], and uncertainty about funding [22] were mentioned as barriers in the collaboration between the primary care and the sport sector.

Some of the barriers were caused by differences in shared interests and culture in both sectors $[21,22,56]$. Differences between the shared interest of professional organisations (interest in the programme) and that of volunteer groups (increased club memberships) [56], and different cultures in the primary care and the sport sector (preferred meeting time and target groups) [22] led to difficulties in engaging sport organisations in the partnership [21, $22,56]$. Sport organisations did not always recognise the benefits of the partnership $[21,56]$ or were not familiar with the types of participant in the intervention programme (obese people, often in combination with low socio-economic status) [22]. In addition, health professionals' lack of time to establish partnerships [21] or to refer patients [22] hindered the collaboration.

\section{Barriers to, and facilitators of, intersectoral collaboration}

Six publications reported on barriers and/or facilitators without specifically addressing these in relation to the collaboration between the primary care and the sport sector. However, the facilitators and barriers identified in these publications largely resembled facilitators and barriers found for the collaboration between the primary care and the sport sector. In addition, factors identified as barriers or facilitators were often the inverse of the facilitators or barriers. So, recruiting diverse partners and engaging key stakeholders [53, 59, 62], time to build relationships, shared interest among partners, consistent meeting attendance, leadership skills [53], the involvement of more than one person from the organisations in the partnership [53], communication [43, 53, 62], funding [53, 59], clarity about roles and responsibilities $[53,59]$, and building upon an existing structure [43] were identified as factors that facilitated the development of these collaborative initiatives, or whose absence hindered it. 


\section{Discussion}

This review has shown that collaboration between the primary care and the sport sector, and the performance of these collaborative initiatives, are still unexplored. Most publications reported on the effects of PA promotion on patients' health status or PA behaviour. Of the 40 publications, only 13 mentioned facilitators and barriers, of which nine specifically aimed to study partnership-related processes. In addition, one of these publications [22] made use of a framework for intersectoral collaboration, Koelen et al.'s [4] HALL framework, to identify factors that hinder or facilitate the success of alliances. These findings are consistent with two other reviews considering intersectoral collaboration, which also noted a lack of empirical research evaluating the functioning and effectiveness of partnerships $[5,20]$ and the failure to use theoretical frameworks [20].

Despite the limited number of studies on partnership-related processes in the collaboration between the primary care and the sport sector, this review has identified facilitators and barriers specific to such collaboration, alongside facilitators and barriers for intersectoral collaboration in general. The facilitators and barriers specific to the collaboration between the primary care and the sport sector differed in the two approaches to promote PA identified in this review; this can be explained by differences in the structure of the collaborative initiatives.

The initiatives focusing on the referral of primary care patients can be characterised as a coordination; this means that organisations or professionals modify their activities so that together they can provide better services and make these services more user friendly [23]. In these initiatives, professionals work in their own field in order to provide a PA programme for primary care patients. This form of collaboration can also be characterised as multidisciplinary, whereby different disciplines work independently on different aspects of a project [63]. Therefore, in these initiatives, facilitators and barriers relating to their joint services were identified, such as: a better understanding and awareness among health professionals about PA, sport professionals' limited medical knowledge and their failure to provide feedback to health professionals, and health professionals' lack of time.

The initiatives focusing on the organization of activities to promote PA through community networks can be characterised as (intersectoral) collaboration, in which organisations share resources, alter activities, and enhance their capacity for mutual benefit and to achieve a common purpose [23]. In these networks, professionals work together in order to develop or implement programmes for PA promotion. This form of collaboration can also be characterised as interdisciplinary, whereby different disciplines work together on the same project [63]. Therefore, professionals in these networks are dealing with differences in both sectors' shared interest (interest in the programme or increased club membership) and cultures (target groups and meeting time).

The identified general facilitators of intersectoral collaboration, such as communication, clarity about roles and responsibilities, agency capacity, leadership skills, and trust, were often the inverse of the barriers and are mostly similar to other studies on intersectoral collaboration $[4,5,20]$. These factors are inherent in intersectoral collaboration because this means working in a new area with partners with different interests and backgrounds $[1,4$, 6]. Therefore, it is not surprising that in collaborative initiatives between the primary care and the sport sector these general factors for intersectoral collaboration were also identified.

This review is a first step towards an insight into collaboration between the primary care and the sport sector and the factors that facilitate or hinder collaboration between them. This is 
valuable information, especially for professionals deployed to facilitate collaboration between these two sectors, like the CSC. For example, it is useful to know that health professionals need to receive adequate feedback on patients' progress or that more than one person from a sport organisation should be engaged in the collaboration. However, there is need for more studies focusing on partnership-related processes between the primary care and the sport sector. The evaluation of intersectoral collaboration and the use of frameworks for intersectoral collaboration to assess prerequisites in partnerships are important because focusing on more intermediate outcomes enhances the functioning of a partnership by helping to identify and provide feedback on what is (and is not) working [5]. Consequently, this can contribute to the success of the partnership, because many partnerships do not survive their first year or remain in the development phase of plans or of the implementation of interventions $[6,64]$.

To study the effectiveness of the different collaborative initiatives on stimulating PA was not the aim of this review, but some included studies reported on the effectiveness. These studies mentioned an improvement on different outcomes. Some studies reported on an increased number of PA activities organised $[57,58]$, other studies reported on an increased level of PA behaviour [29, 31, 34, 35, 37, 42, 47, 54], and others on improved health outcomes [30,34, 37, 39, 50,51], However, due to the different measuring methods, target groups, and different outcomes it is not possible to relate the outcomes to the different forms of collaboration. Other studies are necessary to study which of these different collaborative initiatives are effective for increasing PA.

\section{Study limitations}

Although the literature was systematically searched, it is possible that relevant studies were not found or included. Publications for which no full text was available were excluded from the search. In addition, only publications that described very clearly the partners in the collaborative initiative could be included. Many publications did not mention the professions of the partners in the collaborative initiative, thereby making it hard to ascertain whether professionals from the primary care and the sport sector were involved. In particular, publications reporting about networks often do not mention the type of partner. Another limitation has to do with the study quality of the included publications. Although all publications were assessed as medium or high quality, some of the medium quality studies scored low on data collection method $[43,57]$. These publications in comparison with other studies did not describe clearly the processes of data collection and analysis, and therefore the validity and reliability of the results of these publications was difficult to determine.

\section{Conclusion}

Collaboration between the primary care and the sport sector is unexplored. This review provides a first insight into factors that facilitate or hinder collaboration between these sectors. However, there is need for more studies focusing on partnership-related outcomes between the primary care and the sport sector. 


\section{References}

1. Granner ML, Sharpe PA: Evaluating community coalition characteristics and functioning: A summary of measurement tools. Health education research 2004, 19(5):514-532.

2. Green L, Daniel M, Novick L: Partnerships and coalitions for community-based research. Public health reports 2001, 116(SUPPL. 1):20-31.

3. Koelen MA, Vaandrager L, Wagemakers A: What is needed for coordinated action for health? Family Practice 2009, 25(SUPPL. 1):i25-i31.

4. Koelen MA, Vaandrager L, Wagemakers A: The healthy alliances (HALL) framework: Prerequisites for success. Family Practice 2012, 29(SUPPL. 1):i132-i138.

5. Roussos ST, Fawcett SB: A review of collaborative partnerships as a strategy for improving community health. Annual Review of Public Health 2000, 369-402.

6. Lasker RD, Weiss ES, Miller R: Partnership Synergy: A Practical Framework for Studying and Strengthening the Collaborative Advantage. The Milbank quarterly 2001, 79(2):179205.

7. Harting J, Kunst AE, Kwan A, Stronks K: A 'health broker' role as a catalyst of change to promote health: An experiment in deprived Dutch neighbourhoods. Health Promotion International 2011, 26(1):65-81.

8. Chimen M, Kennedy A, Nirantharakumar K, Pang TT, Andrews R, Narendran P: What are the health benefits of physical activity in type 1 diabetes mellitus? A literature review. Diabetologia 2012, 55(3):542-551.

9. Pavey TG, Taylor AH, Fox KR, Hillsdon M, Anokye N, Campbell JL, Foster C, Green C, Moxham T, Mutrie $\mathrm{N}$ et al.: Republished research: Effect of exercise referral schemes in primary care on physical activity and improving health outcomes: systematic review and meta-analysis. British journal of sports medicine 2013, 47(8):526.

10. Semlitsch T, Jeitler K, Hemkens LG, Horvath K, Nagele E, Schuermann C, Pignitter N, Herrmann KH, Waffenschmidt S, Siebenhofer A: Increasing physical activity for the treatment of hypertension: a systematic review and meta-analysis. Sports medicine 2013, 43(10):1009-1023.

11. Vaes AW, Cheung A, Atakhorrami M, Groenen MT, Amft O, Franssen FM, Wouters EF, Spruit MA: Effect of 'activity monitor-based' counseling on physical activity and healthrelated outcomes in patients with chronic diseases: A systematic review and metaanalysis. Annals of medicine 2013, 45(5-6):397-412.

12. Lawlor DA, Hanratty B: The effect of physical activity advice given in routine primary care consultations: a systematic review. Journal of public health medicine, 2001, 23(3):219226.

13. Neidrick TJ, Fick DM, Loeb SJ: Physical activity promotion in primary care targeting the older adult. Journal of the American Academy of Nurse Practitioners 2012, 24(7):405-416.

14. Orrow G, Kinmonth AL, Sanderson S, Sutton S: Effectiveness of physical activity promotion based in primary care: systematic review and meta-analysis of randomised controlled trials. BMJ 2012, 344:e1389.

15. Sanchez A, Bully P, Martinez C, Grandes G: Effectiveness of physical activity promotion interventions in primary care: A review of reviews. Preventive medicine 2014.

16. Stevens Z, Barlow C, Kendrick D, Masud T, Skelton DA, Dinan-Young S, Iliffe S: Effectiveness of general practice-based physical activity promotion for older adults: systematic review. Primary health care research \& development 2014, 15(2):190-201.

17. Vuori IM, Lavie CJ, Blair SN: Physical activity promotion in the health care system. Mayo Clinic proceedings 2013, 88(12):1446-1461. 
18. Hebert ET, Caughy MO, Shuval K: Primary care providers' perceptions of physical activity counselling in a clinical setting: a systematic review. British journal of sports medicine 2012, 46(9):625-631.

19. Hinrichs $T$, Brach $M$ : The general practitioner's role in promoting physical activity to older adults: a review based on program theory. Current aging science 2012, 5(1):41-50.

20. Zakocs RC, Edwards EM: What explains community coalition effectiveness?: a review of the literature. American journal of preventive medicine 2006, 30(4):351-361.

21. Casey MM, Payne WR, Eime RM: Partnership and capacity-building strategies in community sports and recreation programs. Managing Leisure 2009, 14(3):167-176.

22. den Hartog F, Wagemakers A, Vaandrager L, van Dijk M, Koelen MA: Alliances in the Dutch BeweegKuur lifestyle intervention. Health Education Journal 2014, 73(5):576-587.

23. Himmelman A: Collaboration for Change: Definitions, Decision making models, Roles and Collaboration Process Guide. In. https://depts.washington.edu/ccph/pdf files/4achange.pdf; 2002.

24. Boulton M, Fitzpatrick R, Swinburn C: Qualitative research in health care: II. A structured review and evaluation of studies. Journal of evaluation in clinical practice 1996, 2(3):171179.

25. Helmink JH, Kremers SP, van Boekel LC, van Brussel-Visser FN, de Vries NK: Factors determining the motivation of primary health care professionals to implement and continue the 'Beweegkuur' lifestyle intervention programme. Journal of evaluation in clinical practice 2012, 18(3):682-688.

26. Helmink JHM, Meis JJM, de Weerdt I, Visser FN, de Vries NK, Kremers SPJ: Development and implementation of a lifestyle intervention to promote physical activity and healthy diet in the Dutch general practice setting: the BeweegKuur programme. International Journal of Behavioral Nutrition and Physical Activity 2010, 7.

27. Berendsen BA, Hendriks MR, Verhagen EA, Schaper NC, Kremers SP, Savelberg HH: Effectiveness and cost-effectiveness of 'BeweegKuur', a combined lifestyle intervention in the Netherlands: rationale, design and methods of a randomized controlled trial. $B M C$ public health 2011, 11:815.

28. Foley M, Frew M, McPherson G, Reid G: Healthy public policy: a policy paradox within local government. Managing Leisure 2000, 5(2):77-90.

29. Harrison RA, Roberts C, Elton PJ: Does primary care referral to an exercise programme increase physical activity 1 year later? A randomized controlled trial. Journal of Public Health 2005, 27(1):25-32.

30. Taylor AH, Fox KR: Effectiveness of a primary care exercise referral intervention for changing physical self-perceptions over 9 months. Health Psychology 2005, 24(1):11-21.

31. Trinh L, Wilson R, Williams HM, Sum AJ, Naylor PJ: Physicians promoting physical activity using pedometers and community partnerships: a real world trial. British journal of sports medicine 2012, 46(4):284-290.

32. Wiles R, Demain S, Robison J, Kileff J, Ellis-Hill C, McPherson K: Exercise on prescription schemes for stroke patients post-discharge from physiotherapy. Disability and Rehabilitation 2008, 30(26):1966-1975.

33. Hardcastle S, Taylor AH: Looking for more than weight loss and fitness gain: psychosocial dimensions among older women in a primary-care exercise-referral program. Journal of Aging \& Physical Activity 2001, 9(3):313-328.

34. Annesi JJ, Tennant G, Chapman A, Sewell K: Effects of The Coach Approach intervention on psychosocial predictors of exercise and subsequent changes in glucose metabolism, 
cardiorespiratory functioning, and body composition: a pilot project of the interior health of British Columbia and a. Archives of Exercise in Health \& Disease 2012, 3(1/2):162-167.

35. James DVB, Johnston LH, Crone D, Sidford AH, Gidlow C, Morris C, Foster C: Factors associated with physical activity referral uptake and participation. Journal of Sport Science 2008, 26(2):217-224.

36. Schmidt M, Absalah S, Nierkens V, Stronks K: Which factors engage women in deprived neighbourhoods to participate in exercise referral schemes? BMC public health 2008, 8.

37. Wormald H, Waters H, Sleap M, Ingle L: Participants' perceptions of a lifestyle approach to promoting physical activity: targeting deprived communities in Kingston-Upon-Hull. BMC public health 2006, 6.

38. Crone D, Johnston LH, Gidlow C, Henley C, James DV: Uptake and participation in physical activity referral schemes in the UK: an investigation of patients referred with mental health problems. Issues in mental health nursing 2008, 29(10):1088-1097.

39. Lee ASW, Griffin SJ, Simmons RK, Council FHD: An evaluation of the effectiveness of 'Active for Life': An exercise referral scheme in West Suffolk. Journal of Public Health 2009, 123(10):670-672.

40. Moore GF, Moore L, Murphy S: Facilitating adherence to physical activity: exercise professionals' experiences of the National Exercise Referral Scheme in Wales. a qualitative study. BMC public health 2011, 11.

41. Murphy S, Raisanen L, Moore G, Edwards RT, Linck P, Williams N, Ud Din N, Hale J, Roberts C, McNaish E et al: A pragmatic randomised controlled trial of the Welsh National Exercise Referral Scheme: protocol for trial and integrated economic and process evaluation. BMC public health 2010, 10:352.

42. Kallings LV, Leijon M, Hellenius ML, Stahle A: Physical activity on prescription in primary health care: a follow-up of physical activity level and quality of life. Scandanvian Journal of Medicine and Science in Sports 2008, 18(2):154-161.

43. De Civita M, Dasgupta K: Using diffusion of innovations theory to guide diabetes management program development: an illustrative example. Journal of Public Health 2007, 29(3):263-268.

44. Hofreuter-Gatgens K, Mnich E, Thomas D, Salomon T, von dem Knesebeck O: Active health promotion among the aged in a rural region. Participants, acceptance, and implementation. Bundesgesundheitsblatt 2011, 54(8):933-941.

45. Nasmith L, Cote B, Cox J, Inkell D, Rubenstein H, Jimenez V, Rodriguez R, Larouche D, Contandriopoulos AP, Cote-des-Neiges Diabetes Project T: The challenge of promoting integration: conceptualization, implementation, and assessment of a pilot care delivery model for patients with type 2 diabetes. Family medicine 2004, 36(1):40-45.

46. Fortier MS, Hogg W, O'Sullivan TL, Blanchard C, Reid RD, Sigal RJ, Boulay P, Doucet E, Sweet $\mathrm{S}$, Bisson E et al: The physical activity counselling (PAC) randomized controlled trial: rationale, methods, and interventions. Applied Physiology Nutrition and Metabolism-Physiologie Appliquee Nutrition Et Metabolisme 2007, 32(6):1170-1185.

47. Fortier MS, Hogg W, O'Sullivan TL, Blanchard C, Sigal RJ, Reid RD, Boulay P, Doucet É, Bisson É, Beaulac J et al: Impact of integrating a physical activity counsellor into the primary health care team: physical activity and health outcomes of the Physical Activity Counselling randomized controlled trial. Applied Physiology, Nutrition \& Metabolism 2011, 36(4):503-514.

48. Fortier MS, Wiseman E, Sweet SN, O'Sullivan TL, Blanchard CM, Sigal RJ, Hogg W: A moderated mediation of motivation on physical activity in the context of the Physical 
Activity Counseling randomized control trial. Psychology Sport Exercice 2011, 12(2):7178.

49. O'Sullivan TL, Fortier MS, Faubert C, Culver D, Blanchard C, Reid R, Hogg WE: Interdisciplinary physical activity counseling in primary care A qualitative inquiry of the patient experience. Journal of Health Psychology 2010, 15(3):362-372.

50. Boyd ST, Scott DM, Augustine SC: Exercise for low-income patients with diabetes - A continuous quality improvement project. Diabetes Educator 2006, 32(3):385-393.

51. Candib LM, Silva M, Cashman SB, Ellstrom D, Mallett K: Creating open access to exercise for low-income patients through a community collaboration for quality improvement: if you build it, they will come. The Journal of ambulatory care management 2008, 31(2):142-150.

52. Cashman SB, Flanagan P, Silva MA, Candib LM: Partnering for health: collaborative leadership between a community health center and the YWCA central Massachusetts. Journal of public health management and practice : JPHMP 2012, 18(3):279-287.

53. Baker EA, Wilkerson R, Brennan LK: Identifying the role of community partnerships in creating change to support active living. American journal of preventive medicine 2012, 43(5 Suppl 4):S290-299.

54. Balcazar H, Wise S, Rosenthal EL, Ochoa C, Rodriguez J, Hastings D, Flores L, Hernandez L, Duarte-Gardea M: An ecological model using promotores de salud to prevent cardiovascular disease on the US-Mexico border: the HEART project. Preventing chronic disease 2012, 9:E35-E35.

55. Barnes M, MacLean J, Cousens L: Understanding the structure of community collaboration: the case of one Canadian health promotion network. Health Promotion International 2010, 25(2):238-247.

56. Casey MM, Payne WR, Brown SJ, Eime RM: Engaging community sport and recreation organisations in population health interventions: Factors affecting the formation, implementation, and institutionalisation of partnerships efforts. Annals of Leisure Research 2009, 12(2):129-147.

57. Cheadle A, Egger R, LoGerfo JP, Schwartz S, Harris JR: Promoting Sustainable Community Change in Support of Older Adult Physical Activity: Evaluation Findings from the Southeast Seattle Senior Physical Activity Network (SESPAN). Journal of Urban HealthBulletin of the New York Academy of Medicine 2010, 87(1):67-75.

58. Cheadle A, Egger R, LoGerfo JP, Walwick J, Schwartz S: A community-organizing approach to promoting physical activity in older adults: the southeast senior physical activity network. Health promotion practice 2010, 11(2):197-204.

59. de Groot FP, Robertson NM, Swinburn BA, de Silva-Sanigorski AM: Increasing community capacity to prevent childhood obesity: challenges, lessons learned and results from the Romp \& Chomp intervention. BMC public health 2010, 10.

60. Evans AB, Sleap M: "Swim for Health": Program Evaluation of a Multiagency Aquatic Activity Intervention in the United Kingdom. International Journal of Aquatic Research \& Education 2013, 7(1):24-38.

61. Litt JS, Reed HL, Tabak RG, Zieff SG, Eyler AA, Lyn R, Goins KV, Gustat J, Tompkins NO: Active Living Collaboratives in the United States: Understanding Characteristics, Activities, and Achievement of Environmental and Policy Change. Preventing Chronic Disease 2013, 10.

62. Meisel JD, Sarmiento OL, Montes F, Martinez EO, Lemoine PD, Valdivia JA, Brownson RC, Zarama R: Network analysis of Bogota's Ciclovia Recreativa, a self-organized 
multisectorial community program to promote physical activity in a middle-income country. American journal of health promotion : AJHP 2014, 28(5):e127-136.

63. Choi BC, Pak AW: Multidisciplinarity, interdisciplinarity and transdisciplinarity in health research, services, education and policy: 1 . Definitions, objectives, and evidence of effectiveness. Clinical and investigative medicine Medecine clinique et experimentale 2006, 29(6):351-364.

64. Kreuter MW, Lezin, N.A., Young, L.A.: Evaluating Community-Based Collaborative Mechanisms: Implications for Practitioners. Health promotion practice 2000, 1(1):49-63.

65. Brownson RC, Brennan LK, Evenson KR, Leviton LC. Lessons from a Mixed-Methods Approach to Evaluating Active Living by Design. American Journal of Preventive Medicine 2012, 43 (5), S271-S280. 
Appendix 


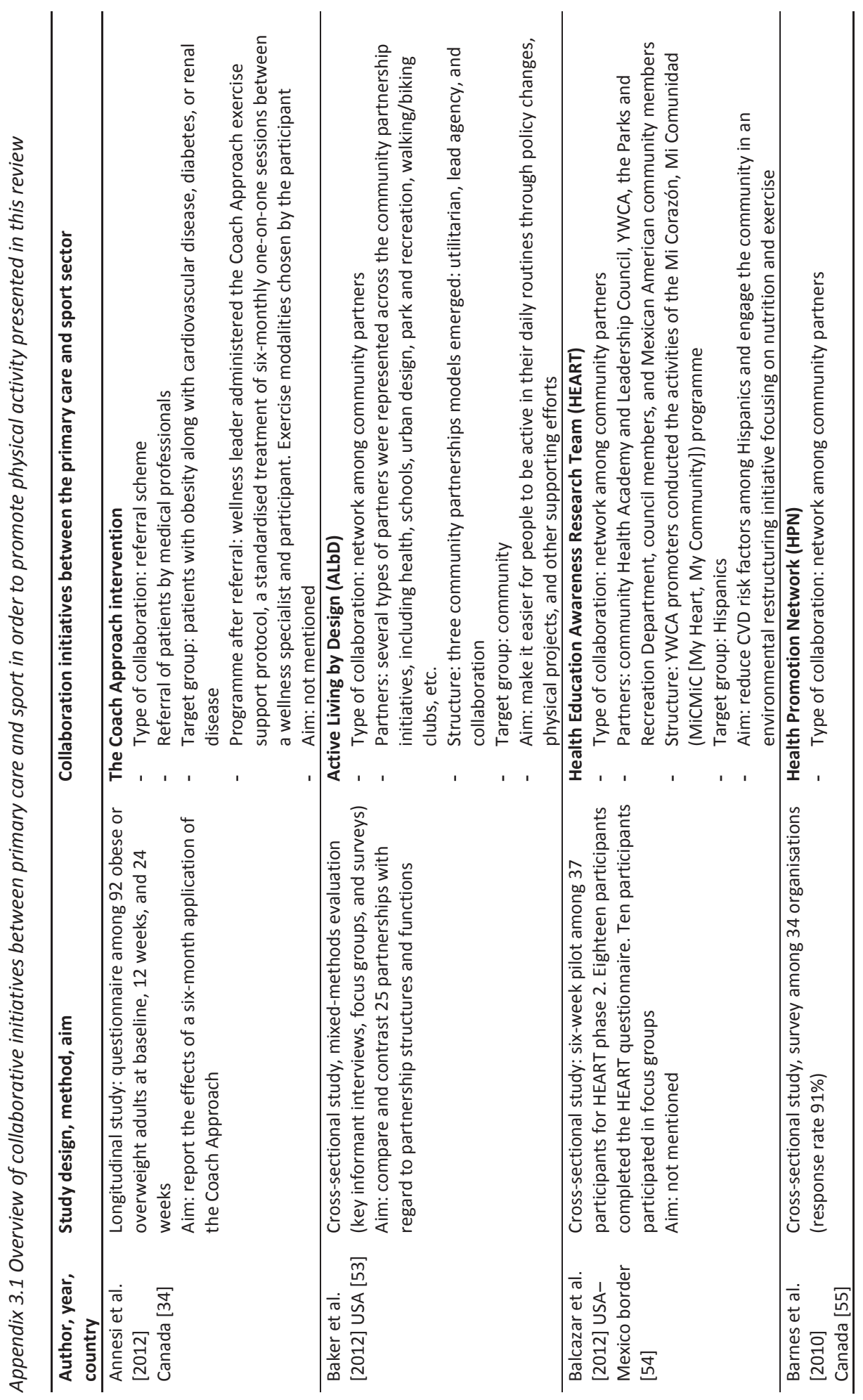




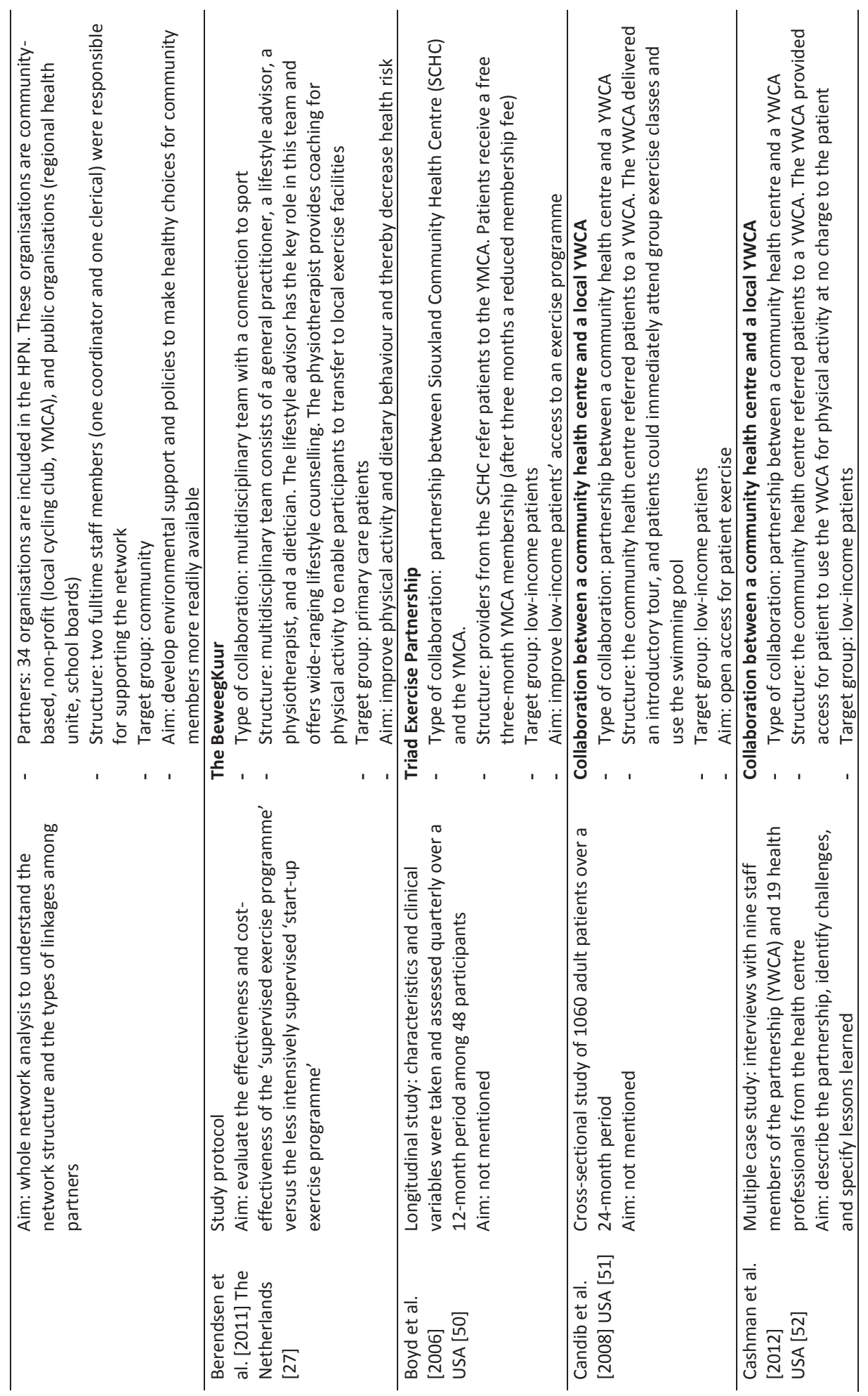




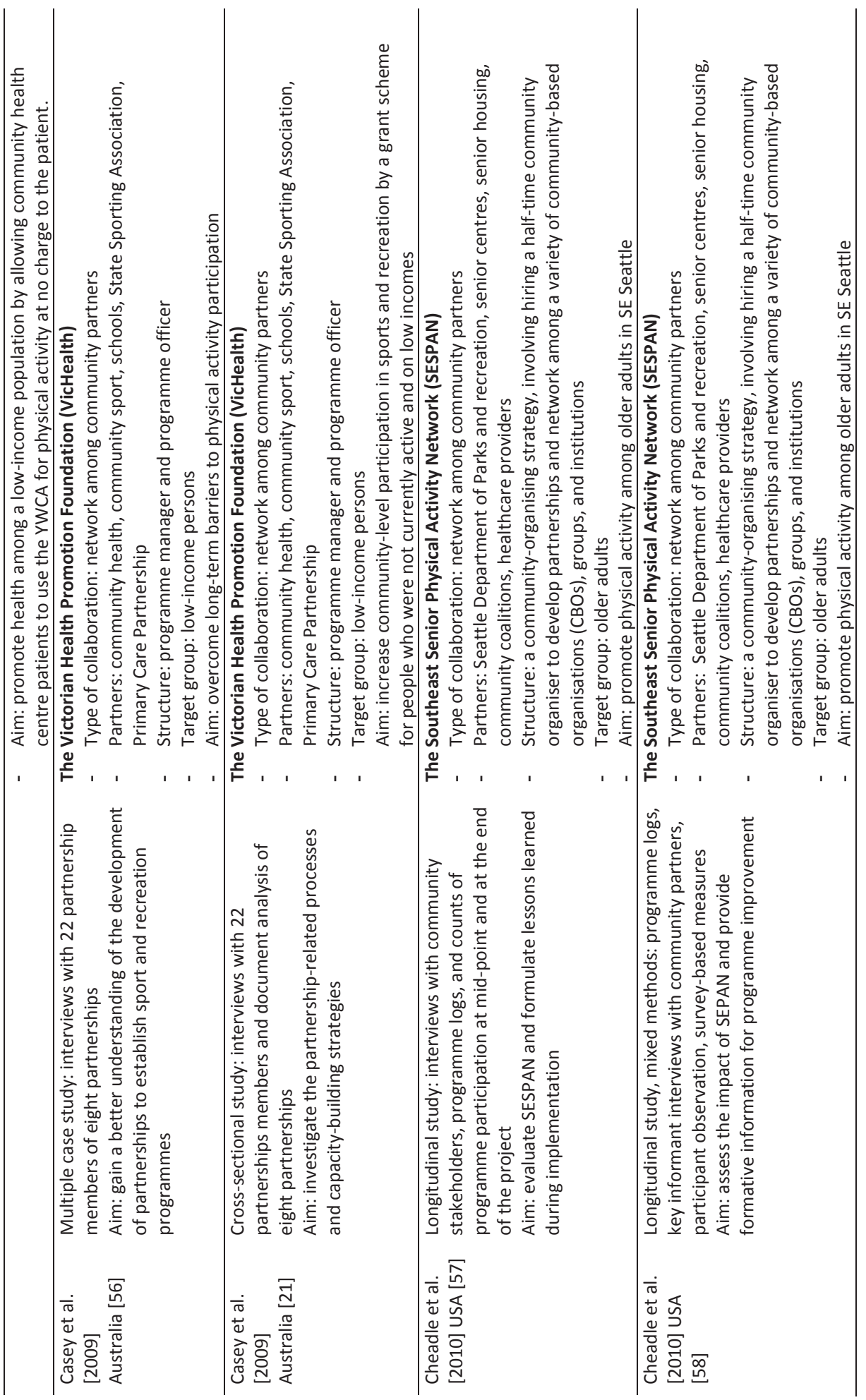




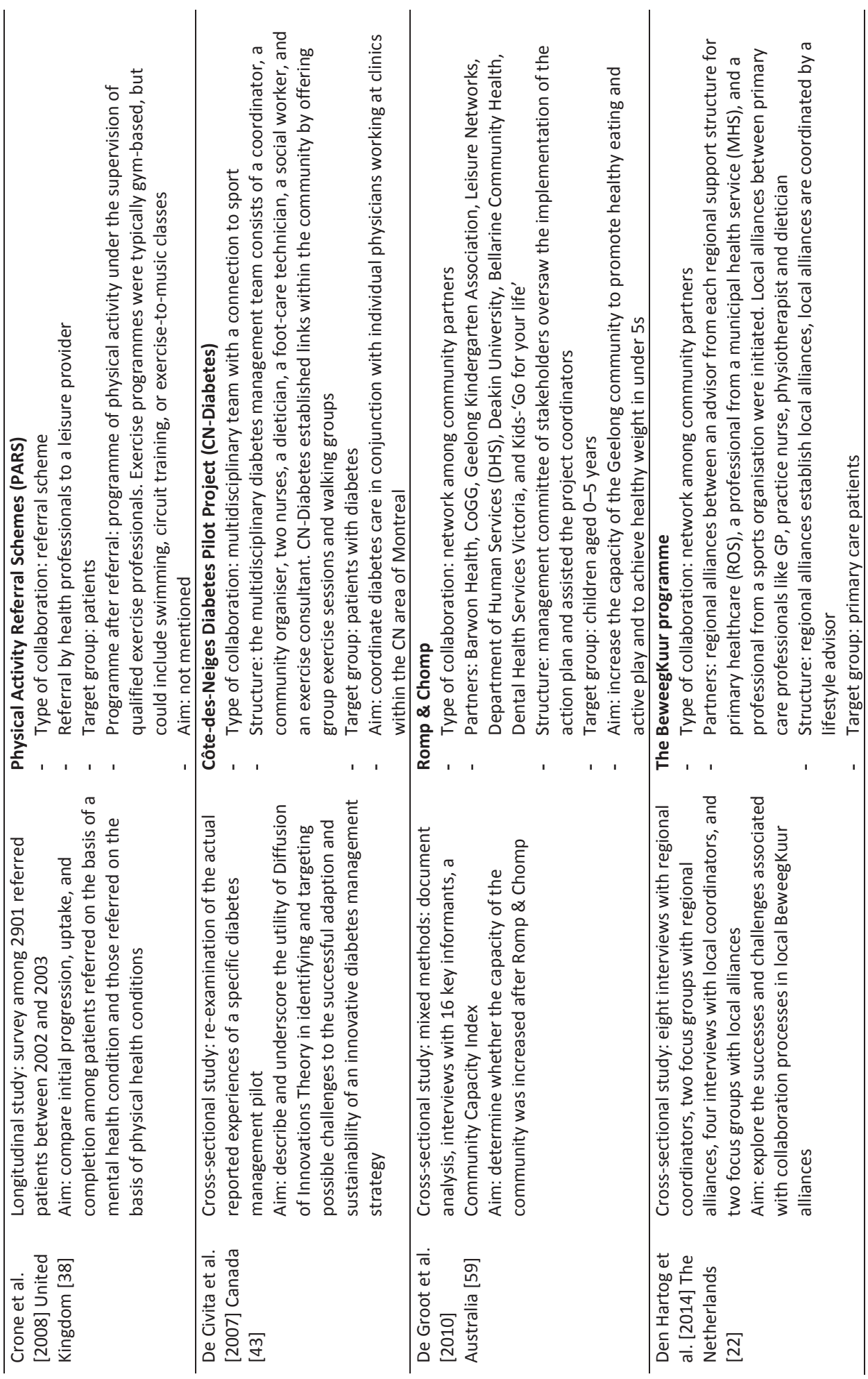




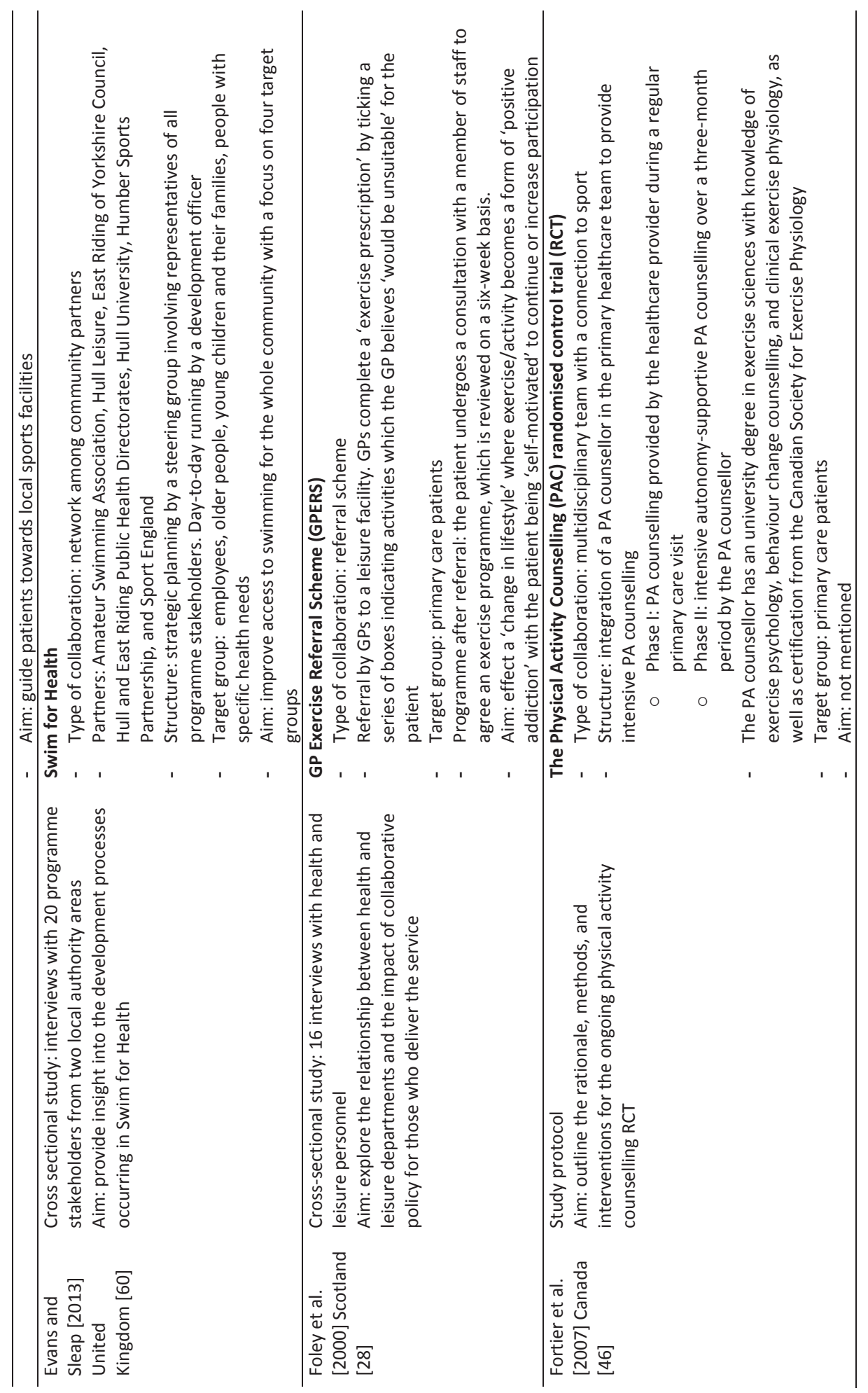




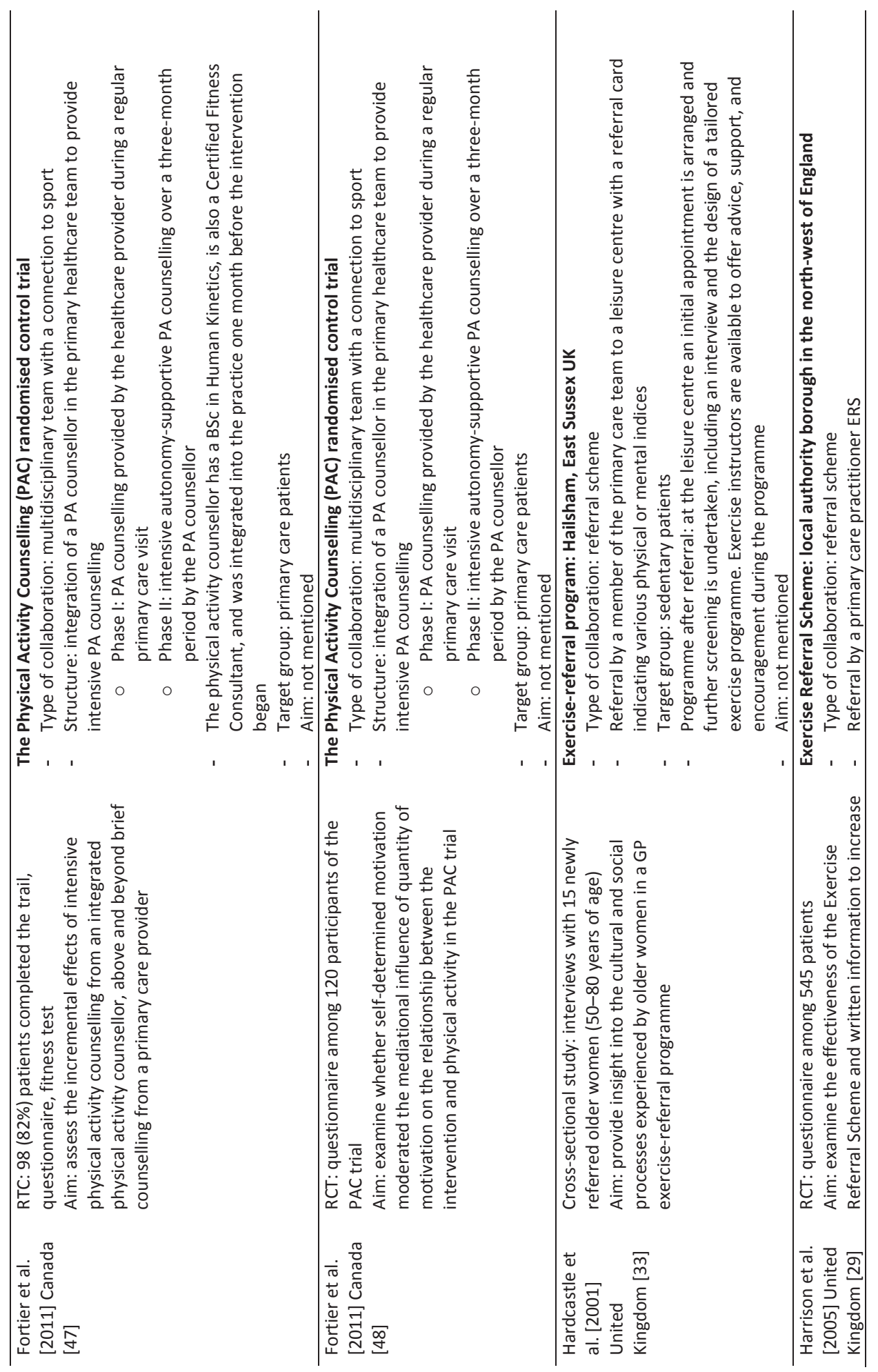




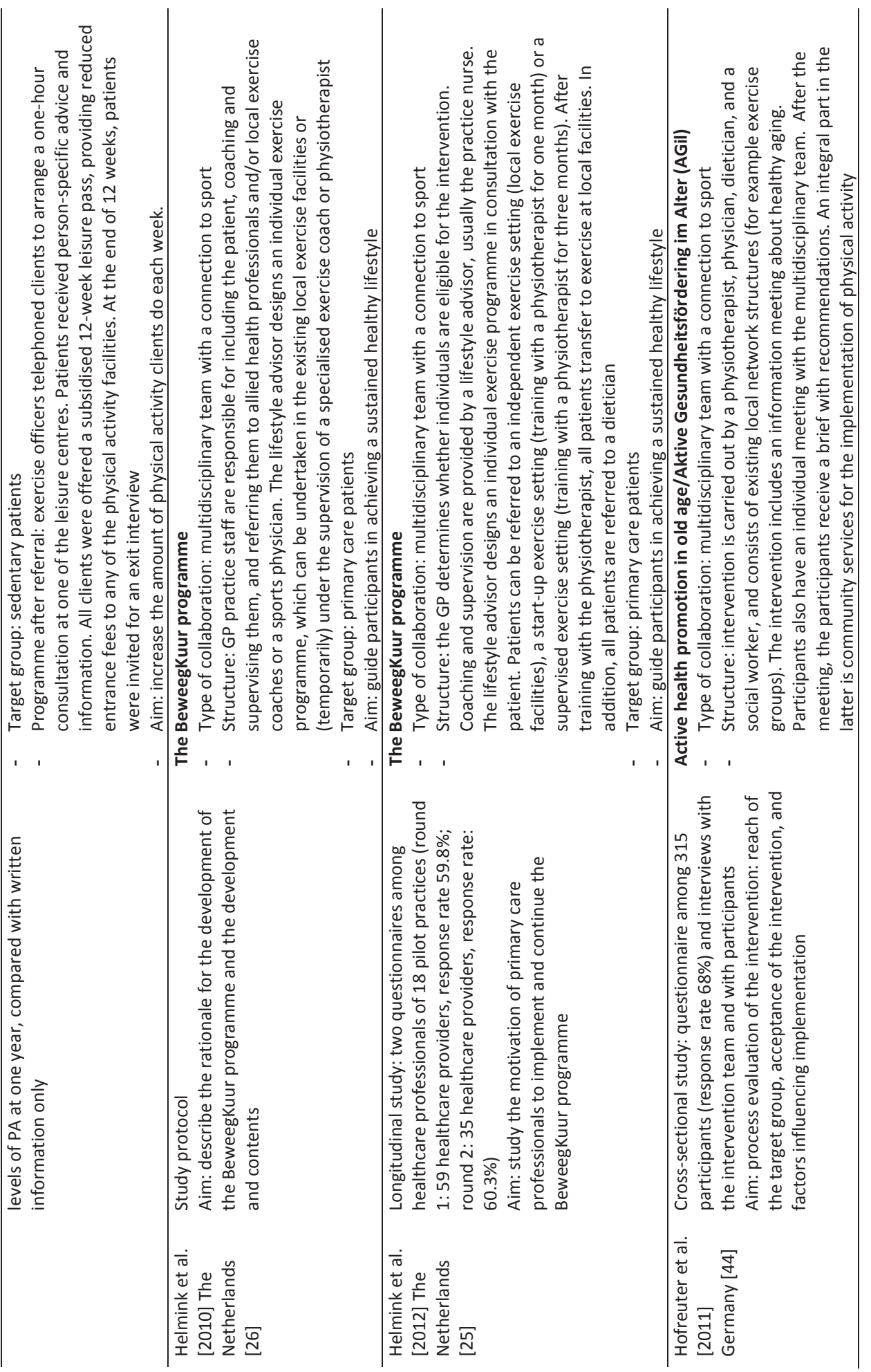




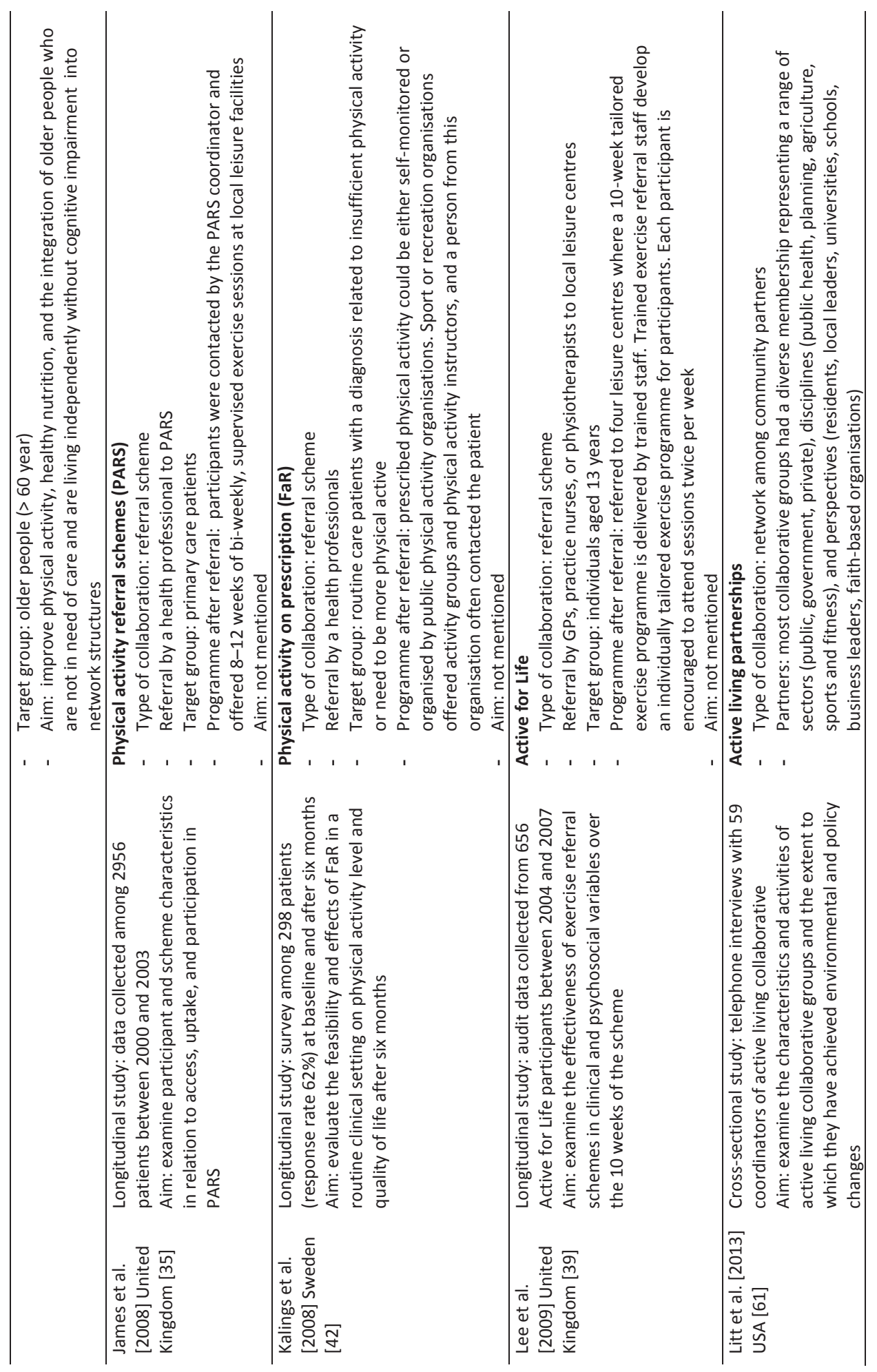




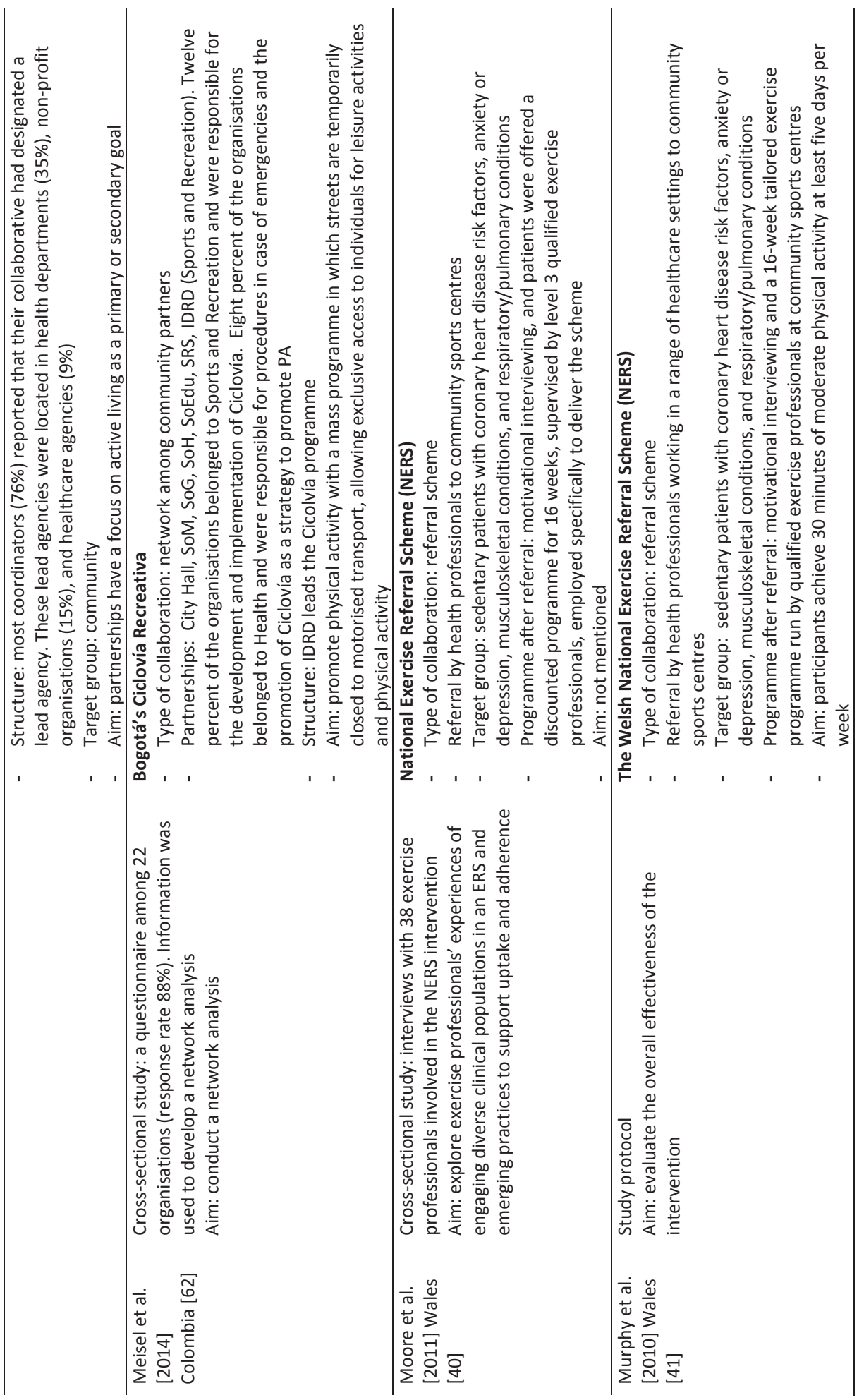




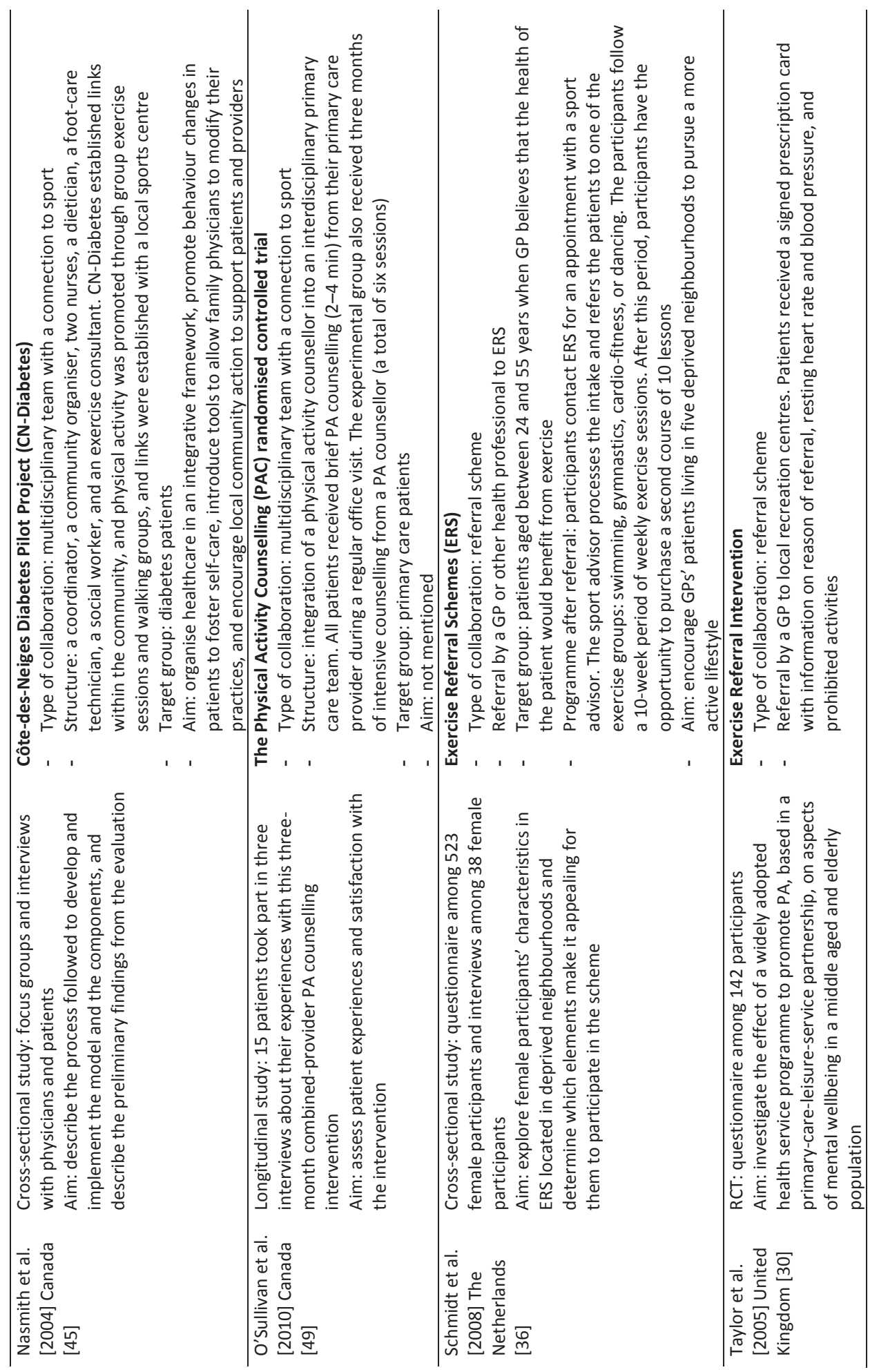




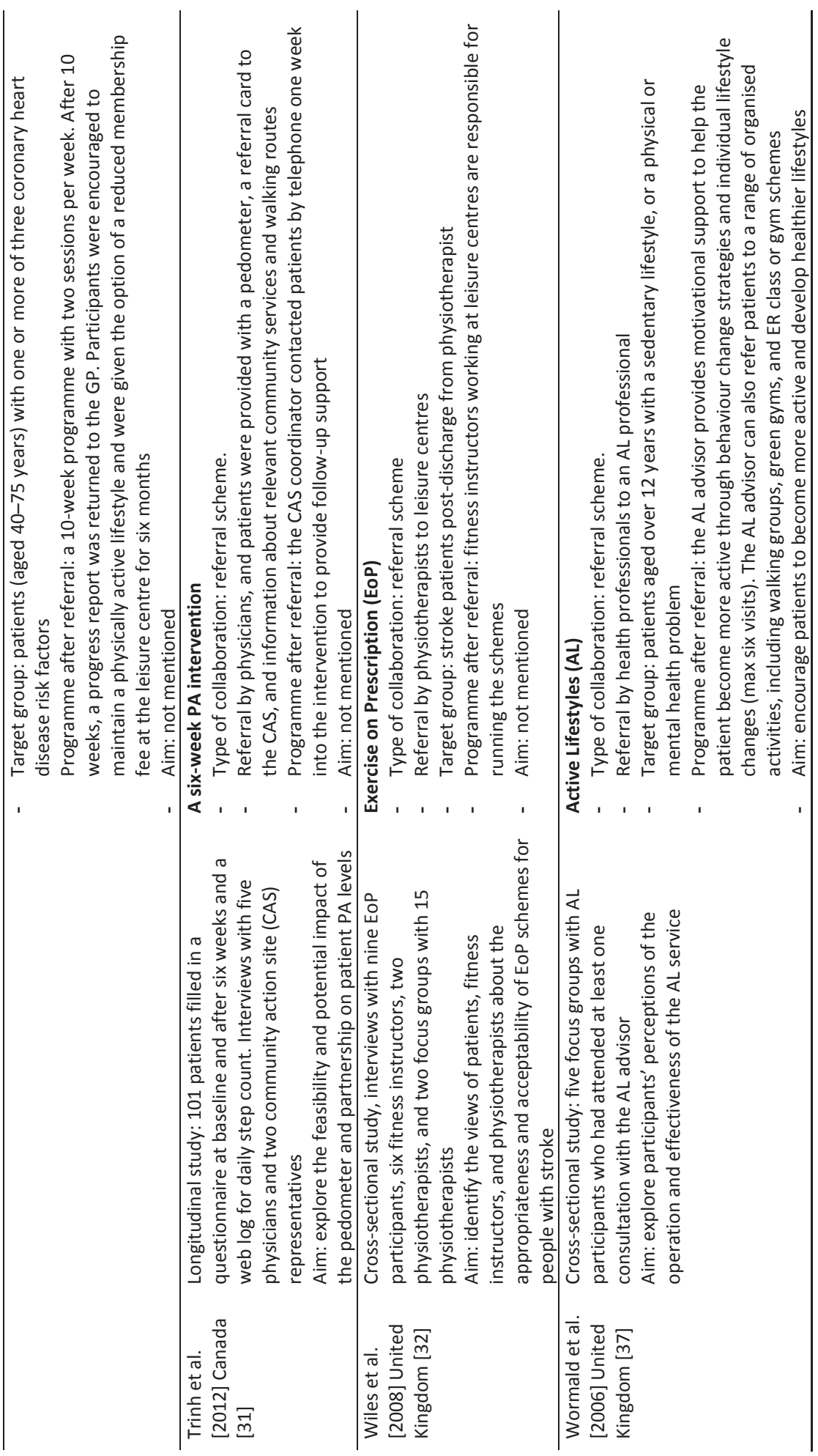




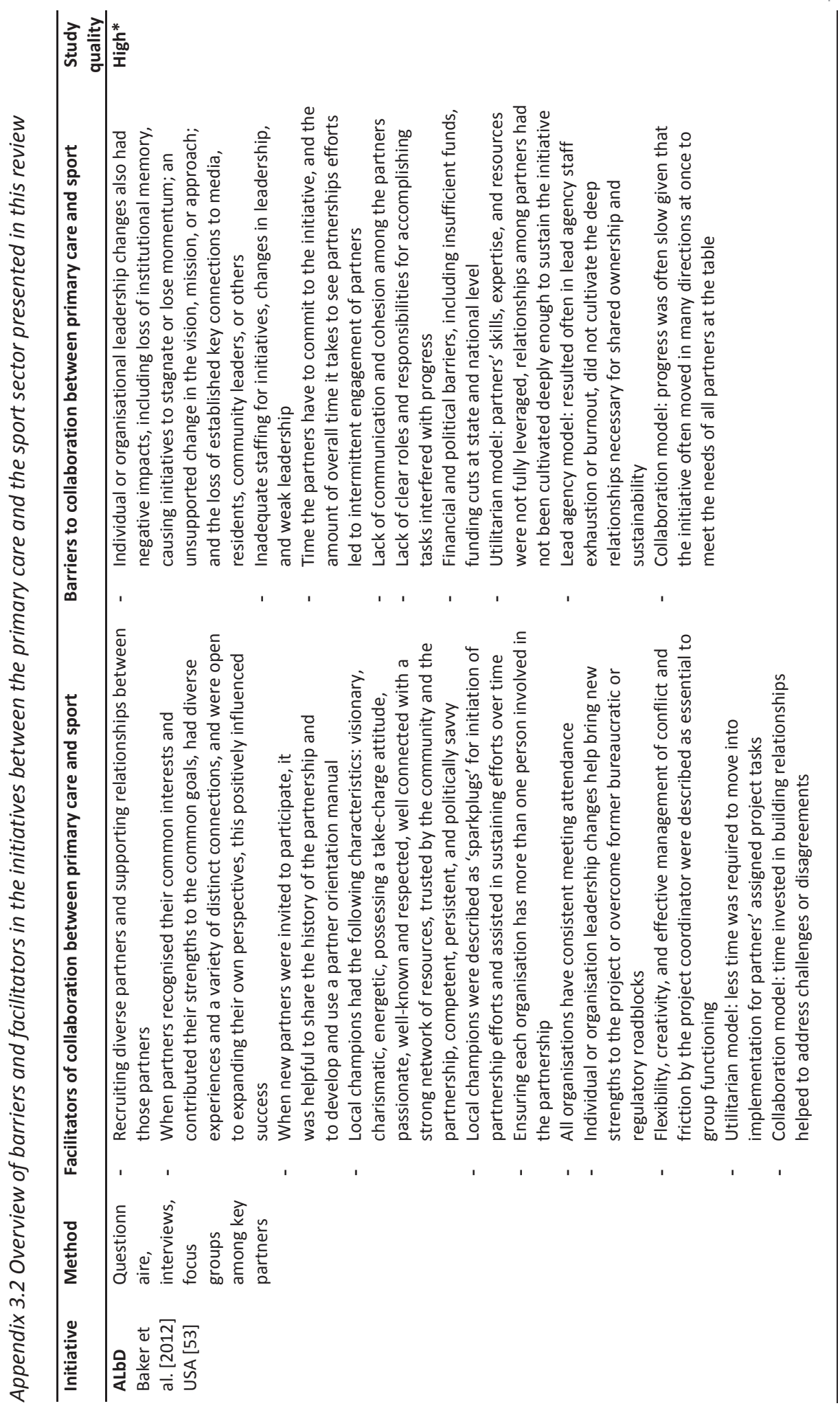




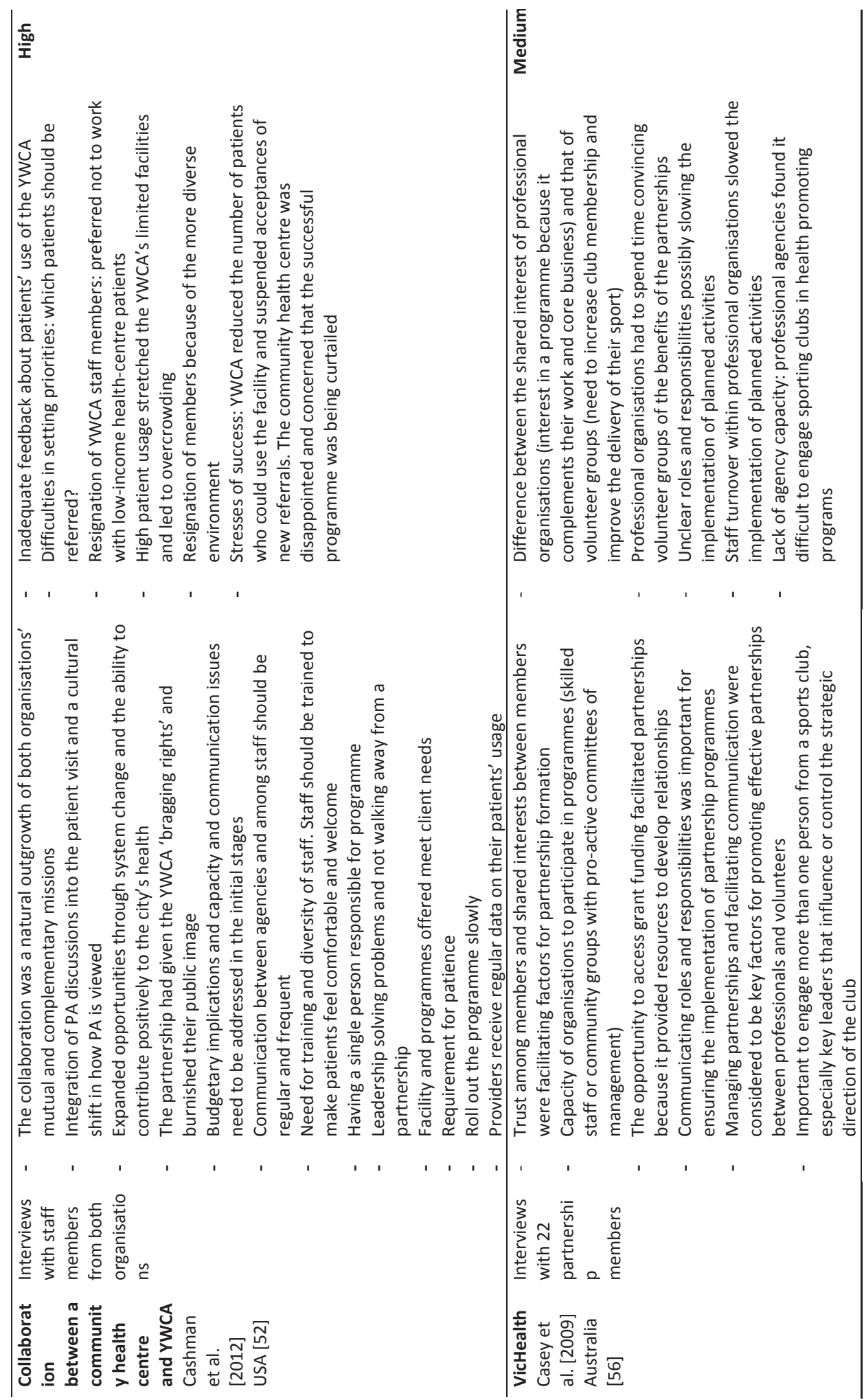




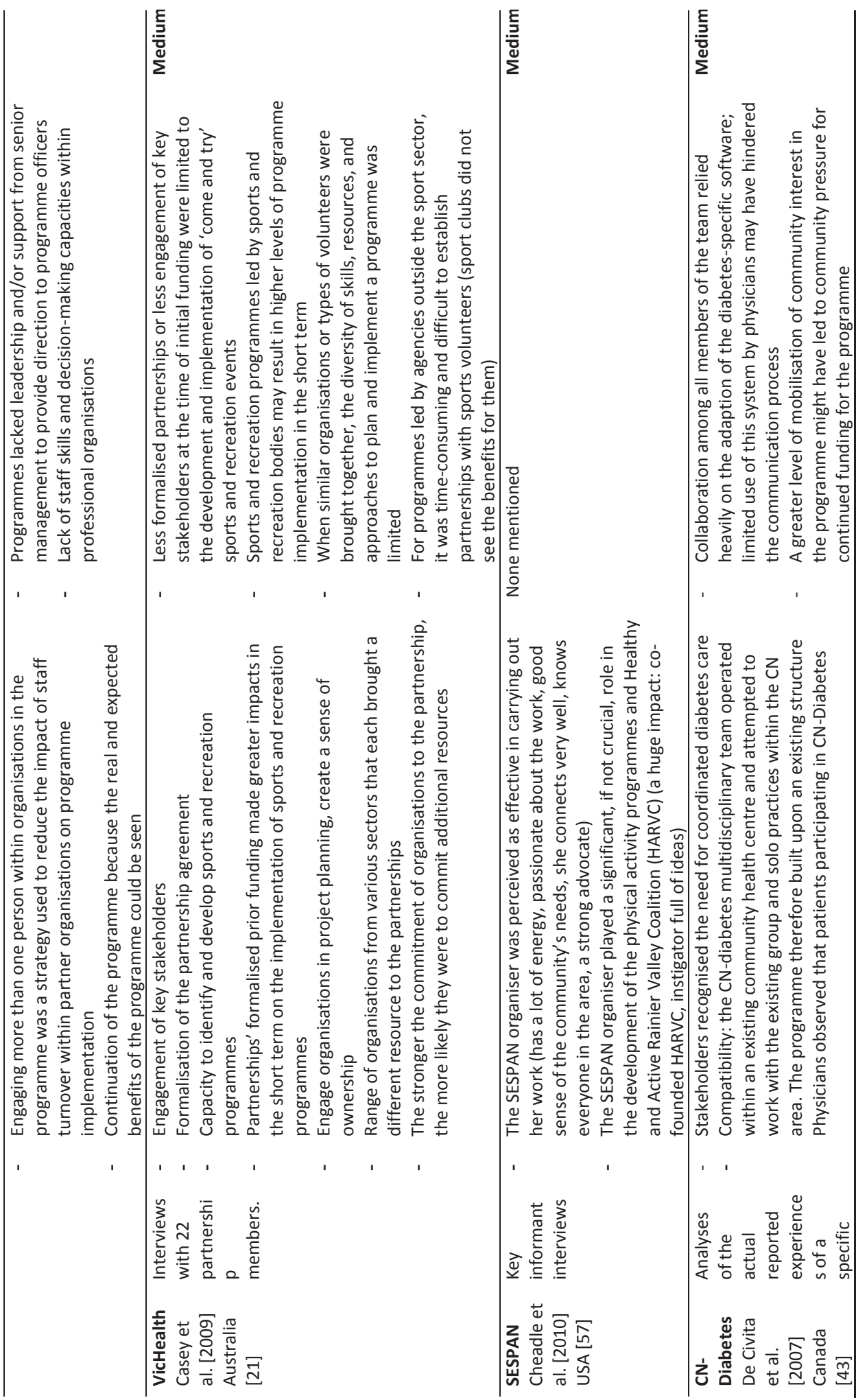




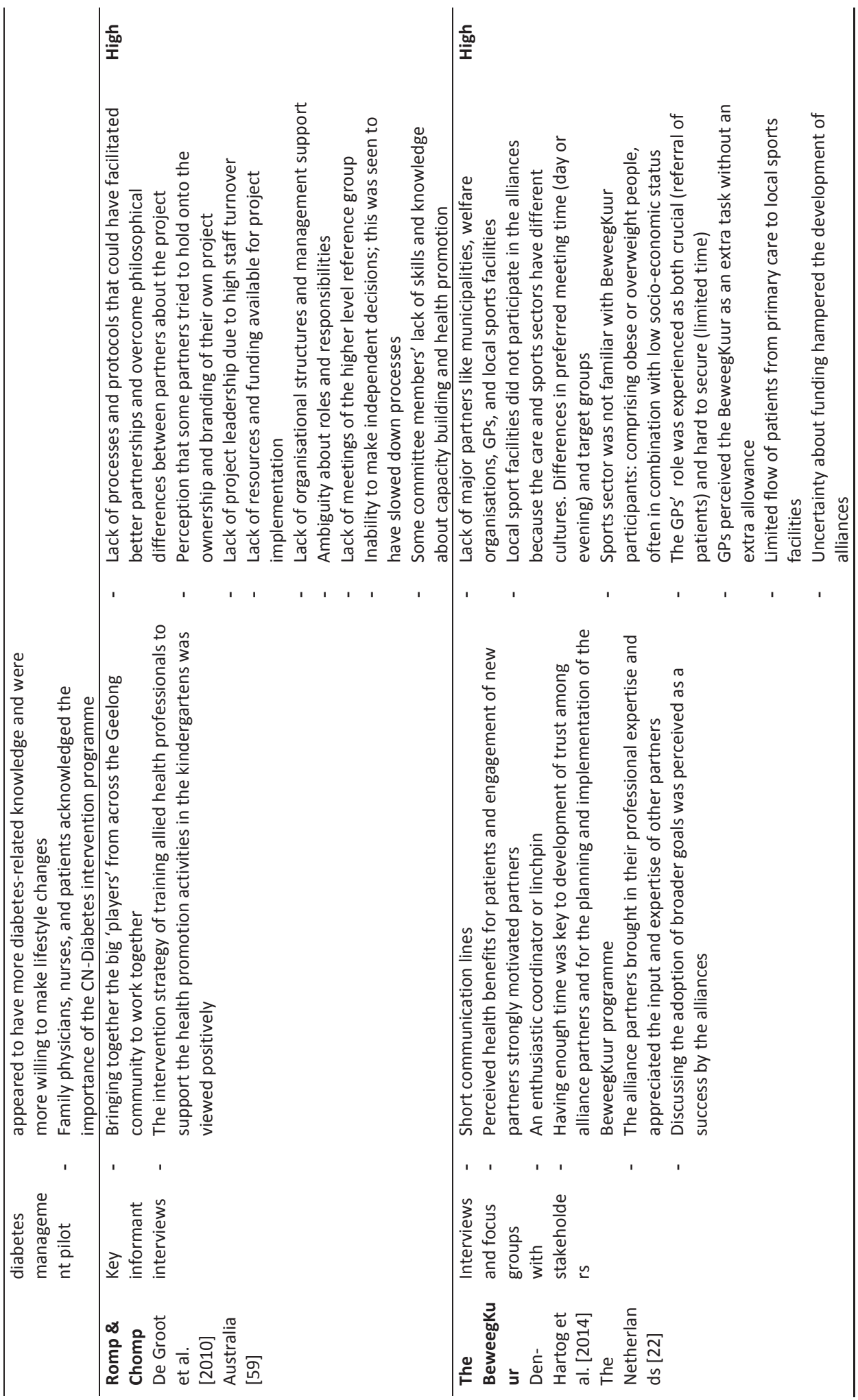




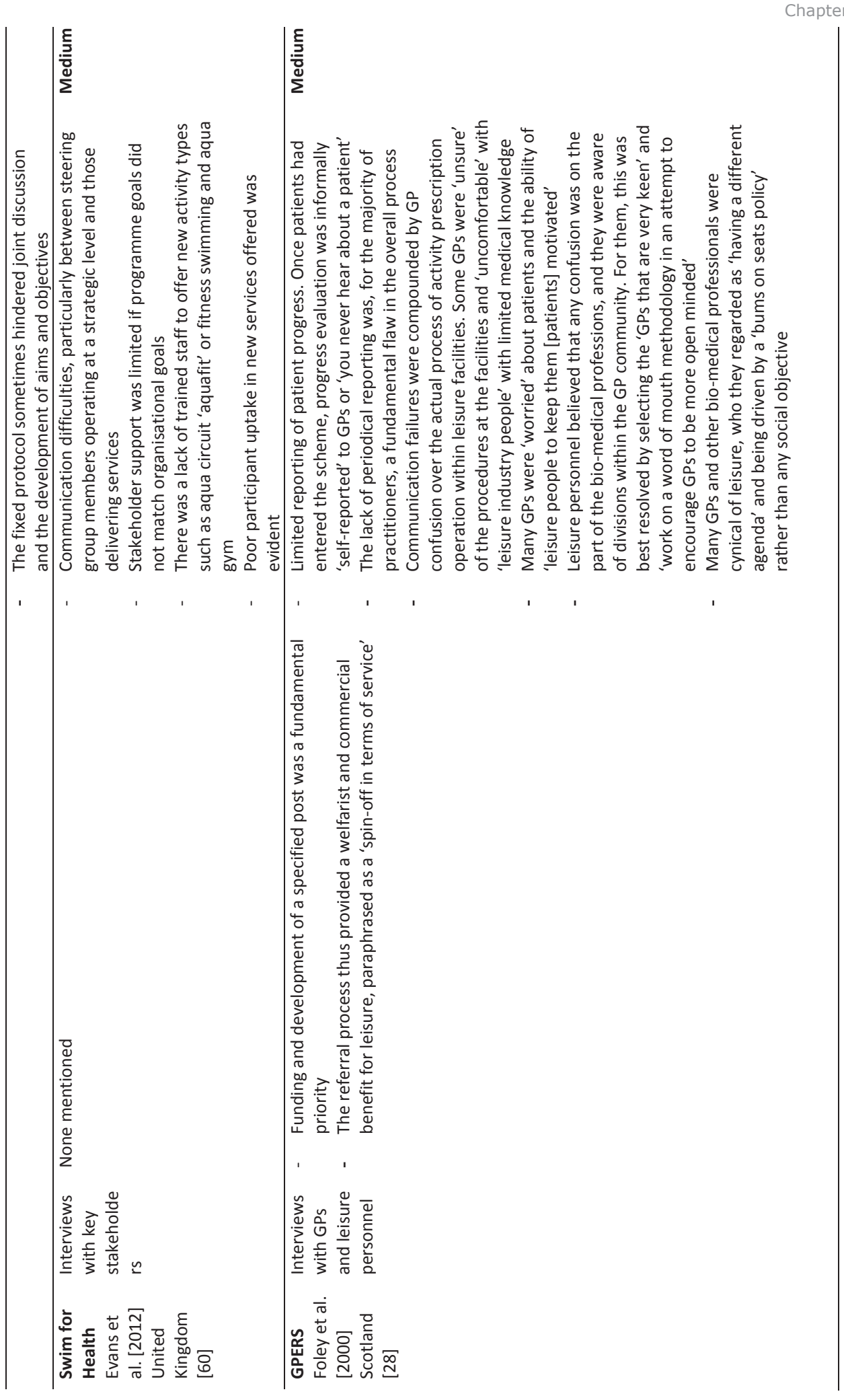




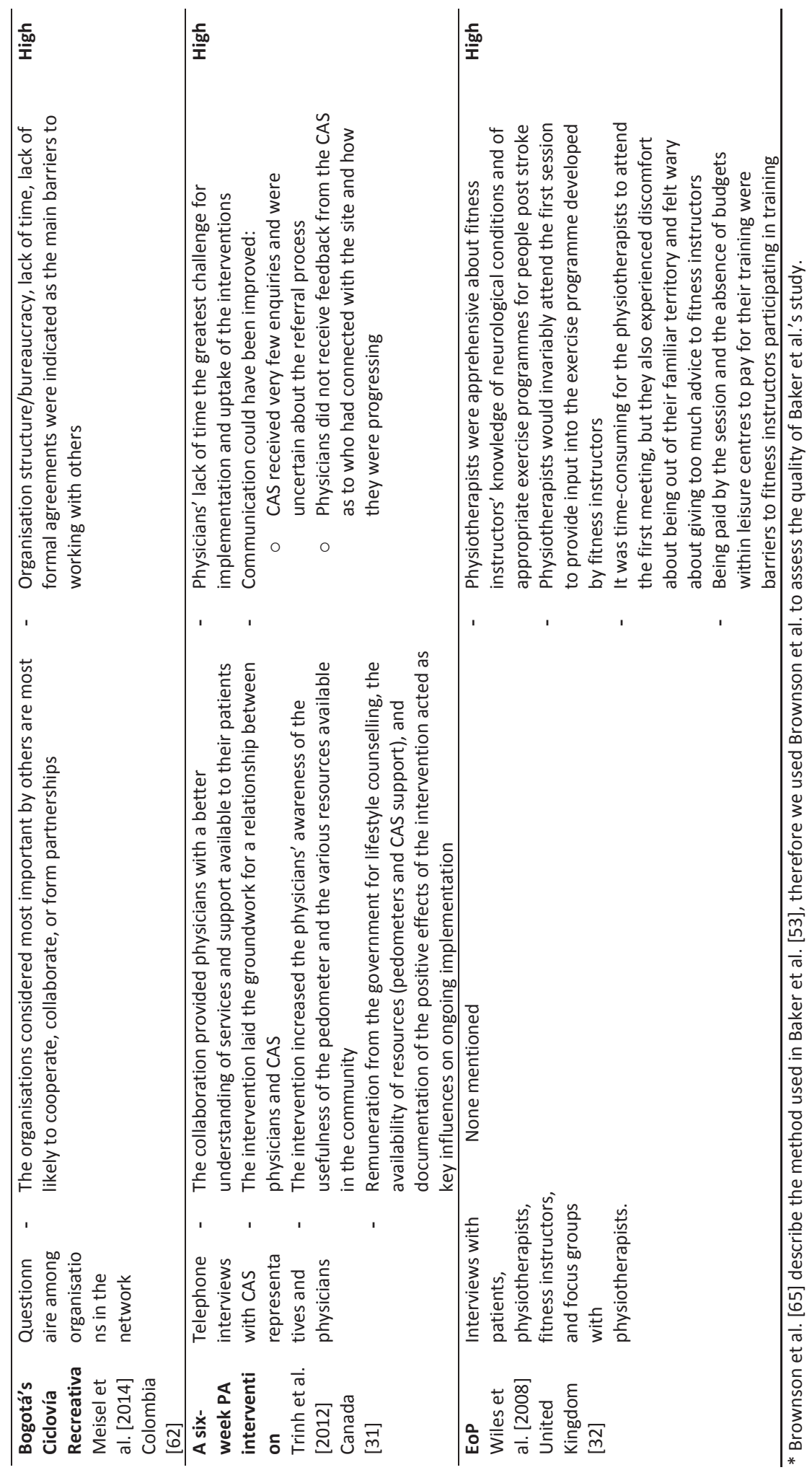




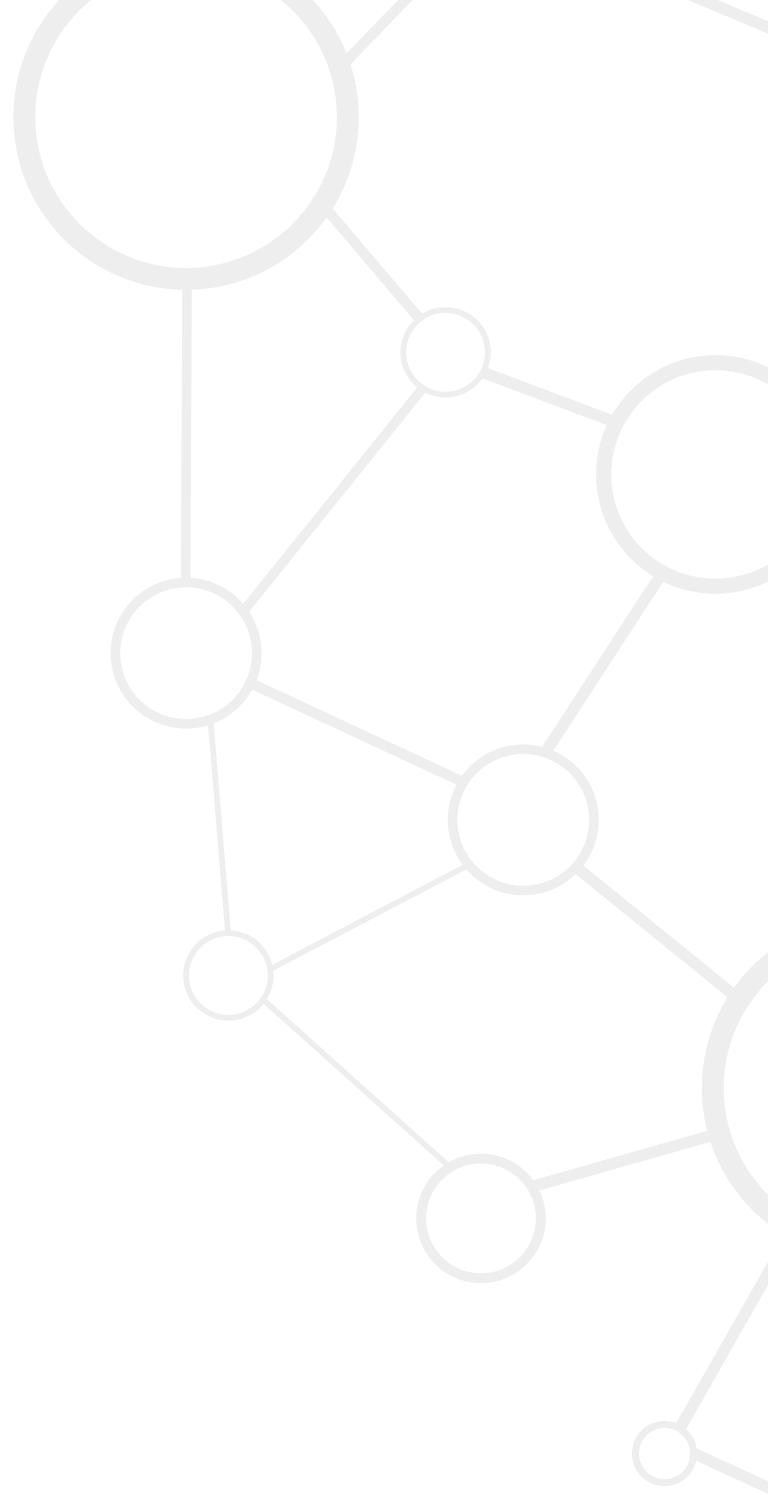




\section{Chapter 4}

\section{The role of the Care Sport Connector in the Netherlands}

\section{Published as:}

Leenaars KEF, Smit E, Wagemakers A, Molleman GRM, Koelen MA. The role of the Care Sport Connector in the Netherlands. Health Promotion International, 2016 


\begin{abstract}
Introduction

To stimulate physical activity and guide primary care patients towards local sport facilities, Care Sport Connectors (CSC), to whom a broker role has been ascribed, were introduced in 2012 in the Netherlands. The aim of this study was to explore CSCs' role in connecting the primary care sector and the PA sector.
\end{abstract}

\title{
Method
}

Fifteen CSCs were selected to participate in this study and were followed in their work of connecting both sectors. Over the course of one year, three rounds of interviews were held with these CSCs on the topics of their role and the connection between the primary care and the PA sector. Both top-down and bottom-up codes were used to analyse the interviews.

\section{Results}

CSCs fulfilled three roles: 1) broker, 2) referral, 3) organiser. The extent to which CSCs fulfilled these roles was influenced by the way municipalities implemented the CSC funding. CSCs set up two forms of collaboration structures: 1) project basis and 2) referral scheme. CSCs perceived the following barriers to connecting the primary care and the PA sector: lack of knowledge and time, primary care professionals' own interests, and lack of suitable sport activities for the target group.

\section{Conclusion}

The CSC role seems to hold the promise of improving collaboration between the primary care and the PA sector, especially, because the roles that CSCs perceive themselves as having seem to be directed at eliminating barriers in this connection. Future research is needed to study whether CSCs are capable of establishing a connection over time. 


\section{Introduction}

Regular physical activity (PA) is associated with enhanced health and reduced risk of allcause mortality, and has many health benefits [1]. Therefore, regular PA is deemed to contribute to the primary and secondary prevention of several chronic diseases, like diabetes mellitus, cancer, cardiovascular diseases, and osteoporosis [2]. Although the health benefits are clear, rates of PA promotion by primary care professionals are far from optimal [3].

About $40 \%$ of Dutch adults do not meet the Dutch recommendation about being moderately active for 30 minutes at least five days per week [4]. In order to stimulate PA, in 2012 the Dutch Ministry of Health, Welfare, and Sport introduced neighbourhood sport coaches (Buurtsportcoach), ascribing to them a broker role. These coaches are $40 \%$ funded by the state and the $60 \%$ funded by the municipality or other local organisations. Some of these coaches, so-called Care Sport Connectors (CSCs), are employed specifically to connect the primary care sector and the PA sector in order to guide primary care patients towards local sport facilities. This connection is desirable because primary care-based PA interventions are effective in reaching physically inactive adults [5]. However, patients prefer to stick in the known and secure environment of the primary care sport facilities instead of participating in unknown or untried local facilities [6-7]. The general idea is that CSCs facilitate the connection between the primary care and the PA sector; professionals in these sectors collaborate; activities to promote PA are implemented; these activities reach certain target groups; target groups will become more physically active; and health outcomes will improve. A blueprint for the CSC implementation was deliberately not presented, allowing municipalities to deploy CSCs in line with local needs and contexts.

This new CSC function is challenging because previous studies have shown that differences between the primary care and the PA sector can hinder their mutual collaboration. For example, research on networks to promote PA within the community identified differences in shared interests and cultures as barriers thereto [6, 8-9]. In the referral of primary care patients towards local sport facilities, it became apparent that sport professionals' lack of medical knowledge and their failure to provide feedback to health professionals, and health professionals' lack of time, were seen as barriers in the collaboration between the sectors [10-13].

Although a broker role seems promising for improving intersectoral collaboration [14], our recent review study found only one initiative between the primary care and the PA sector which made use of a broker role to establish a connection between both sectors [15]. The review also showed that most publications reported on the effects of PA promotion on patients' health status or PA behaviour and that the performances of collaborative initiatives were still unexplored [15]. To our knowledge, no study has yet explored a broker role and its impact on improving intersectoral collaboration between the primary care and the PA sector.

The CSC funding provides an excellent opportunity to explore the impact of a broker role on improving intersectoral collaboration. A first step towards exploring the impact of CSCs in connecting the primary care and the PA sector is to gain an insight into their role in this connection, especially as the CSC function is new and not much is known about how CSCS will fulfil their role. Therefore, the aim of this study was to explore CSCs' role in connecting the two sectors. Research questions addressed were: 1) how do CSCs perceive their role in connecting the primary care and the PA sector and 2) how do CSCs establish a connection between the primary care and the PA sector, and what factors are perceived as barriers and 
facilitators in this connection?

\section{Method}

This study is part of a larger project in which a multiple case study is being conducted in nine municipalities spread over the Netherlands from 2014 to the end of 2016 to study the role and impact of the CSC in connecting the primary care and the PA sector, and the participation of the target group [16].

\section{Setting and study population}

The nine municipalities were selected through convenience sampling based on project partners' contacts. The main criterion for municipalities was that the municipalities were implementing the CSC funding for four years (until 2017). In addition, the region, size of the municipality, and the way the municipality implemented the CSC funding were taken into account in choosing the municipalities. In consultation with the representative policymaker in each municipality, CSCs were selected to participate in this study. Inclusion criteria were: the CSC 1) aims to connect the primary care and the PA sector and 2) is working with the target group of adults, preferably adults who could benefit from PA (primary care patients, the elderly). The total number of CSCs in the study is 15 . This is approximately $15 \%$ of the CSCs employed to connect primary care and sport for adults in the Netherlands (for more detailed information see Smit et al., 2015 [16]).

The nine selected municipalities were spread over the Netherlands, and differed in size $(\geq$ 300,000 inhabitants [n=2], 100,000 - 300,000 inhabitants [n=4], $\leq 100,000$ inhabitants [n=3]. The CSC funding was implemented differently in the nine municipalities. Three CSCs in the same municipality were part of a different partnership between primary care, welfare, and sport professionals organised by the municipality and were working for a care organisation $(n=1)$ or a welfare organisation $(n=2)$. Three CSCs were working for the municipal sport department, one was working for a welfare organisation, and six were working for a sport organisation. Two CSCs were being paid from CSC funding, but one was a health broker working for the Municipal Health Service and the other was a representative of a community health centre. All CSCs had the task (sometimes mandated by the municipality) to stimulate PA and/or a healthy lifestyle among the target group. One CSC had the task of facilitating collaboration between professionals in order to create an integrated approach to stimulate a healthy lifestyle.

The average age of the 15 CSCs ( 5 men, 10 women) was 38 years (min 27 years, max 57 years). Eleven CSCs had a bachelor's degree, two had a master's degree, and two had a vocational education diploma. At the time of the first interview, seven CSCs had been in position for 0 - 6 months, five CSCs were working for 6 - 12 months, and three for longer than a year.

\section{Data collection}

To study how CSCs perceive their role and how CSCs establish a connection between the primary care ant the PA sector, the selected CSCs were interviewed every six months. The topics addressed in the interviews and the number of interviews with each CSC varied, depending on CSC availability (Table 4.1). A first interview was held with all 15 CSCs. Seven CSCs were interviewed three times, six CSCs were interviewed twice, and two CSCs were 
interviewed once. At the start of this study, not all CSCs $(n=5)$ in the nine selected municipalities, had started their function. Therefore, these five CSCs were only interviewed twice. In their second interview, we combined the topics for interviews 2 and 3 . In consultation with one CSC (the community health centre), it was decided not to conduct the third interview because the operations of the community health centre remained the same and this had already been outlined in the first two interviews. During the project, one CSC resigned and another temporarily ceased functioning. With those two CSCs, only one interview was conducted In total, 35 interviews were held with the CSCs selected for this study. The interviews took place at the CSCs' workplace and lasted between 1 to 1.5 hours. The first two interview rounds were conducted by KL and ES, the third interview round was conducted by KL.

The interview topic list (Table 4.1) for the first and third rounds were initially based on Koelen et al.'s (2012) [17] HALL framework. The main topics were how CSCs perceive their role and the structure and the organisation of each CSC's network, to study how CSCs establish a connection between the primary care and the PA sector. To study the CSCs' network, two existing, validated collaboration assessment tools were used: Frey et al.'s (2006) [18] levels of collaboration survey and Zaalmink et al.'s (2008) [19] network analysis tool. Both tools provided an insight into the CSCs' network and professionals' role in connecting the primary care and the PA sector, and this was used as a starting point for questions about the organisation of each CSCs' network (Table 4.2). 


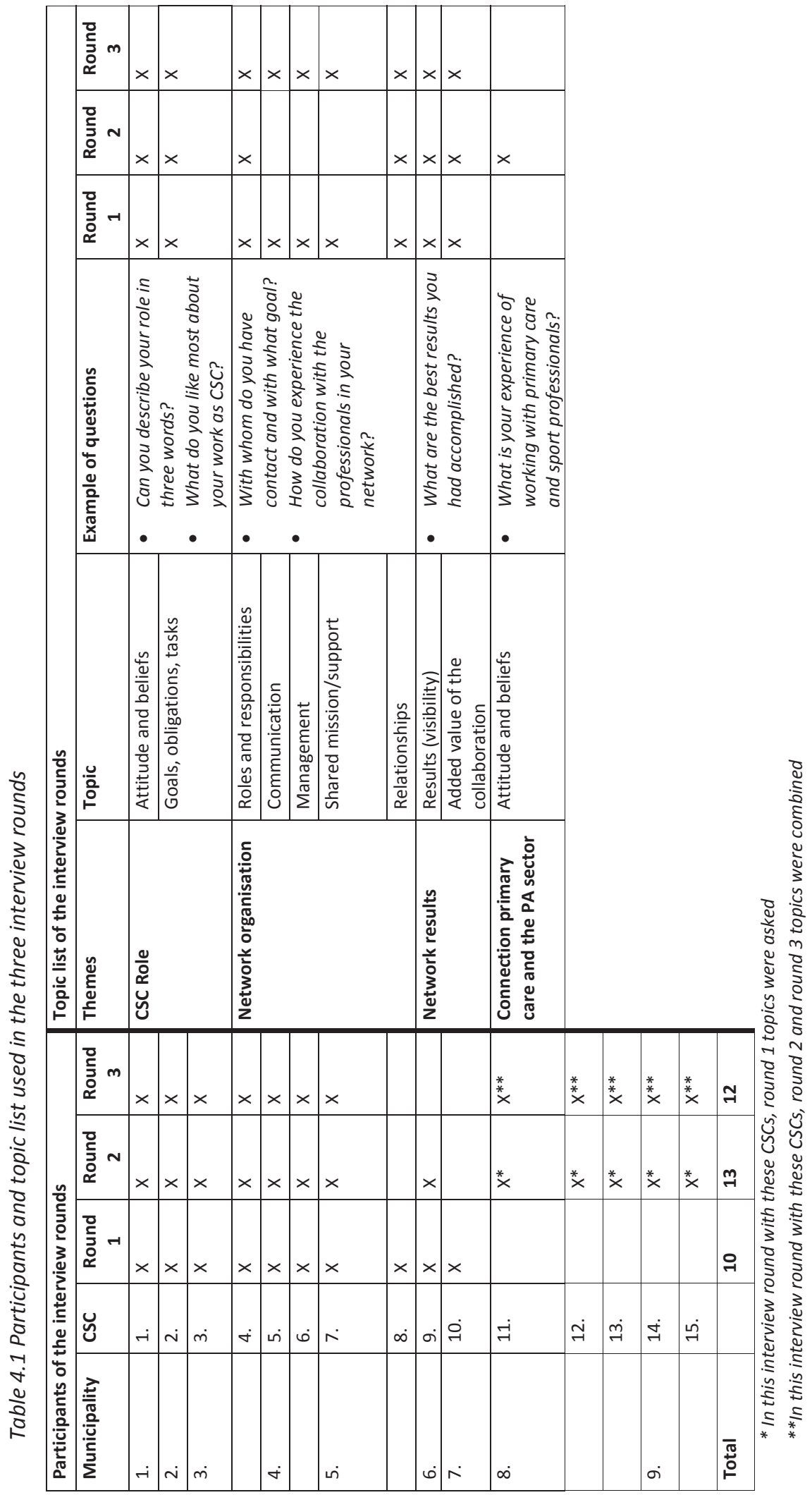




\section{Data analysis}

The interviews were audiotaped and transcribed (intelligent verbatim style). The data analysis was based on Creswell's (2009) [20] six steps for qualitative data analysis. So, after the data were organised and prepared for analysis (step 1), the transcripts were read (step 2). In the third step, the transcripts were coded and analysed using software for qualitative analysis (Atlas.ti, version 7.1.8). The data were coded top-down with predefined codes based on factors from the HALL framework. However, after the first round of interviews it appeared that some of these top-down topics, especially those relating to the organisation of alliances, were less relevant because of the lack of structured collaboration in the CSC network. Consequently, thereafter we included more bottom-up codes, themes that emerged in the interviews, on the code list: topics relating to collaboration in connecting the primary care and the PA sector (Table 4.2). In the fourth step, the codes were clustered into the following themes: the CSC role, establishing a connection between the primary care and the PA sector, and perceived barriers and facilitating factors in the connection between the primary care and the PA sector. In steps 5 and 6, more bottom-up codes were assigned to the various themes; for example, the new codes identified in the theme 'CSC role' were: broker, referral, organiser (Table 4.2). In addition, because we followed the CSCs in their work of establishing a connection between the two sectors over time, we examined a shift in perceptions towards their role and their role in connecting the two sectors. For two CSCs this was not possible, because we interviewed them only once.

Step 1 to 4 of the data analysis process were performed by one researcher (KL). Thirty percent of the transcripts were also examined by other researchers (ES, GM and AW) in order to check the way of coding. Steps 5 and 6 were performed independently by two researchers ( $K L$ and $A W)$. The interpretation of the data was discussed to reach consensus between the two researchers. After the data analysis was completed, the results were discussed within the research team. 


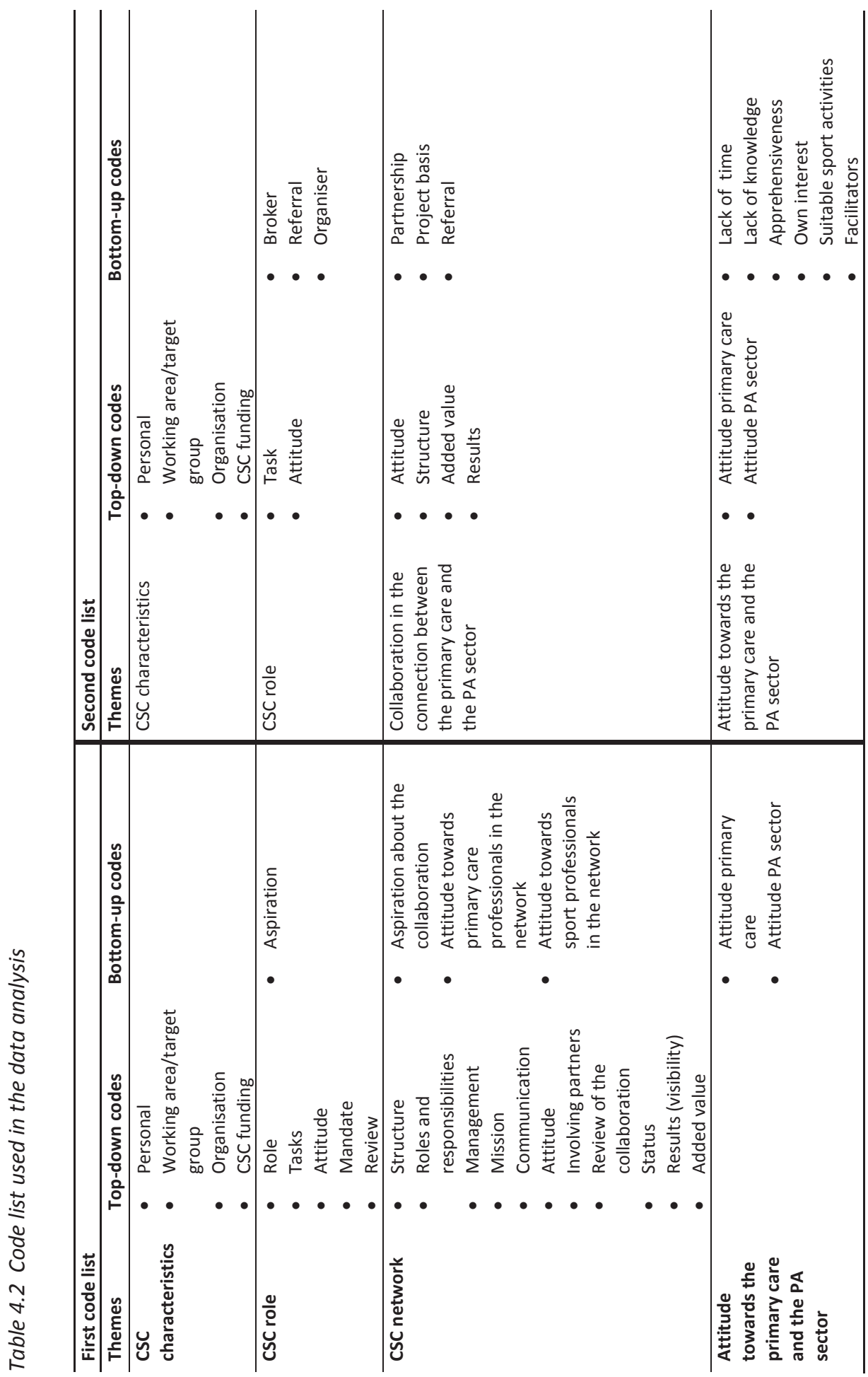




\section{Results}

\section{Care Sport Connector role}

CSCs perceived themselves as having three roles: 1) a broker between professionals from the primary care and the PA sector, 2) a CSC referral function whereby they guide patients or residents after referral by primary healthcare or welfare professionals towards suitable sport activities, 3 ) organiser of activities to promote PA. Eleven CSCs fulfilled all three roles, but to different extents. Four CSCs fulfilled only one or two roles: three CSCs fulfilled the broker role and the organiser role, and one fulfilled the referral and the organiser role (Table 4.3).

\section{Broker role}

Fourteen CSCs described their role as broker to connect the primary care and the PA sector. One CSC, the community health centre representative, did not describe her role as that of broker, because in the partnership organised by the municipality different sectors were already connected.

For 13 CSCs, it was important to create a network of primary care, welfare, and sport professionals in order to connect both sectors. Contact with those professionals was mostly sought to carry out the other two roles: the referral function and organiser of activities. In these networks, CSCs saw themselves as the linchpin in the network.

Networking was an important feature of this broker role, thereby exploiting existing collaboration structures or activities. Most CSCs networked to make themselves known and inform professionals about the CSC role and the opportunities for them if the sectors were connected. Some CSCs compared themselves with marketers, because they had to sell themselves and their activities.

"I am marketing myself, who am I, why am I here, what do I want, what do you expect of others, and what can you expect from me. What I usually do is introduce myself. You should briefly get to know one another and see what you can do for one another. That is how I usually approach it." (CSC 11)

One CSC fulfilled the broker role differently than the other CSCs. This CSC focused on establishing more sustainable collaboration between primary care professionals, and supported and encouraged professionals to develop an integrated approach to stimulating health and PA. Being independent and being supportive of the professionals were mentioned as important features of this role.

\section{Referral function}

Twelve CSCs mentioned the referral function as part of their work. Three CSCs did not fulfil this function. The $12 \mathrm{CSCs}$ saw it as their role to guide the target group towards local sport facilities. These CSCs used contacts with the professionals to guide patients or residents after referral towards suitable sport activities.

"Very simple, a patient visits their GP [general practitioner] or physiotherapist, the GP says, you have to exercise more. Just a matter of sending me an email and I will contact them. It couldn't be simpler." (CSC 6)

According to CSCs, the target group was often apprehensive of PA, and therefore it was important to be accessible and approachable in guiding the target group towards local sport facilities. Motivating these people was mentioned as an important feature of the CSCs' work. 


\section{Organiser of activities}

All CSCs, sometimes in collaboration with other professionals, organised activities to promote PA, like fitness tests or a fall prevention course. Four CSCs also organised and carried out sport activities themselves. Some CSCs mentioned supporting sport clubs and sport instructors as part of their CSC role: for example, helping with applying for grants. Therefore, facilitating was also frequently mentioned as a CSC role.

\section{"Initiator of new ideas, you could say I also am, and a bit of facilitating facilitator, setting up new ideas that find their way to me from the neighbourhood. I can pick these up and then I can adopt and activate them with others." (CSC 1)}

According to the CSCs, an important feature of the organiser role was to be demand driven to ensure that activities align with the needs of the target group. In addition, embedding activities in local organisations to create a sustainable approach was mentioned as an important feature. Some CSCs mentioned that in most cases they were the drivers of activities.

\section{Fulfilling the roles}

The extent to which a CSCs focused on one of the three roles was strongly intertwined with how their network functioned, the municipality mandate, and their own preferences. Some CSCs had difficulty receiving referrals from primary care professionals, or had less affinity with the primary care sector than with the PA sector. Therefore, these CSCs focused more on the organisation and coordination of activities in order to recruit residents and to promote PA.

\footnotetext{
"I have 20 hours and try to set up as many activities as possible so as to encourage inactive seniors, but I do not put a great deal of time into actually drumming up those GPs and physiotherapists to have them finally refer those people." (CSC 2)
}

Over time, the CSCs' role remained broadly the same, and CSCs performed the same roles. In one case, the focus changed due to funding for a project to promote PA among the elderly. Consequently, the CSC had to organise project activities and focused less on connecting professionals from different sectors. 


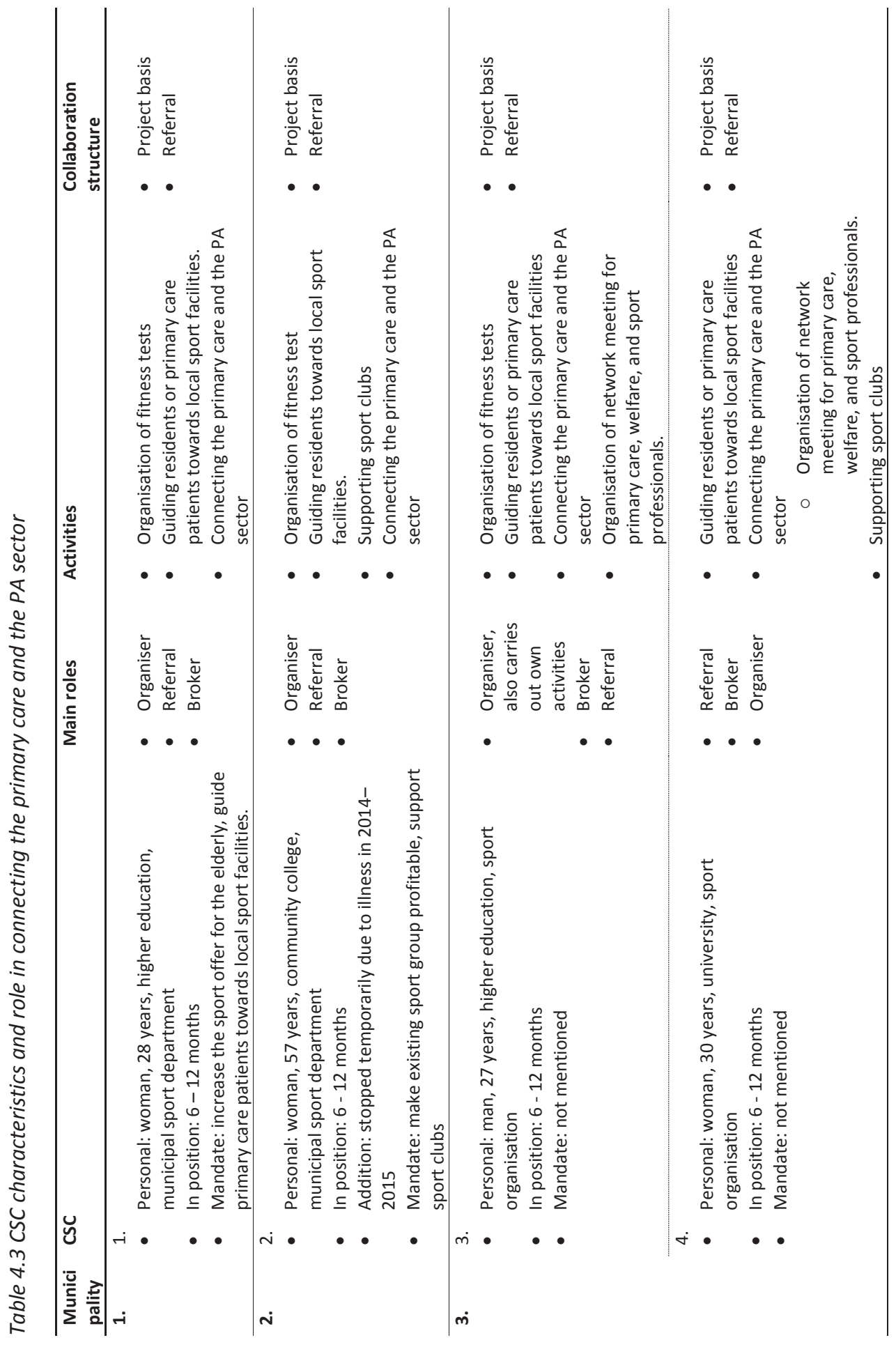




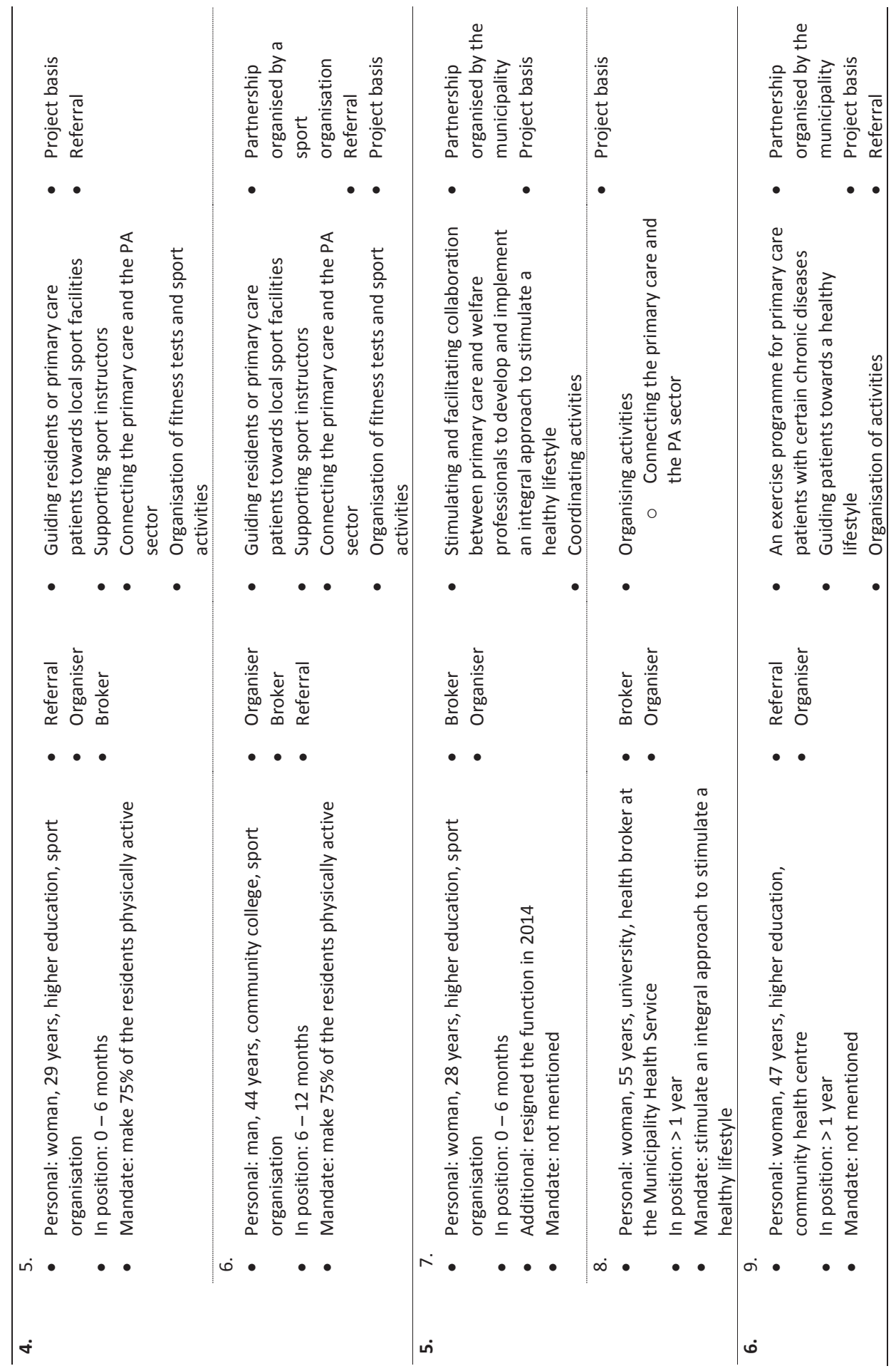




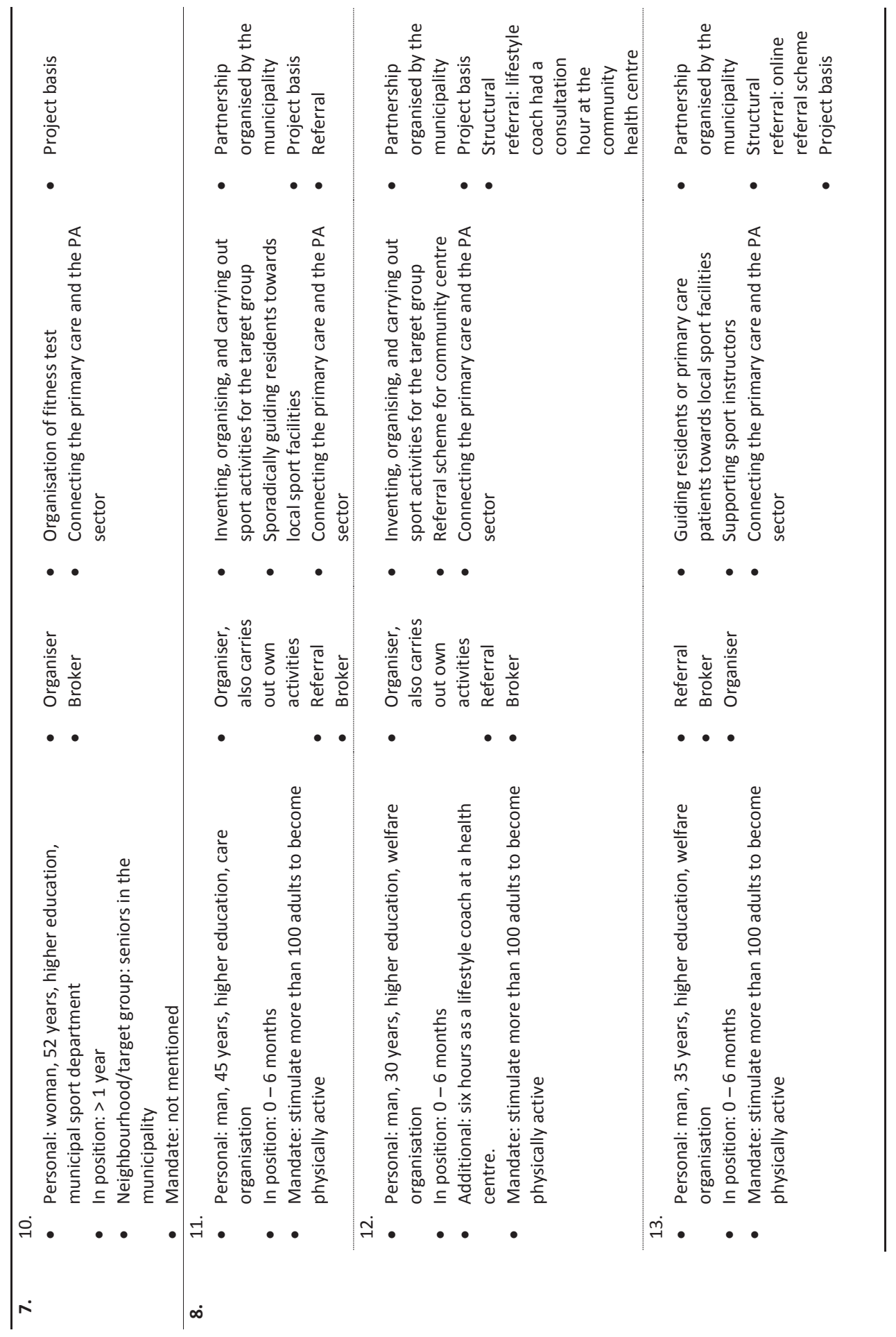




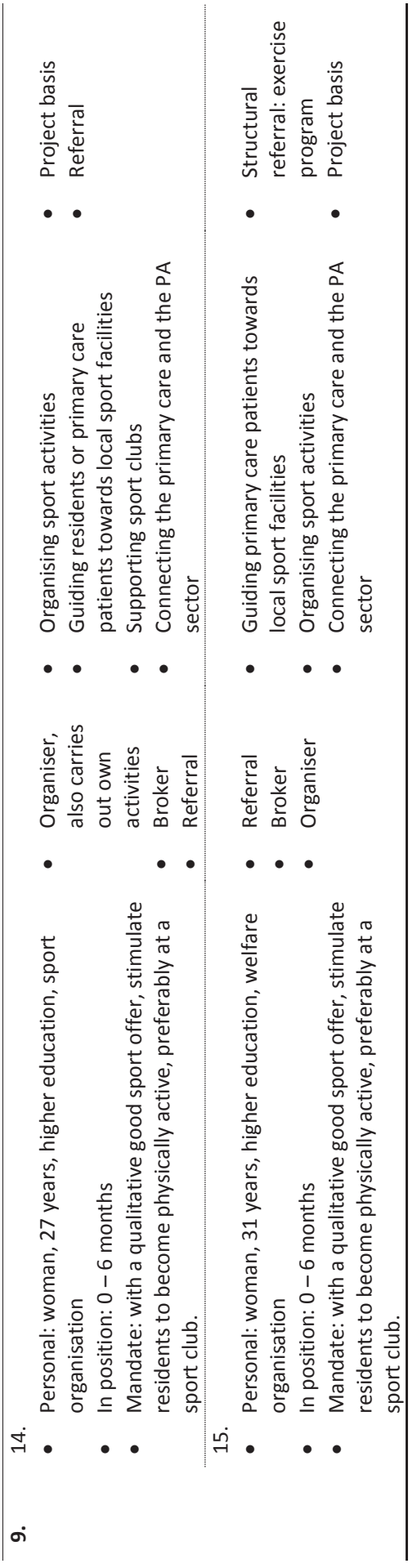




\section{Establishing a connection between the primary care and the PA sector}

To connect both sectors, CSCs created a network in which the following professionals were engaged: physiotherapists $(n=12)$, welfare professionals $(n=11)$, sport instructors $(n=7)$, sport clubs $(n=12), G P s(n=7)$, practice nurses $(n=6)$, and community centres $(n=4)$. Therefore, the CSCs' networks looked similar, but the level of collaboration with these professionals differed. In the networks, three types of collaboration could be distinguished: 1) partnership, 2) project basis to organise activities, and 3) referral (Table 4.3).

\section{Partnership}

Six CSCs were part of a partnership between primary care, welfare, and/or sport professionals. Four partnerships were organised by the municipality as part of the CSC funding. The added value of this partnership was sharing information, developing a plan of action, and using the professionals in the partnership to reach other primary care, welfare, or sport professionals.

"That has its advantages; before I had to hold the first steering group meeting anyway, the partners were also known and I began emailing, asking can we talk and meet sometime." (CSC 13)

Two CSCs were part of an existing partnership in the neighbourhood. One partnership was organised by a sport organisation, and the other was organised by the municipality. The goal of these partnerships was to collaboratively organise activities to promote PA among residents, or to develop a mutual approach to stimulate a healthy lifestyle.

\section{Project basis}

All CSCs worked on a project basis together with the professionals in their network. They sought collaboration with professionals when they wanted to organise an activity. Most CSCs organised fitness tests as a way to reach the target group and to promote PA. The added value of such collaboration was that CSCs could use the professionals' expertise, (medical) knowledge, and networks.

"And, like, he [physiotherapist] also takes care of a bit of education. If [during a project] people drop out with injuries at any time, we have someone at hand who can deal with it, so to speak." (CSC 3)

\section{Referral}

Collaboration with professionals in the referral of primary care patients or residents towards local sport facilities could be seen as a chain. Primary care and welfare professionals referred patients to the CSC, and the CSC guided them towards local sport activities. The added value of collaboration with especially the primary care and the welfare professionals was reaching the target group.

Although 12 CSCs collaborated with the professionals in their network around the referral of primary care patients or residents, only four of them had a structured form of referral:

referral scheme, exercise programme $(n=2)$, sport consultation at a health centre. Those four CSCs were part of a partnership $(n=2)$ or working for a care $(n=1)$ or welfare $(n=1)$ organisation. CSCs without a structured form of referral by primary care professionals were working for a sport organisation or a sport department $(n=7)$, and a welfare organisation $(n=1)$.

"We have referred someone or another. But that is precisely what I mean - it's in dribs and drabs, there should be a structural flow coming on and that is what I am constantly working on." (CSC 6) 
Two of the four CSCs with a structured form of referral were part of a partnership in which primary care professionals were represented. The other two were working for a welfare organisation or represented a community health centre.

One year after the first interviews with the CSCs, not many changes had occurred in most CSC networks. The networks of five had expanded considerably after six months; however, at the time of the first interview, those CSCs had just started working and still had to build a network of professionals.

In general, CSCs were satisfied with the contact and collaboration with the professionals in their network. However, all CSCs would like to see a more structured and intensified form of collaboration. CSCs who were working for a sport organisation or the municipal sport department in particular mentioned that they wanted primary care professionals to be more involved in their work. They often had to push and spend a lot of time to involve them in their network and to reach the desired target group through referrals by primary care professionals. Those CSCs often organised their own activities to reach the target group, like fitness tests. CSCs who were working for a care or welfare organisation or who belonged to a partnership had easier access to, and better and more contact with, primary care professionals.

\section{Perceived barriers and facilitating factors in the connection between the primary care and the PA sector}

In their work to establish a connection between the primary care and the sport sector, CSCs mentioned perceived factors that could hinder or facilitate the connection between the both sectors.

\section{Perceived barriers}

Professionals' lack of time and knowledge

According to CSCs, primary care professionals were busy and did not have time to discuss PA with patients and to refer them towards CSCs. In addition, they did not know what kind of sport activities were suitable for their patients and did not consider PA as important and gave little priority to it.

"On his advice, she needed to exercise and then the GP says, like, I don't know, you have to find out for yourself. That's when I think, like, you can't be serious! I am there, and I have also let the GPs know, but then they don't follow up on it. That is another reason for me to focus on the fitness tests." (CSC 1)

Lack of time was also a perceived barrier to contact with the PA sector, because sport clubs are often run by volunteers. Therefore, they often did not have an active role in the collaboration and the CSCs needed to take the initiative. Another barrier mentioned by CSCs was volunteers' lack of knowledge and experience of working with the target group. According to CSCs, primary care professionals' apprehensiveness about sport clubs was a reason for the lack of referral. In addition, CSCs shared this apprehensiveness and had a preference for qualified sport instructors.

"So I also find it a bit scary myself, if I, if I refer someone with diabetes or heart problems to wherever a volunteer is leading the group, who may be lucky enough to have passed his first aid course." (CSC 1) 
Lack of suitable PA activities

Another perceived barrier was the lack of suitable sport activities for the target group. The sport clubs' level was too high for this group, and therefore some CSCs were supporting sport clubs to adapt their sport offer for other target groups.

"Everyone should join a sports club, but now we believe, the sports clubs are not ready for it and these people are certainly not ready for it." (CSC 14)

\section{Primary care professionals' own interests}

Another perceived barrier was primary care professionals' own interests, because, according to CSCs, GPs and physiotherapists were often working in the same health centre and a referral towards a physiotherapist was easier and better for their own interests. In addition, some physiotherapists had their own exercise lessons for their patients and preferred to refer their patients towards their own sport offer instead of to a CSC.

"But I believe that, for physiotherapists, they might also be a bit scared to, er, are you not taking our place, are you not taking work away from us?" (CSC 13)

\section{Perceived facilitating factors}

Willingness to participate

Professionals' willingness to participate in the connection between the primary care and the PA sector or with CSC activities were mentioned by CSCs as a facilitating factor. This willingness to participate was mostly mentioned in relation to the PA sector. In general, most CSCs were more positive about the PA sector than about the primary care sector. It was easier for CSCs to involve sport professionals in their work than primary care professionals. Sport clubs were often enthusiastic about collaborating, because CSC activities contributed to increasing the number of sport club members.

"The gymnastics club is of course thrilled, because they get 44 new members handed to them on a silver platter, and the instructor has been arranged, and the room, and they basically do not have to do anything." (CSC 2)

However, some CSCs with more and better contacts with primary care professionals mentioned that primary care professionals were enthusiastic about CSC initiatives and collaboration.

"Primary care is where your energy can be found. You can achieve really nice things there. So that is a great development." (CSC 8)

Factors facilitating the involvement of primary care professionals

CSCs mentioned that it took time and trust to increase the involvement of the primary care professionals. In addition, showing the result after referral and having regular contact with primary care professionals about their role increased their involvement. Other facilitating factors were making use of ambassadors as a way to get in contact with primary care professionals, opting for an easily accessible form of collaboration, for example an online referral form, and inviting physiotherapists to attend a sport lesson.

Factors facilitating the involvement of PA professionals

With regard to the PA sector, it was important for CSCs not to have high expectations of the sport clubs Because the volunteers lacked time and knowledge. 
General facilitating factors

According to CSCs, s shared goal and a concrete plan of action were general facilitating factors in establishing a connection between the primary care and the PA sector.

\section{Discussion}

The aim of this study was to explore CSCs' role in connecting the primary care and the PA sector. CSCs in our study perceived themselves as having three roles: broker role, referral function, and organiser of activities. The extent to which these roles were fulfilled and how the CSC could establish a (structured) collaboration between the primary care and the PA sector depended on the way municipalities implemented the CSC funding, and to a certain extent on the involvement of primary care professionals.

Most CSCs had a mandate from the municipality to stimulate residents to become more physically active. Therefore, these CSCs focused mainly on organising activities or guiding residents towards local sport facilities (often in collaboration with primary care, welfare, and sport professionals) as a way to stimulate PA among residents rather than stimulating collaboration between professionals.

The way municipalities appointed CSCs and organised partnerships influenced the extent to which sectors were involved in collaboration structures and the ease with which the CSC could establish these collaboration structures. Most CSCs found difficult to involve primary care professionals in their work. The involvement of primary care professionals influenced the role that CSCs performed: CSCs with a lack of involvement by primary care professionals fulfilled mostly the organiser role rather than the referral function. However, CSCs working for a care or a welfare organisation had easier access to primary care professionals than CSCs working for a sport organisation or the municipal sport department, and could therefore better fulfil the referral function and guide primary care patients towards local sport facilities. Also, as part of the CSC funding, some municipalities organised a partnership between primary care, welfare and sport professionals. These partnerships supported the CSCs in their work and made it easier for them to connect both sectors.

CSCs in our study set up collaboration structures centred on patient referral or the organisation of activities to connect the primary care and the PA sector. In the referral of primary care patients, CSCs worked in a multidisciplinary manner, whereby different disciplines worked independently on different aspects of a project [21]. In the organisation of activities, CSCs worked in an interdisciplinary manner, whereby different disciplines work together on the same project [21]. These different collaboration structures were also identified in a systematic literature review on collaborative initiatives between the primary care and the PA sector [15].

CSCs in this study mentioned several barriers to connecting the primary care and the PA sector, such as the lack of suitable sport activities for the target groups at sport clubs and the capabilities of volunteers working for sport clubs. This was also identified in a study by Ooms et al. (2015) [22], which showed that sport activities at sport clubs were not suitable for the target group. According to the CSCs, barriers relating to the primary care sector were primary care professionals' lack of time to participate or to refer patients, their lack of knowledge about PA, and their own interests. These barriers were also identified in other studies on barriers to PA promotion by primary care professionals [23-25]. Given the roles that CSCs perceived themselves as having, CSCs should be able to eliminate some of the 
perceived barriers and further improve the connection between both sectors. For example, as part of their organiser role, they could support sport clubs in offering PA activities for the target group, or they could provide an insight for primary care professionals into the PA offer in the neighbourhood. The CSC role could also be of interest to other countries, because studies on initiatives to promote PA among primary care patients in the USA, the UK, and Australia [10-13] identified the same barriers to collaboration between the primary care and the PA sector. However, further studies will be required to show whether CSCs are actually capable of eliminating these barriers and improving collaboration between both sectors. By following CSCs for a year and conducting multiple interviews, we have been able to convey a first impression of their role and to identify perceived barriers and facilitating factors in connecting both sectors. This first impression of how CSCs perceive their role is necessary to enable study of the CSCs' impact on connecting these two sectors and to further improve the CSC function. The CSC is a new function and, although the broker role was ascribed to the function by the Dutch Ministry of Health, Welfare, and Sport, a blueprint for the municipalities with regard to its implementation has not been developed. As a consequence, municipalities and CSCs are still searching for the best way to implement and fulfil the CSC role and connect the primary care and the PA sector. The results of this study are therefore relevant for municipalities, organisations, and professionals implementing a CSC function. Insight into barriers and facilitating factors for the connection between both sectors may be helpful to further improve the connection, especially because most CSCS found structured collaboration difficult to establish.

As the CSC function is new, CSCs were still exploring their own function at the time of the interviews. Initially, we expected structured forms of collaboration between the CSC, primary care, and the PA sector. However, these structured forms of collaboration have not yet been developed. . Therefore, Koelen et al.'s (2012) [17] HALL framework preselected to study the CSC role in connecting the primary care and the PA sector appears to be less relevant, especially the factors relating to the organisation of the alliance. Institutional (municipality mandate) and personal factors (attitudes and beliefs) do seem to influence the CSC role in connecting these sectors. Various studies have shown that it takes time to build relationships and collaboration structures $[6,8,26]$. More time is therefore needed for the CSCs to establish a more structured and sustainable connection between the primary care and the PA sector. This could mean that the CSC role will change over time. Therefore, a study will be needed to further assess CSCs' impact on improving intersectoral collaboration between the primary care and the PA sector. In addition, future studies, which are a planned part of the larger project, will be required to show the effectiveness of the CSC role in stimulating PA among the target group.

\section{Conclusion}

This study has shown that the CSC role seems to hold the promise of improving collaboration between the primary care and the PA sector, especially because the roles that CSCs perceived themselves as having seem to be directed at eliminating barriers in this connection. Future research is needed to study whether CSCs are really capable of establishing collaboration between both sectors over time. In addition, this study has shown that the way municipalities implement the CSC funding seems to influence the CSCs' impact on establishing this connection. The insights from this study can be used to improve policy 
108 | The role of the Care Sport Connector in the Netherlands

and preconditions for the CSC role and the connection between the primary care and the PA sector. 


\section{References}

1. Kahn EB, Ramsey LT, Brownson RC, Heath GW, Howze EH, Powell KE, Stone EJ, Rajab $\mathrm{MW}$, Corso $\mathrm{P}$. The effectiveness of interventions to increase physical activity. A systematic review. American Journal of Preventive Medicine 2002, 22(4), 73-107.

2. Warburton DE, Nicol CW, Bredin SS. Health benefits of physical activity: the evidence. Canada Medical Association Journal 2006,174, 801-809.

3. Huijg JM, Gebhardt WA, Verheijden MW, van der Zouwe N, de Vried, JD, Middelkoop BJ, and Crone MR.Factors influencing primary health care professionals' physical activity promotion behaviors: A systematic review. International Journal of Behavioral Medicine 2015, 22, 32-50.

4. Hildebrandt VH, Chorus AMJ, Stubbe JH. Trend report on physical activity and health 2010/2011. TNO Innovation for Life. Leiden: TNO; 2013.

5. Eakin EG, Glasgow RE, Riley KM. Review of primary care-based physical activity intervention studies. Family Practice 2000, 49(2), 158-68

6. Den Hartog F, Wagemakers A, Vaandrager L, van Dijk M, and Koelen MA. Alliances in the Dutch Beweegkuur lifestyle intervention. Health Education Journal 2014, 73, 576-587.

7. Meijer S, Hesselink A, Martens M. Leefstijlbeïnvloeding in de eerstelijn. Verkenning naar de ervaringen van zorgverleners. Bilthoven: RIVM; 2012.

8. Casey M, Payne W, Brown S, and Eime R. Engaging community sport and recreation organisations in population health interventions: factors affecting the formation, implementation, and institutionalisation of partnerships efforts. Annals of Leisure Research 2009,12, 129-147.

9. Casey M, Payne W, and Eime R. Partnership and capacity-building strategies in community sports and recreation programs. Managing Leisure 2009, 14, 67-176.

10. Cashman SB, Flanagan P, Silva MA, and Candib LB. Partnering for health: collaborative leadership between a community health center and the YWCA central Massachusetss. Journal of Public Health Management and Practice, 2012, 18, 279-287.

11. Foley M, Frey M, McPherson G, and Reid G. Healthy public policy: A policy paradox within local government. Managing Leisure 2000, 5, 77-90.

12. Thrinh L, Wilson R, Williams HM, Sum AJ, and Naylor PJ. Physicians promoting physical activity using pedometers and community partnerships: A real world trial. British Journal of Sports Medicine 2012, 46, 284-290.

13. Wiles R, Demain S, Robinson J, Kileff J, Ellis-Hill C, and McPherson K. Exercise on prescription schemes for stroke patients post-discharge from physiotherapy. Disability Rehabilitation 2008, 30, 1966-1975.

14. Harting J, Kunst AE, Kwan A, and Stronks K. A 'health broker' role as a catalyst of change to promote health: An experiment in deprived Dutch neighbourhoods. Health Promotion International 2011, 26, 65-81.

15. Leenaars KEF, Smit E, Wagemakers A, Molleman GRM, Koelen MA. Facilitators and barriers in the collaboration between the primary care and the sport sector in order to promote physical activity: a systematic literature review. Preventive Medicine 2015, 81, 460-78. doi:10.1016/j.ypmed.2015.10.010.

16. Smit E, Leenaars KEF, Wagemakers AM, Molleman GRM, Koelen MA, van der Velden J. Evaluation of the role of care sport connectors in connecting primary care, sport, and physical activity, and residents' participation in the Netherlands: study protocol for a longitudinal multiple case study design. BMC Public Health 2015,15, 510.

doi:10.1186/s12889-015-1841-z 
17. Koelen MA, Vaandrager $L$, and Wagemakers $A$. The healthy alliances (HALL) framework: Prerequisites for success. Family Practice 2012, 29 (SUPPL.1), 132-138.

18. Frey BB, Lohmeier JH, Lee SW, and Tollefson N. Measuring collaboration among grand partners. American Journal of Evaluation 2006, 27, 383-392

19. Zaalmink W, Wielinga E, Bergevoet R, Geerling-Eiff F, Holster H, Hoogerwerf L. et al. Networks with Free Actors. Wageningen: Wageningen University' 2008

20. Creswell JW Research design: Qualitative, quantitative, and mixed methods approaches. London: Sage; 2009.

21. Choi BC, and Pak AW. Multidisciplinarity, interdisciplinarity and transdisciplinarity in health research, services, education and policy: 1 . Definitions, objectives, and evidence of effectiveness. Clinical and Investigative Medicine 2006, 29, 351-364.

22. Ooms L, Veenhof C, Schipper-van Veldhoven N, and de Bakker DH. Sporting programs for inactive population groups: Factors influencing implementation in the organized sports setting. BMC Sports Science, Medicine and Rehabilitation 2015, 7, 12. doi: 10.1186/s13102-015-0007-8

23. Huijg JM, van der Zouwe N, Crone MR, Verheijden MW, Middelkoop BJC, Gebhardt WA. Factors influencing the introduction of physical activity interventions in primary health care: a qualitative study. International Journal of Behavioral Medicine 2015, 22(3), 404414.

24. Leemrijse C, de Bakker D, Ooms L, and Veenhof C. Collaboration of general practitioners and exercise providers in promotion of physical activity a written survey among general practitioners. BMC Family Practice 2015, 16(1), 96. doi:10.1186/s12875-015-0316-8

25. Hébert ET, Caughy MO, and Shuval K. Primary care providers' perceptions of physical activity counselling in a clinical setting: A systematic review. British Journal of Sports Medicine 2012, 46, 625-631.

26. Baker EA, Wilkerson R, Brennan LK. Identifying the role of community partnerships in creating change to support active living. American Journal of Preventive Medicine 2012, 43(5 Suppl 4), S290-299. 


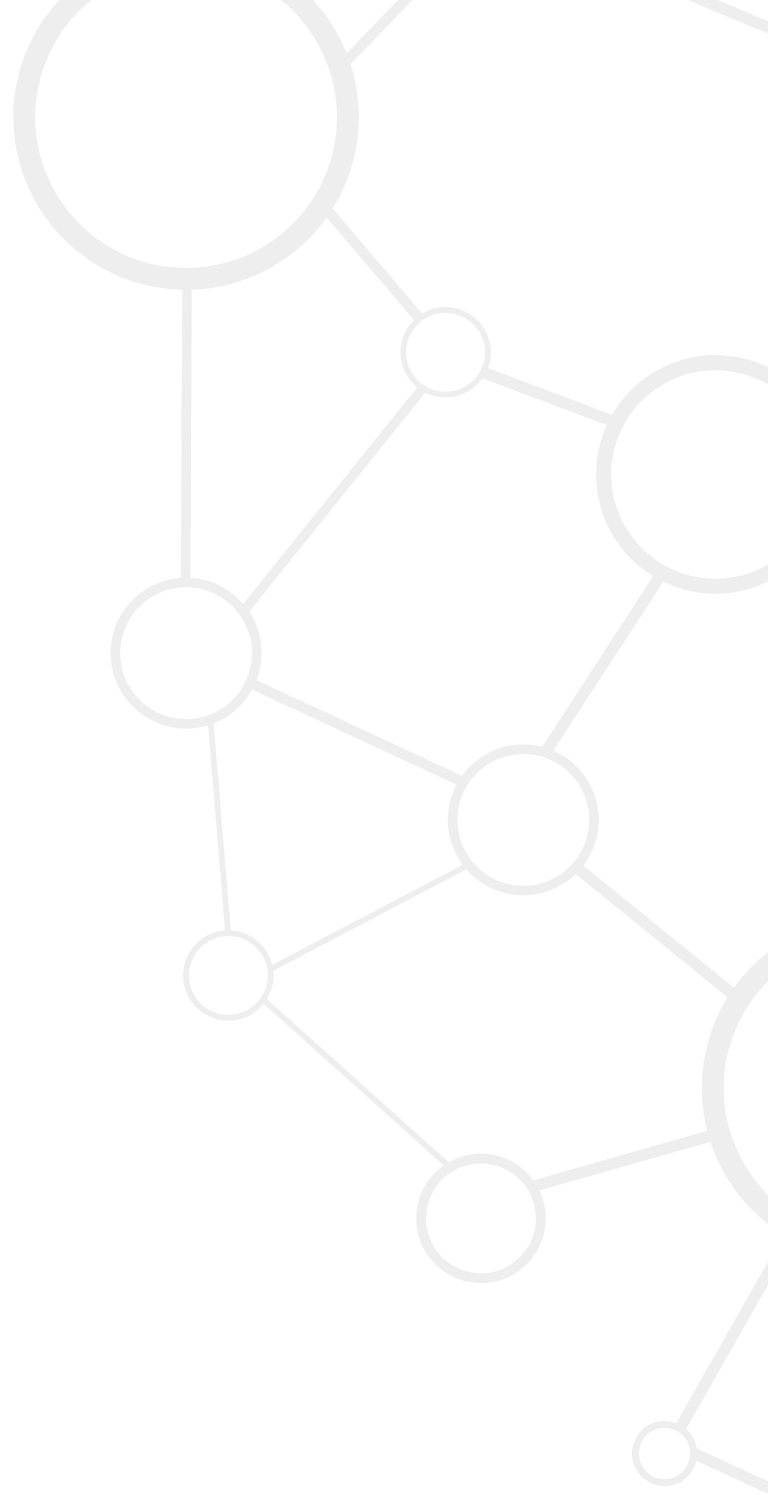




\section{Chapter 5}

The role of the Care Sport Connector over time 


\begin{abstract}
Introduction

To stimulate physical activity and guide primary care patients towards local sport facilities, Care Sport Connectors (CSC), to whom a broker role has been ascribed, were introduced in 2012 in the Netherlands. The aim of this study is to 1) follow up on how CSCs fulfilled their role over time and 2) gain a more in-depth insight into how CSCs fulfilled specifically their role as broker.
\end{abstract}

\title{
Methods
}

Interviews were held with 12 CSCs in March 2016, two years after the first interview in March 2014. Questions were asked concerning the following themes: CSCs' role, network organisation and results, and the connection between both sectors. The data analysis was based on Creswell's [9] six steps for qualitative data analysis

\section{Results}

CSCs in our study fulfilled three roles: broker, referral, and organiser. These roles remained the same over time. CSCs fulfilled the broker role by fulfilling the referral and organiser role. CSCs differed in the way they fulfilled their broker role. Most CSCs continued their involvement in the connection, while other CSCs withdrew themselves from the connection after they had initiated collaboration between both sectors.

\section{Conclusion}

CSCs in our study fulfil their broker role by engaging in the referral and organiser role. It appeared that these roles remained the same over time. Regarding CSCs' active role in the connection, continuation of the CSC funding seems to be important for the preservation of the connection established. 


\section{Introduction}

In 2012, the Dutch Ministry of Health, Welfare, and Sport introduced Care Sport Connectors (CSCs), to whom a broker role is ascribed. These CSCs are employed specifically to stimulate intersectoral collaboration between the primary care and the PA sector in order to guide primary care patients towards local PA facilities. A broker role stimulating a connection between the primary care and the PA sector is desirable because currently factors related to each sector [1] and differences between the primary care and the PA sector hinder their mutual collaboration [2]. The general idea is that CSCs facilitate the connection between the primary care and PA sector; professionals in these sectors collaborate; activities to promote PA are implemented; these activities reach certain target groups; target groups become more physically active; and health outcomes improve.

Therefore, the value of a broker is to bridge a structural hole, which manifests itself between two unconnected actors [3]. Brokers are said to generate innovative ideas, mediate and resolve conflicts, make advice and knowledge more accessible, and create an environment in which collaboration can succeed [4]. To our knowledge, a broker's role in improving intersectoral collaboration between the primary care and the PA sector is unexplored. In our review study, we found only one initiative using a broker role to stimulate collaboration between both sectors [2]. The implementation of CSC funding provides us with an excellent opportunity to explore how a broker fulfils this role in the connection between the primary care and the PA sector.

In our previous study in which we studied how CSCs perceive their role in this connection, it appeared that CSCs ascribed three roles to themselves: broker, referral, and organiser (Chapter 4). CSCs focus mainly on organising activities and implementing referral schemes in which CSCs guide primary care patients towards PA facilities after referral by primary care professionals, rather than on stimulating collaboration between both sectors. However, several studies have shown that it takes time to build relationships and collaboration structures [5-8], and, at the time of the study as described in Chapter 4, CSCs were still exploring their own role. Therefore, the aim of the current study is to 1) follow up on how CSCs fulfilled their role over time and 2) gain a more in-depth insight into how CSCs fulfilled specifically their role as broker to establish the connection between both sectors.

\section{Method}

\section{Study design}

This study is part of a larger project in which a multiple case study is being conducted in nine municipalities spread over the Netherlands from 2014 to the end of 2016 to study the role and impact of 15 CSCs in connecting the primary care and the PA sector, and the participation of the target group (Chapter 2).

\section{Study population}

To follow up on CSCs' broker role over time, a qualitative study was conducted among 12 of the 15 CSCs participating in the larger project. For various reasons, three CSCs were not available for interview. Two CSCs had ceased their function, and it was decided not to conduct a fourth interview with one participant because the operations at the community health centre (outlined in Chapter 4) had not changed. The average age of the 12 CSCs (4 men, 8 women) was 30.2 years (min 27 years, max 57 years). Nine CSCs had a bachelor's degree, two had a master's degree, and one had a vocational education diploma. At the start 
of the project in 2014, seven CSCs had been in position for 0-6 months, four CSCs were working for 6-12 months, and two for longer than a year.

\section{Setting}

The municipalities participating in this project were selected through convenience sampling based on project partners' contacts. The main criterion for municipalities to be included was that the municipalities would be implementing CSC funding for four years (until 2017). In addition, the region, size of the municipality, and the way the municipality implemented the CSC funding were taken into account in choosing the municipalities. In consultation with the representative policymaker in each municipality, CSCs were selected to participate in this study. Inclusion criteria were: the CSC 1) aims to connect the primary care and the PA sector and 2 ) is working with the target group of adults, preferably adults who could benefit from PA (primary care patients, the elderly). In total, 12 CSCs participated in the study, representing eight municipalities. This is approximately $15 \%$ of the CSCs employed to connect primary care and sport for adults in the Netherlands (for more detailed information see Chapter 2).

These eight municipalities were spread over the Netherlands and differed in size $(\geq 300,000$ inhabitants ( $n=2), 100,000-300,000$ inhabitants $(n=3), \leq 100,000$ inhabitants $(n=3))$. The CSC funding was implemented differently in the eight municipalities. Three CSCs in the same municipality were part of a different partnership between primary care, welfare, and sports professionals organised by the municipality and were working for a care organisation $(n=1)$ or a welfare organisation $(n=2)$. Three CSCs were working for the municipal sports department, four were working for a sports organisation, one was working for a welfare organisation, and one CSC was working for the Municipal Health Department. All CSCs had the task (sometimes mandated by the municipality) of stimulating PA and/or a healthy lifestyle among the target group. One CSC had the task of facilitating collaboration between professionals in order to create an integrated approach to stimulate a healthy lifestyle.

\section{Data collection}

To follow up on how CSCs fulfilled their role over time, interviews with the 12 CSCs were held in March 2016, two years after the first interview in March 2014 (described in Chapter 4). The interviews took place at the CSCs' workplace, lasted between 1 and 1.5 hours, and were conducted by KL. The interview topic list used in round 4 was based on the topic list used in interview rounds 1-3, part of the study described in Chapter 4. Similar to the other rounds, questions were asked concerning the themes: CSC role, network organisation and results, and the connection between the primary care and the PA sector. However, based on results of the interviews in rounds 2 and 3, some adjustments were made to the topic list (Table 5.1). To identify CSCs' role, instead of asking how CSCs described their role, we now specifically asked in round 4 how they fulfilled the broker, referral, and organiser role as identified in previous interviews. Additional questions were asked about their activities to connect both sectors to further clarify the roles fulfilled by CSCs. To gain a more in-depth insight into how CSCs fulfilled their broker role, we asked questions regarding the established connection between both sectors, their future plans regarding a (sustainable) connection between both sectors, and prerequisites for these future plans. Additional questions were asked about their role in this connection and their future role. The themes 'network organisation' and 'network results' were part of this interview round, but the results are discussed in Chapter 8. 


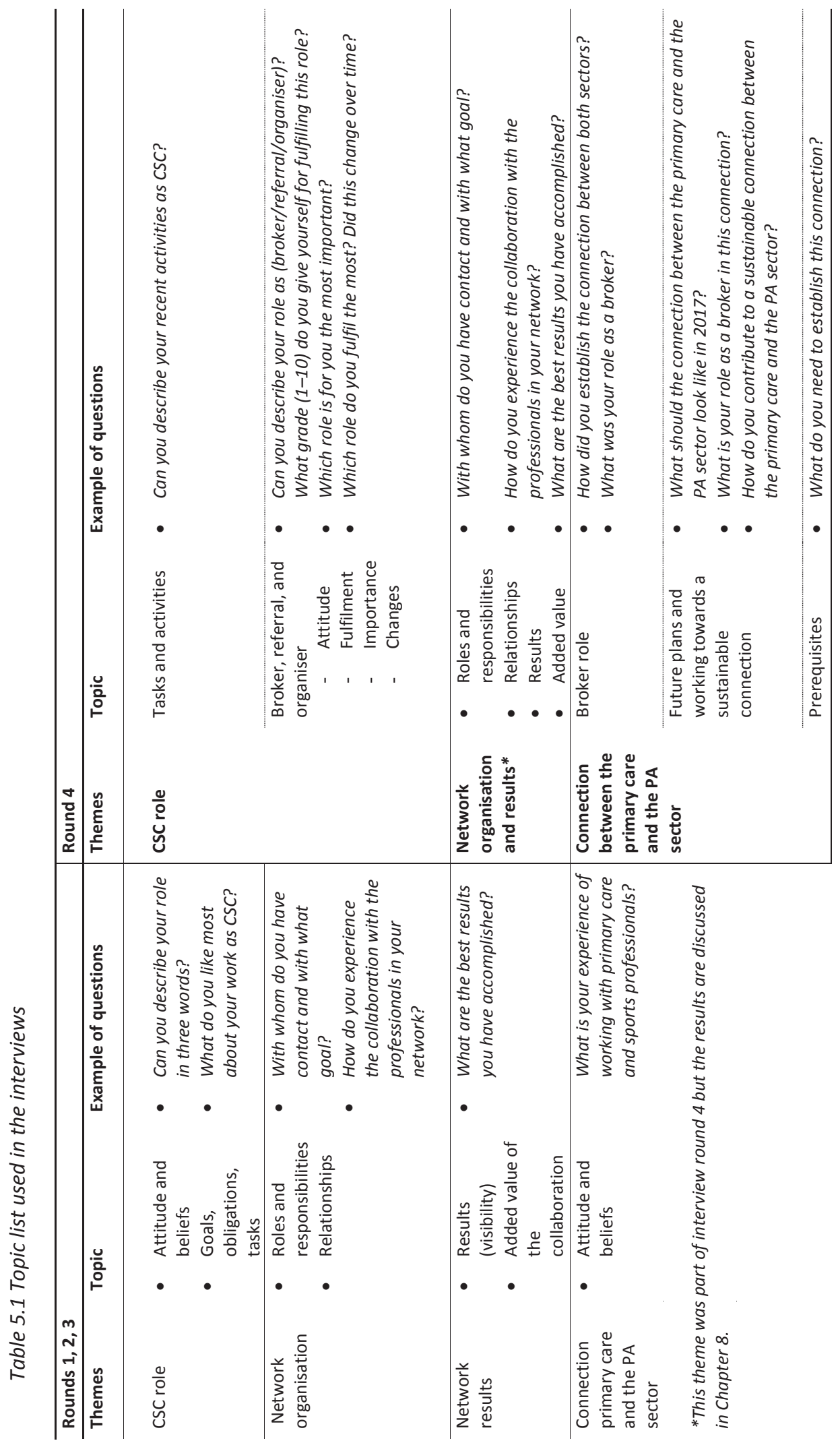




\section{Data analysis}

The interviews were audiotaped and transcribed (intelligent verbatim style). The data analysis was based on Creswell's [9] six steps for qualitative data analysis. So, after the data were organised and prepared for analysis (step 1), the transcripts were read (step 2). In the third step, the transcripts were coded and analysed using software for qualitative analysis (Atlas.ti, version 7.1.8). The data were coded top-down with predefined codes based on the results from the previous interview rounds (Chapter 4 ). In the fourth step, the codes were clustered into the following themes: the CSC role and a broker in the connection between the primary care and the PA sector. In steps 5 and 6, more bottom-up codes were assigned to the various themes; for example, the new codes identified in the theme-a broker in the connection between the primary care and the PA sector - were 'around own activities' and 'withdrawing' (Table 5.2). All steps of the data analysis were performed independently by two researchers (author and research assistant). The interpretation of the data was discussed to reach consensus between the two researchers. Most discussion related to dividing the different broker roles ascribed to CSCs.

Table 5.2 Code list used in the data analysis

\begin{tabular}{|c|c|c|}
\hline Themes & Top-down codes & Bottom-up codes \\
\hline CSC role & $\begin{array}{ll}\text { - } & \text { Broker } \\
\text { - } & \text { Referral } \\
\text { - } & \text { Organiser } \\
\text { - } & \text { Focus } \\
\end{array}$ & \\
\hline \multirow[t]{3}{*}{$\begin{array}{l}\text { A broker in the connection between } \\
\text { the primary care and the PA sector }\end{array}$} & - Broker role & $\begin{array}{ll}\text { - } & \text { Around own activities } \\
\text { - } & \text { Withdrawing }\end{array}$ \\
\hline & - Future plans & $\begin{array}{l}\text { - Continue } \\
\text { - } \quad \text { Expand } \\
\text { - } \quad \text { Structural form of collaboration }\end{array}$ \\
\hline & - Prerequisite & $\begin{array}{ll}\text { - } & \text { Retain CSC function } \\
\text { - } & \text { Municipal policy } \\
\text { - } & \text { Vision of professionals }\end{array}$ \\
\hline
\end{tabular}

The analyses led to a description of how each CSC fulfilled his/her broker role between 2015 and 2016. Next, the description was compared to the description of the roles that CSCS ascribed to themselves in 2014-2015 (interview rounds 1-3, Chapter 4). This enabled us to follow up on how CSCs fulfilled their broker role over time and identify possible changes and new approaches. After the data analysis was completed, the results were discussed within the research team.

\section{Results}

\section{CSCs' role over time}

The roles fulfilled by CSCs did not change over time. CSCs fulfilled the same roles in the second year of the study period as the roles CSCs ascribed to themselves in the first year of the study period: referral, organiser, and broker (Table 5.3). The extent to which CSCs fulfilled each of these roles depended on the activities at the time. 
It is...l, you are organising a major event, it is difficult at first. You are then focusing on that organising role, but as soon as you have the time and can take a breather, you can actually bring it all back together again. Sometimes it is just too much. Sometimes, I really have to focus on just one or two things instead of 10. (CSC 7)

Although all roles are more or less present in the work of all CSCs, just like in the first year of the study period, differences could be distinguished about the roles on which they focused the most. Ten CSCs focused on the same role(s) as in the first year of the study period. That is: four CSCs focused mostly on the organiser role, in which they organised activities together with other professionals to stimulate PA (mostly fitness tests); two CSCs focused mostly on the referral role, in which they guided primary care patients towards local PA facilities; two CSCs combined the organiser and the referral role; and two CSCs combined the organiser and the broker role, in which professionals were supported to collaborate with one another (Table 5.3).

For two CSCs, the focus of their role changed over time. In both cases, the CSCs focused more on the broker role than on the referral role. One of these CSCs mentioned that the referral structure was established and therefore the focus could be more on the connection between both sectors. The other CSC mentioned a change in the vision of what the role entailed (Table 5.3).

Because I believe that if you connect both sectors, if you put a great deal of effort and time into this, the other two roles will, er, automatically come along. So, you will get more referrals and you will be providing more support. This takes up most of my time, and I think this is where the challenge lies for us here in the municipality. (CSC 12)

\section{The broker role in the connection between the primary care and the PA sector}

Even though the broker role was not always the main role, all CSCs somehow fulfilled a broker role. According to the CSCs, the broker role means connecting the primary care and the PA sector. Just as identified in the previous interview rounds (Chapter 4), CSCs fulfilled this broker role by the referral and/or organiser role.

I can really recognise this connecting role, the fact that you are a linchpin between parties. Between both care and sports. (CSC 1)

The way in which the broker role was fulfilled differed between the CSCs. Eight CSCs connected the primary care and the PA sector around their own activities (organising activities, referral), whereas the other four CSCs connected both sectors by initiating collaboration between both sectors but withdrew from this connection once it was established (Table 5.3). This is further elaborated upon below.

Connecting the primary care and the PA sector with CSCs' own activities

Eight CSCs fulfilled the broker role by collaborating with professionals to organise activities to stimulate PA and/or by guiding the target group towards PA facilities. These CSCs had therefore an executive role in the connection between the primary care and the PA sector.

We get a referral from the community care services. We have already seen the referring source by then, which is the care system, and in the intake that we have had we have seen what the needs are, what he wants to do. For example, the gentleman wanted to take up adapted swimming. We then go and see what arrangements we can make for him... You have a triangle this way, a network around you. You can look at us as a means, where things come in and things also go out. (CSC 8) 
These CSCs planned to continue their current activities and to expand these to other neighbourhoods or to ensure that the activities become more structural. A prerequisite for their work is therefore that the CSC function will be retained. In this way, professionals and the target group could rely continually on the CSC.

Connecting the primary care and the PA sector with a withdrawing CSC

Four CSCs established a connection between the primary care and the PA sector by initiating collaboration between both sectors but withdrawing from this connection. These CSCs mostly implemented programmes together with primary care, welfare, and PA professionals in order to stimulate PA. These programmes could be a referral scheme, network meetings, but also the organisation of new PA activities. The aim of these CSCs was that professionals would take over the programmes and that the CSCs could withdraw and have a more coordinating role.

Look, I try to make myself superfluous. At first I have been into organising quite a lot and now I sometimes drop things on purpose, and then the club thinks like 'how about this' and then it will be taken up as a matter of course. I am simply making myself superfluous. (CSC 9)

These CSCs planned to work towards a sustainable collaboration between the primary care and the PA sector. The CSCs differed in their view of how this structured collaboration should look. Two CSCs mentioned a structural referral scheme between the primary care and the PA sector.

So, I would like there to be more of these types of projects, that there is still intensive, er - that someone transfers from care to the exercise programme. Without it always having to involve an intensive intake and what they are about to do. But that instead there is a far more smoothly transferring inflow. That would be great. That, er, you now visit the physiotherapist but that they already know that in 20 weeks you will be going to a fitness centre. That this all will be a type of usual route. (CSC 11)

According to these CSCs, the retention of the CSC function was a prerequisite for this connection so that they could stimulate this structural form of collaboration by offering more tools and methods for the professionals.

The other CSCs mentioned that their plans for the future were to establish a more structural connection between both sectors in which intersectoral collaboration was part of the vision and operations of primary care, welfare, and PA professionals.

What I believe is that it is about the long term, in other words that the collaboration or the joined search for shifts, the search for solutions, that this collective work is not used simply because it is a hot topic, but that it is still going on in 15 years' time. Or... or not as hot because it has become the usual thing, but, er, that is sustainability. (CSC 10)

According to these CSCs, the prerequisite for this connection is an integral policy on the part of the municipality, welfare, and primary care professionals that includes PA in its vision. 


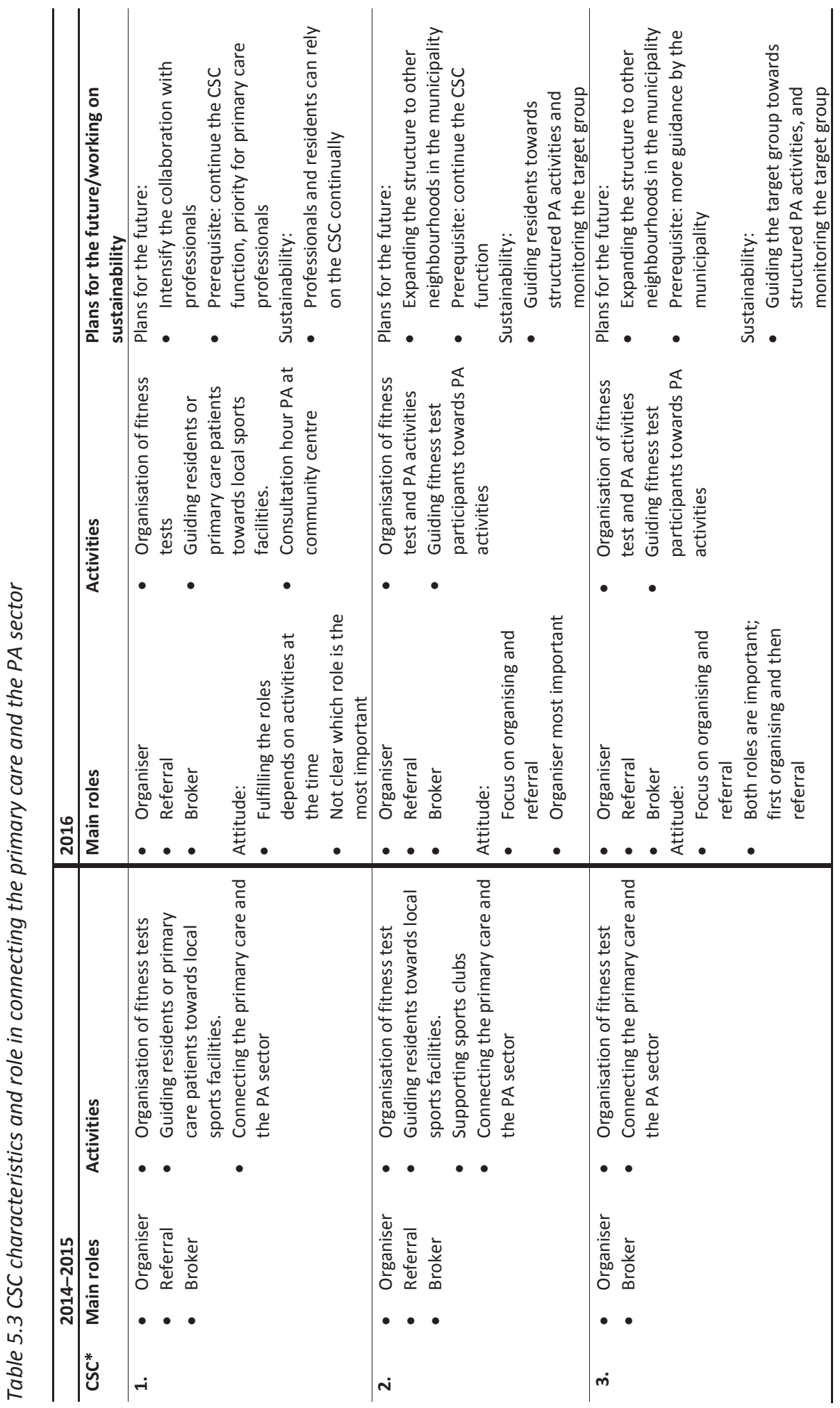




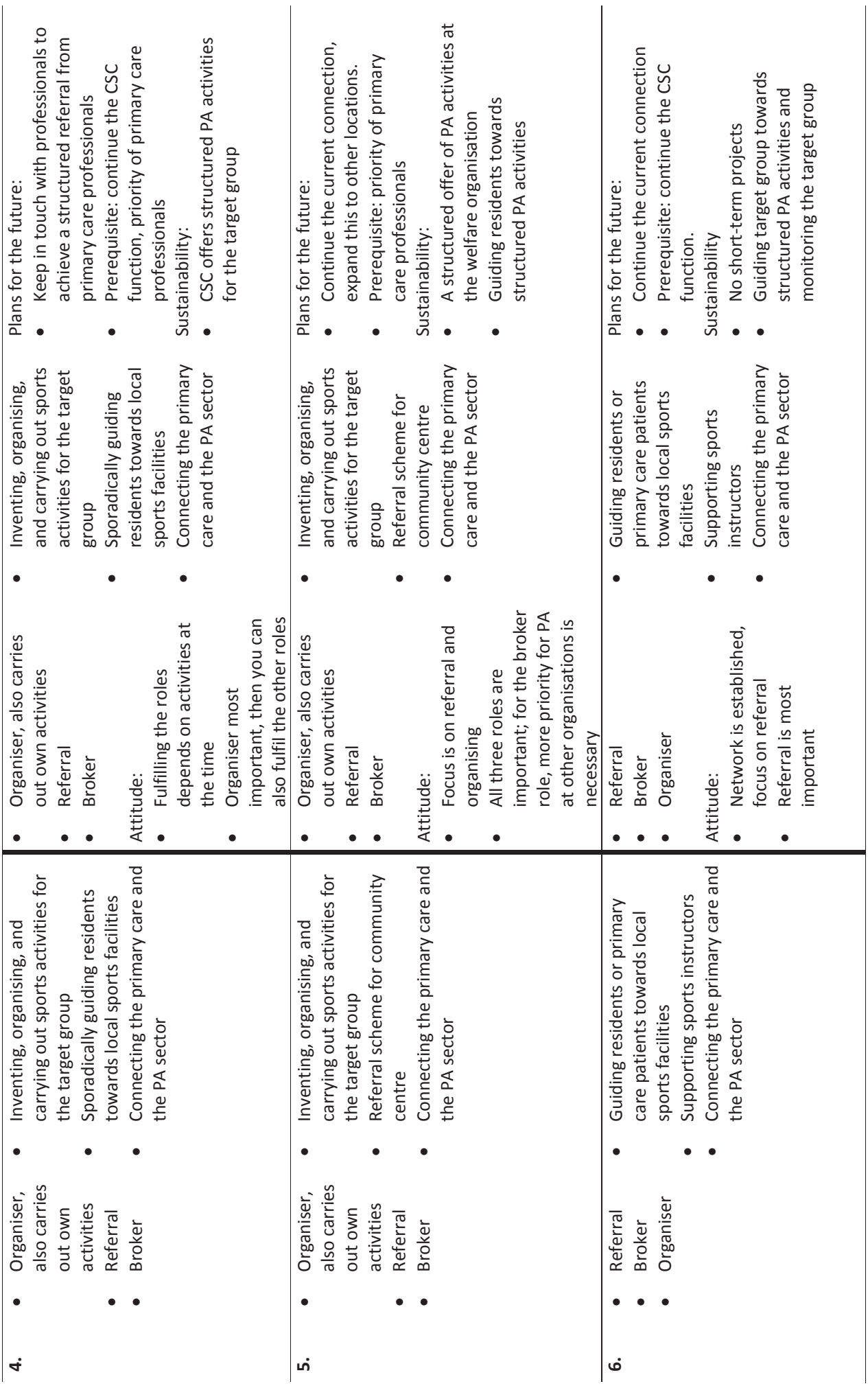




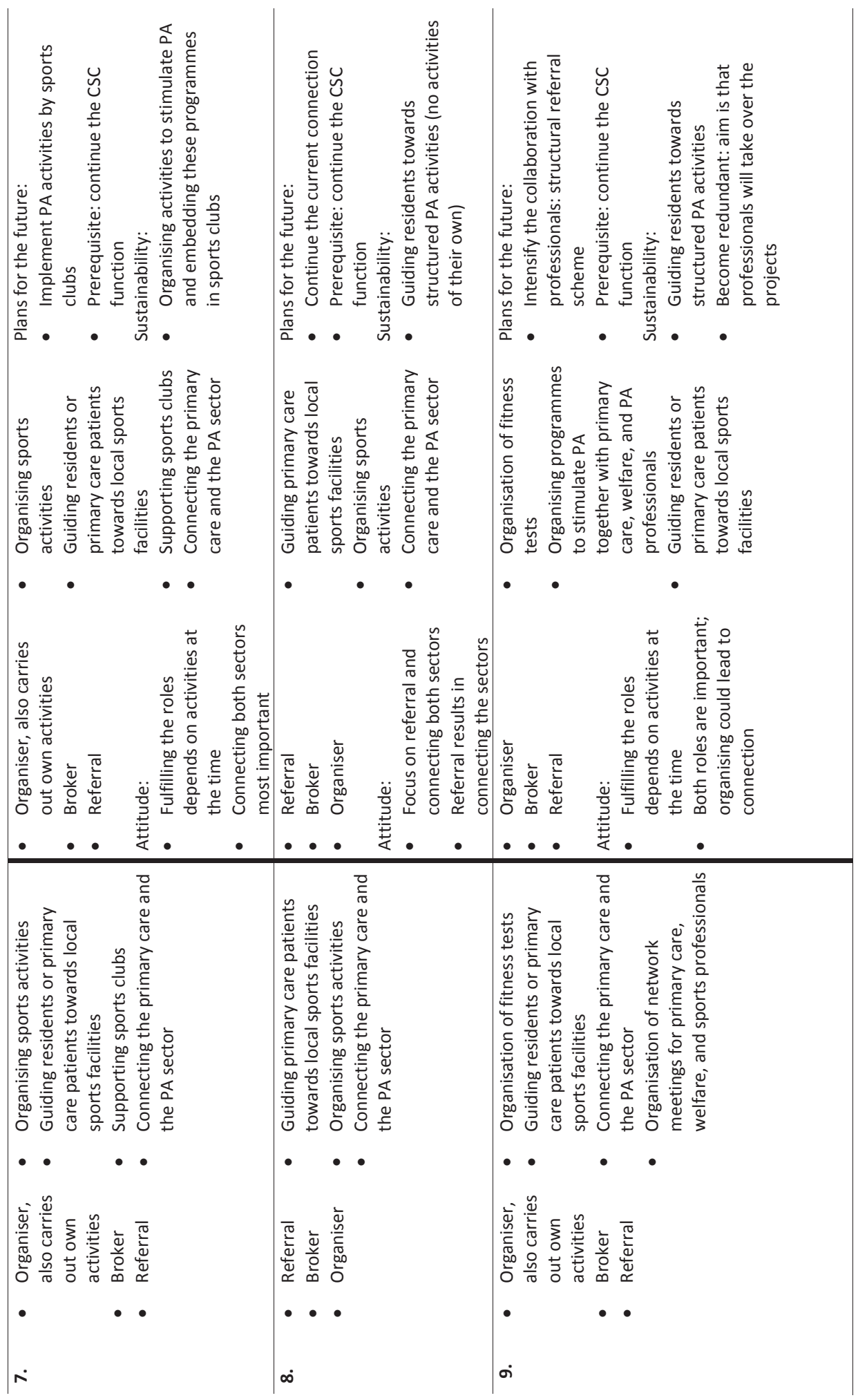




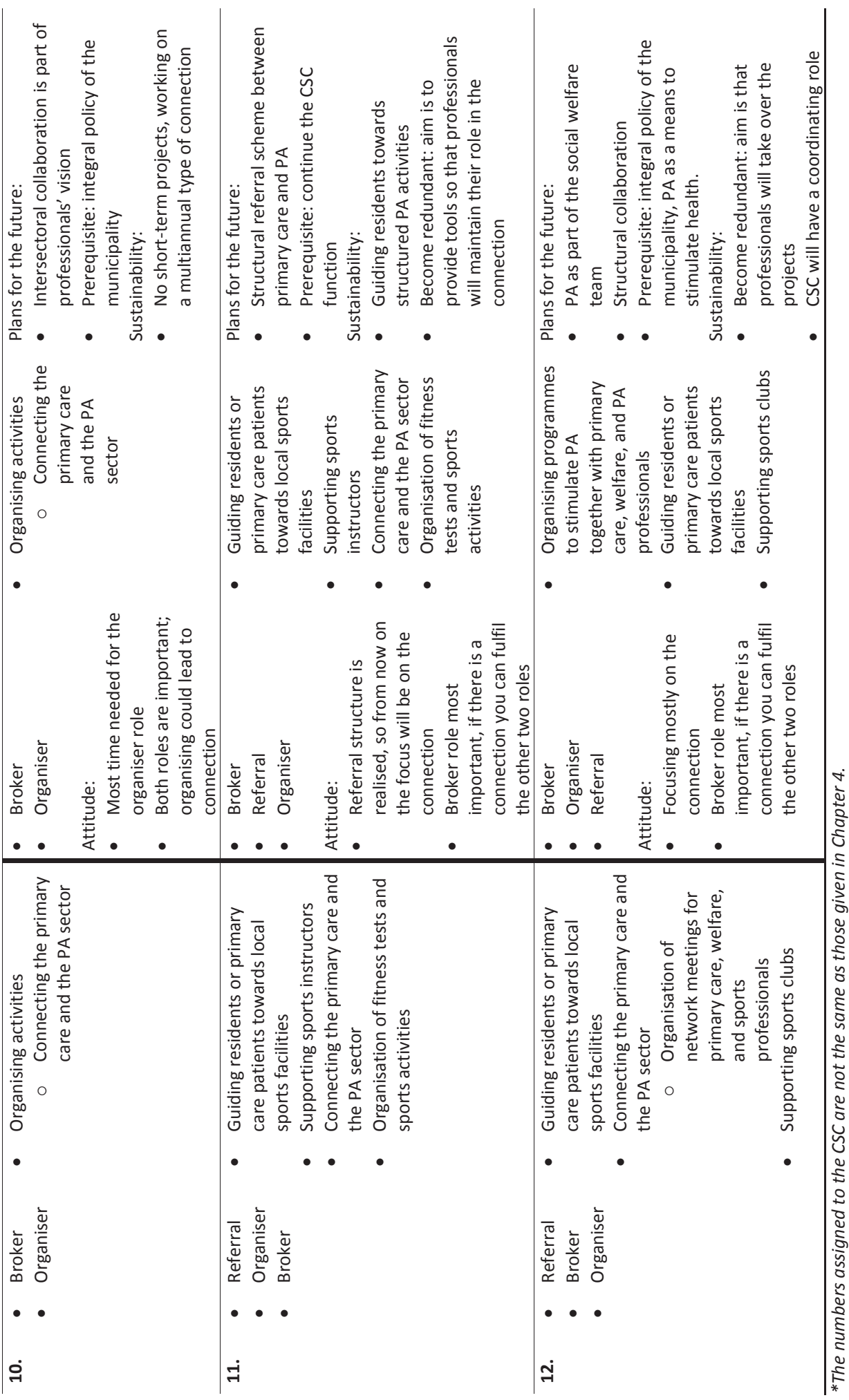




\section{Discussion}

The aim of this study was to 1) follow up on how CSCs fulfilled their role over time and 2) gain a more in-depth insight into how CSC fulfilled specifically the broker role to establish the connection between the primary care and the PA sector. CSCs in our study fulfilled three roles: broker, referral, and organiser. These roles remained the same over time, but for two CSCs their focus on the broker role became more important. CSCs fulfilled the broker role, which they described as stimulating collaboration between the primary care and the PA sector by fulfilling the referral and organiser role. CSCs differed in the way they fulfilled their broker role. Most CSCs connected both sectors around their own activities (referral or organising activities) and therefore continued their involvement in the connection. Other CSCs mentioned that they withdrew from the connection after they had initiated collaboration (by organising a PA promotion programme or setting up a referral scheme) between both sectors.

The way CSCs fulfilled their broker role seems to be in line with what has been found in other studies exploring the broker role in the public health setting. Brokers in those studies also connected different sectors by facilitating and organising services or programmes to stimulate a healthy lifestyle among the general population or specific target groups [10-12]. Therefore, it seems that fulfilling the broker role in a public health setting mostly involves focusing on organising services and programmes to generate benefits for a third party (e.g. promotion of health among inhabitants), instead of on facilitating and managing networks of actors to collaborate and achieve a common goal as identified in studies that explored the broker role in other settings, such as corporate, public-private partnerships [13-16]. Regarding the future of CSCs, continuity of the CSC funding seems to be important for preserving the established connection between both sectors. By continuing the CSC funding, the CSC role and therefore also the established connection will be maintained.

This study contributes to a further insight into the function profile of CSCs. Although the focus of some CSCs changed over time, the roles they fulfilled remained the same.

Therefore, it can be said that CSCs stimulate a connection between the primary care and the PA sector, guide the target groups towards PA facilities, and organise PA activities. This function profile resulting from our study can help policymakers with the implementation of the CSC funding and to formulate a vision and focus concerning the CSC role - especially because the CSC is a new function and a blueprint for the municipalities with regard to its implementation has not been developed. In addition, this function profile can provide an insight into the manner in which professionals in the connection between both sectors can collaborate with CSCs. This is especially relevant, because focus groups with professionals within the CSC network [1] mentioned that the CSC function was not always clear for them.

\section{Study limitation}

By following CSCs for two years in their work and conducting multiple interviews, we have been able to provide a comprehensive insight into the way CSCs fulfilled their role in connecting the primary care and the PA sector. At this juncture, no major changes regarding the roles fulfilled by CSCs have been identified. Most CSCs continued to have the same focus on their roles over time. However, the timeframe of this study may be too short to identify a change of focus in how CSCs fulfil their role. It is possible that, when the connection between both sectors is further established, the CSC role will change into a more 
coordinating and facilitating role. Further research may reveal whether the CSC role will change over a longer period of time.

\section{Conclusion}

From the results of this study, it can be concluded that the CSCs in our study fulfil their broker role by engaging in the referral and organiser role. It appeared that these roles remained the same over time, and no major changes in the focus on these roles were identified. A function profile, resulting from our study, could facilitate policymakers with the implementation of the CSC funding. In addition, regarding CSCs' active role in the connection, continuation of the CSC funding seems to be important for the preservation of the connection established. 


\section{References}

1. Leenaars KEF, Florisson AM, Smit E, Wagemakers A, Molleman GRM, and Koelen MA. The connection between the primary care and the physical activity sector: professionals' perceptions. BMC Public Health 2016,16(1), 1001.

2. Leenaars KEF, Smit E, Wagemakers A, Molleman GRM, Koelen MA. Facilitators and barriers in the collaboration between the primary care and the sport sector in order to promote physical activity: a systematic literature review. Preventive Medicine 2015;81:460-478. doi: 10.1016/j.ypmed.2015.10.010

3. Burt RS. Structural Holes: The Social Structure of Competition. Cambridge: Harvard University Press;1992.

4. Long JC, Cunningham FC, and Braithwaite J. Bridges, brokers and boundary spanners in collaborative networks: a systematic review. BMC Health Services Research 2013, 13(1).

5. Baker EA, Wilkerson R, Brennan LK. Identifying the role of community partnerships in creating change to support active living. American Journal of Preventive Medicine 2012, 43(5 Suppl 4), S290-299.

6. Den Hartog F, Wagemakers A, Vaandrager L, van Dijk M, and Koelen MA. Alliances in the Dutch Beweegkuur lifestyle intervention. Health Education Journal 2014;73, 576-587.

7. Casey M, Payne W, Brown S. and Eime R. Engaging community sport and recreation organisations in population health interventions: Factors affecting the formation, implementation, and institutionalisation of partnerships efforts. Annals of Leisure Research 2009;12, 129-147.

8. Koelen MA, Vaandrager $L$, and Wagemakers A. The healthy alliances (HALL) framework: Prerequisites for success. Family Practice 2012, 29 (SUPPL.1), 132-138.

9. Creswell JW. Research Design: Qualitative, Quantitative, and Mixed Methods Approaches. London: Sage; 2009.

10. Nissen LB. Boundary spanners revisited: A qualitative inquiry into cross-system reform through the experience of youth service professionals. Qualitative Social Work 2010. 9(3), 365-384.

11. McKenna B, Fernbacher S, Furness T, and Hannon M. "Cultural brokerage" and beyond: piloting the role of an urban Aboriginal Mental Health Liaison Officer. BMC Public Health 2015, 15(1), 881.

12. Hogan A, and Stylianou M. School-based sports development and the role of NSOs as 'boundary spanners': benefits, disbenefits and unintended consequences of the Sporting Schools policy initiative. Sport, Education and Society 2016, 1-14.

13. Hanna V, and Walsh K. Interfirm cooperation among small manufacturing firms. International Small business Journal 2008, 26(3), 299-321.

14. Jones R, and Noble G. Managing the implementation of public-private partnerships. Public Money and Management 2008, 28(2), 109-114.

15. Stadtler L, and Probst G. How broker organizations can facilitate public-private partnerships for development. European Management Journal 2012, 30(1), 32-46.

16. Williams P. The competent boundary spanner. Public administration 2002, 80(1), 103124. 


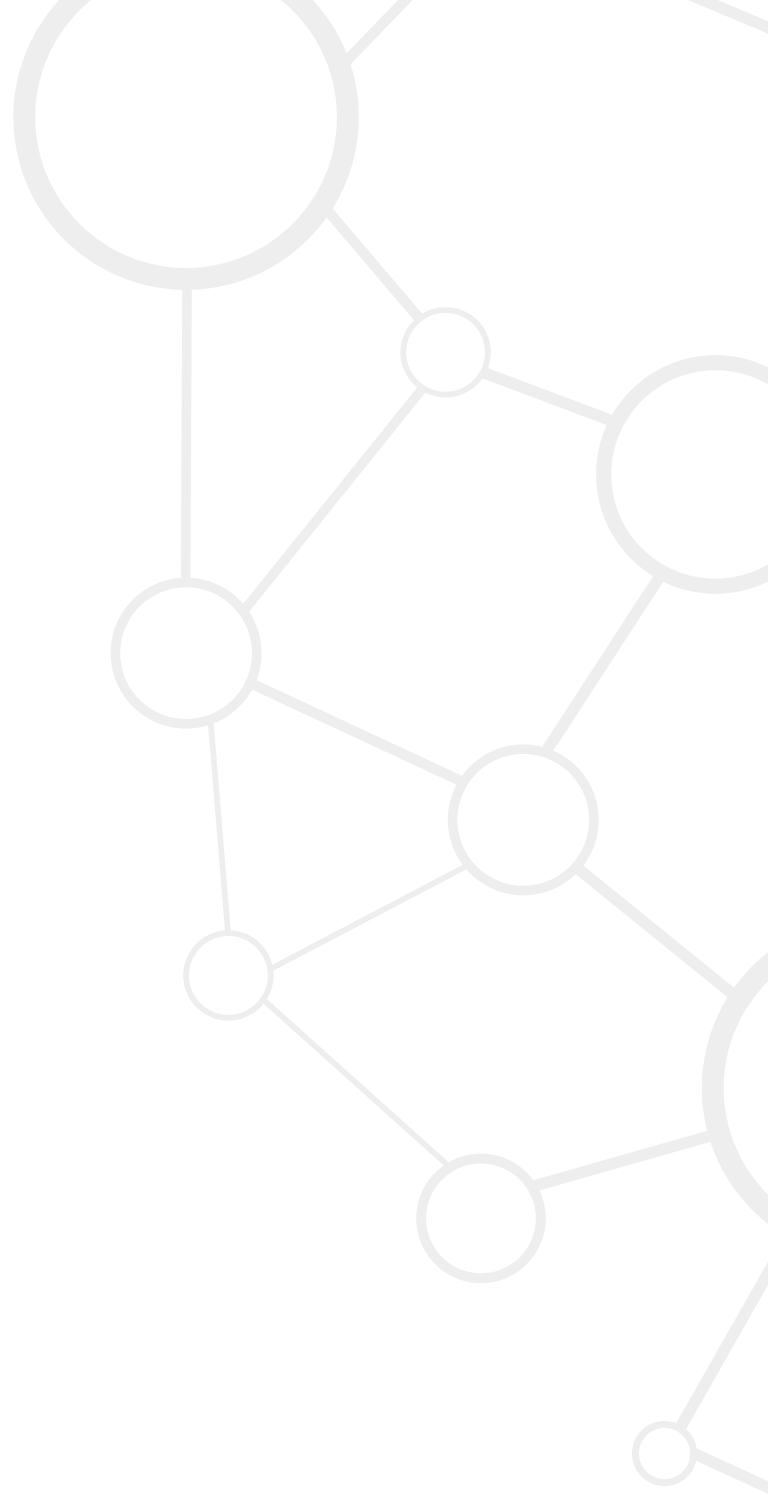




\section{Chapter 6}

The connection between the primary care and the physical activity sector: professionals' perceptions 


\begin{abstract}
Background

To stimulate physical activity (PA) and guide primary care patients towards local PA facilities, Care Sport Connectors (CSC), to whom a broker role has been ascribed, were introduced in 2012 in the Netherlands. The aim of this study is to assess perceptions of primary care, welfare, and sport professionals towards the CSC role and the connection between the primary care and the PA sector.
\end{abstract}

\title{
Methods
}

Nine focus groups were held with primary care, welfare and sport professionals within the CSC network. In these focus groups the CSC role and the connection between the sectors were discussed. Both top-down and bottom-up codes were used to analyse the focus groups.

\section{Results}

Professionals ascribed three roles to the CSC: 1) broker role, 2) referral, 3) facilitator. Professionals were enthusiastic about how the current connection was established. However, barriers relating to their own sector were currently hindering the connection: primary care professionals' lack of time, money and knowledge, and the lack of suitable PA activities and instructors for the target group.

\section{Conclusions}

This study provides further insight into the CSC role and the connection between the sectors from the point of view of primary care, welfare, and sport professionals. Professionals found the CSC role promising, but barriers are currently hindering the collaboration between both sectors. More time for the CSC and changes in the way the primary care and PA sector are organized seem to be necessary to overcome the identified barriers and to make a success of the connection. 


\section{Background}

Intersectoral collaboration - defined as people and organizations from multiple sectors working

together for a common purpose - has become an increasingly popular health promotion strategy [1]. Intersectoral collaboration is challenging because it means working in a new area or setting, with new people with different backgrounds, interests, and perspectives [24]. A health broker seems to offer the promise of improving intersectoral collaboration [5]. In 2012, the Dutch Ministry of Health, Welfare, and Sport introduced neighbourhood sport coaches (in Dutch Buurtsportcoach) - to whom a broker role has been ascribed - to stimulate physical activity (PA) and connect the sport sector with other sectors. Some of these coaches, the so-called Care Sport Connectors (CSCs), are employed specifically to connect the primary care and the PA sector in order to guide primary care patients towards local PA facilities.

Previous studies have shown that connecting the primary care and the PA sector is challenging for various reasons. First, differences between both sectors, such as culture (professional organization versus voluntary organization) and different shared interests (program interest versus increasing member numbers) can hinder collaboration between the primary care and the PA sector [6]. Secondly, factors relating to both sectors can hinder the referral of primary care patients towards local PA facilities. Health professionals consider their lack of time, formal education, competing priorities, and their perception of patients' lack of motivation to be physically active as factors that negatively influence PA promotion [7-9]. In addition, the lack of suitable PA activities for the target group [10], sport professionals lack of medical knowledge, and lack of feedback on patients' progress were seen as factors relating to the PA sector that could hinder the referral of primary care patients [6]. CSCs revealed similar perceived barriers in their work to connect both sectors: a lack of time and knowledge of primary care and sport professionals, lack of suitable PA activities, and own interests of primary care professionals [11]

Although experience of professionals is already contributing somewhat to our understanding of the connection between the primary care and the PA sector, to our knowledge this has not been studied in relation to a broker role employed to connect both sectors. In our previous study, in which we described a first impression of the CSC role, it appeared that most CSCs found it hard to establish a structural collaboration because of perceived barriers [11]. The aim of this study is to assess perceptions of primary care, welfare, and sport professionals towards the CSC role and their experiences in the connection between the primary care and the PA sector in order to further optimize this connection. Research questions addressed were: 1 ) what is the perception of professionals within the CSC network towards the CSC role and 2) what is the perception of these professionals towards the connection between the primary care and the PA sector? 


\section{Methods}

This study is part of a larger project in which a multiple case study is being conducted in nine municipalities spread over the Netherlands from 2014 to the end of 2016 to study the CSCs' role and impact in connecting primary care and the PA sector, and residents' participation [12].

\section{Study design}

To gain a comprehensive insight into perceptions on the CSC role and the connection between the primary care and the PA sector, we conducted a qualitative study in which focus groups were held within the CSC network.

\section{Selection and study population}

Nine focus groups were held with primary care, sport, and welfare professionals within the network of 10 CSCs. The selection differed for professionals working with the CSC in a partnership and those who worked individually on a project basis with the CSC. In five cases, we conducted a focus group in a meeting of a partnership in which representatives of the municipality, CSC, primary care, welfare, and sport professionals worked together to promote PA within the community. Therefore, in these focus groups, representatives of the municipality were also present. All professionals $(n=29)$ part of the partnerships attended these focus group. In the other four cases, CSCs working on a project basis with the professionals in their network provided the names of 63 professionals. CSCs and professionals were invited by e-mail to participate in the focus group. In total, 24 professionals attended these focus groups, the other invited professionals were due to a lack of time not available to participate in the focus group.

In total, 21 primary care professionals (13 physiotherapists, three GPs, three representatives of a home care organization, one exercise therapist, and one representative of a community health centre), 16 sport professionals (eight representatives of a sport club, six exercise instructors, and two representative of a fitness centre), eight representatives of welfare organizations (four of which offer exercise lessons, and four of which do not), and nine representatives of the municipality attended the focus groups. One professional was both a primary care professional and a sport professional, and therefore part of both groups. In addition, CSCs attended the focus group ( $n=9$ ) (Table 6.1). 


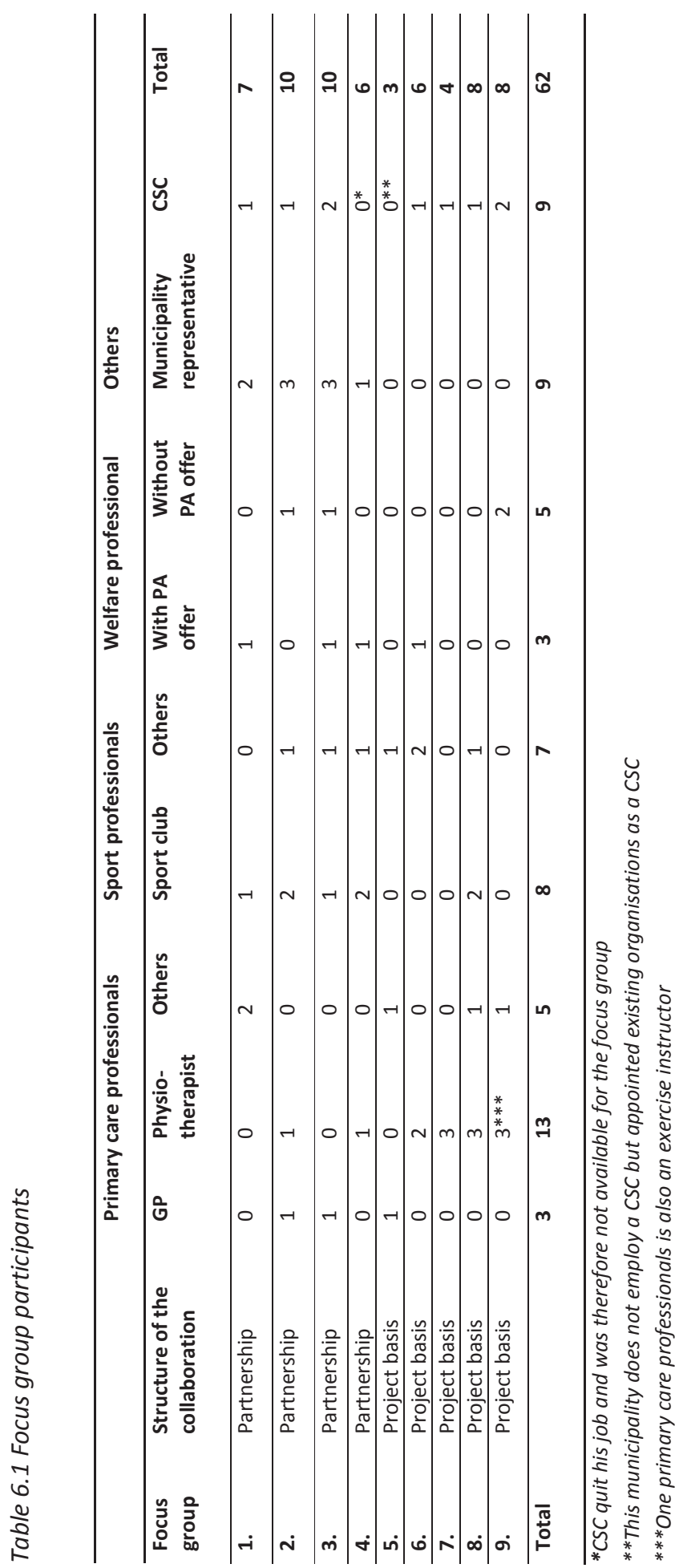




\section{Procedure}

The focus groups were held between June and October 2015. They took place at the CSCs' workplace and lasted approximately 1.5 hours. Eight focus groups were conducted by two researchers ( $K L$ and $E S$ or $A F)$; one focus group was conducted by one researcher ( $K L)$. At the beginning of each focus group, professionals were informed about the procedure and signed an informed consent.

The focus group consisted of two parts: the CSC role (part I), and the connection between the primary care and the PA sector (part II). CSCs only participated in the second part of the focus groups. In this way, professionals could speak freely about the CSC role, and in the second part, professionals and the CSC could provide one another with direct feedback to stimulate collaboration between the CSC and the professionals. At the beginning of part I, all professionals completed a form in which they had to prioritize 10 possible CSC tasks, based on the Dutch Knowledge Centre Sport's CSC competence profile [12], by degree of importance (1=very important, 10=not at all important). Then, each participant explained one by one his/her choice of the three most important tasks. Subsequently, a discussion took place about the CSC in their municipality. To facilitate this discussion the following question was asked: "To what extent is the CSC an added value to you as a primary care, welfare, or sport professional?". In part II, the topic was the attitude and expectation towards the connection between the sectors. To facilitate the discussion, all professionals first described their own role and their expectations about other professionals.

Subsequently, the connection between the sectors was discussed. Guiding questions were for example: "How do you evaluate the current connection between the primary care and the PA sector in your neighbourhood/municipality?" and "How do you see the connection between the primary care and the PA sector in the course of two years?". In one focus group, we performed only part II of the focus group. In this municipality, no CSC was employed, but existing organizations received the CSC funding, and therefore part I was not applicable.

\section{Data analysis}

The focus groups were audiotaped and transcribed. The data analysis was based on Creswell's [14] six steps for qualitative data analysis. So, after the data were organized and prepared for the analysis, with the participants divided in four groups (primary care, sport, welfare, others) and the focus groups divided in two groups (partnership or project basis), the transcripts were read. Focus groups were divided in these two groups, due to the different starting point. It is possible that professionals of the partnership share a similar vision towards the CSC role and the connection between both sectors because they work together on stimulating PA, while professionals of the other four focus groups did not work together and worked on a individually basis with the CSC. In the third step, the transcripts were coded and analysed using software for qualitative analysis (Atlas.ti). Top-down codes related to the structure of the collaboration and facilitators and barriers in the connection between the primary care and the PA sector were defined based on the results of the interviews with the CSCs [11] and on existing literature on the connection between both sectors [6]. In the fourth step, the codes were clustered into the following themes: the CSC role, the connection between the primary care and the PA sector, and facilitators and barriers relating to the sector and not relating to the sector. During steps five and six, more bottom-up codes were assigned to the various themes, for example in the theme 'the CSC role', the new codes identified were: broker role, referral, facilitator (Table 6.2). 
Table 6.2 Code list

\begin{tabular}{|c|c|c|}
\hline Themes & Top-down codes & Bottom-up codes \\
\hline CSC role & $\begin{array}{ll}\text { - } & \text { Attitude } \\
\text { - } & \text { Added value }\end{array}$ & $\begin{array}{ll}\text { - } & \text { Broker role } \\
\text { - } & \text { Referral } \\
\text { - } & \text { Facilitator } \\
\end{array}$ \\
\hline $\begin{array}{l}\text { Collaboration in the } \\
\text { connection between the } \\
\text { primary care and the PA } \\
\text { sector }\end{array}$ & $\begin{array}{ll}\text { - } & \text { Role } \\
\text { - } & \text { Partnership } \\
\text { - } & \text { Project basis }\end{array}$ & $\begin{array}{ll}\text { - } & \text { Attitude } \\
\text { - } & \text { Expectations }\end{array}$ \\
\hline $\begin{array}{l}\text { Barriers and facilitators } \\
\text { relating to sector }\end{array}$ & $\begin{array}{ll}\text { - } & \text { Time and money } \\
\text { - } & \text { Lack of knowledge of the PA offer } \\
\text { - } & \text { Own interest } \\
\text { - } & \text { Suitable PA activities } \\
\text { - } & \text { Adequate PA instructors }\end{array}$ & $\begin{array}{ll}\text { - } & \text { Reimbursement } \\
\text { - } & \text { Awareness of the PA offer } \\
\text { - } & \text { Competitive position }\end{array}$ \\
\hline $\begin{array}{l}\text { Barriers and facilitators not } \\
\text { relating to the sector }\end{array}$ & - $\quad$ Personal perceptions & $\begin{array}{ll} & \text { Effectiveness } \\
\text { - } & \text { Policy } \\
\text { - } & \text { Target group } \\
\end{array}$ \\
\hline
\end{tabular}

The whole data analysis process was performed independently by two researchers ( $K L$ and AF). After step three, the transcripts were discussed until consensus on the assigned codes was reached between the researchers. Also, the researchers discussed the interpretation of the data to reach consensus. The most discussion was held on the theme attitude of the collaboration between the primary care and the PA sector, because some professionals were satisfied while other professionals mostly mentioned points for improvement. Once the data analysis was completed, the results were discussed within the research team.

As our aim was to study the perceptions of primary care, welfare, and sport professionals, citations of others (municipal representatives and CSCs) were not included in the analysis. The municipal representatives were policymakers and consequently involved in policymaking to implement CSCs, but they did not fulfil an active role in the connection between both sectors. CSCs did not have an active role in the focus groups and used the focus groups as a way to explain their work to the professionals.

The assignment in part I was analysed by calculating a mean of each of the possible CSC tasks, ranked by degree of importance ( $1=$ very important, $10=$ not at all important) (Table $6.3)$. 


\section{Results}

\section{Role of the Care Sport Connector}

In the focus groups, primary care, welfare, and sport professionals ascribed three roles to the CSC: 1) broker role, 2) referral, and 3) facilitator.

Table 6.3 Results of the assignment in part I of the focus group

\begin{tabular}{|c|c|c|c|}
\hline & $\begin{array}{l}\text { Sport } \\
(n=10)\end{array}$ & $\begin{array}{l}\text { Primary } \\
\text { health care } \\
(\mathrm{n}=20)\end{array}$ & $\begin{array}{l}\text { Welfare } \\
(n=7)\end{array}$ \\
\hline $\begin{array}{l}\text { 1. Acts like a broker and matcher between the demand determined and the } \\
\text { supply realized }\end{array}$ & $\begin{array}{c}5.5 \\
(S D=4.2)\end{array}$ & $\begin{array}{c}5.1 \\
(S D=3.1)\end{array}$ & $\begin{array}{c}5.7 \\
(\mathrm{SD}=2.8)\end{array}$ \\
\hline $\begin{array}{l}\text { 2. Takes care of/arranges the inventory of the needs for sport and exercise } \\
\text { activities within the work field(s) }\end{array}$ & $\begin{array}{c}3.5 \\
(\mathrm{SD}=1.6)\end{array}$ & $\begin{array}{c}4.8 \\
(S D=2.7)\end{array}$ & $\begin{array}{c}6.3 \\
(S D=2.8)\end{array}$ \\
\hline $\begin{array}{l}\text { 3. Creates a network with the parties from the care, sports, and welfare } \\
\text { sectors relevant to the target group or links up with existing networks } \\
\text { and expands these, if necessary }\end{array}$ & $\begin{array}{c}3.4 \\
(S D=2.6)\end{array}$ & $\begin{array}{c}3.8 \\
(S D=2.3)\end{array}$ & $\begin{array}{c}3.4 \\
(S D=2.1)\end{array}$ \\
\hline $\begin{array}{l}\text { 4. Maps out the range of activities available to the target group and also } \\
\text { considers the exercise activities made available by other sectors like } \\
\text { welfare, apart from the regular sports and exercise activities provided }\end{array}$ & $\begin{array}{c}5.5 \\
(\mathrm{SD}=2.3)\end{array}$ & $\begin{array}{c}3.5 \\
(S D=1.6)\end{array}$ & $\begin{array}{c}3.7 \\
(S D=1.3)\end{array}$ \\
\hline $\begin{array}{l}\text { 5. Helps sports and exercise providers in developing an appropriate range } \\
\text { of activities }\end{array}$ & $\begin{array}{c}5 \\
(S D=2.5)\end{array}$ & $\begin{array}{c}6.8 \\
(\mathrm{SD}=2.6)\end{array}$ & $\begin{array}{c}6.7 \\
(\mathrm{SD}=2.3)\end{array}$ \\
\hline $\begin{array}{l}\text { 6. Organizes and coordinates at the execution level a coherent range of } \\
\text { activities in the areas of sports and exercise }\end{array}$ & $\begin{array}{c}6.2 \\
(S D=2.0)\end{array}$ & $\begin{array}{c}6.4 \\
(S D=2.2)\end{array}$ & $\begin{array}{c}4.7 \\
(S D=3.3)\end{array}$ \\
\hline $\begin{array}{l}\text { 7. Acquires/scouts active participants for various activities at the relevant } \\
\text { target group's specific care and welfare organizations }\end{array}$ & $\begin{array}{c}6 \\
(S D=3.2)\end{array}$ & $\begin{array}{c}5.8 \\
(S D=2.9)\end{array}$ & $\begin{array}{c}7 \\
(S D=2.2)\end{array}$ \\
\hline $\begin{array}{l}\text { 8. Guides participants towards sports and exercise activities, in consultation } \\
\text { and, if necessary, in collaboration with a care and welfare organization }\end{array}$ & $\begin{array}{c}5.5 \\
(S D=2.9)\end{array}$ & $\begin{array}{c}4.4 \\
(S D=3.1)\end{array}$ & $\begin{array}{c}3.1 \\
(\mathrm{SD}=2.9)\end{array}$ \\
\hline $\begin{array}{l}\text { 9. Provides information and arranges for the enhancement of the expertise } \\
\text { of trainers and managers at sport-providing organizations }\end{array}$ & $\begin{array}{c}7.9 \\
(S D=1.7)\end{array}$ & $\begin{array}{c}8.6 \\
(S D=1.7)\end{array}$ & $\begin{array}{c}8.9 \\
(S D=1.1)\end{array}$ \\
\hline $\begin{array}{l}\text { 10. Organizes, coordinates, and performs other health promoting activities in } \\
\text { the neighbourhood in collaboration with relevant parties from the } \\
\text { neighbourhood }\end{array}$ & $\begin{array}{c}6.5 \\
(S D=3.2)\end{array}$ & $\begin{array}{c}5.9 \\
(S D=2.6)\end{array}$ & $\begin{array}{c}5.4 \\
(S D=3.2)\end{array}$ \\
\hline
\end{tabular}

Note: Mean scores of assignment I in eight focus groups. Tasks were ranked by degree of importance (1=very important, $10=$ not at all important

Note: participants of the focus group in municipality 9 did not full in assignment 1 because this municipality did not employed a CSC function, therefore the assignment was not applicable. In addition, 2 sport professionals in 2 other focus groups only prioritized 3 tasks, therefore the results of these assignments were not included. 


\section{Broker role}

Almost all professionals, regardless of whether they were already part of a partnership, mentioned that an important task for the CSC was to fulfil the broker role and stimulate collaboration between professionals (task 3, mean=3.4, mean=3.8, mean=3.4). Primary care professionals in particular stressed the importance of a connection between sectors, because more collaboration may result in increased referral of patients.

"I believe that, right now, to me it is important that the CSC makes it so that the separate domains... that preferably there are no separate domains anymore between care, sports, and welfare. That these come into contact and start using one another's strength." (Physiotherapist, \#9)

An important feature of the CSC was to have a bird's eye view of the whole neighbourhood and to be the driving force and/or initiator in the connection between both sectors.

\section{Referral}

The referral of primary care patients and residents towards local PA facilities was also highly prioritized as a CSC task, especially by primary care (task 8 , mean $=4.4$ ) and welfare professionals (task 8, mean=3.1), as a way to stimulate PA and increase the health of their patients and residents.

"Guiding our patients towards appropriate exercise activities so that they will visit me less frequently and also feel better both physically and mentally." (GP, \#2)

Although in the assignment the referral function was not highly prioritized by sport professionals (task 8, mean=5.5), in the focus groups they often mentioned it as an important CSC task. They would like to have more participants in their exercise lessons. Identifying the need for PA activities for residents is therefore an important prerequisite.

"That she also encourages the target group towards exercise and sports and helps people find their way to PA activities more easily." (Sport instructor, \#6)

\section{Facilitator}

Providing an insight into the current PA offer was another task that was highly prioritized by primary care (task $4: \mathrm{m}=3.8$ ), and welfare professionals (task $4: \mathrm{m}=3.7$ ). Primary care and welfare professionals mentioned in the focus groups that this is an important task because neither the target group nor the professionals are familiar with all PA activities in the neighbourhood. Therefore, welfare professionals would like to have an insight into existing PA activities for the target group, and primary care professionals would like to know this so that they could refer patients towards these activities.

"You will then have to properly map out what range is available and apart from regular sports... it would be nice if a professional, if we did not have to do so in our own time, our limited time." (GP, \#5)

Providing an insight in the needs for PA activities (task 2, $\mathrm{m}=3.5$ ), and helping sport professionals in developing new PA activities (task 5 : $\mathrm{m}=5$ ) were highly prioritized by sport professionals as important tasks. However, sport professionals did not elaborate on this in the focus groups and mostly mentioned providing an insight in existing PA activities as an important task. Especially because according to sport professionals, primary care and welfare professionals are not familiar with the PA offer. 


\section{Added value of the CSC}

In general, professionals in all nine focus groups were positive about the way the CSCS fulfilled their role. The CSC's personality was often perceived as pleasant. CSCs were enthusiastic, visible, stimulating, approachable, and active.

\footnotetext{
"What I believe to be an added value is that she is visible through... that she actually does something... Like, ehm, just as you put it: 'I am glad, I am glad, for if I call the CSC, some action is taken'." (Welfare professional, \#6)
}

Although the CSC role was perceived as positive by all professionals, in four focus groups some professionals mentioned that the CSC was not yet seen as an added value for their organisation. Either because up to now there was not much collaboration in the network or because the results of the CSCs' work were so far not of sufficient value to these professionals.

"Well, you can sometimes hear someone say: 'it is somewhere in the proximity of the [welfare organization] and not visible enough in other areas of the neighbourhood'." (Welfare professional, \#3)

\section{Connection between the primary care and the PA sector}

The connection between the primary care and the PA sector was differently established in each CSC network. In five CSC networks, a partnership had been established between primary care, sport, and welfare professionals: four partnerships were organized by the municipality, one by a sport organization. Professionals in these partnerships worked together to organize activities to promote PA or implemented a referral scheme. In the other four networks, professionals worked individually on a project basis together with the CSC in the organization of activities to promote PA or in the referral of primary care patients. Because of the differences in the form of collaboration, professionals had different attitudes and expectations about the connection between both sectors (Table 6.4). 


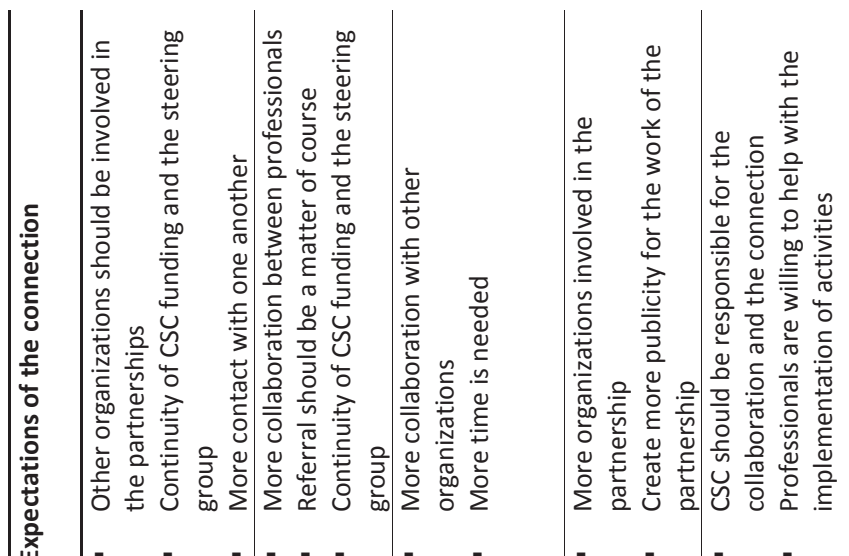




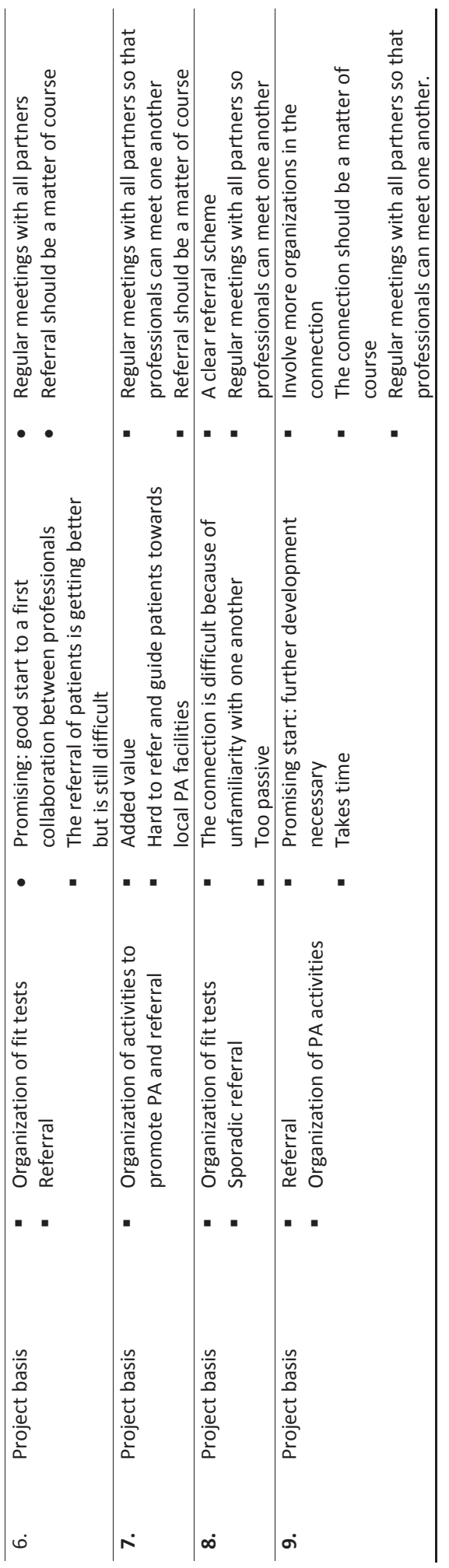


Partnership: attitude and expectations about the connection between both sectors Professionals who belonged to a partnership mentioned that they were enthusiastic about the partnership and that it was a good first step towards more collaboration between the sectors. Professionals in three partnerships mentioned a shared mission, which facilitated the collaboration.

"I now have seven people around the table whom I can deploy now. 'Hey, I have seen you around somewhere, couldn't we have some time?' That is a joint part, isn't it? We also have a joint goal and we also have, well, joint interests." (Sport professional, \#4)

However, two partnerships had not yet achieved the desired results, and more time and attention was needed to further improve the collaboration between the sectors. In these partnerships, professionals did not have a clear shared mission on the CSC role and the connection between the sectors.

"But I do hear a number of different points of departure here; we have different points of departure. For instance, [...] says emphatically that there is a shortage in the range available and I hear others say 'the range is adequate, there is quite a lot on offer, but there, it doesn't get here.' There are, there are a number of things about which we simply reason from different assumptions; that makes it rather..." (GP, \#3)

The professionals expect to expand the current connection, to involve more partners, and the referral of primary care patients should be a matter of course for organizations. More time and continuity of the CSC role is therefore needed.

Project basis: attitude and expectations about the connection between both sectors Professionals in networks working on a project basis with the CSC were also enthusiastic about how the connection between both sectors was established. The organization of an activity was seen as a good way to stimulate collaboration between the professionals.

"A collaboration is simply very difficult if you start from scratch. Everyone needs to be brought together first, with a goal that involves all the sectors." (Physiotherapist, \#6)

In all four networks, professionals mentioned that there was a good foundation for collaboration between the sectors. The current form of collaboration was therefore promising, because professionals got to know one another, and the gap between the primary care and the PA sector was reduced. However, more time was needed to further develop the connection, especially because of their unfamiliarity with one another.

"... We simply just are in too little contact with one another, for you just don't really know what we... You just don't really know what we do exactly." (Sport professional, \#8)

The professionals expected to have a more structural form of collaboration, with regular contact with other professionals, a clear referral scheme, and more involvement of other organizations. The CSC should take the lead in this.

Perceived barriers and facilitators in the connection between the primary care and the PA sector

In the connection between the primary care and the PA sector two sets of facilitators and barriers were identified: facilitators and barriers relating to the professionals' own sector, 
and facilitators and barriers not relating to a sector. Perceived facilitators and barriers did not differ for professionals who worked together in a partnership or who collaborate on project basis.

\section{Facilitators and barriers relating to the sector}

\section{Primary care}

In relation to primary care, primary care professionals mentioned: time and money, knowledge about the PA offer, and their own interest as facilitators or barriers in the connection between the primary care and the PA sector. These factors were also mentioned by sport and welfare professionals as their explanation for the lack of involvement of primary care professionals.

Time and money

Lack of time and money was often mentioned as a barrier to participation, as also the lack of referral by primary care professionals. In addition, the lack of remuneration in the current health insurance system for preventive work was often mentioned as a barrier for the participation of physiotherapists.

"We have had this and done so, but we haven't followed up on it, but that is also where part of the problem lies, this, this picture sketched by [participant], we are extremely busy and everything we do here, sitting here, is free. This is my own time; I do not get paid for it." (Physiotherapist, \#7)

Lack of knowledge about the PA offer

A lack of knowledge about the PA offer made it hard for primary care professionals to refer patients. They refer patients towards the PA offer with which they are familiar.

"And you can only refer towards PA activities you know of. For example, I know there are some walking groups on different levels in [neighbourhood], so sometimes I refer patients towards them. But where to I don't know. They have to, then I say: 'you have to look it up yourself'." (Physiotherapist, \#8)

Some primary care professionals also mentioned unfamiliarity with the CSC role as a barrier in the referral of patients.

\footnotetext{
"Yes, time, and it is as yet unclear to me as to what the steps are. I would call [name CSS] for the people with a disability, and [name other CSC] for the elderly, I would know whom to call, but I don't know how things go from there on. It should actually be clearer how ehm." (Physiotherapist, \#9)
}

Own interest

According to primary care professionals, especially physiotherapists, their own interests can contribute to whether or not they participate in the CSC's work. Some physiotherapists have their own PA offer, and therefore they guide patients towards that.

\section{PA sector}

In relation to the PA sector, sport professionals mentioned awareness of the PA offer, suitable PA activities, and adequate sport instructors as a barrier or facilitator for the connection between the sectors.

Awareness of the PA offer

According to sport professionals, there is plenty of PA on offer in the neighbourhood, but 
this sport offer is insufficiently known by other organizations, mostly because sport professionals do not publicize their PA offer enough.

"Well, what I believe is important is that the providers, in any field, that they are not known well enough. So, the promotion of those providers is very important, I think. Wherever. A touch of PR." (Sport professional, \#8)

Suitable PA activities and adequate instructors

Primary care and welfare professionals mentioned that the PA offer is not always suitable for the target group. The level at sport clubs is too high for the target group, and there are not enough adequate PA instructors. In particular, volunteers working at the sport club are not adequately trained. This was confirmed by the sport professionals, and therefore having enough adequate PA instructors was mentioned as an important facilitator in the connection between the sectors.

"Make sure that you have good teachers, that you have groups, and that you bring people in. That's all." (Sport professionals, \#6)

Welfare

Welfare professionals and sport professionals commented on their possible position as rivals: some welfare organizations also offer sport activities and therefore they focus more on their own activities.

\section{Facilitators and barriers not relating to the sector}

Facilitators and barriers not relating to the sector were also identified: personal perception, effectiveness, policy of the municipality, and the target group.

Personal perception

All professionals had an interest in PA and a belief in PA promotion as a means of stimulating a healthy lifestyle, and these were often mentioned as reasons to participate.

"Have always practiced a lot of sports, still do actively and passively, and so I am very interested in PA sport in our health centre, so I have been aware of the importance of PA for quite some time." (GP, \#5)

\section{Effectiveness}

The use of effective projects or activities, according to the professionals, was important for collaboration with the work of the CSC. Showing results and successes can lead to more involvement by professionals and organizations.

"I say, especially these Exercise Buddies; that really is a fantastic project in my view. That is truly fantastic, for it gets people out of their isolation. Yes, they dare do far more." (Physiotherapist, \#7)

\section{Policy of the municipality}

Municipal policy was perceived by the professionals as a facilitator when the policy was supportive of organizations participating in the connection. For example, the current decentralization policy provides an opportunity for primary care professionals to work more preventively, and funding has supported welfare and sport organizations to create PA activities. However, discontinuation of funding was mentioned as a barrier.

\section{Target group}

The professionals perceived the target group themselves as a barrier in this connection. 
According to the primary care and welfare professionals, the target group is hard to stimulate, and sport professionals mentioned problems with keeping the target group motivated to continue with the PA activities.

"Yes, I have also noticed this. People who are not used to exercise very soon find reasons to quit. So, some of the participants that he acquired simply stayed away again." (Sport professional, \#2)

\section{Discussion}

The aim of this study was to explore the perceptions of primary care, welfare, and sport professionals on the CSC role and the connection between the primary care and the PA sector. Primary care, welfare, and sport professionals ascribed three roles to the CSC: 1) broker role, 2) referral, 3) facilitator. No major differences were identified between the different professionals in their perceptions on the CSC role. The roles that professionals ascribed to the CSC were similar with the roles CSCs fulfilled [11]. Professionals found the CSC role and the current connection promising. However, professionals working on a project basis would like to have more contact with one another, and professionals who belong to a partnership would like to expand the connection towards other organizations.

Prior to the study, it was expected that differences between both sectors would hinder collaboration, especially because a review of the literature showed that collaboration between the primary care and the sport sector was hindered by differences in culture and interests in both sectors [6]. However, these barriers were not identified in this study. Professionals in this study found the connection between both sectors promising, but factors relating to their own sector were currently perceived to hinder this connection. This probably has to do with the form in which the professionals are collaborating. In most cases, the form of collaboration can be characterized as multidisciplinary, whereby different disciplines work independently on different aspects of a project [15]. Therefore, facilitators and barriers relating to their joint services were identified instead of barriers relating to differences between the sectors.

The identified barriers relating to their own sector have also been identified in other studies: lack of time [16-31], lack of remuneration [16, 17, 23, 24,31], lack of priority [20, 21, 23, 29, $30]$, and lack of knowledge about the PA offer [18-30; 22, 26, 30] were mentioned as barriers in PA promotion by primary care professionals. In addition, a study of Ooms et al. [10] showed that PA activities at sport clubs in the Netherlands were not suitable for the target group. What is remarkable is that, in spite of the introduction of the CSC function, and especially because this study's population consisted of professionals who were enthusiastic and willing to participate in this connection, the perceived barriers remain the same and CSCs have not yet succeeded in overcoming them. It is possible that in course of time the CSC will manage to overcome these barriers. Especially because the CSC is a new function and building collaboration structures takes time $[32,33]$. Time for the CSC is therefore needed to continue to work on overcoming the perceived barriers and establishing a connection between both sectors. However, the question is also whether the CSC is singlehandedly capable of, and responsible for, overcoming these barriers.

The results of this study are therefore relevant for policymakers, municipalities, and organizations working on a connection between the primary care and the PA sector, and can be helpful to further improve the connection. This is particularly so because some of the identified barriers relate to the system in which CSCs and professionals are working. Changes 
are therefore needed at the system level, because not only a CSC can influence this. For example, the current insurance system in the Netherlands, which only reimburses primary care professionals for their curative treatments, hinder these professionals from participating in projects aimed at prevention or health promotion.

Nevertheless, insights from this study are also relevant for CSCs because some of the identified barriers can be influenced by CSCs, and they can start by eliminating these barriers. For example, CSCs could provide an insight for primary care professionals into all PA activities in the municipality, or support sport clubs and their trainers in working with a new target group. More research is necessary to study perceptions of primary care, sport, and welfare professionals about possible strategies to overcome current barriers hindering the collaboration between the primary care and the PA sector.

\section{Study's strength and limitations}

Some limitations need to be taken into account when these results are being interpreted. Although the aim of this study was to study the perceptions of primary care, welfare, and sport professionals, other professionals were also present as we invited CSCs to attend the second part of the focus groups, and some focus groups took place at a meeting of an existing partnership organized by the municipality. The perceptions of these professionals were not included in the analysis but may have affected the results of the focus groups. However, focus group participants first had to articulate their own opinion as a result of the assignments in part I and part II, thus ensuring that the influence of municipal representatives was limited.

It is possible that the population of this study consisted of professionals with a more positive attitude towards the CSC role and the connection between both sectors. This could have resulted in more positive results. Nevertheless, in the focus groups, professionals still critically discussed the CSC role and the connection between both sectors. In addition, the discussion helped professionals to gain insight into perceived barriers of professionals working in other sectors, which might be a constructive way to support collaboration, overcome some of the barriers and thus, connecting sectors.

In some focus groups not all sectors were represented due to cancellations. As a result professionals of these sectors could not elucidate on the comments made by professionals of other sectors. However, it did not affect the results of this study because we discussed perceived barriers of professionals in the connection between the primary care and the PA sector. In addition, there was a limited number of GPs and practice nurses who participated in this study. Their involvement is considered to be important in the connection between both sectors and therefore also their perception on the connection between both sector. However, not in all CSCs networks a GP or practice nurse were present [11]. Therefore, only a small number of GPs and practice nurses could be invited to participate in this study. Only the GPs part of a partnership attended the focus groups. In these cases the focus group took place during an meeting of the partnership.

The roles that primary care, sport, and welfare professionals ascribed to the CSC could have been influenced by the assignment in part I of the focus groups. However, professionals were asked to explain their choices and in the assignment were able to give their own interpretation of the tasks. In addition, the scores were sometimes different than the explanation given by the professionals in the focus groups. For example, almost all sport professionals mentioned that it was important for them to get participants for their PA 
activities, but they did not highly prioritize this as a role for the CSC. Using both the results meant that a good representation of their perceptions of the CSC role was provided.

\section{Conclusion}

This study provides further insight into the CSC role and the connection between the primary care and the PA sector from the point of view of primary care, welfare, and sport professionals. Although professionals found the CSC function and the current connection between the sectors promising, barriers related to the sectors are at this moment hindering the connection between the primary care and the PA sector. Time must be given to the CSC to further improve the connection and overcome some of the barriers. Changes in the way the primary care and the PA sector are organized seem to be necessary to overcome some of the identified barriers and to make a success of the connection. 


\section{References}

1. Roussos ST, Fawcett SB. A review of collaborative partnerships as a strategy for improving community health. Annual Review of Public Health 2000,21;369-402.

2. Garner ML, Sharpe PA. Evaluating community coalition characteristics and functioning: a summary of measurement tools. Health Education Research 2004,19(5):514-532.

3. Koelen MA, Vaandrager L, Wagemakers $A$. What is needed for coordinated action for health? Family Practice 2008,25:25-31.

4. Lasker RD, Weiss ES, Miller R. Partnership synergy: a practical framework for studying and strengthening the collaborative advantage. Milbank Quarterly 2001,79(2):179-205.

5. Harting J, Kunst A, Kwan A, Stronks K. A 'health broker' role as a catalyst of change to promote health: an experiment in deprived Dutch neighbourhood. Health Promotion International 2010,26(1):65-81.

6. Leenaars KEF, Smit E, Wagemakers A, Molleman GRM, Koelen MA. Facilitators and barriers in the collaboration between the primary care and the sport sector in order to promote physical activity: a systematic literature review. Preventive Medicine 2015,81:460-478. doi: 10.1016/j.ypmed.2015.10.010

7. Huijg JM, Gebhardt WA, Verheijden MW, van der Zouwe N, de Vried JD, Middelkoop BJ, and Crone MR. Factors influencing primary health care professionals' physical activity promotion behaviors: a systematic review. International Journal of Behavioral Medicine 2015,22:32-50.

8. Hébert ET, Caughy MO, Shuval K. Primary care providers' perceptions of physical activity counselling in a clinical setting: a systematic review. British journal of sports medicine 2012,46(9):625-631.

9. Leemrijse C, de Bakker D, Ooms L, Veenhof C. Collaboration of general practitioners and exercise providers in promotion of physical activity: a written survey among general practitioners. BMC family practice 2015,16(1):96.

10. Ooms L, Veenhof C, Schipper-van Veldhoven N, et al. Sporting programs for inactive population groups: factors influencing implementation in the organized sports setting. BMC Sports Science, Medicine and Rehabilitation 2015,7:12. doi:10.1186/s13102-0150007-8

11. Leenaars KEF, Smit E, Wagemakers A, Molleman GRM, Koelen MA. Factsheet connecting the primary care and the PA sector. Wageningen: Wageningen University; 2015.

12. Smit E, Leenaars KEF, Wagemakers AM, et al. Evaluation of the role of Care Sport Connectors in connecting primary care, sport, and physical activity, and residents' participation in the Netherlands: study protocol for a longitudinal multiple case study design. BMC Public Health 2015,15:510. doi: 10.1186/s12889-015-1841-z

13. Dutch Knowledge Centre Sport. MEETSTANDAARD voor Erkenning Verworven Competenties van buurtsportcoaches (BSC). Ede: Dutch Knowledge Centre Sport, 2015.

14. Creswell JW. Research Design: Qualitative, Quantitative, and Mixed Methods Approaches. London: Sage; 2009.

15. Choi BC, Pak AW. Multidisciplinarity, interdisciplinarity and transdisciplinarity in health research, services, education and policy: 1 . Definitions, objectives, and evidence of effectiveness. Clinical and Investigative Medicine 2006,29(6):351-364.

16. Allen M, Mann K, Putnam W, Richard J, Carr C, Pottle K, Sargeant J. Prescribing exercise for cardiac patients: knowledge, practices, and needs of family physicians and specialists. Journal of Cardiopulmonary Rehabilitation 2000,20(6):333-339. 
17. Bize R, Cornuz J, Martin B. Opinions and attitudes of a sample of Swiss physicians about physical activity promotion in a primary care setting. chweizerische Zeitschrift fur Sportmedizin und Sporttraumatologie 2007,55(3):97-100.

18. Crisford P, Winzenberg T, Venn A, Venn T, Cleland V. Understanding the physical activity promotion behaviours of podiatrists: a qualitative study. Journal of Foot and Ankle Research 2013,6(1). doi: 10.1186/1757-1146-6-37

19. Dillman C J, Shields CA, Fowles JR, Perry A, Murphy RJL, Dunbar P. Including physical activity and exercise in diabetes management: diabetes educators' perceptions of their own abilities and the abilities of their patients. Canadian Journal of Diabetes 2010,34(3):218-226.

20. Din NU, Moore GF, Murphy S, Wilkinson C, Williams NH. Health professionals' perspectives on exercise referral and physical activity promotion in primary care: findings from a process evaluation of the National Exercise Referral Scheme in Wales. Health Education Journal, 2014. doi:10.1177/0017896914559785

21. Douglas F, van Teijlingen E, Torrance N, et al. Promoting physical activity in primary care settings: health visitors' and practice nurses' views and experiences. Journal of Advanced Nursing 2006,55(2):159-168. doi: 10.1111/j.1365-2648.2006.03903.x

22. Goodman C, Davies SL, Dinan S, Tai SS, Lliffe S. Activity promotion for community dwelling older people: a survey of the contribution of primary care nurses. British Journal of Community Nursing 2011,16(1):12-17.

23. Graham RC, Dugdill L, Cable NT. Health professionals' perspectives in exercise referral: implications for the referral process. Ergonomics 2005;48(11-14):1411-1422. doi: 10.1080/00140130500101064

24. Haas R, Maloney S, Pausenberger E, Keating JL, Sims J, Molloy E, Haines T. Clinical decision making in exercise prescription for fall prevention. Physical Therapy 2012,92(5):666-679. doi: 10.2522/ptj.20110130

25. Healey WE, Broers KB, Nelson J, Huber G. Physical therapists' health promotion activities for older adults. Journal of Geriatric Physical Therapy 2012,35(1):35-48. doi: 10.1519/JPT.0b013e318220d1f0

26. Hong Y, Ory MG, Lee C, Wang S, Pulczinksi J, Forjouh SN. Walking and neighborhood environments for obese and overweight patients: perspectives from family physicians. Family Medicine 2012,44(5):336-341.

27. Kennedy MF, Meeuwisse W. Exercise counselling by family physicians in Canada. Preventive Medicine 2003,37(3):226-232.

28. Matthews L, Kirk A, Mutrie N. Insight from health professionals on physical activity promotion within routine diabetes care. Practical Diabetes 2014,31(3):111-116. doi: 10.1002/pdi.1844

29. Presseau J, Sniehotta FF, Francis JJ, Campbell NC. Multiple goals and time constraints: perceived impact on physicians' performance of evidence-based behaviours. Implementation Science 2009,4(1). doi: 10.1186/1748-5908-4-77

30. Ribera AP, Mckenna J, Riddoch C. Attitudes and practices of physicians and nurses regarding physical activity promotion in the Catalan primary health-care system. The European Journal of Public Health 2005,15(6):569-575.

31. Huijg JM, van der Zouwe N, Crone MR, Verheijden MW, Middelkoop BJC. Factors influencing the introduction of physical activity interventions in primary health care: a qualitative study. International journal of behavioral medicine 2015,22(3):404-414. doi: 10.1007/s12529-014-9411-9 
32. Casey M, Payne W, Brown S. and Eime R. Engaging community sport and recreation organisations in population health interventions: Factors affecting the formation, implementation, and institutionalisation of partnerships efforts. Annals of Leisure Research 2009,12, 129-147.

33. Den Hartog F, Wagemakers A, Vaandrager L, van Dijk, M and Koelen, MA Alliances in the Dutch Beweegkuur lifestyle intervention. Health Education Journal 2014,73, 576-587. 


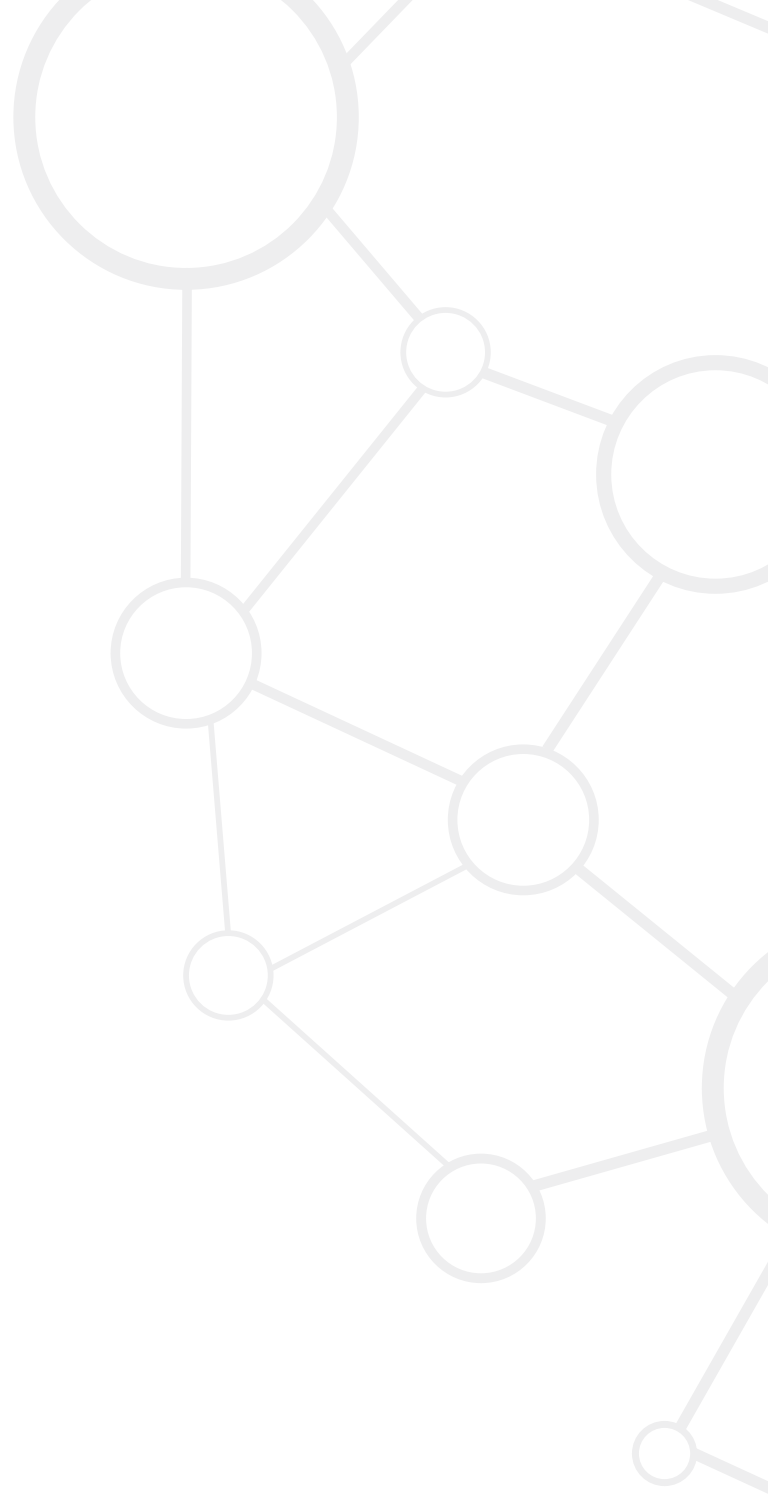




\section{Chapter 7}

The operational context of care sport connectors in the Netherlands

\section{Published as:}

Leenaars KEF, van der Velden-Bollemaat EC, Smit E, Wagemakers A, Molleman GRM, Koelen MA. The operational context of care sport connectors in the Netherlands. Health Promotion International, 2016. 


\begin{abstract}
Introduction

To stimulate physical activity (PA) and guide primary care patients towards local sport facilities, Care Sport Connectors (CSCs), to whom a broker role has been ascribed, were introduced in 2012 in the Netherlands. The aim of this study is to describe CSCs' operational context.

\section{Method}

A theoretical framework was developed and used as the starting point for this study. Group interviews were held with policymakers in nine participating municipalities, and, when applicable, the CSC's manager was also present. Prior to the interviews, a first outline of the operational context was mapped, based on the analysis of policy documents and a questionnaire completed by the policymakers. A deductive content analysis, based on the theoretical framework, was used to analyse the interviews.
\end{abstract}

\title{
Results
}

Differences were found in CSCs' operational context in the different municipalities, especially the extent to which municipalities adopted an integral approach. An integral approach consists of an integral policy in combination with an imbedding of this policy in partnerships at management level. This integral approach is reflected in the activities of other municipal operations, for example the implementation of health and PA programs by different organisations.

\section{Conclusion}

Given the CSC mandate, we think that this integral approach may be supportive of the CSCs' work, because it is reflected in other operations of the municipalities and thus creates conditions for the CSCs' work. Further study is required to ascertain whether this integral approach is actually supporting CSCs in their work to connect the primary care and the PA sector. 


\section{Introduction}

In order to stimulate physical activity (PA), in 2012 the Dutch Ministry of Health, Welfare, and Sport introduced neighbourhood sport coaches (Buurtsportcoach), to whom a broker role is ascribed. Some of these coaches, the so-called Care Sport Connectors (CSCs), are employed specifically to stimulate intersectoral collaboration between the primary care and the PA sector in order to guide primary care patients towards local PA facilities. The PA sector covers all PA services in the neighbourhood, i.e. sport clubs, fitness centres, PA lessons at community centres, and walking groups. This connection is desirable because primary care-based PA interventions are effective in reaching physically inactive adults [1]. However, patients prefer to stick with the known and secure environment of primary care PA facilities rather than participate in unknown or untried local facilities [2-3]. The general idea is that CSCs facilitate the connection between the primary care and the PA sector; professionals in these sectors collaborate; activities to promote PA will be implemented; these activities reach certain target groups; target groups will become more physically active; and health outcomes will improve. A blueprint for CSC implementation was deliberately not presented, allowing municipalities to implement CSCs in line with local needs and contexts.

Almost simultaneously with the CSC funding, the Dutch government delegated tasks in the field of public health to the municipalities, in order to organise the care and support of residents closer to the residents. Therefore, responsibilities and resources regarding the organisation of care were transferred from central government to local government. Municipalities are also expected to work on a more integrated basis in the social domain [4]. This decentralisation requires a change in the method of care, in which integrated community care with a focus on prevention and health is central [4]. The manner in which municipalities shape these changes will have an impact on the functioning of professionals with responsibility for prevention and health promotion.

Because of the differences in the implementation of the CSC funding and the current changes in the Dutch public health system, the context in which the CSCs are working can and will be different. These context-related factors might influence the success of an intervention, program, and policy, and are therefore important to take into consideration in studies on the impact of an intervention, program, or policy [5-6]. An important step in studying the impact of a broker role on improving intersectoral collaboration is to have insight into how the CSC role is integrated in other operations of the municipality. Although some studies focus on the broker role [7-9], to our knowledge not much is known about the impact of the operational context on brokers' work. Therefore, the aim of this study is to describe the operational context of the CSC.

\section{Method}

This study is part of a larger project in which a multiple case study is being conducted in nine municipalities spread over the Netherlands from 2014 to the end of 2016 to study the role and impact of the CSC in connecting the primary care and the PA sector, and residents' participation [10].

\section{Study design}

This study was a qualitative study, started with the development of a theoretical framework 
used for an analysis of policy documents, and questionnaires and semi-structured interviews with policymakers of nine municipalities to study the operational context in which CSCs were working.

\section{Theoretical framework}

In order to study the context in which CSCs were working, a theoretical framework had to be developed. The CSC is a new function, and a framework specific to the context in which CSCS are working was not yet available. Although existing frameworks in the field of political science [11-12] or organisational science [13] are available, these frameworks were not suitable for this study, as these are only directed at municipal policy. To study the operational context of the CSC, the broader system in which the CSC is working needs to be studied, including the primary care and the PA sector. As CSCs have the task of connecting the primary care and the PA sector and stimulating primary care patients to become physically active, it can be argued that CSCs are working in the public health system. Therefore, public health capacity mapping was used as a starting point, because it evaluates a system's ability to fulfil its specific functions within a set of resource constraints and does not provide answers about the actual performance of health systems [14].

On the basis of a literature search, in-depth interviews with experts in the field of public health, and a workshop at the Dutch conference for Public Health, we developed with the research team a framework to study the CSCs' operational context. This framework was based on Aluttis et al.'s country-level framework for public health capacity, Meyer et al.'s [15] conceptual model for public health systems and services research [14], and Bagley and Lin's rapid assessment tool for public health system capacity [16] in Australia. These frameworks and tools were used because they were developed recently, were based on a literature search on public health capacity, and were the most applicable to the aim of this study. Aluttis et al.'s [14] conceptual model contains the following domains: leadership and governance, organisational structures, workforce, financial resources, knowledge development, and country-specific context with relevance for public health. Meyer et al.'s [15] conceptual model is an adaptation of Handler et al.'s model [17] and contains eight fundamental elements of organisation capacity: fiscal and economic resources, workforce and human resources, physical infrastructure, inter-organizational relationships, information resources, system boundaries and size, governance and decision-making structure, and organization culture. Bagley and Lin's [16] tool consists of four categories: policy development, resources, programs, and organizational environment. Based on their frameworks, a first framework was developed. In order to ensure that the framework fitted with the Dutch context, we consulted three experts in the field of public health to discuss the final design of the framework.

This approach resulted in a framework to study CSCs' operational context, which consisted of five domains: policy, organisation, resources, programs, and partnerships (Appendix 7.1). The tools developed by Aluttis et al. [14] and Bagley and Lin [16] were used to operationalise the domains for the CSC context (Table 7.1).

\section{Policy}

Policy is operationalised for both the public health and the PA sector, and consists of the existence of a public health policy, a PA policy, an integral policy relating to health and PA, and the implementation of an integral policy. To identify municipal integral policy relating to health and PA, the following indicators were used: 1) PA was part of the health policy, and 2) 
vitality and participation were part of the PA policy. Implementation was operationalised if other initiatives in the area of healthcare, public health, and PA promotion besides the CSC were implemented, and if the CSC role was stated in the policy.

\section{Organisation}

Organisation consists of the structure and culture of the organisation. Structure was operationalised by how the CSC funding was implemented (number of CSCs, target group, sector), CSC' function profile, and the presence of professionals in the field of public health and PA promotion. Culture was operationalised in terms of who and how professionals in the field of public health and PA promotion were directed in their work.

\section{Resources}

Resources was operationalised on the basis of availability of financial resources for health promotion, PA promotion, and an activity budget for the CSC.

\section{Programs}

This domain was operationalised on the basis of the existence of health promotion and PA programs implemented in the municipality.

\section{Partnerships}

This domain was operationalised by the existence of different partnerships in the field of public health, the PA sector, between both sectors, and at management level between the municipality and other organisations in the field of public health and the PA sector in the municipality.

How these domains influence one another and their potential interaction is not known yet [14-16]. In addition, the theoretical framework was presented and discussed at the Dutch Conference for Public Health [18]. During this workshop, participants discussed the importance of certain domains and interactions between the domains and added some minor nuances, but no relevant issues were raised in relation to the theoretical framework that would lead to an adjustment of the framework. Therefore, it was decided within the research team to not determined possible interaction in the framework, but to identify whether a possible interaction could be determine based on the different context of this study. 
Table 7.1 Operationalisations of the theoretical framework to map the operational context of the CSC

\begin{tabular}{|c|c|}
\hline Domains & Operationalisation \\
\hline Policy & $\begin{array}{l}\text { Integral health and PA policy } \\
\text { - } \quad \text { Other sectors were involved in: the development of the health policy / PA policy (e.g. } \\
\text { welfare, PA) } \\
\text { - State the priorities of the health policy / PA policy } \\
\text { - } \quad \text { Vitality and participation is part of the health policy / PA policy } \\
\text { - Sport and PA is part of the health policy / PA policy } \\
\text { Implementation } \\
\text { - The CSC has a role in the implementation of the health policy / PA policy } \\
\text { - } \quad \text { Other initiatives besides the CSC are implemented to establish a connection between } \\
\text { both sectors }\end{array}$ \\
\hline Organisation & $\begin{array}{l}\text { Structure } \\
\text { - The number of CSCs in the municipality } \\
\text { - The sectors in which the CSCs are working } \\
\text { - The target group they are targeting } \\
\text { - The most import tasks and competences of the CSC in your municipality } \\
\text { - Other professionals working in the field of public health and the PA sector (for } \\
\text { example, health broker, sport consultant, elderly adviser) } \\
\text { Culture } \\
\text { - The direction of the CSC (whom and how) } \\
\text { - The municipality role in connecting the CSC with other professionals in the field of } \\
\text { public health and PA sector. }\end{array}$ \\
\hline Resources & $\begin{array}{l}\text { Financial resources } \\
\text { - The budget for preventive activities } \\
\text { - The budget for PA promotion } \\
\text { - The availability of an activity budget for the CSC }\end{array}$ \\
\hline Programs & $\begin{array}{l}\text { - Existing health promotion programs implemented in the municipality (implementation } \\
\text { by which organisation, and target group) } \\
\text { - Existing PA promotion programs implemented in the municipality (implementation by } \\
\text { which organisation, and target group) }\end{array}$ \\
\hline Partnerships & 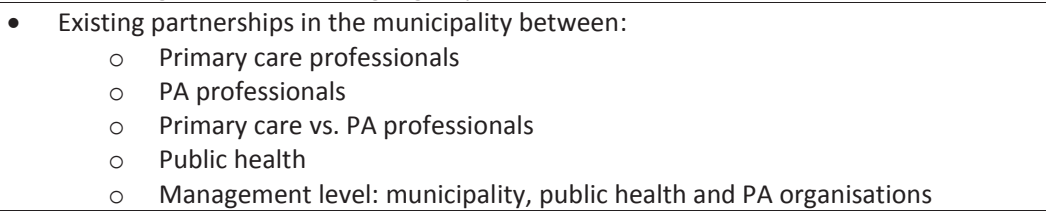 \\
\hline
\end{tabular}




\section{Setting and study population}

This study was conducted in the nine municipalities that were also participating in the larger project [10]. In two municipalities, the number of inhabitants was more than 300,000 , in four municipalities the number of inhabitants was between 100,000 and 300,000 , in three municipalities the number of inhabitants was fewer than 100,000 [19].

To study the CSCs' operational context, group interviews were held with policymakers from both the public health department and the PA department of each municipality, and CSCs' manager. In this way, relevant stakeholders of the CSC could interact with one another and this enabled us to gain more information about the CSCs' operational context. Together with the CSC manager, a health department policymaker and a PA department policymaker were selected and invited to participate in the interview. In two cases, the policymaker of the PA department was also CSCs' manager (Table 7.2).

\section{Procedure}

In total, nine group interviews were held with 25 participants between November 2015 and January 2016. The interviews took place at the policymakers' workplace and lasted on average 1.5 hours. The interviews were conducted by two researchers (KL and EB) in Dutch. At the beginning of each group interview, participants were informed about the procedure and signed an informed consent.

Before the interviews, current policy documents regarding the municipalities' health and PA policy were analysed regarding the five domains of the theoretical framework by one researcher (KL or EB). In addition, participating policymakers received a questionnaire prior the interview to enable the collection of information regarding the five dimensions of the theoretical framework. Questions asked were for example: 'How is the CSC funding implemented in the municipality? and 'Name five major partnerships available to the CSC in the municipality.' The document analysis and questionnaires were used to gain a first insight into the operational context of the CSC and to summarise and describe this operational context in each municipality in line with the five domains of the theoretical framework. This summary was presented to the policymakers and used to guide the interviews.

The interview topic list was based on the theoretical framework. At the beginning of each topic (one of the five domains of the theoretical framework), the researcher presented a summary of the domain based on the questionnaire and policy analysis. In this way, participants could check the data and were invited to make corrections or additions. Subsequently, in-depth questions were asked regarding the participants' perceptions about the CSC role in the five domains of the operational context. Questions asked were for example: 'What is the reasoning for the way the CSC funding is implemented?' and 'In what manner is the CSC stimulated to join/use the partnerships/programs for his work to connect the primary care and the PA sector?'

\section{Data analysis}

All interviews were audiotaped and transcribed (intelligent verbatim style). Both the interview transcripts and the policy documents were coded (Table 7.2) and analysed using software for qualitative analysis (Atlas.ti). A deductive content analysis was conducted to study the CSCs' operational context [20]. After the data were read, meaningful text fragments were identified, coded, and clustered by two researchers ( $K L$ and $E B$ ) on the basis of the theoretical framework as described above. During the analysis process, no new concept surfaced that could not be tied in with the other five domains and variables in the framework. The coding was compared between both researchers and differences were 
discussed to reach consensus about the codes assigned by the researchers. After the data analysis was completed, the results were discussed within the research team. Citations were translated into English by a translation agency.

In order to describe the CSCs' operational context, the results of the three data collection methods were combined. The data from the policy documents and questionnaires were used to describe the five domains of the theoretical framework, and the interviews with the policymakers were used as a further explanation of the CSCs' operational context. 


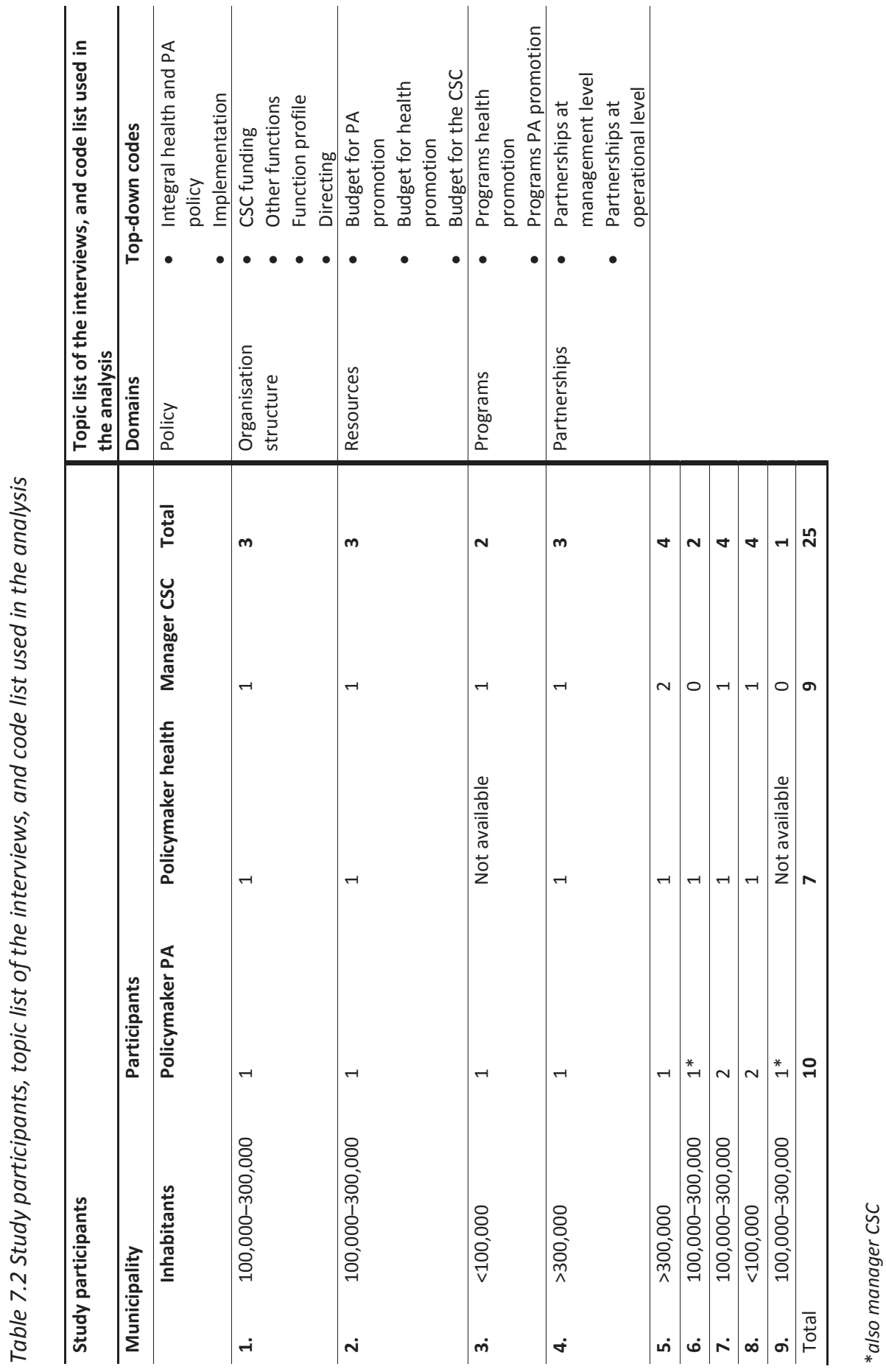




\section{Results}

\section{Policy}

Integral health and PA policy

In eight municipalities, PA was part of health policy. However, in three of these, the focus was mostly on youth. Therefore, an integral health policy was under development in these municipalities. In one municipality, PA was not part of health policy. Seven of the nine municipalities included vitality and participation in their PA policy. In the other two municipalities, PA policy focused mostly on youth, and therefore an integral PA policy was under development.

Irrespective of whether PA or vitality and participation were mentioned in their health and PA policy, all policymakers stated in the interviews that PA was used as a means to stimulate a healthy lifestyle among their residents. Therefore, PA was an essential part of the implementation of both health and PA policy.

"Why do you, as a council, want people to exercise more? Why would you? Well, because it contributes to healthy citizens, citizens in good health and vitality, a healthy and vital town." (Municipality \#6)

\section{Implementation}

All policymakers mentioned the importance of the connection between the primary care and the PA sector, mostly as a means to stimulate the health of their residents, especially residents who could benefit from PA, like primary care patients and the elderly.

"It truly is about people getting more involved in PA and then you automatically focus on the target groups that now, as yet, do not or hardly exercise and then you step into the care domain and so the relationship with care work is extremely important." (Municipality \#7)

In five municipalities, other initiatives besides the CSC were implemented in order to establish a connection between the primary care and the PA sector; for example, a pilot project in which professionals collaborated in order to stimulate primary care patients to become physically active. In some municipalities, the CSC was directly involved in these programs. In the other four municipalities, no other initiatives to stimulate a connection between the primary care and the PA sector were implemented. In these municipalities, the CSC was responsible for this connection.

Four municipalities stated the role of the CSC in their health policy $(n=3)$ or in their PA policy $(n=1)$, and the CSC was partially responsible for policy implementation. Although te other five municipalities did not state the CSC's role in their policy, policymakers mentioned that the CSC role was important for the implementation of both health and PA policy.

"The CSCS are actually working within their community on behalf of the council. So yes, they are in fact our most advanced posts in these villages and neighbourhoods." (Municipality \#2)

\section{Organisation}

\section{Implementation of CSC funding}

Two different approaches to the implementation of the CSC funding could be distinguished: 1) CSCs working only from the PA sector and 2) an integral approach in which CSCs were working from care, welfare, and PA organisations, or a partnership between primary care, welfare, and PA organisations. 


\section{CSCs working only from the PA sector}

In four municipalities, CSCs were working from the PA sector: in three municipalities, CSCs were working at the municipality's PA department, and, in one municipality, the CSCs were working at a PA organisation in the municipality. According to the policymakers, it was the most logical choice, because other matters concerning PA in the municipality were also organised at the department or the organisation. In addition, the CSC had a central part in the implementation of PA policy and therefore the PA department could better direct the CSC.

"The PA department here had the expertise at their disposal, and the people who were responsible for the execution and who had more or less done the same work for years on end were there. And we also would like to have more say over the things the CSC is about to do, and, if you have this within your department, you have more control over it." (Municipality \#2)

\section{Integral approach}

Three municipalities employed the CSC at both primary care, welfare, and PA organisations. The policymakers in these three municipalities believed that, in this way, the connection between the primary care and the PA sector would be established more easily.

"And you can only connect if people are half in the one and half in the other or, in any case, this makes it easier." (Municipality \#1).

Another advantage of this approach was that the different organisations' expertise could be used and the co-funding was easily arranged. Despite the advantages, two municipalities also mentioned some difficulties in this approach: the organisations' own interests and differences in work conditions.

\section{"So you do have a directing issue. Of course, it is about collaboration at the level of content, but the question is, yes, to what degree do people do their thing, which might lean towards the interests of an organisation itself rather than towards the interests of your funding." (Municipality \#4)}

In two municipalities, a partnership was created between primary care, welfare, and PA organisations as part of the CSC funding. In one municipality, the CSC was part of this partnership and together they developed a plan of action to stimulate PA in the neighbourhood. According to the policymakers, this would lead to support among professionals in the neighbourhood and support the CSCs in their work.

\footnotetext{
"We wanted to have support in the neighbourhood and we actually wanted to just also say they know, they know and they themselves have a sense of what works best in that neighbourhood. So just let us have confidence in that, and we let it go." (Municipality \#5)
}

In the other municipality, the partnership organisations received the CSC funding to enable them to organise an activity to promote PA among the residents together with an organisation from another sector. A CSC was not appointed in this municipality, because the partnership already existed and the CSC funding was used to support the participating organisations in their work. finance that it now starts to crunch. ... And we have now more or less used it as a financial impetus, but so that 
people would not quit for the reason that they could not financially... ehm, are put under time pressure by their own organisation, that they would not be in this situation." (Municipality \#9)

\section{Function profile}

In one municipality, conditions and requirements were determined for organisations as a prerequisite for receiving the CSC funding. In order to receive the funding, the organisation had to organise an activity to promote PA among residents together with an organisation from another sector and be part of the partnership for at least six months. In the other eight municipalities, a CSC function profile was outlined.

In two of the eight municipalities, in which CSCs had a broader aim, stimulating PA was mentioned as a means to promote residents' health. The CSC in one municipality was employed to decrease health inequalities, promote residents' health, and build preventive structures with professionals. In the other municipality, the CSC was employed to stimulate a healthy active lifestyle among residents.

\footnotetext{
"Look, the CSC funding is actually mainly focused on using sports as a tool, for other goals. It is not so much about these sports and exercise as it is about sports and exercise in order to become healthy and participate. This is also how it is looked upon within the PA domain, like yes, we believe PA is very important, including in terms of health and also in terms of participation. And we believe that this in itself already provides opportunities to enhance PA and the PA infrastructure." (Municipality \#4)
}

CSCs in these municipalities had a broker role in which they had to stimulate collaboration between professionals so that activities would be organised or existing activities would be connected with one another. An important feature was that activities needed to be assured by existing organisations and that the CSC would not remain responsible for the activities. One municipality focused mostly on primary healthcare professionals and stimulating an integral approach to promote residents' health.

\footnotetext{
"They have been assigned to put health into the limelight in the neighbourhood and to ensure that there are sufficient collective activities and look into the need for health-improving initiatives and, to do so, they need other parties. For this, they need their network." (Municipality \#1)
}

The other municipality focused mostly on the PA sector and increasing sports clubs' capacity to work with other target groups or offer new PA activities.

\footnotetext{
"In other words, the CSC in particular is required to play an important role in this, to make it possible for these clubs to develop the capacity to set up these types of activities, to be able to guide and support them and also provide continuity in this. The CSC plays an important role in the initial stage, with the aim of having them focus on new things once it is up and running...and that these clubs take over." (Municipality \#4)
}

In the other eight municipalities, the CSCs' main formulated aim was to stimulate PA among residents. Health promotion was often mentioned by policymakers as a side effect. In the other two municipalities, CSCs had a broader aim, and stimulating PA was mentioned as a means of improving residents' health.

In four of the six municipalities in which CSCs had the task of stimulating PA, policymakers stated that CSCs should guide residents towards local PA facilities or eliminate barriers that hinder residents from becoming physically active by, for example, coordinating a coherent PA offer. Collaboration with other professionals was often mentioned as an important task 
because it enabled the CSC not only to reach the target group, but also to stimulate collaboration between sectors.

"Yes, in my view they [CSCs] should act as a kind of intermediary and let's say attract people who are interested, and only if it is not possible, only then do something in the way of execution. I would prefer to use the existing $P A$ range as much as possible, there is already quite a lot. It is only the way to get there, to find them, that is too difficult for some people." (Municipality \#8)

In the other two of these six municipalities, policymakers attributed particularly an organiser role to the CSC. The CSCS in these municipalities were responsible for the organisation of PA activities or for strengthening initiatives in the neighbourhood. Collaboration with professionals was mentioned as an important task in order to work together on activities or initiatives to stimulate PA.

"You now see that the one plays a greater role in the organisation in the implementation, which is more the CSC, so to say. However, like, the guidance, support, and referrals of a vulnerable group and becoming aware of such needs, that is more the territory of welfare officers. And these two seek out each other far more, like, you know, the one observes and the other one also has intentions with this target group, and they do need a party that can subsequently develop and implement the supply. (Municipality \#3)

\section{Other professionals related to health promotion and PA promotion}

The number and diversity of functions differed for each municipality, and in most municipalities it was difficult to gain an insight into the different functions, particularly as these professionals generally do not work at a municipal department, but rather for a public health, welfare, or PA organisation. However, in all municipalities, other professionals working in the fields of health promotion and PA promotion were employed, for example a PA consultant and a health broker. These other professionals can be supportive of the CSCs' work.

"In a general position as a community worker, but they do lack this specific senior citizens' support worker as, say, their liaison officer." (Municipality \#2)

\section{Directing}

Different forms of directing, related to the different forms of implementation of the CSC funding, could be distinguished. Municipalities that appointed the CSC to their PA department provided direct guidance to the CSC, whereas municipalities that appointed the CSC to an external organisation all directed the CSC indirectly by using a performance agreement with the organisation, in which desired outcomes were formulated. The organisations that appointed the CSC were responsible for the direct guidance of the CSC.

"In the decision on the subsidy, or in the requirements that go with the allocation of the grant, we specifically point out that attention should be paid to this connection. However, we as civil servants do not necessarily go around to a neighbourhood team with a view to making this connection. That is...should be at neighbourhood level." (Municipality \#7)

However, in all municipalities, the management of the CSC or the organisation that appointed the CSC had a facilitating role in which conditions for the CSC were created. It was up to the CSC to actually made a connection with other functions, use, and/or strengthen relevant existing programs and partnerships in the work of establishing collaboration between the sectors at community level and of stimulating the target group to become physically active. 
"You set a framework and especially create room to manoeuvre and to use the framework to get started."

(Municipality \#1)

\section{Resources}

It was hard to obtain information on the budgets for health promotion activities and PA promotion in the municipalities. There was no figure in the budget for health promotion activities per resident in five municipalities, and no figure in the budget for PA promotion available per resident in four municipalities. These budgets were part of the entire public health budget and entire PA budget available in the municipality and therefore hard to assign specifically.

The budget for health promotion activities in four municipalities varied between $€ 0.93$ and $€ 2.83$ per resident, and the budget in five municipalities for PA promotion varied between $€ 1.00$ and $€ 14.12$ per resident. In all municipalities, an activity budget for the CSC was available.

\section{Programs}

In seven municipalities, programs for health promotion and PA promotion were implemented, targeting different target groups. In two municipalities, the programs mostly targeted youth. These two municipalities were in the process of developing a program for the target group, adults. In six of the nine municipalities, the programs were being implemented by different organisations in the fields of public health, PA, and welfare. In the other three municipalities, the programs were being implemented by the municipality only. Some of these programs were implemented by the CSC.

In addition, in five municipalities, programs that CSCs could use or were using in their work to guide residents towards local PA facilities were being implemented.

"This is, as it were, the toolbox for the CSC and then you get a vast range of programs around it, which, naturally, do coincide with PA." (Municipality \#4)

\section{Partnerships}

Two types of partnership could be distinguished in the municipalities: partnerships at management level and partnerships at operational level. In three municipalities, partnerships were mostly organised at operational level; for example, a partnership between sports clubs, a meeting of professionals working in the neighbourhood, or sounding-board groups. Some of these partnerships were organised by the CSC. In the other six municipalities, partnerships at both management level and operational level were organised; for example, collaboration between the municipality and a health insurer, or a partnership between represented organisations. According to the policymakers, partnerships at the strategic level are mostly supportive of the work of the CSC.

"A great many of these things are mainly at the tactical and strategic level. However, these do set the conditions for a number of other things." (Municipality \#1)

Table 7.3 presents a summary of the operational context in the nine municipalities. A complete overview of the operational context in the nine municipalities is presented in Appendix 7.3. 


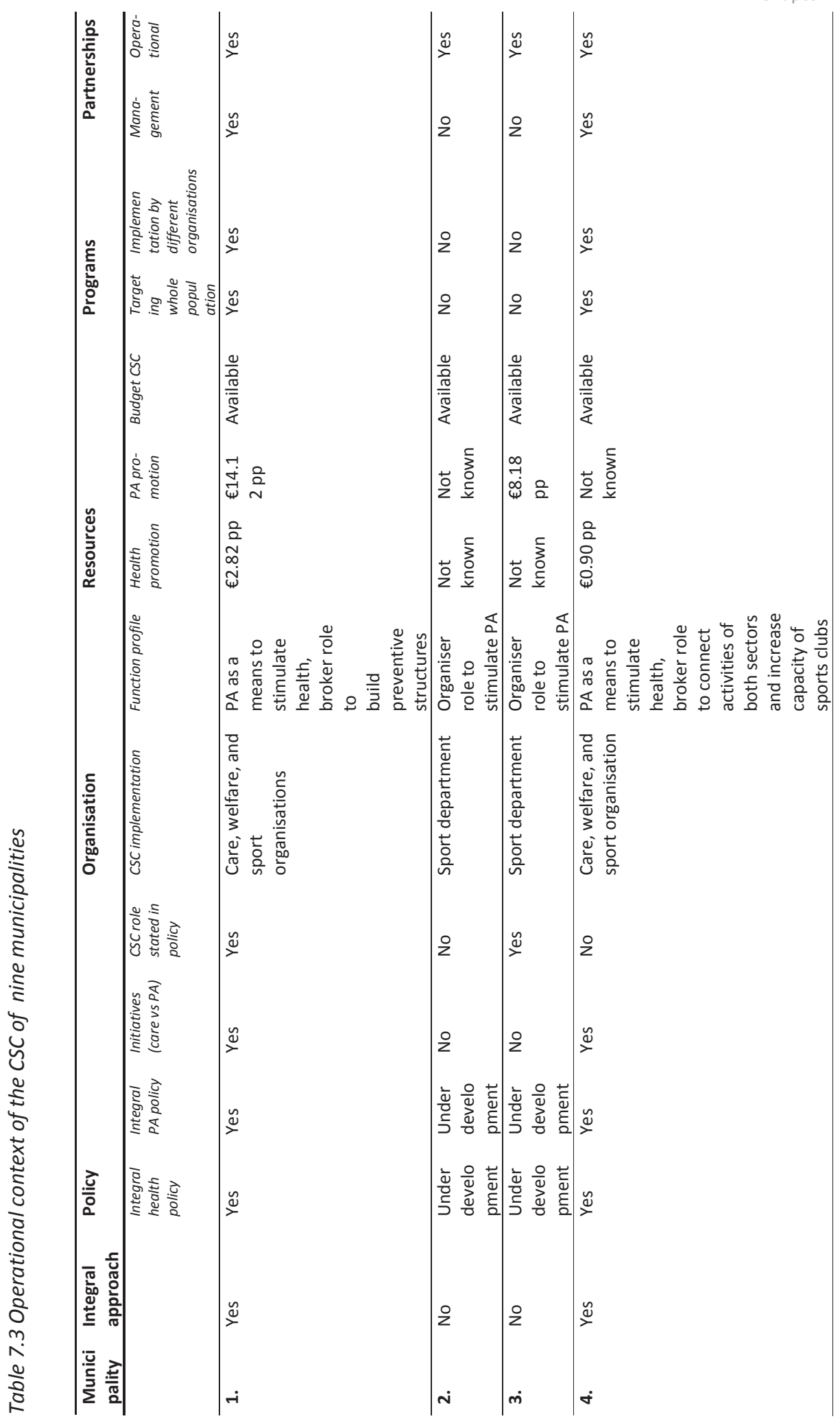


166 | The operational context of care sport connectors in the Netherlands

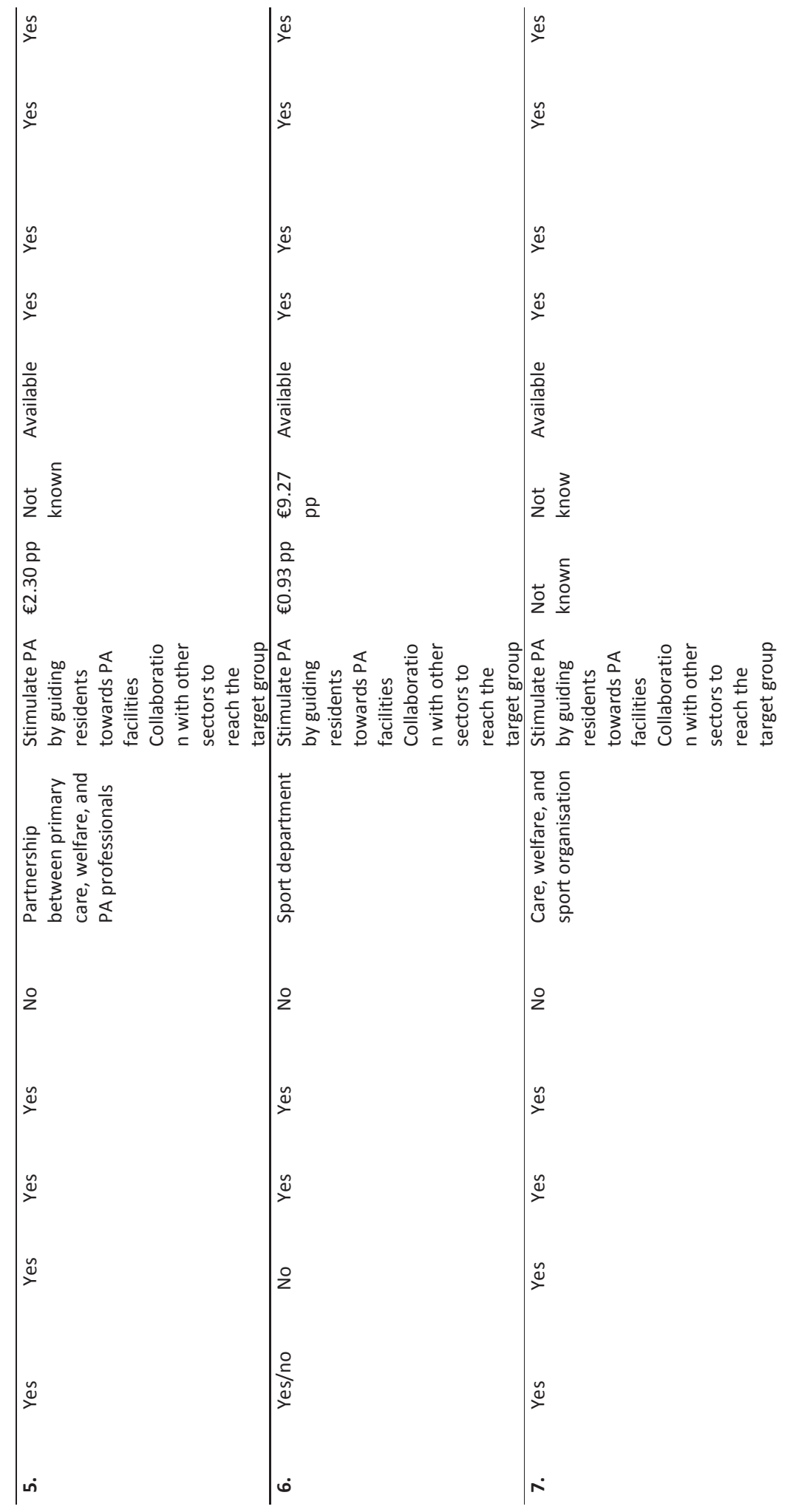




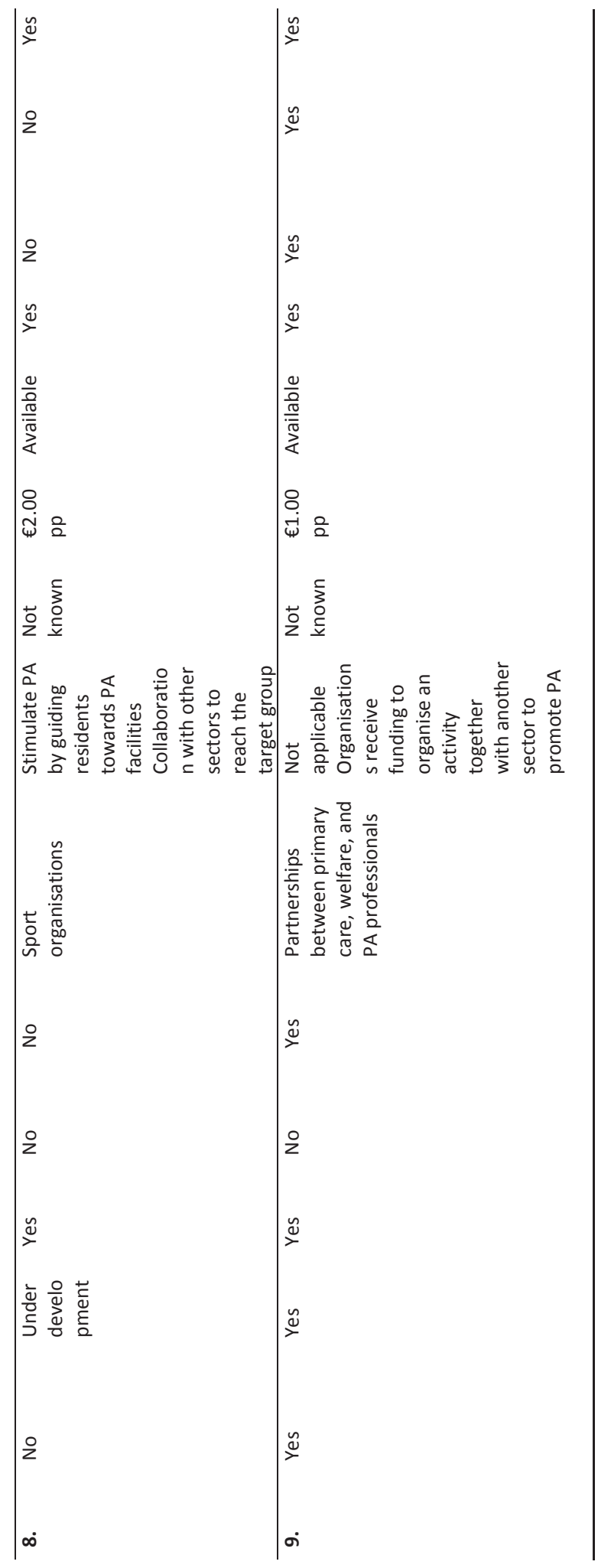




\section{Discussion}

The aim of this study was to describe the operational context of the CSC in nine Dutch municipalities. The results show that this operational context differs. In particular, the extent to which municipalities had adopted an integral approach seems to be different. An integral approach consists of an integral health and PA policy in combination with an imbedding of this policy in partnerships between health and the PA sector at management level. More specifically, this integral approach is reflected in the implementation of other municipal operations: the implementation of CSC funding; the implementation of other initiatives in the fields of public health, care, and PA; and the availability of health promotion and PA promotion programs implemented by different organisations.

The results of this study show that municipalities with an integral approach $(n=5)$ implemented the CSC funding in such a way that CSCs were working from different sectors (e.g. care, welfare, PA organisation). In these municipalities, other initiatives in the fields of public health, care, and PA were also implemented, and programs to promote health and PA were implemented by different organisations. In municipalities that adopted a less integral approach $(n=4)$, this was hardly present, and CSCs were working only from the PA sector. CSCs in these municipalities were mainly responsible for the connection between the primary care and the PA sector. Given the CSC mandate, we think that the integral approach may be supportive of the CSCs' work, because it is reflected in other operations of the municipalities and thus creates conditions for the CSCs' work.

This integral approach can be characterised as a governance for health, and supports therefore our idea that this integral approach is supportive of the CSCs' work. Governance of health promotes joint action of health and non-health sectors, and requires an integral policy which must be supported by structures and mechanisms that enable collaboration. A governance for health gives strong legitimacy for public health professionals to help them reach out and perform new roles in shaping policies to promote health and well-being [21]. This integral approach supports CSCs thus directly and indirectly in their work, because it determines the way in which CSCs are organised and how other municipal operations are organised. However, whether this integral approach is actually supporting CSCs in their work to connect the primary care and the PA sector, or whether other factors could be supportive of the CSCs' work, needs to be further studied; especially because municipalities adopting a less integral approach were often of a small size. Possibly, an integral approach is less necessary because of their small size. Other factors in these municipalities could be supportive of the CSCs' work; for example, short communication lines between departments, and the municipality and organisations. One the other hand, there could also be a difference in the educational level between policymakers of a municipality of a small size, compared to policymakers of municipalities of a large size.

Before the study, it was not known how the domains of the presented theoretical framework influence on another and the possible interaction [14-16]. The results of this study suggest that an integral policy, in combination with an embedding of this policy in partnerships at management level, is an important concept and influence other municipal operations, like organisation and programs. These possible influences of the domains, based on this study's results, are presented in Appendix 7.2. Our findings seem to be in line with other studies investigating factors influencing public health capacity and intersectoral action. These studies mention leadership and strong governance [16, 22], partnerships [16, 23], resources [22-24], and policy and a strategic plan [25] as important concepts influencing public health capacity and prerequisites for intersectoral action. Although (financial) 
resources were also mentioned as an important concept in other studies, in this study it was hard to determine the interaction of resources with the other domains because it was hard to obtain information on municipal budgets.

This study provides an insight into how to study the operational context of professionals working in the field of health promotion. This insight is useful because, when the impact of an intervention, program and policy is being studied, contextual factors need to be taken into consideration [5-6]. The results of this study are therefore relevant for other researchers because they provide: 1 ) a theoretical framework for researchers to study the operational context and 2) an insight into factors that need to be taken into consideration in studies on operational context. First, the theoretical framework seems to be a useful way to describe the operational context of professionals working in the field of public health. During the interviews, no other domains relating to CSCs' operational context were identified, and so it seems that the framework includes all relevant domains. It became clear that it is important to have a connection between the strategic and operational level. However, it is not clear how the different domains influence one another. Other studies should reveal whether and how these domains influence one another and the operational context. Whether this framework is, after some changes, applicable to other professionals working in the field of public health should also be explored. Secondly, studying an operational context appeared to be complex and time consuming for both the researcher and the participants, especially because not all municipalities monitor their activities. Using different data collection methods ensured that as much information as possible was collected. In addition, providing the participants a first outline of the operational context, based on information already available to the researchers (for example policy documents), limited the work burden for the participants. The method used in this study is therefore recommended, especially because in a short period of time a comprehensive insight into the work of the municipality could be outlined.

Evidence is lacking on which operational context or implementation of the CSC funding is the most supportive of, and effective for, CSCs' work, but providing an insight into the current operational context is an important part of any attempt to improve it. Participation in this study was therefore relevant for policymakers because it enabled them to reflect jointly on their policy regarding the CSC role and provided an opportunity to identify strengths and areas for improvement. In addition, the results of this study are relevant for policymakers and municipalities working on a connection between the primary care and the PA sector, especially because the CSC funding was implemented differently and there were differences in municipalities' integral approaches. Results of these study may therefore lead to new insights for policymakers about the CSC role and connections between the primary care and the PA sector.

\section{Study's limitations}

Some limitations need to be taken into account when these results are being interpreted. In order to describe the operational context, information on many different topics was needed. Therefore, it is possible that during the interviews we had not enough time to reflect extensively on all topics. In addition, not all municipalities monitor their activities and therefore it was not always possible to gain a complete overview of the context. However, by using different data collection methods, we were able to collect rich data to describe the operational context of the CSC.

In this study, we described CSCs' operational context in nine municipalities. These 
municipalities were different in size and population, and the local government is in all probability different in structure, power, and political representativeness. Although these factors may influence how municipalities give meaning to their operations, we disregarded these factors because we were interested in the context in which the CSCs were operating and not in the processes that had led to this operational context.

\section{Conclusion}

This study provided a first insight into CSCs' operational context; this context was organised differently in the nine municipalities. In particular, the extent to which a municipality adopted an integral approach seemed to influence its existing operations and thus whether the operational context was supportive of the work of the CSC. Whether this integral approach is actually supporting CSCS in their work to connect the primary care and the PA sector needs to be further studied. In addition, this study provided a new framework to study the operational context of professionals working in the field of public health. Further research is needed to explore whether this framework is applicable to other professionals. 


\section{References}

1. Eakin EG, Glasgow RE, and Riley KM.Review of primary care-based physical activity intervention studies. Family Practice 2000, 49(2), 158-168.

2. den Hartog F, Wagemakers A, Vaandrager L, van Dijk M, and Koelen MA. Alliances in the Dutch Beweegkuur lifestyle intervention. Health Education Journal 2014, 73, 576-587.

3. Meijer S, Hesselink A, and Martens M. Leefstijlbeïnvloeding in de eerstelijn. Verkenning naar de ervaringen van zorgverleners. Bilthoven: RIVM; 2012.

4. Dutch Ministry BKZ (2013) Decentralisations in the Netherlands. Retrieved from: https://www.rijksoverheid.nl/onderwerpen/gemeenten/inhoud/decentralisatie-vanoverheidstaken-naar-gemeenten Last accessed 4 April 2016.

5. Ndumbe-Eyouh $\mathrm{S}$, and Moffat $\mathrm{H}$. Intersectoral action for health equity: A rapid systematic review. BMC Public Health 2013, 13, 1056. doi: 10.1186/1471-2458-13-1056

6. Glasgow RE, Green LW, Taylor MV, and Stange KC. An evidence integration triangle for aligning science with policy and practice. American Journal of Preventive Medicine 2012, 42(6), 646-654. doi:10.1016/j.amepre.2012.02.016

7. Harting J, Kunst AE, Kwan A, and Stronks K. A 'health broker' role as a catalyst of change to promote health: An experiment in deprived Dutch neighbourhoods. Health Promotion International 2011, 26, 65-81

8. Langeveld K, Stronks K, and Harting J. Use of a knowledge broker to establish healthy public policies in a city district: A developmental evaluation. BMC Public Health 2016, 16, 271. doi: 10.1186/s12889-016-2832-4

9. Hagen S, Helgesen M, Torp S, and Fosse E. Health in all policies: A cross-sectional study of the public health coordinators' role in Norwegian municipalities. Scandinavian Journal of Public Health 2015, 43(6), 597-605. doi: 10.1177/1403494815585614

10. Smit E, Leenaars KEF, Wagemakers A, Molleman GRM, Koelen MA, van der Velden J. Evaluation of the role of Care Sport Connectors in connecting primary care, sport, and physical activity, and residents' participation in the Netherlands: study protocol for a longitudinal multiple case study design. BMC Public Health 2015, 15: 510

11. Sabatier $P$, and Mazmanian D. The conditions of effective implementation: a guide to accomplishing policy objectives. Policy Analysis1979, 5, 481-504.

12. Rütten A, Gelius $P$, Abu-Omar K. Policy development and implementation in health promotion - from theory to practice: the ADEPT model. Health Promotion International 2010. doi:10.1093/heapro/daq080.

13. Mintzberg, H. (1979) The Structuring of Organizations. Englewood Cliffs, NJ: PrenticeHall.

14. Aluttis C, Van den Broucke S, Chiotan C, Costongs C, Michelsen K, and Brand H. Review of Public Health Capacity in the EU: Final Report. Luxembourg: European Commission Directorate General for Health and Consumers; 2013.

15. Meyer AM, Davis M, and Mays GP. Defining organizational capacity for public health services and systems research. Journal of Public Health Management and Practice 2012, 18(6), 535-544.

16. Bagley $\mathrm{P}$, and Lin $\mathrm{V}$. The development and pilot testing of a rapid assessment tool to improve local public health system capacity in Australia. BMC Public Health 2009, 9(1), 413. doi: $10.1186 / 1471-2458-9-413$

17. Handler A, Issel M, Turnock B. A conceptual framework to measure performance of the public health system. American Journal of Public Health 2001, 91(8), 1235-1239. 
18. Leenaars KEF, Tijhuis K, Smit E, Wagemakers A, Molleman GRM, Koelen MA. Workshop: Het in kaart brengen van gemeentelijke capaciteit voor publieke gezondheid in Nederland. Nederlands Congres voor Volksgezondheid, Rotterdam 9-10 april 2015.

19. CBS (2015) Characteristics of municipalities in the Netherlands. Retrieved from: http://statline.cbs.nl/Statweb/?LA=nl Last accessed 2 November 2015.

20. Elo $S$, and Kyngäs $H$. The qualitative content analysis process. Journal of Advanced Nursing 2008, 62(1), 107-115.

21. Kickbusch I, Gleicher D. Governance for health in the $21^{\text {st }}$ century. Copenhangen: World Health Organization; 2012.

22. Aluttis C, Van den Broucke S, Chiotan C, Costongs C, Michelsen K, and Brand H. Public health and health promotion capacity at national and regional level: A review of conceptual frameworks. Journal of Public Health Research 2014, 3, 199. doi: 10.4081/jphr.2014.199

23. Rantala R, Bortz M, and Armada F. Intersectoral action: Local governments promoting health. Health Promotion International 2014, 29, 92-102.

24. St Pierre L, Hamel G, Lapointe G, McQueen D, and Wismar M. Governance Tools and Framework for Health in All Policies. National Collaborating Centre for Healthy Public Policy, International Union for Health Promotion and Education, and European Observatory on Health Systems and Policies, Montreal, Paris, Brussels, 2008. Retrieved from: https://www.raadrvs.nl/uploads/docs/Achtergrondstudie Governance tools and framework1.pdf. Last accessed 15 May 2016.

25. PHAC and WHO. Health Equity through Intersectoral Action: An Analysis of 18 Country Case-Studies. Geneva and Ottawa: Public Health Agency of Canada and World Health Organization; 2008. 
Appendix 


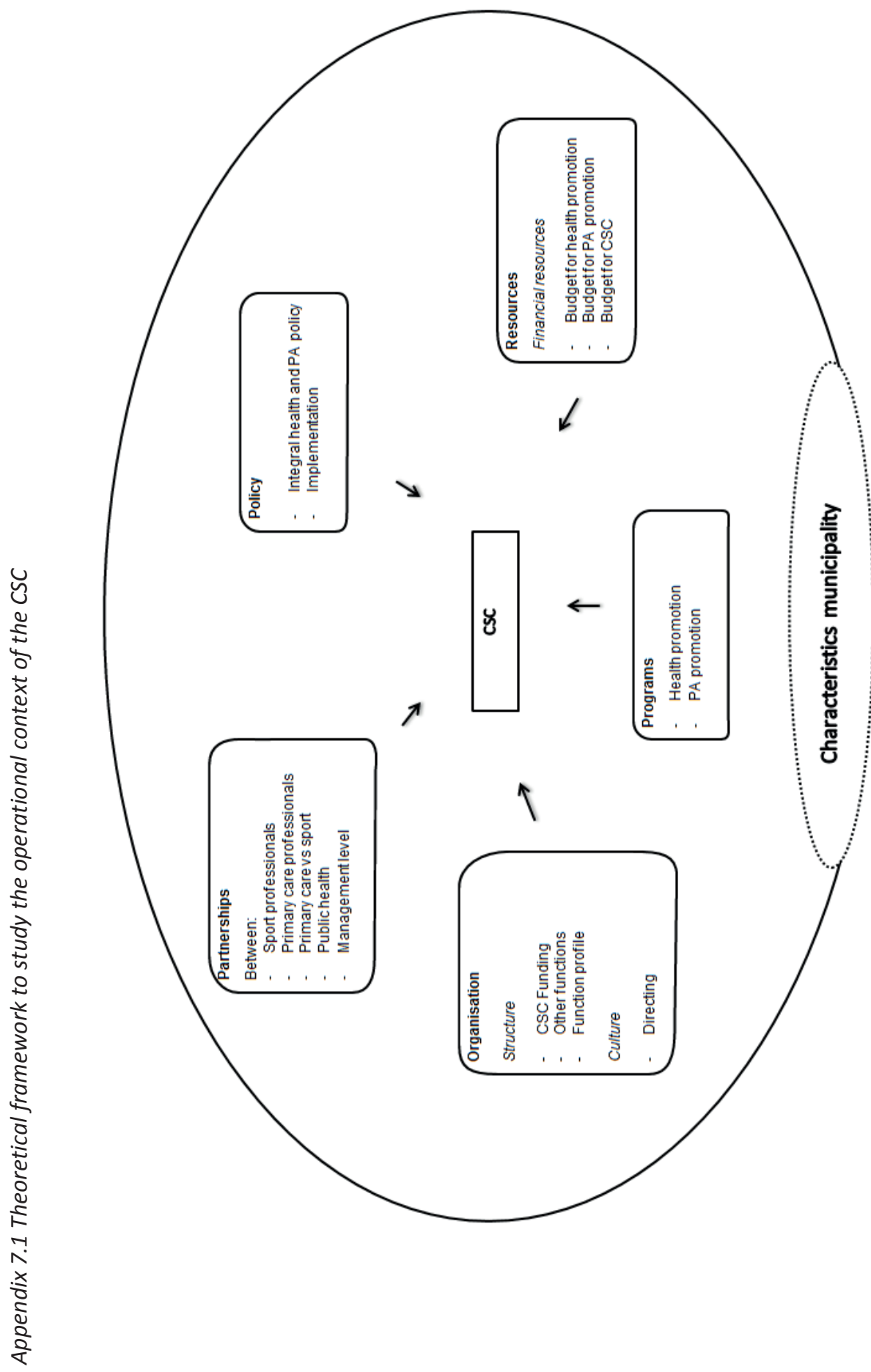




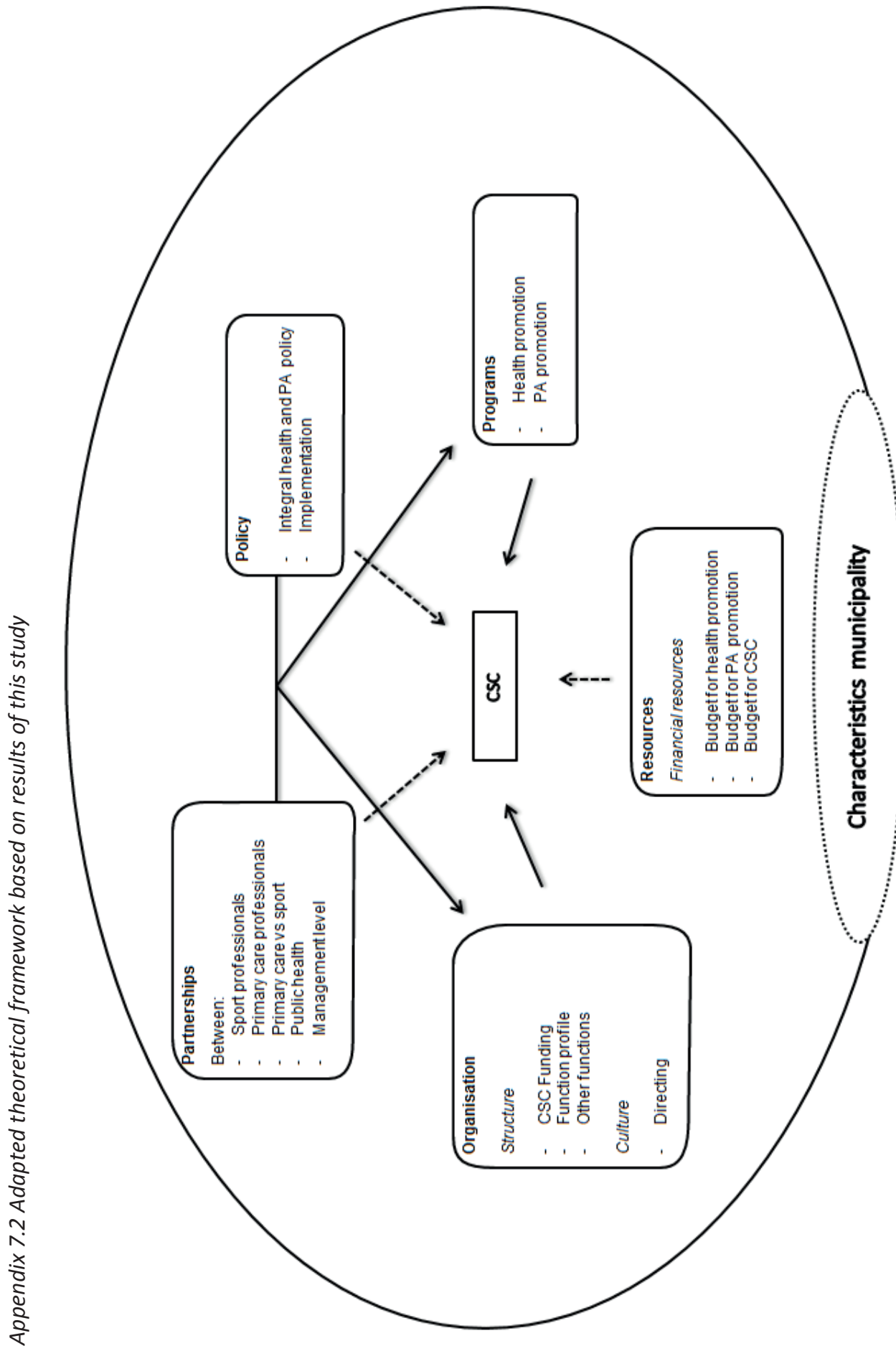




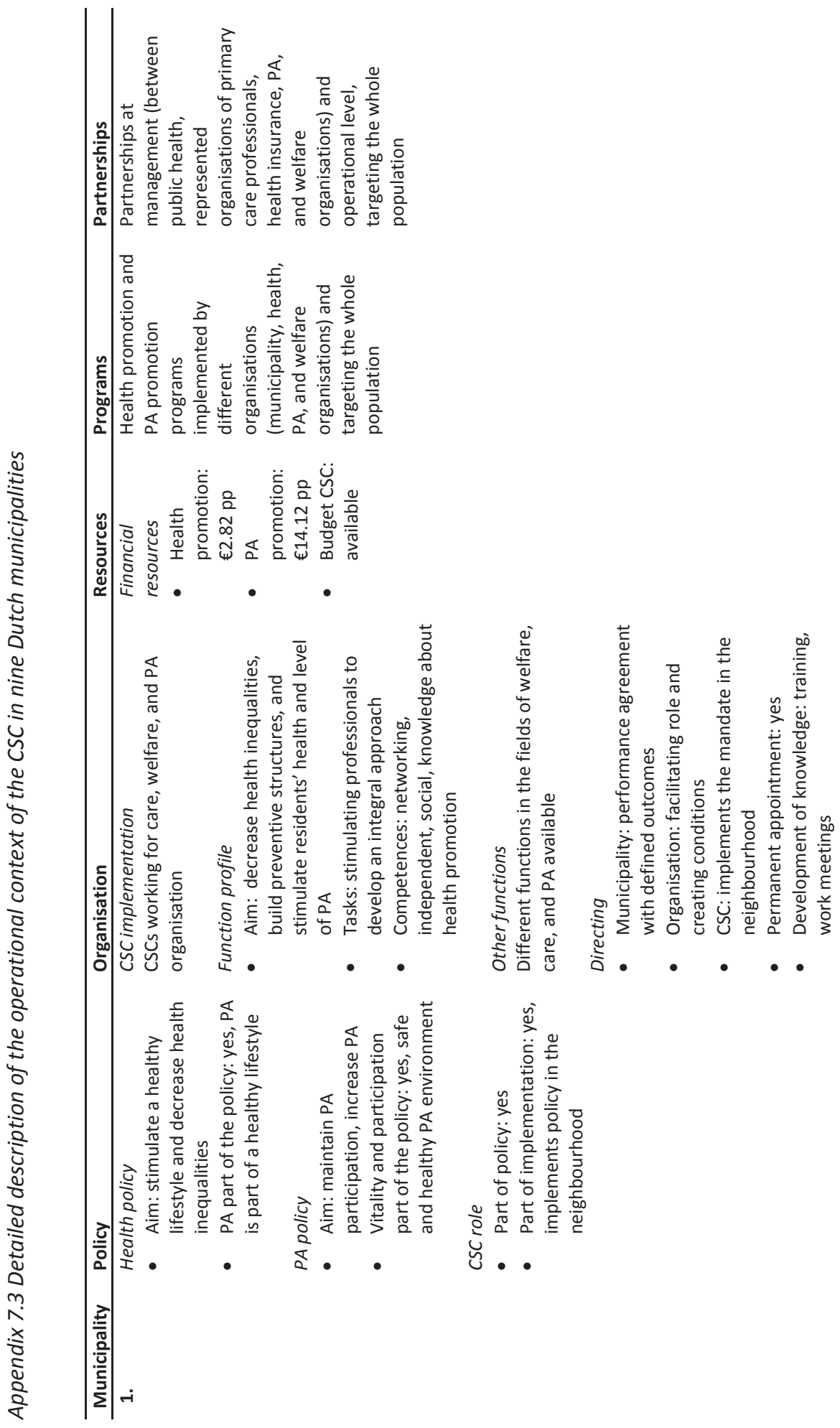



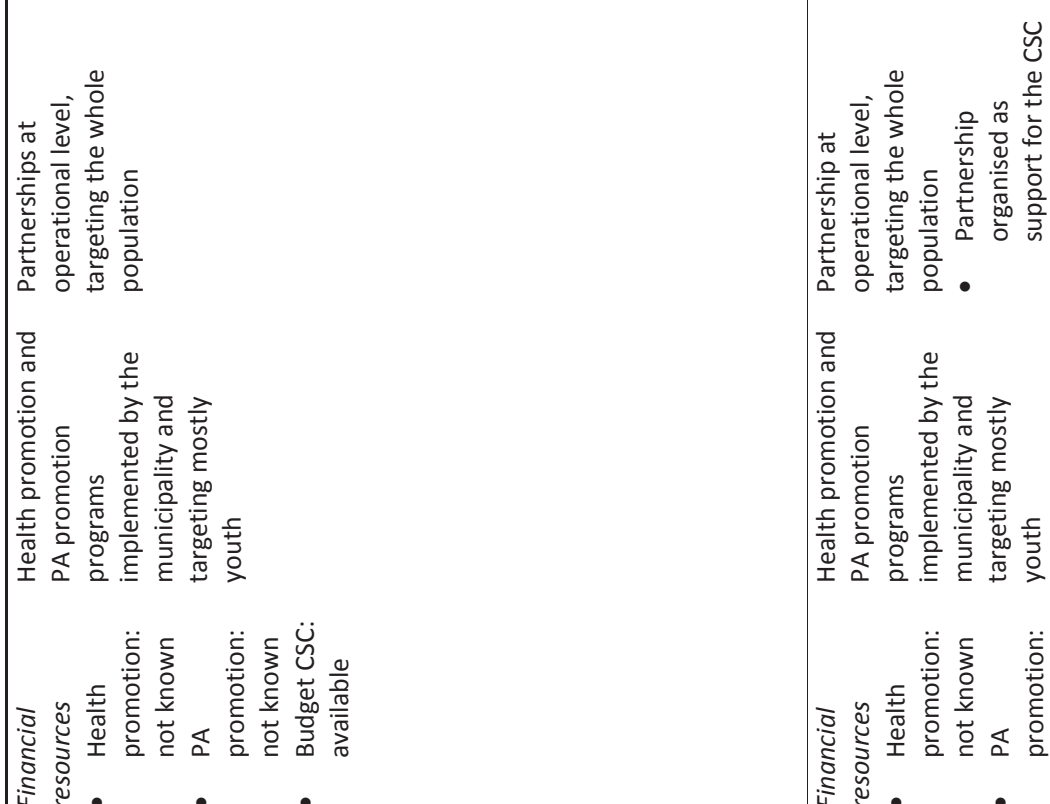

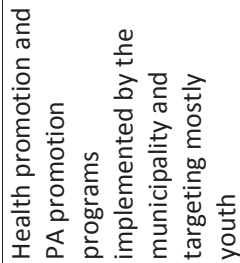

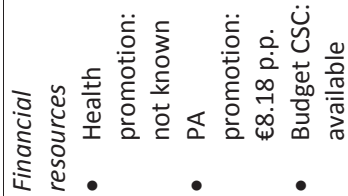

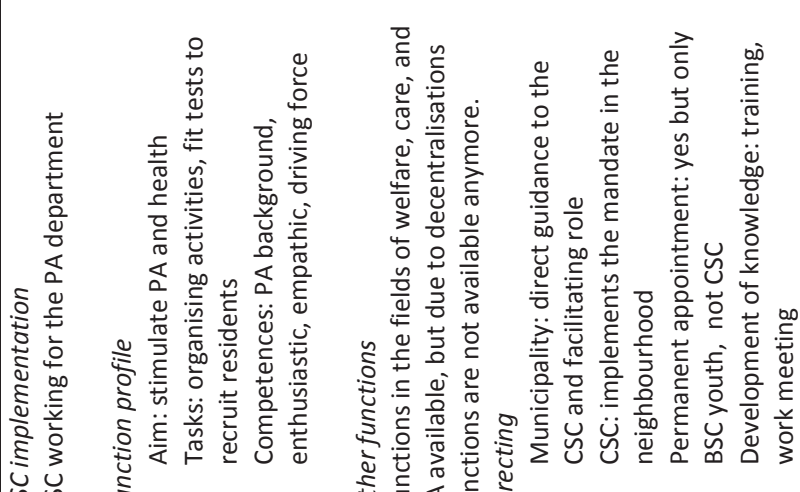

论 言言造部。

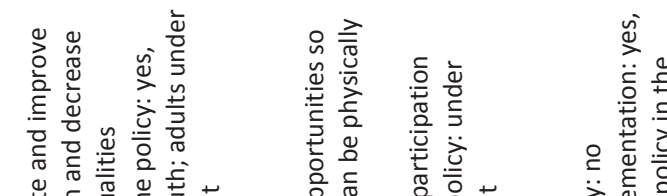

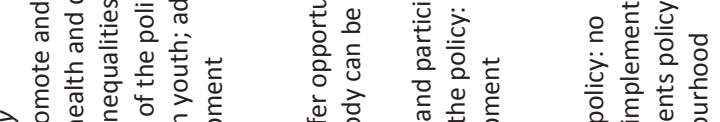

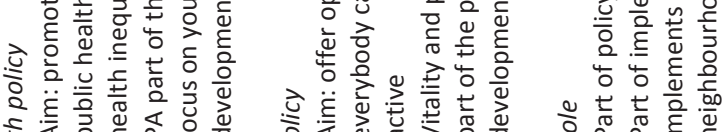

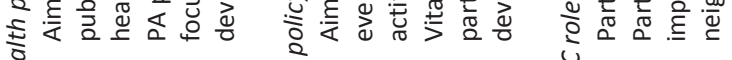

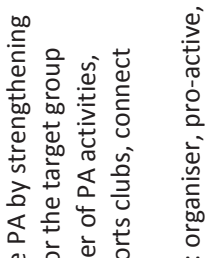

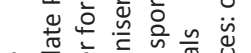

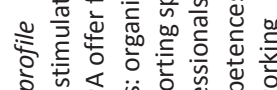

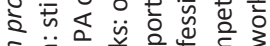

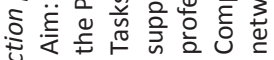

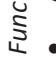
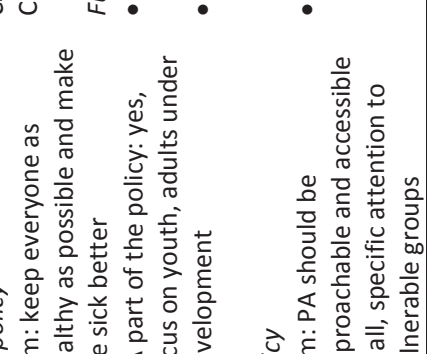

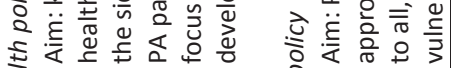
a. 


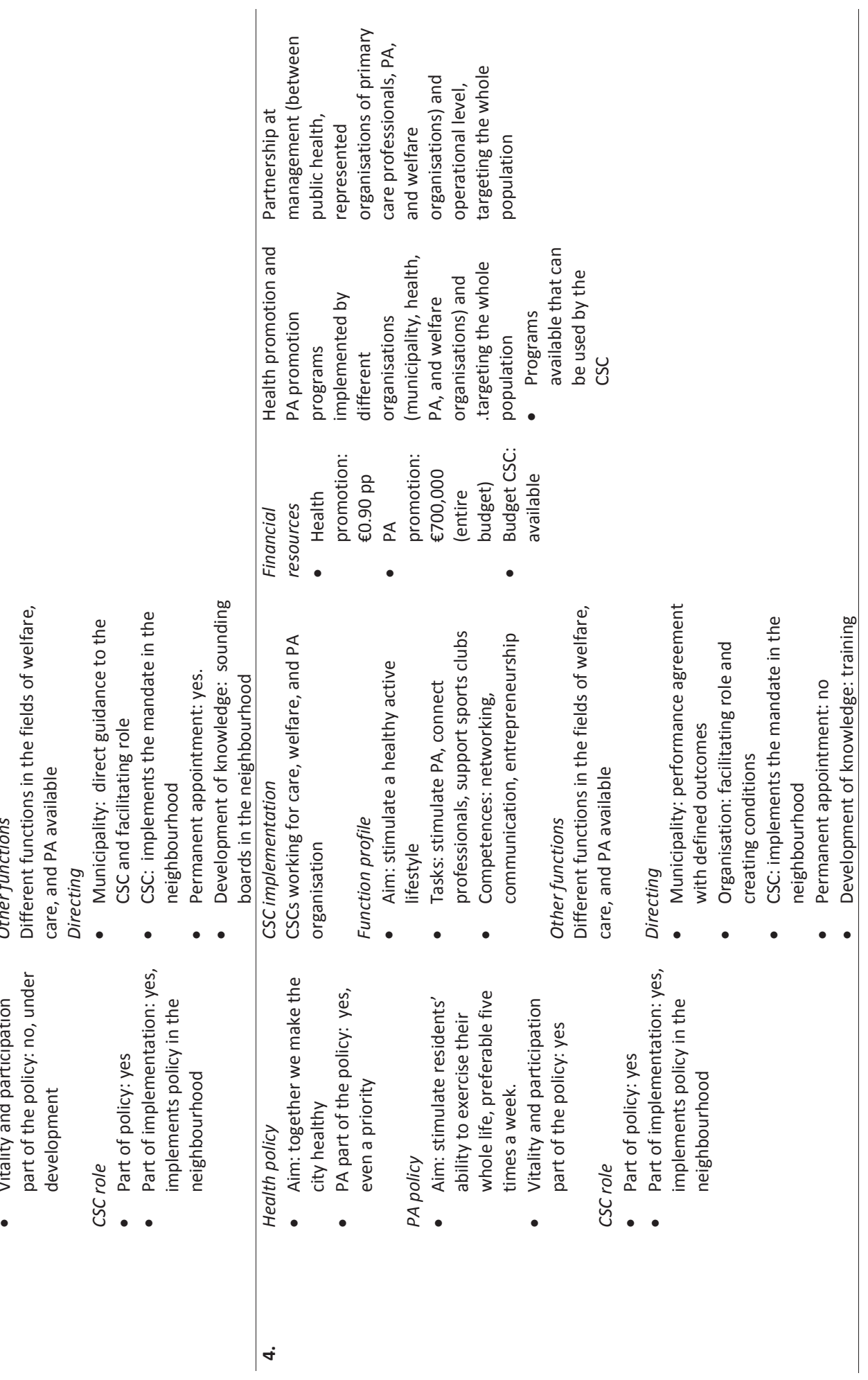




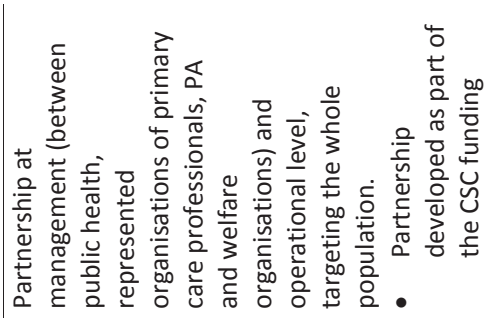

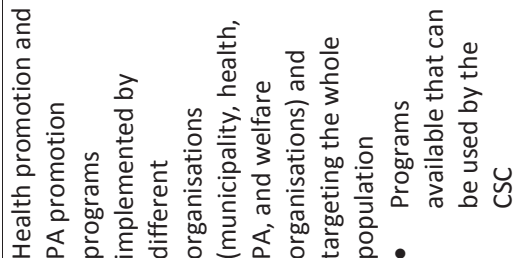

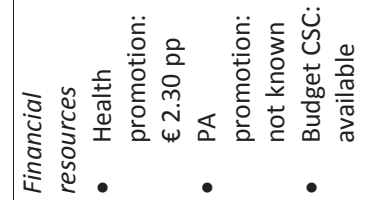

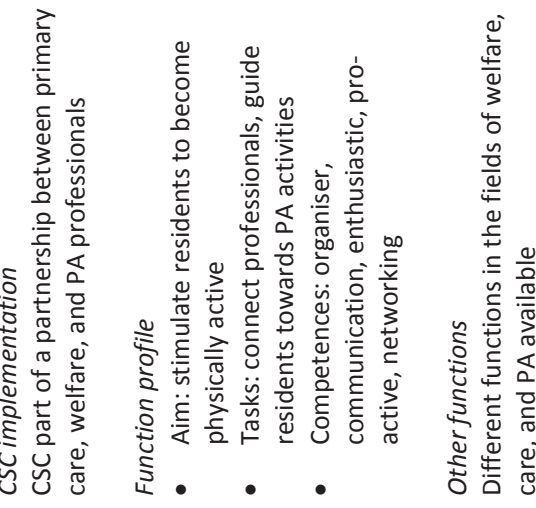

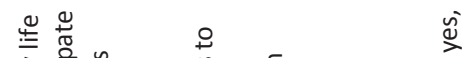

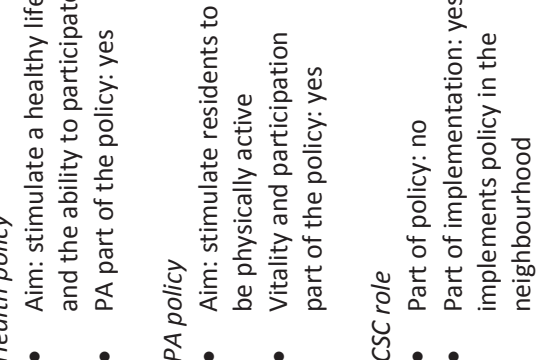

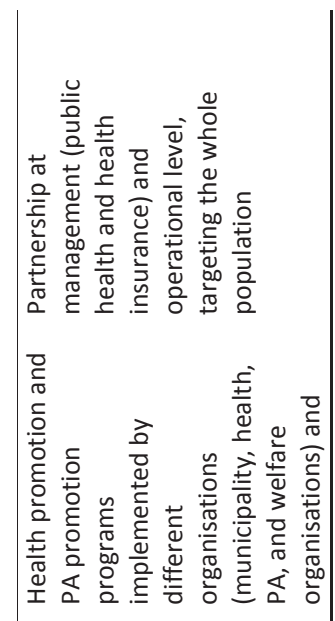

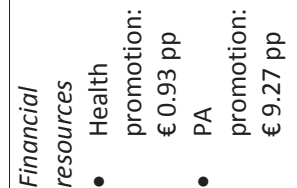

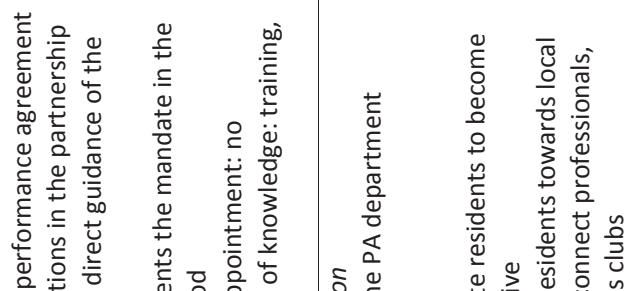

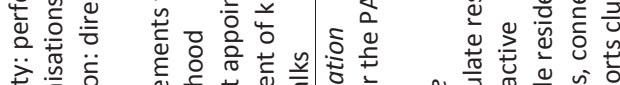

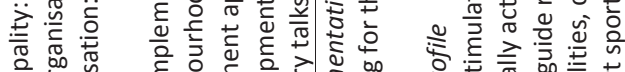

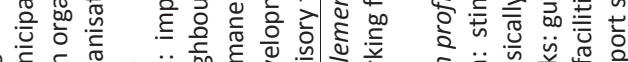

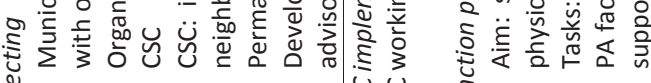
• • • • •

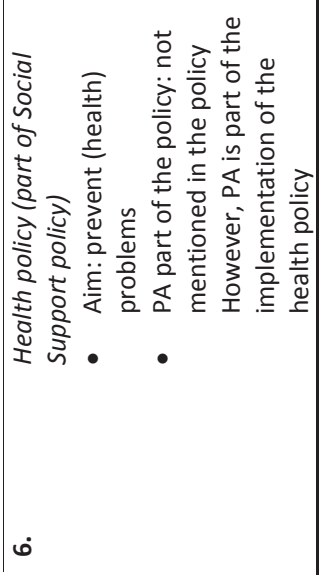



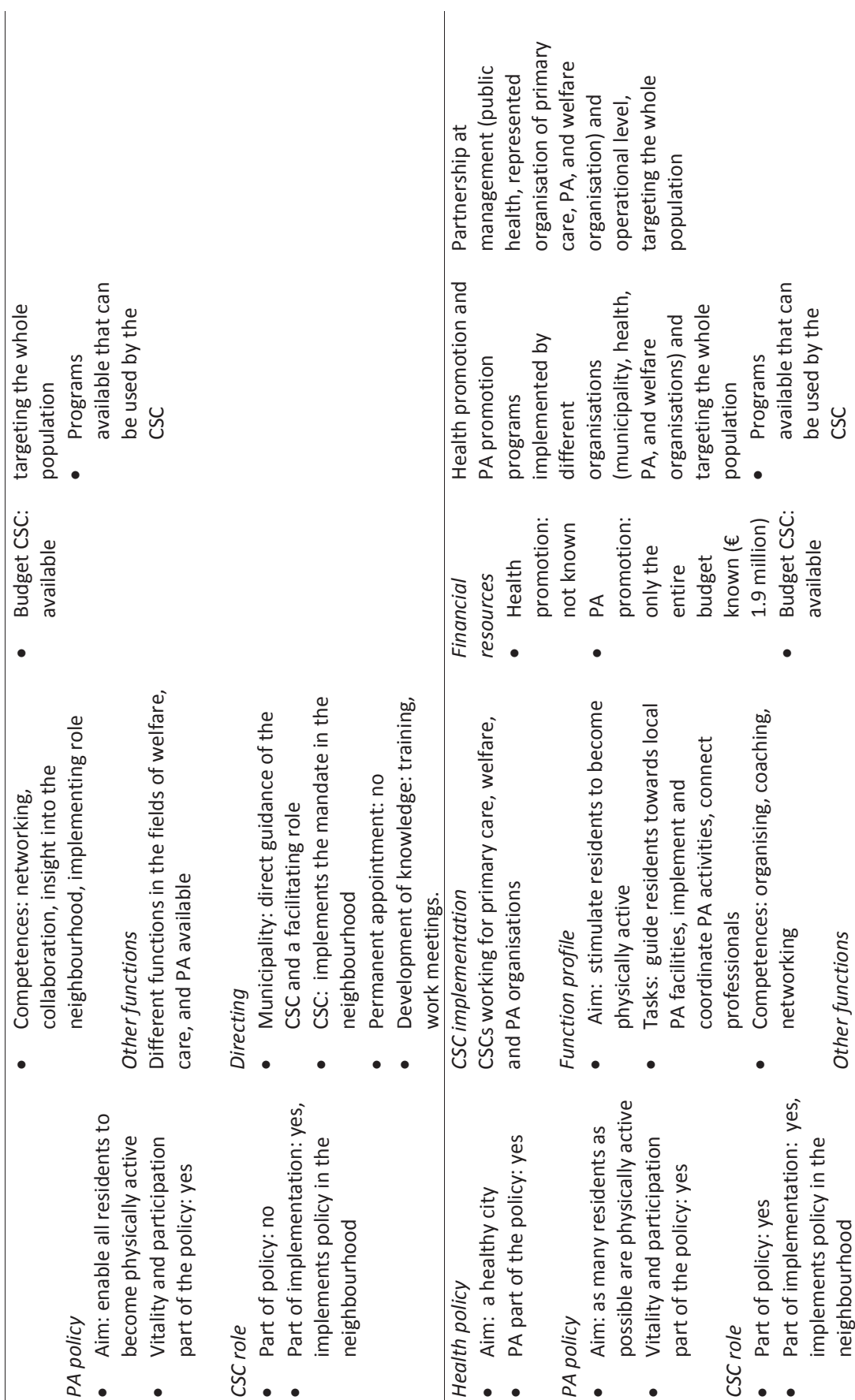

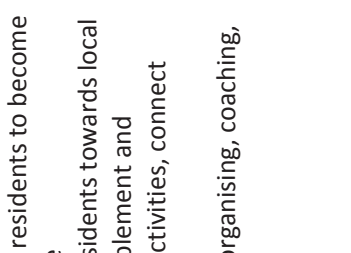

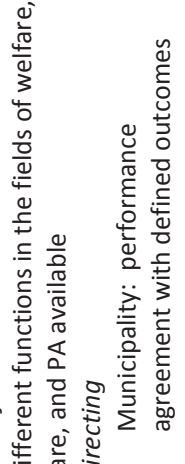

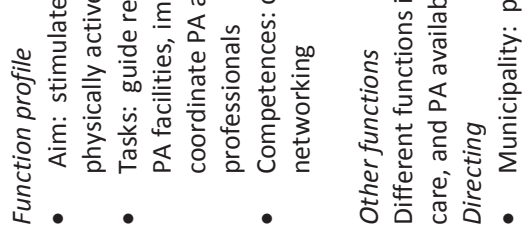

$\stackrel{\text { ஸे }}{2}$

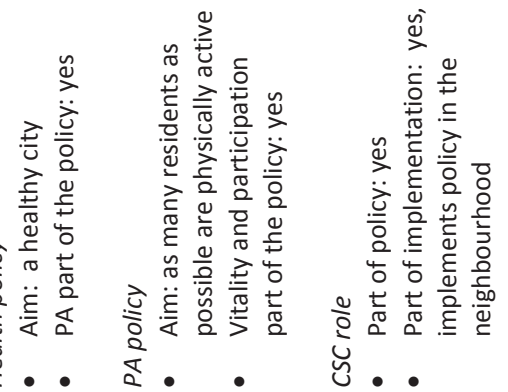




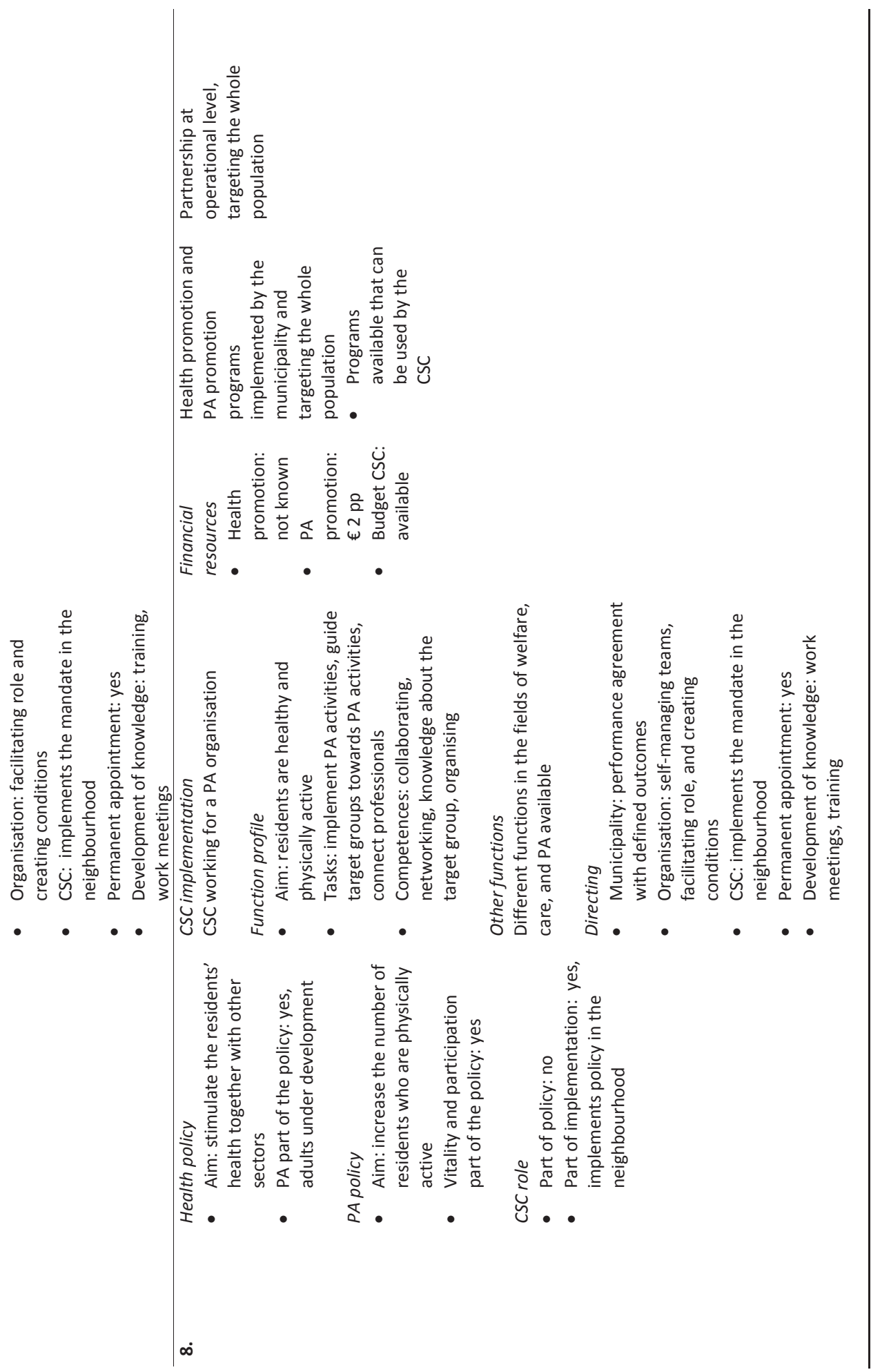



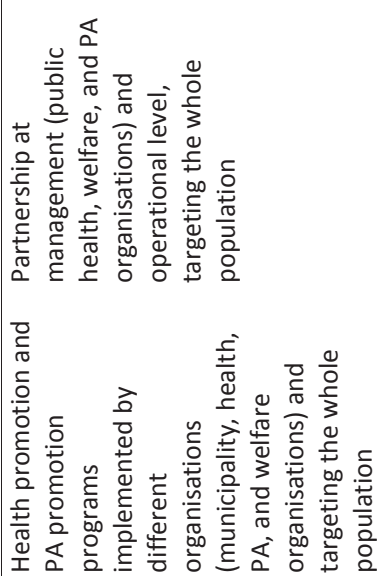

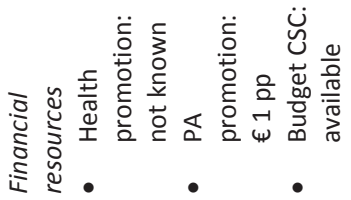

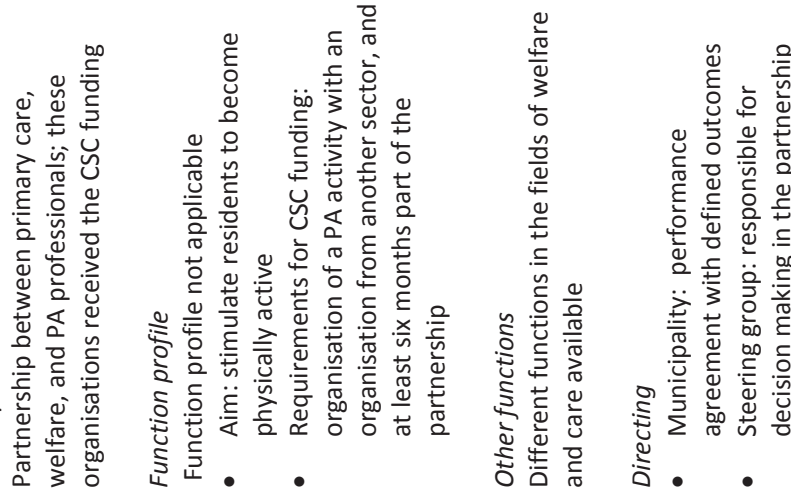

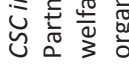

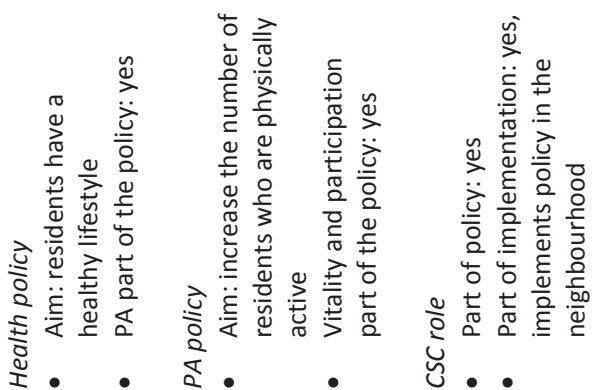

कं 


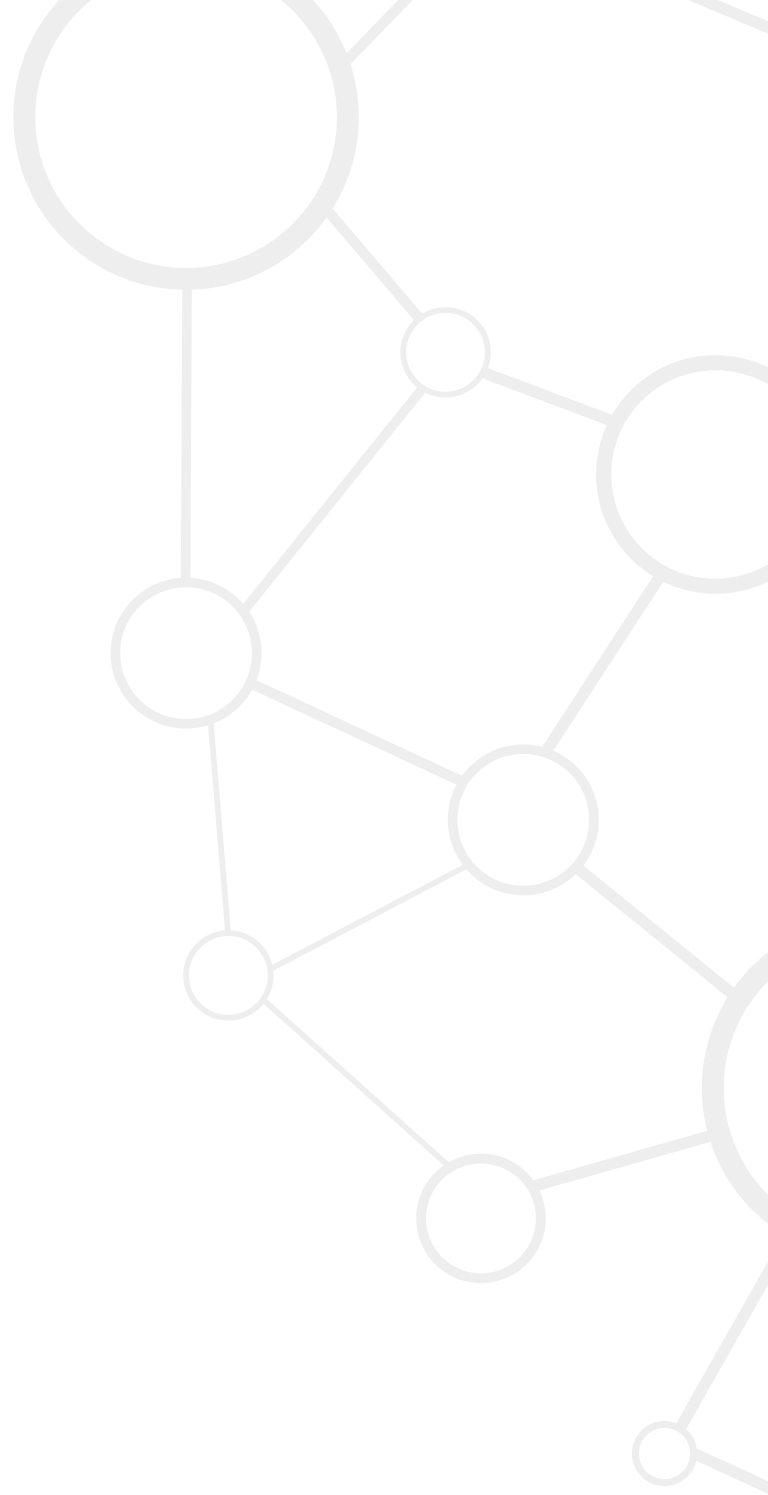




\section{Chapter 8}

\section{Exploring the impact of the Care Sport Connector in the Netherlands}

\section{Submitted as:}

Leenaars KEF, Smit E, Wagemakers A., Molleman GRM, Koelen MA. Exploring the impact of the Care Sport Connector in the Netherlands. BMC Public Health. 


\begin{abstract}
Background

Regular physical activity (PA) is deemed to contribute to the primary and secondary prevention of several chronic diseases, like diabetes mellitus, cancer, cardiovascular diseases, and osteoporosis. In 2012, Care Sport Connectors (CSC), to whom a broker has been ascribed, were introduced in the Netherlands to stimulate PA and guide primary care patients towards local sport facilities. The aim of this study was to explore CSCs' impact on connecting both sectors and to identify the most promising structural embedding of the CSC for CSCs' work.
\end{abstract}

\title{
Methods
}

In three rounds of interviews, 13 CSCs were followed for two years in their work. In these interviews, a network survey was used to identify organisations in CSCs' network, whether they collaborated with these organisations, and the role of the organisations in the connection. Data from the network survey were analysed using the RE-AIM framework and disaggregated into how CSCs were structurally embedded (Type A: only PA sector; Type B: different sectors; Type C: partnership).

\section{Results}

Type A CSCs established the connection mostly around their own activities, supported PA organisations with their activities, and collaborated with primary care and welfare professionals around their own activities. Type B and C CSCs established the connection by organising, supporting, and implementing different kinds of activities targeting different kinds of audiences, and collaborated mostly with primary care professionals around the referral of professionals' patients.

\section{Conclusions}

The results of this study suggest that adopting an integral approach (Type B and C) for the structural embedding of the CSC is more promising for reaching the desired outcomes. Whether CSCs really improve the target groups' PA level and health needs to be further studied. 


\section{Background}

Regular physical activity (PA) is associated with enhanced health and reduced risk of allcause mortality, and has many health benefits [1]. Therefore, regular PA is deemed to contribute to the primary and secondary prevention of several chronic diseases, like diabetes mellitus, cancer, cardiovascular diseases, and osteoporosis [2]. About $40 \%$ of Dutch adults do not meet the Dutch recommendation about being moderately active for 30 minutes at least five days per week [3].

In order to stimulate PA, in 2012 the Dutch Ministry of Health, Welfare, and Sport introduced neighbourhood sport coaches (in Dutch Buurtsportcoach), ascribing to them a broker role. These coaches are $40 \%$ funded by the state and $60 \%$ funded by the municipality or other local organisations. Some of these coaches, so-called Care Sport Connectors (CSCs), are employed specifically to connect the primary care sector (all care that is directly accessible to the patient, i.e. GP, physiotherapist, dietician) and the PA sector (covers all PA services in the neighbourhood, i.e. sport clubs, fitness centres, PA lessons at community centres, and walking groups) in order to guide primary care patients towards local PA facilities. A blueprint for the implementation of CSCs' funding or function was not prescribed, allowing municipalities to implement CSCs in line with local needs and contexts. The general idea is that CSCs facilitate that professionals in the primary care and PA sector collaborate; that activities to promote PA are implemented; and reach target groups that need to be more physical active. The overall aim is that target groups will become more physically active and health outcomes will improve.

It is desirable to connect the primary care and the PA sector because of the potential for reaching physically inactive adults [4]. Primary care professionals have an ideal position to motivate their patients to be physical active, whereas the PA sector has a range of PA activities. However, previous studies have shown that differences between both sectors (different cultures and interests) [5-7] and barriers relating to their own sector (primary care professionals' lack of time and knowledge, and lack of suitable PA activities) [8-12] can hinder their mutual collaboration. A broker role holds the promise of improving intersectoral collaboration [13].

Although a broker role seems promising for improving intersectoral collaboration, to our knowledge no study has yet evaluated the impact of a broker role on connecting both sectors. In our review study that described collaborative initiatives between the primary care and the PA sector, we found one initiative [14] that made use of a broker to organise a partnership of community organisations to promote PA [15]. Although that study showed that, according to professionals, the broker role was effective in carrying out their work, the study focused on the results of the partnership for PA promotion rather than on the broker role for improving intersectoral collaboration [14]. The CSC function provides an excellent opportunity to study the impact of the broker role on improving intersectoral collaboration. A previous study in which we explored CSCs' role, revealed that the role of the CSC is promising in improving collaboration between the primary care and the PA sector. However, the way in which municipalities structural embedded CSCs influenced the ease with which CSCs could initiate collaboration structures [16]. For example, CSCs working from the PA sector found it harder to involve primary care professionals than CSCs working from other organisations. Therefore, the aim of this study is to try to determine which structural embedding is the most promising for CSCs' work. Research questions addressed were: 1) what is the impact of the CSC on connecting the primary care and the PA sector, and 2) what is the impact of the structural embedding of CSCs on CSCs' work? 


\section{Method}

\section{Study design}

A multiple case study was conducted from 2014 to the end of 2016 in nine municipalities spread over the Netherlands. To analyse CSCs' impact and the structural embedding on connecting both sectors, 13 CSCs were, in three rounds of interviews, followed for two years in their work.

\section{Setting and study population}

The nine municipalities were selected through convenience sampling based on project partners' contacts. The main inclusion criterion was: municipalities implementing the CSC function for four years (until 2017). During the selection, we made sure that municipalities of different sizes and from different regions of the Netherlands were included $(\leq 300,000$ inhabitants ( $n=2), 100,000-300,000$ inhabitants $(n=4), \leq 100,000$ inhabitants $(n=3))$. In these municipalities, the CSC was differently structural embedded. In four municipalities, CSCS $(n=5)$ were structural embedded in only the PA sector (Type A). In the other five municipalities, an integral approach was adopted to structural embed CSCs. Two forms of this integral approach could be distinguished: four CSCs were working from either care, welfare, or PA organisations (Type B), and four other CSCs were part of a partnership between primary care, welfare, and PA organisations (Type C).

In consultation with the representative policymaker in each municipality, CSCs were selected to participate in this study. Inclusion criteria were: the CSC 1) aims to connect primary care and the PA sector, and 2) is working with an adult target group, preferable adults who could benefit from PA. The selected 13 CSCs represent approximately $15 \%$ of the CSCs employed to connect primary care and sport for adults in the Netherlands.

The average age of the 13 CSCs ( 4 men, 9 women) was 33 years (min 27 years, max 57 years). Ten CSCs had a bachelor's degree, two had a master's degree, and one had a vocational education diploma. At the time of the first interview in 2014, six CSCs had been in position for 0-6 months, four CSCs had been working for 6-12 months, and three for longer than a year. Type A CSCs worked on average 26.4 hours, type B CSCs worked on average 28.5 hours, and type CSCs worked on average 27.5 hours (Table 8.1 ).

\section{Data collection}

To analyse CSCs' impact and the structural embedding on connecting both sectors, we analysed CSCs' network with the use of Frey et al.'s [17] Levels of Collaboration Survey. We identified organisations in CSCs' network, their role, and the level of collaboration (network - cooperation - coordination - coalition - collaboration) on a scale ranging from 1 to 5 . The different levels of collaboration, characterised as described in Frey et al. [17], are presented in Appendix 8.1. During the first interview round, it appeared that CSCs found it hard to distinguish the different collaboration levels, and often choose only network (an organisation with which they had contact) or collaboration (an organisation with which they collaborated). Therefore, in the second and third interview round, we used the Levels of Collaboration Survey only to identify organisations in CSCs' network, whether they collaborated with these organisations, and the manner in which. The analysis of CSCs' network was completed during three rounds of interviews, each with a time span of approximately 6 to 12 months (March-May 2014, March-May 2015, March-May 2016). In 
one case, a network analysis did not take place in 2015 , because the CSC temporarily ceased functioning. Therefore, the number of CSCs in 2015 was 12. The interviews took place at the CSCs' workplace and lasted between 1 and 1.5 hours. The interview rounds were performed by $\mathrm{KL}$ and $\mathrm{ES}$.

\section{Data analysis}

To analyse CSCs' impact and the structural embedding on connecting both sectors, Glasgow et al.'s RE-AIM framework [18] was used. The RE-AIM framework conceptualises the public health impact of an intervention as a function of five factors: reach, efficacy, adoption, implementation, and maintenance. Normally this framework is used to evaluate intervention impact on individual behaviour change, but the RE-AIM framework has been deemed feasible to evaluate broad, multi-faceted initiatives that incorporate multiple interventions targeted to a variety of audiences [19-20]. CSCs work together with different kind of professionals to implement different kind of activities targeting different kind of audiences (e.g. professionals and target group) in order to promote PA [16], therefore in our opinion the RE-AIM framework is also suitable for this study.

To apply the RE-AIM framework for the context of the CSC, operationalisations of the factors were adopted and based on the operationalisations as described in Sweet et al. [19] and Finch et al. [20].

- Reach: refers to the (average) number of organisations in the CSCs' network with which they actually had contact, but not working together.

- Efficacy: refers to the main objective of the CSC and results of the connection between both sectors [18]: increased level of PA among the target group. Data collection on groups addressed by CSCs and the impact of CSCs on stimulating PA and the health among these groups is still going and therefore efficacy could not be addressed at this moment.

- Adoption: refers to the (average) number of organisations in the CSCs' network with which they collaborated.

- Implementation: refers normally to the extent to which a programme was implemented as intended. However, a blueprint for implementation was not provided, only that they had to connect sectors. Therefore, implementation here refers to how CSCs established the connection. Four forms of collaboration were identified in CSCs' network: collaboration around a specific CSC activity, a referral scheme, CSCs' support to an organisation (for example guiding residents or primary care patients towards PA facilities), or organisations supporting CSCs in their work (for example introducing new partners to CSCs).

- Maintenance: refers to the extent to which CSC sustained collaboration with organisations over the years.

The factors reach, adoption, implementation, and maintenance were calculated from the network survey. For each CSC' network the number of organisations were counted to provide an answer on each factor of the RE-AIM framework. Subsequently, these results were disaggregated into the different types of structural embedding and averages were calculated.

Because the analysis of CSCs' network took place during an interview more detailed information was collected on the way the connection between both sector was established. This information is used to describe implementation more specifically. 


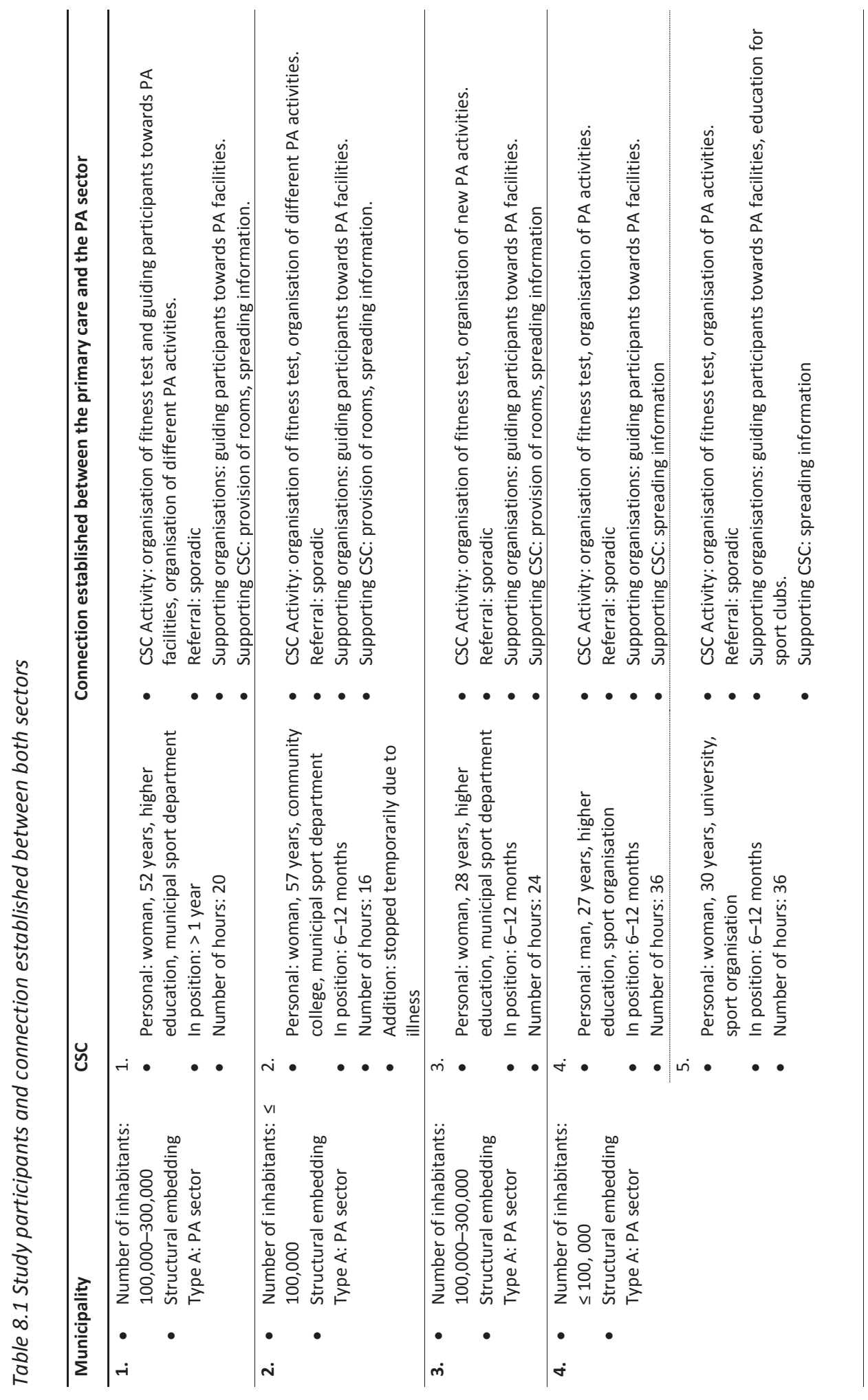




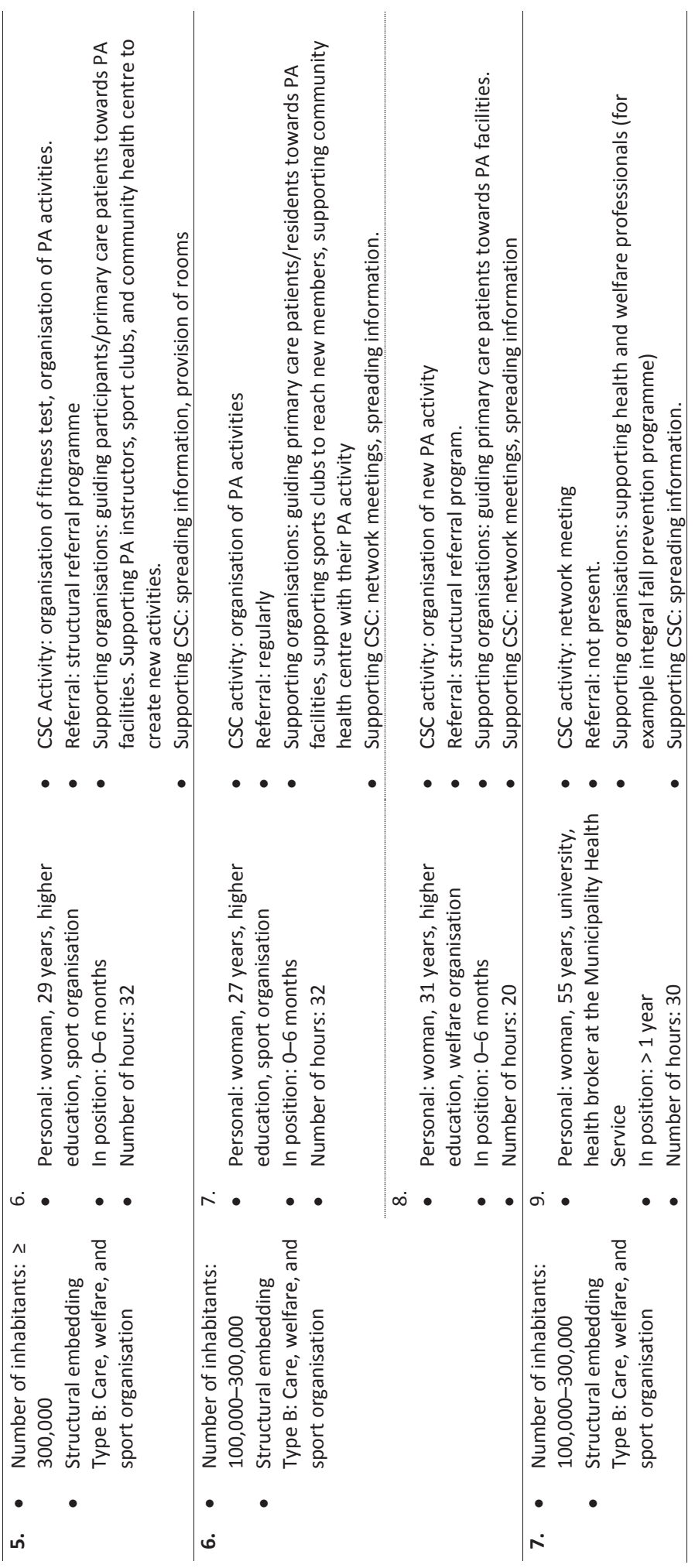




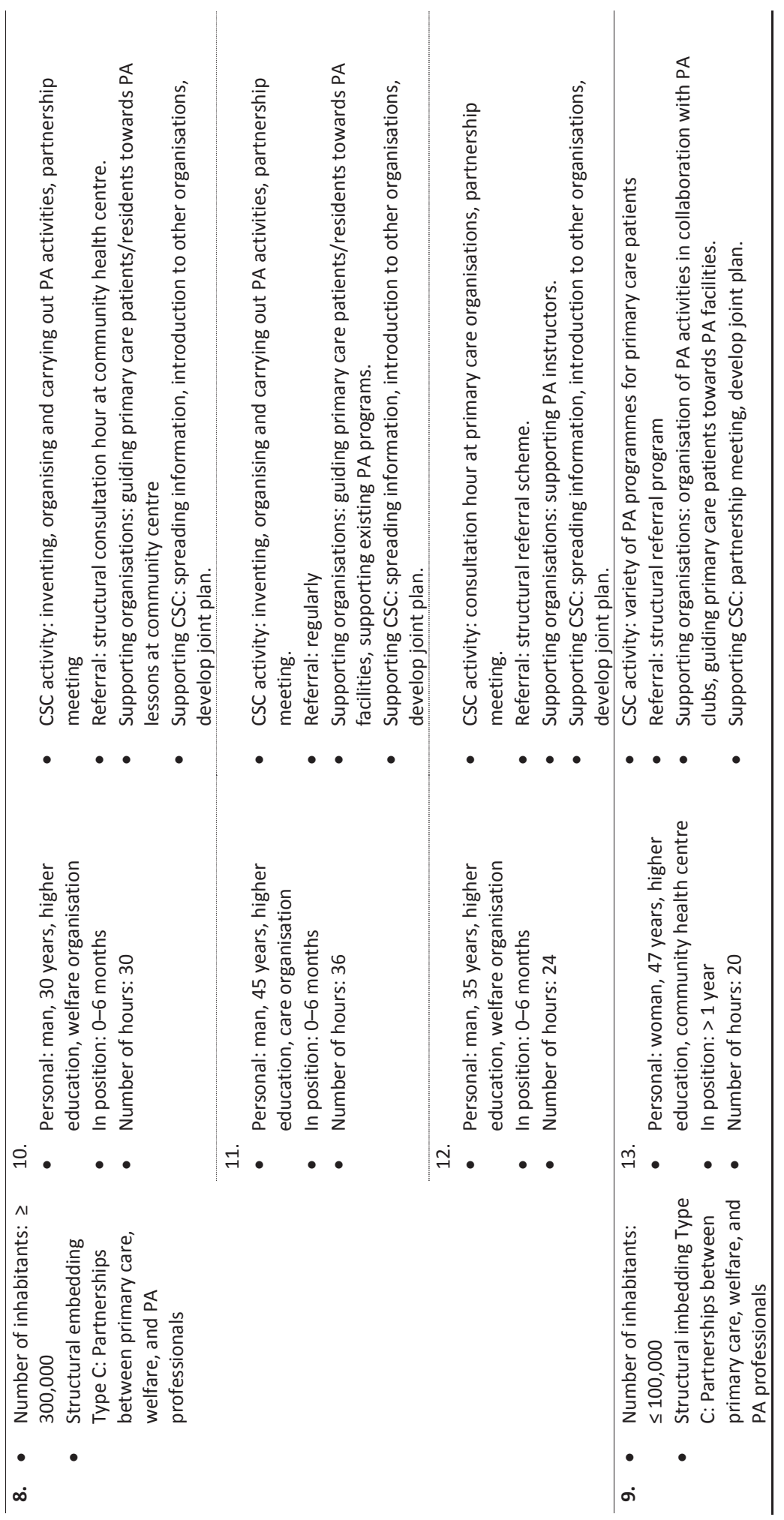




\section{Results}

\section{Reach}

The average number of organisations in the CSCs' network increased over the years. In 2014, CSCs reached on average 12.9 organisations; in 2016 this was 24.5 . All CSC networks consisted of primary care, PA, welfare, and other organisations, like schools, representatives of municipalities, and existing partnerships. Primary care organisations were the most present in the CSC networks over the years (Table 8.2).

No major differences were found between the CSCs' reach of organisations and type of structural embedding (Type A: 22.4, Type B: 27.3, Type C: 24.3). However, minor differences could be seen in the structure of CSCs' networks and type of structural embedding. Type $A$ CSCs' networks consisted mostly of primary care and PA professionals, whereas the network of Type $B$ and Type $C$ were more diverse and consisted also of welfare professionals and other organisations like municipalities and schools (Table 8.2).

\section{Adoption}

The average number of organisations with which CSCs collaborated increased over the years. In 2014, CSCs collaborated on average with 8.3 organisations; in 2016 this was 19.8. Over the years, CSCs collaborated most with primary care professionals (Table 8.2).

Type B CSCs collaborated with more organisations than the other CSCs. Especially in 2016, the average number of organisations with which type B CSCs' collaborated was larger (24.5, $\min =21, \max =32)$ than Type A CSCs $(18.2, \min =12 \max =23)$ and Type C CSCs $(17.3, \min =13$, max=22). Differences could also be found in the structure of the CSCs' network and type of structural embedding. Type A CSCs collaborated mostly with primary care and PA organisations over the years, whereas the other CSCs collaborated with a different range of organisations: primary care, PA, welfare, and other organisations like schools, community centres, and existing partnerships. 


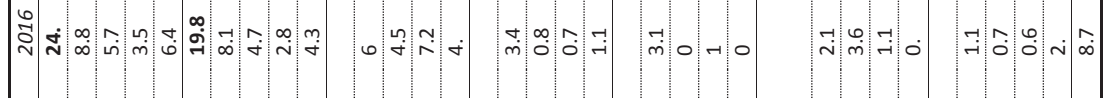

9.

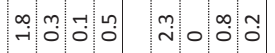

ㄱ:m:

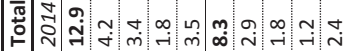

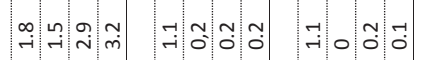

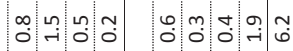

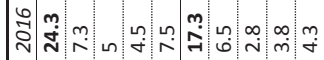

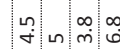

ㄴํ의 $m$

40,40

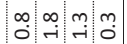

HIIG

站

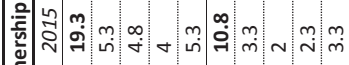

ilm

i.

$m$ min

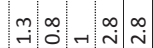

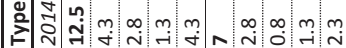

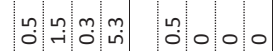

ก:

0.00

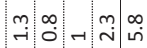

亲

$m$

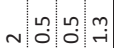

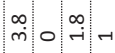

$\operatorname{lin}\left(\begin{array}{lll}\infty \\ m\end{array}\right.$

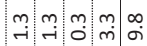

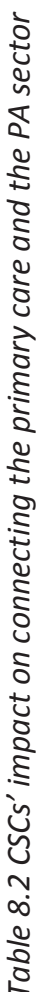

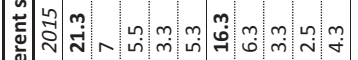

$\ln n$ h n h

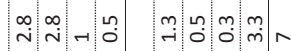

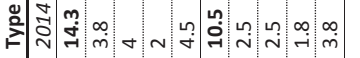

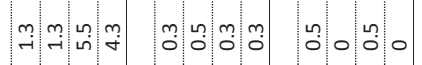

:

$\infty: \infty: m: \infty$

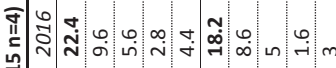

ind

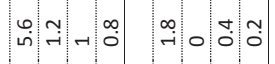

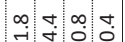

$0,0,0 \frac{1}{0}$

产部 N

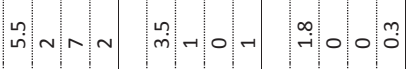

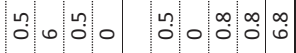

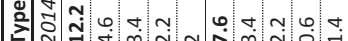

n.

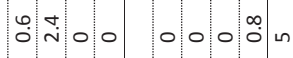

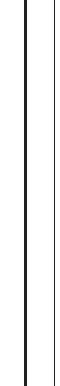

$=\frac{1}{0}$

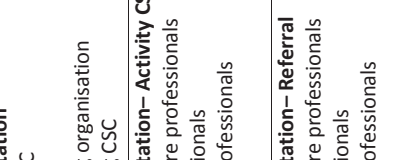




\section{Implementation}

During the study period, all CSCs established a connection between the primary care and the PA sector. Table 8.1 provides detailed information on the established connection.

Differences could be distinguished in how the connection between both sectors was established and type of structural embedding (Figure 8.1 and Table 8.22).

Type A CSCs established a connection between both sectors mostly by organising fitness tests to reach residents and guide them towards local PA facilities (Table 8.1). Type A CSCS collaborated thus mostly with other organisations around their own activities (8.6, $\mathrm{min}=5$, $\max =12$ ) or supported organisations with their activities $(7.4, \min =5, \max =10)$. To a lesser extent, these CSCs collaborated with primary care and welfare professionals around the referral of the target group $(2.4, \min =0, \max =8)$ and with organisations that could support CSCs in their work $(2.4, \min =0, \max =4)$.

Type B and C CSCs established the connection between both sectors in different ways. CSCs organised their own PA activities, implemented a structural referral scheme, supported PA and primary care organisations, or organised network meetings (Table 8.1). They thus collaborated with the professionals around all identified activities: their own activities (Type B: 4.3, $\min =1$, $\max =7$; Type C: $4.5 \min =3, \max =7$ ), referral (Type B: 6.5, $\min =0$, $\max =18$; Type C: 5 , $\min =2, \max =8$ ), supported organisations with their activities (Type B: 10.5, $\min =1$, $\max =19$; Type $C$ : $3.8, \min =1, \max =7)$, and had professionals in their network who supported CSCs with their work (Type B: 6, $\min =4$, $\max =8$; Type C: $6.8, \min =1, \max =11$ ).

The difference in professionals' role in the established connection and type of structural embedding related to the way the connection between both sectors was established. Type A CSCs collaborated mostly with primary care and welfare organisations around their own activities $(6.6, \min =3, \max =10)$ and supported mostly PA organisations with their activities $(4.4, \min =1, \max =7)$. The other CSCs collaborated mostly with primary care and welfare organisations around the referral of their patients (Type B: 5.6, $\min =0, \max =15$; Type $C$ : 5 , $\min =2, \max =8$ ) and supported primary care, welfare, and PA professionals with their activities (Table 8.2). 

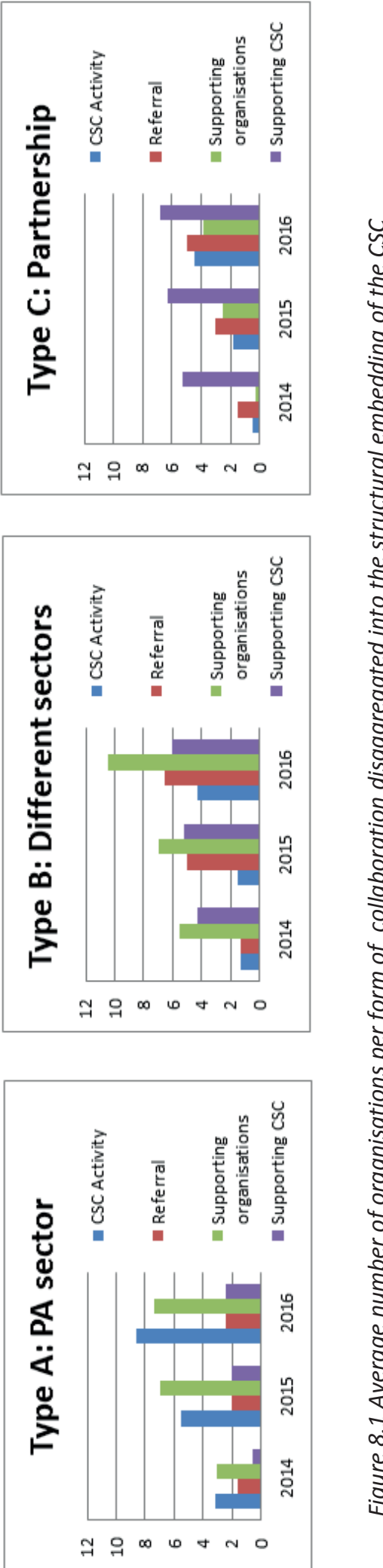

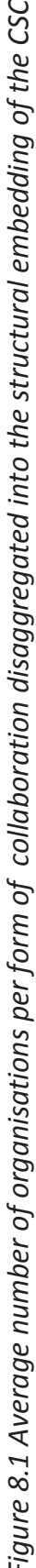




\section{Maintenance}

CSCs sustained collaboration for at least two years with an average of 6.1 organisations $(\min =1, \max =13)$, and for at least one year with an average of 5.5 organisations ( $\min =1$, $\max =13$ ). In 2016, CSCs started collaboration with an average of 8.7 organisations ( $\mathrm{min}=3$, $\max =17$ ). During the two years of this study, an average of 4.1 organisations ( $\min =0, \max =7$ ) stopped their collaboration with the CSC.

Minor differences could be found between type of structural embedding and organisations that sustained their collaboration. Type A CSCs sustained collaboration for at least two years with an average of 5 organisations $(\min =1, \max =13)$ and for at least one year with an average of 6.8 organisations ( $\min =3, \max =10$ ), whereas the other CSCs sustained collaboration for at least two years with an average of $7.8(\min =3, \max =13)$ (type $B)$ or 5.8 organisations $(\min =5, \max =7$ ) (Type $C$ ), and for at least one year with an average 7 organisations $(\min =1, \max =13$ ) (Type $B$ ) or 2.8 organisations $(\min =1, \max =4$ ) (type $C$ ).

\section{Discussion}

In this study, we explored CSCs' impact on connecting the primary care and the PA sector in order to explore which structural embedding is the most promising for CSCs' work in connecting both sectors and guiding primary care patients towards local PA facilities. All types of CSCs had organised a similar network of reached organisations and established a connection between both sectors. The results of this study showed that a structural embedding guided by an integral approach seems the most promising for CSCs' work, although no major differences were found between the two forms of this integral approach (Type B and C CSCs). This structural embedding is the most promising because it is related to: 1 ) the way the connection between both sectors was established and 2) the role of primary care professionals in the connection.

First, type A CSCs established the connection between both sectors mostly around their own activities to promote PA, and supported mostly PA organisations by guiding residents towards their activities. Type B and C CSCs established the connection between both sectors by organising, supporting, and implementing different kinds of activities targeting different kinds of audiences - for example, a structural referral scheme, network meetings, and supporting primary care and PA organisations with their activities. It is plausible that municipalities that adopted an integral approach to structural embed the CSC create a greater impact, because of these different activities targeting different audiences. A minor difference between the two types of the integral approach was noticed. Type B CSCS collaborated on average with more organisations and sustained this collaboration with more organisations than type C CSCs. An explanation for this difference is that the type C CSCs collaborated mostly with the organisations within this partnership.

Secondly, type B and C CSCs collaborated mostly with primary care professionals around the referral of primary care patients, whereas type A CSCs mostly collaborated with these professionals around their own activities in which primary care professionals were involved with the implementation of CSCs' activities. Because of the different roles of primary care professionals, probably a different kind of target group (primary care patients vs. general population) will be reached by CSCs. This is especially true because the connection between the primary care and the PA sector can be characterised as multidisciplinary [21].The connection can mostly be seen as a chain in which CSCs guide the target group towards PA 
facilities after referral by primary care professionals or their own recruitment. The role of primary care professionals in the referral of their patients is therefore important to reach target groups who could benefit from PA. Preliminary results of a study part of the larger project on the reach of target groups, indicated that residents who were reached by CSCS themselves scored better on several health outcomes than residents referred by primary care and welfare professionals towards CSCs.

The differences in impact and type of structural embedding can be understood by the context in which CSCs are working. In a previous study in which we explored CSCs' operational context, it appeared that municipalities that adopted an integral health and PA policy and an embedding of this policy in partnerships at management level, also used an integral approach to structural embed the CSC [22]. These CSCs are thus working in municipalities in which collaboration between different sectors is part of their policy and embedded in other municipal operations, such as the implementation of health and PA promotion programmes by different organisations. In addition, the adoption of an integral approach to structural embed the CSC created support for the connection among primary care, welfare, and PA organisations. For those CSCs, establishing collaboration with especially primary care and welfare organisation was easier than for CSCs working only from the PA sector [16].

In our study, we used Frey et al.'s Level of Collaboration Survey [17]. However, it appeared in the first interview round that it was very hard for CSCs to identify the differences between the levels and often choose one of the extremes. Therefore, in the second and third interview round the scale was not used and changes in the levels were not studied. Nevertheless, the descriptions of the different levels of collaboration used in all interviews caused that CSCs described their form of collaboration with the professionals very precisely. Therefore conducting the Level of Collaboration survey during an interview was useful for gaining a full understanding of the way collaboration between both sectors was established. Especially because at first sight CSCs organised similar networks. In addition, to explore CSCs' impact on connecting the primary and the PA sector, we used the RE-AIM framework. Although normally this framework is used to evaluate intervention impact on individual behaviour change, it appeared that the RE-AIM framework was suitable and useful for analysing the data from the network analysis and for studying the impact of an intervention on intersectoral collaboration. Other studies have experienced the same potential of the REAIM framework to move beyond evaluation of single interventions or settings and to study the impact of multi-faceted real-life initiatives that incorporate multiple interventions targeted to a variety of audiences [19-20]. In line with these studies we used a more pragmatic approach of the RE-AIM framework focussing on utilizing the strengths of different quantitative and qualitative methods to evaluate comprehensively the impact of CSCs' work. Therefore factors of the RE-AIM were operationalised accordingly. Unfortunately proportions of the reach and adoption (\% of number of organisations that was reached by/collaborated with and could be reached by/collaborated with CSCs) could not be calculated due to the absence of an insight of potential partners of CSCs. However as it appeared that all types of CSCs had a similar network, more interesting to know was, as we have studied in the factor implementation, how CSCs established the connection between both sectors, and the role of the organisations in this connection.

As far as we know, this is a first study to explore the impact of a broker role on connecting the primary care and the PA sector. Therefore, a first insight on this topic was presented in this study. This insight is relevant for policymakers, municipalities, and organisations working 
on connecting the primary care and the PA sector. The results of this study implicate that a blueprint to instruct municipalities to adopt an integral approach to structurally embed CSCS may be necessary to successfully connect both sectors and to reach the desired outcomes. Other studies, part of the larger project, need to reveal the impact of the CSC on stimulating PA of residents, and whether using an integral approach to implement the CSC funding is indeed the most promising way to promote PA among the target group of primary care patients.

\section{Study's strength and limitations}

By following 13 CSC in their work for two years, we gained an in-depth insight into the CSCs' impact on connecting the primary care and the PA sector; this is valuable for further studies on CSCs' impact. However, some limitations need to be taken into account when these results are being interpreted. In order to explore CSCs' impact on establishing a connection between both sectors, we used self-reported results. CSCs were asked during the interviews to elaborate on their network partners and their role. It is possible that the CSCs did not give a complete overview of their network or that they were overly optimistic about their established connection and the role of the organisations in this connection. However, networks were checked with CSCs, and they could provide additional information after the interviews were conducted.

This study was conducted among a small population of CSCs, making it hard to formulate firm conclusions about the impact of the CSC on improving intersectoral collaboration. However, at the start of this project, not much was known of the CSC function and therefore an in-depth insight and an exploration of the CSC role is more valuable and necessary at this time.

\section{Conclusion}

This study explored CSCs' impact on connecting the primary care and the PA sector. Although, all CSCs established a connection between both sectors, differences in impact were found between CSCs structural embedded at the PA sector and CSCs structural embedded according to an integral approach . The results of this study suggest that using an integral approach to structural embed the CSC is more promising to reach the desired outcomes. Whether CSCs can really reach the desired target group, improve the target groups' PA level and health needs to be further studied. 


\section{References}

1. Kahn EB, Ramsey LT, Brownson RC, Heath GW, Howze EH, Powell KE, Stone EJ, Rajab $\mathrm{MW}$, Corso, P. The effectiveness of interventions to increase physical activity. A systematic review. American Journal of Preventive Medicine 2002,22(4), 73-107.

2. Warburton DE, Nicol CW, Bredin SS. Health benefits of physical activity: the evidence. Canada Medical Association Journal 2006,174, 801-809.

3. Hildebrandt VH, Chorus AMJ, Stubbe JH Trend report on physical activity and health 2010/2011. Leiden: TNO; 2013.

4. Eakin EG, Glasgow RE, Riley KM. Review of primary care-based physical activity intervention studies. Family Practice 2000, 49(2),158-68

5. Casey MM, Payne WR, Eime RM. Partnership and capacity-building strategies in community sports and recreation programs. Managing Leisure 2009,14(3):167-176.

6. Casey MM, Payne WR, Brown SJ, Eime RM. Engaging community sport and recreation organisations in population health interventions: Factors affecting the formation, implementation, and institutionalisation of partnerships efforts. Annals of Leisure Research 2009,12(2):129-147.

7. den Hartog F, Wagemakers A, Vaandrager L, van Dijk M, Koelen MA. Alliances in the Dutch BeweegKuur lifestyle intervention. Health Education Journal 2014,73(5):576-587.

8. Cashman SB, Flanagan P, Silva MA, Candib LM. Partnering for health: collaborative leadership between a community health center and the YWCA central Massachusetts. Journal of public health management and practice : JPHMP 2012,18(3):279-287.

9. Foley M, Frew M, McPherson G, Reid G. Healthy public policy: a policy paradox within local government. Managing Leisure 2000,5(2):77-90.

10. Trinh L, Wilson R, Williams HM, Sum AJ, Naylor PJ. Physicians promoting physical activity using pedometers and community partnerships: a real world trial. British journal of sports medicine 2012,46(4):284-290.

11. Wiles R, Demain S, Robison J, Kileff J, Ellis-Hill C, McPherson K. Exercise on prescription schemes for stroke patients post-discharge from physiotherapy. Disability Rehabilitation 2008,30(26):1966-1975.

12. Leenaars KEF, Florisson A, Smit E, Wagemakers A, Molleman GRM, Koelen MA. The connection between the primary care and the physical activity sector: professionals' perceptions. BMC Public Health 2016,16:1001.

13. Harting J, Kunst AE, Kwan A, Stronks K. A 'health broker' role as a catalyst of change to promote health: An experiment in deprived Dutch neighbourhoods. Health Promotion International 2011,26(1):65-81.

14. Cheadle A, Egger R, LoGerfo JP, Schwartz S, Harris JR. Promoting Sustainable Community Change in Support of Older Adult Physical Activity: Evaluation Findings from the Southeast Seattle Senior Physical Activity Network (SESPAN). Journal of Urban HealthBulletin of the New York Academy of Medicine 2010,87(1):67-75.

15. Leenaars KEF, Smit E, Wagemakers A, Molleman GRM, Koelen MA. Facilitators and barriers in the collaboration between the primary care and the sport sector in order to promote physical activity: A systematic literature review. Preventive Medicine 2015,81: 460-478.

16. Leenaars KEF, Smit E, Wagemakers A, Molleman GRM, Koelen MA. The role of the Care Sport Connector in the Netherlands. Health Promotion International 2016. doi: 10.1093/heapro/daw097 
17. Frey BB, Lohmeier JH, Lee SW, Tollefson N. Measuring collaboration among grand partners. American Journal of Evaluation 2006,27: 383-392

18. Glasgow RE, Vogt, TM, Boles, SM. Evaluating the Public Health Impact of Health Promotion Interventions: The RE-AIM Framework. American Journal of Public Health 1999,89(9), 1322-1327.

19. Sweet SH, Martin Ginis KA, Estabrooks PA, Latimer-Cheung AE. Operationalizing the REAIM framework to evaluate the impact of multi-sector partnerships. Implementation Science 2014,9:74

20. Finch CF, Donaldson A: A sports setting matrix for understanding the implementation context for community sport. British Journal of Sports Medicine 2010,44:973-978.

21. Choi BC, Pak AW. Multidisciplinarity, interdisciplinarity and transdisciplinarity in health research, services, education and policy: 1 . Definitions, objectives, and evidence of effectiveness. Clinical and investigative medicine Medecine clinique et experimentale 2006,29(6):351-364.

22. Leenaars KEF, Velden van der E, Smit E, Wagemakers A, Molleman GRM, Koelen MA. The operational context of the Care Sport Connector in the Netherlands. Health promotion International 2017. doi: 10.1093/heapro/dax 
202 | Exploring the impact of the Care Sport Connector in the Netherlands

\section{Appendix}




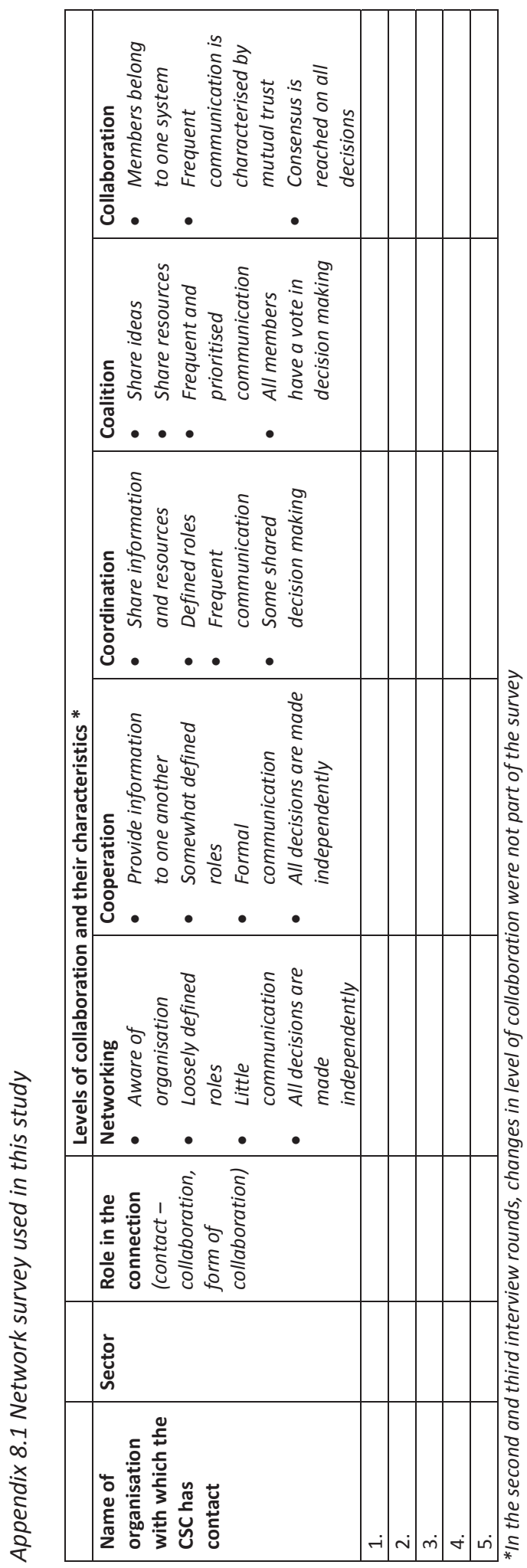




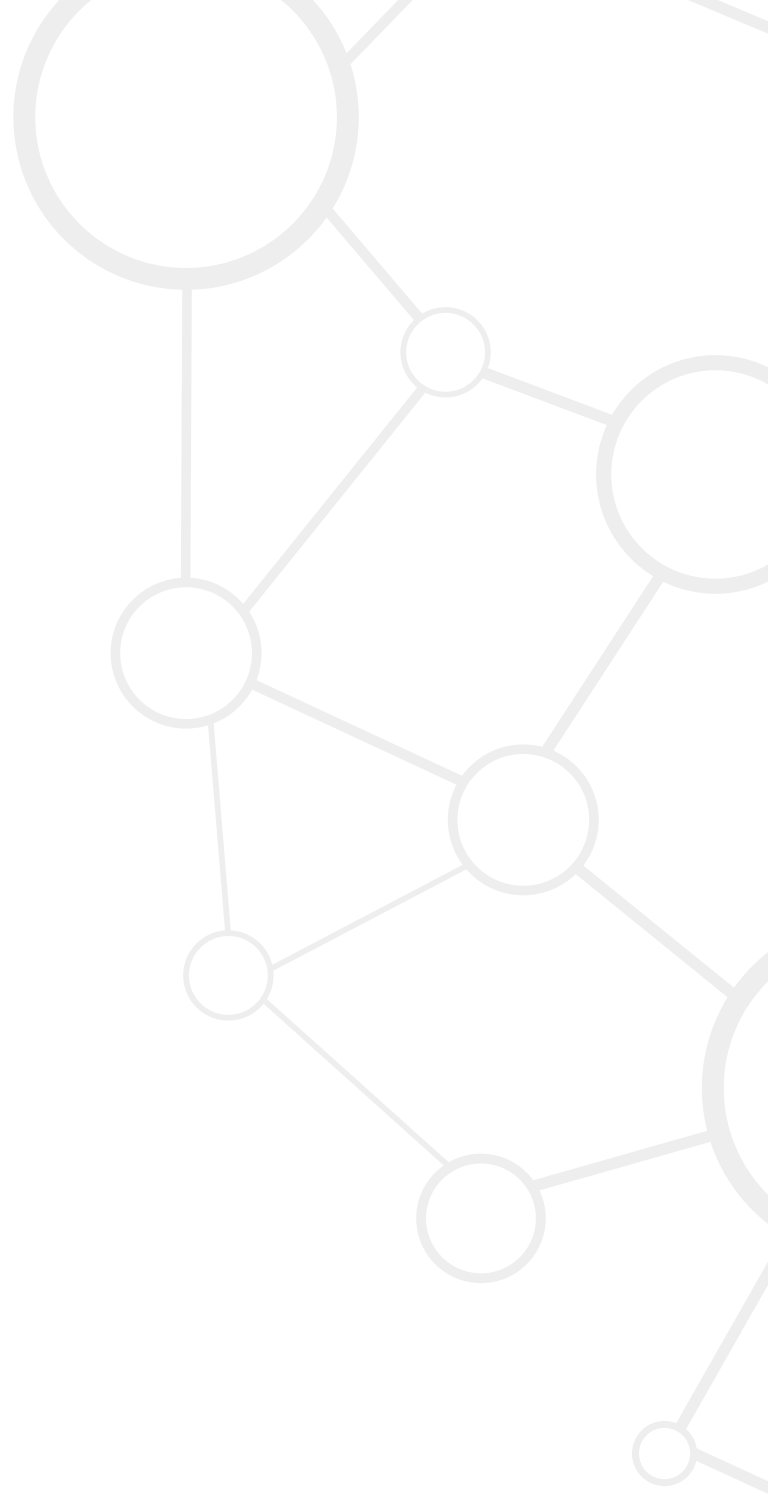




\title{
Chapter 9
}

\author{
General discussion
}




\section{Introduction}

To stimulate physical activity (PA) and guide primary care patients towards local PA facilities, Care Sport Connectors (CSC) (in Dutch Buurtsportcoach), to whom a broker role has been ascribed, were introduced in 2012. This function is new, and to our knowledge no study has yet explored a broker role and its impact on improving intersectoral collaboration between both sectors. The overall aim of this thesis was to explore CSCs' role and impact in connecting the primary care and the PA sector. Therefore, four research questions were formulated. To study the processes that contribute to the connection between the primary care and the PA sector (Q1), four studies were conducted from different perspectives - CSCs, professionals, and policymakers - and on different levels - policy and community level. First, we reviewed the literature to identify collaborative initiatives between the primary care and the PA sector to promote PA and to identify facilitators and barriers in these initiatives (Chapter 3). Secondly, using interviews, we explored how CSCs perceived their role when they initially started their function (Chapter 4) and how they fulfilled their role over time (Chapter 5). In addition, the way CSCs established a connection between the primary care and PA sector and their perceived barriers and facilitators in this connection were identified. And finally, professionals' perceptions of CSCs and the connection between the primary care and PA sector were explored using focus groups with CSCs' networks (Chapter 6). In this study, perceived barriers to, and facilitators of, the connection between both sectors were identified from professionals' point of view. To study the conditions at national and local level that facilitate or hinder CSCs in connecting both sectors (Q2), the operational context of CSCs was studied, based on a theoretical framework that was developed and used for a document analysis of policy documents, a questionnaire among policymakers, and group interviews with policymakers (Chapter 7). Impacts mediated by CSCs and perceived societal benefits for the municipality, neighbourhood, and local residents (Q3) were studied, using an adapted RE-AIM framework to explore CSCs' impact in connecting the primary care and the PA sector (Chapter 8 ). In addition, the studies that explored the CSC role and professionals' perceptions of it contributed to an insight into conditions at national and local level that facilitate or hinder CSCs and into impacts mediated by CSCs. An overview of the main findings is given in Table 9.1.

This chapter summarises the main findings in line with the first three research questions formulated to explore CSCs' role and impact in connecting the primary care and the PA sector, and reflects on these main findings. To translate the lessons learned into suggestions that have the potential to advance health promotion theory and practice (Q4) and thereby answer the fourth research question, we reflect on methodological considerations and the implications for health promotion theory and practice (Q4). Finally, we provide conclusions and implications for further research. 


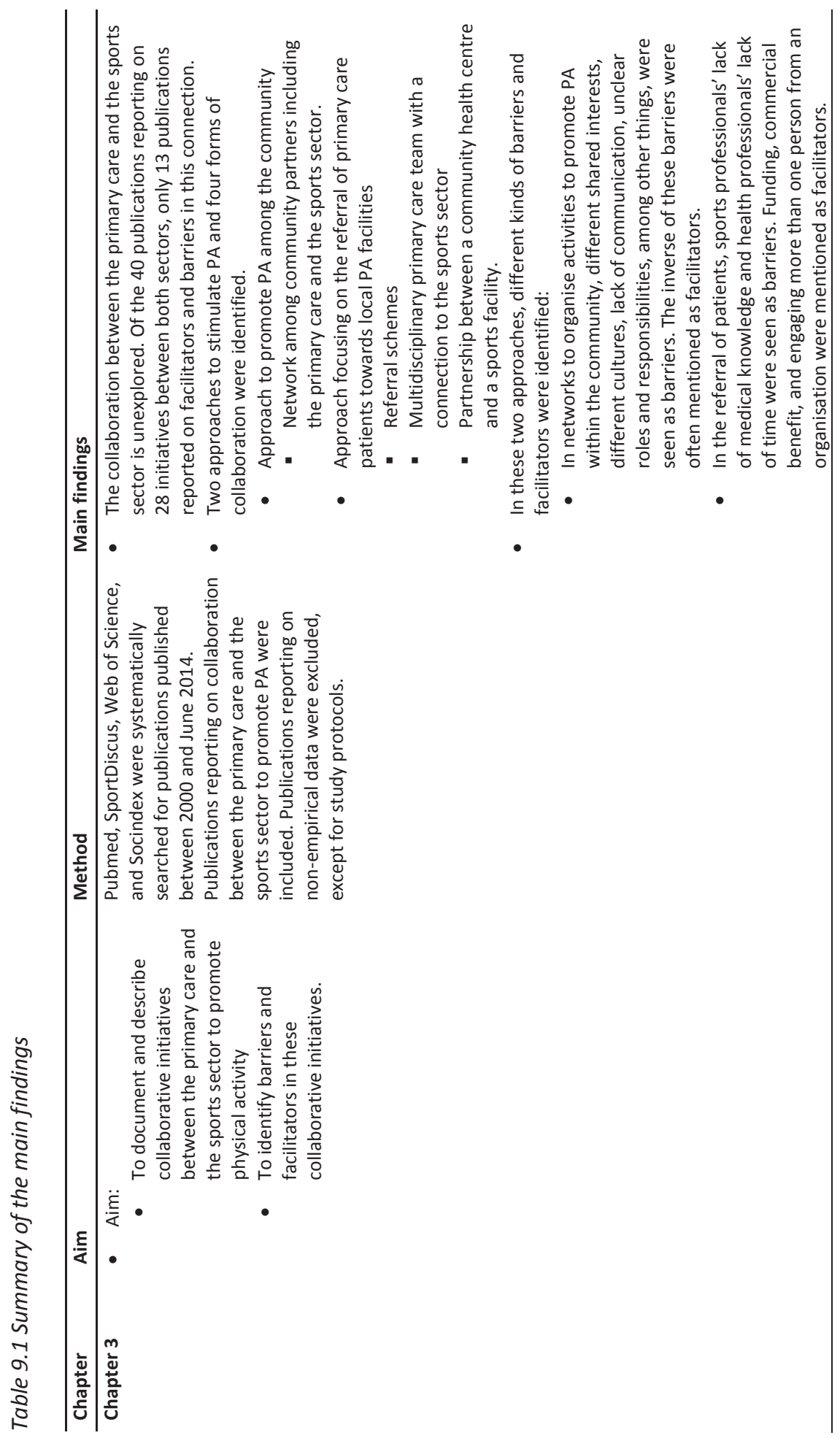




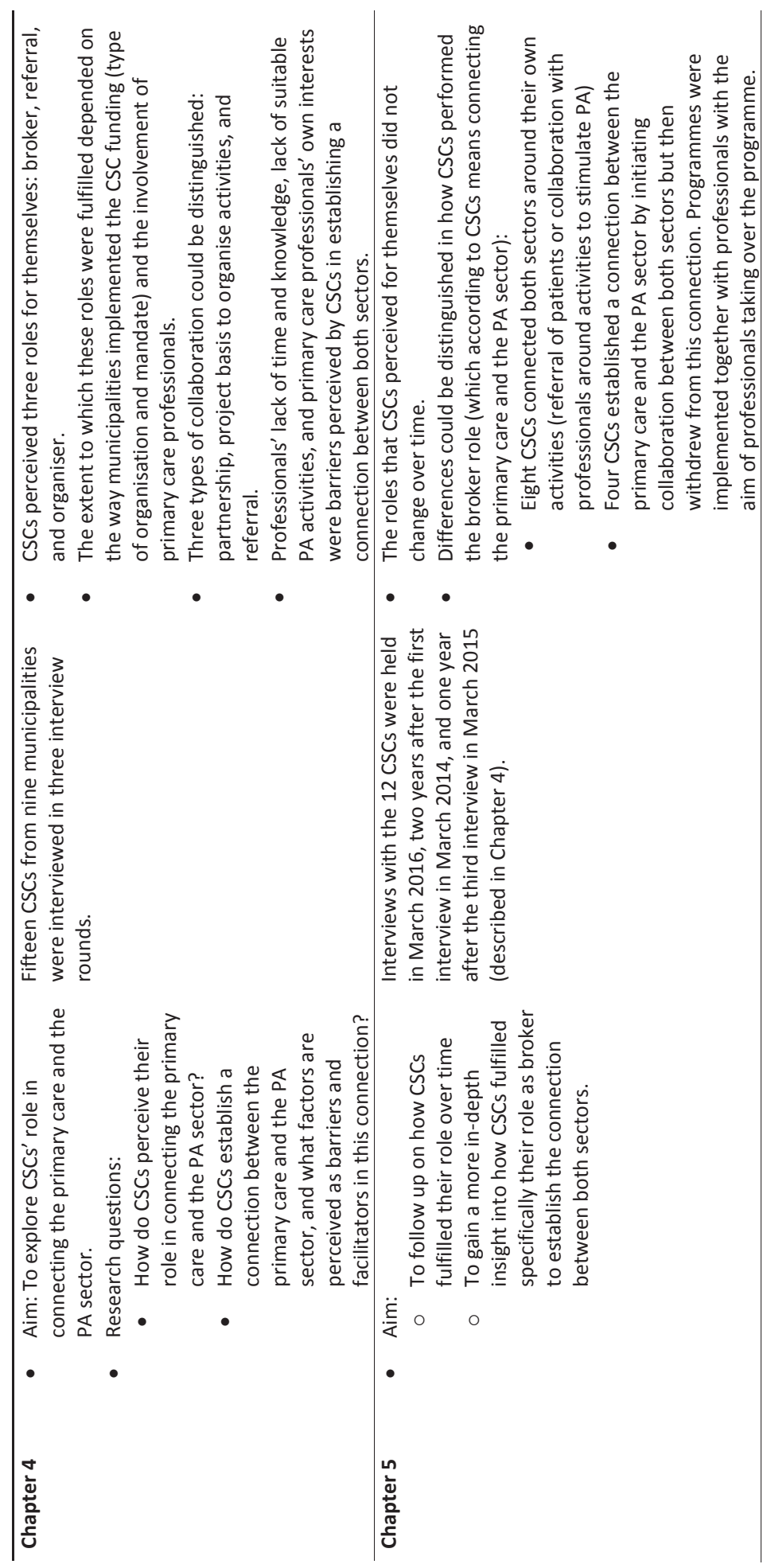




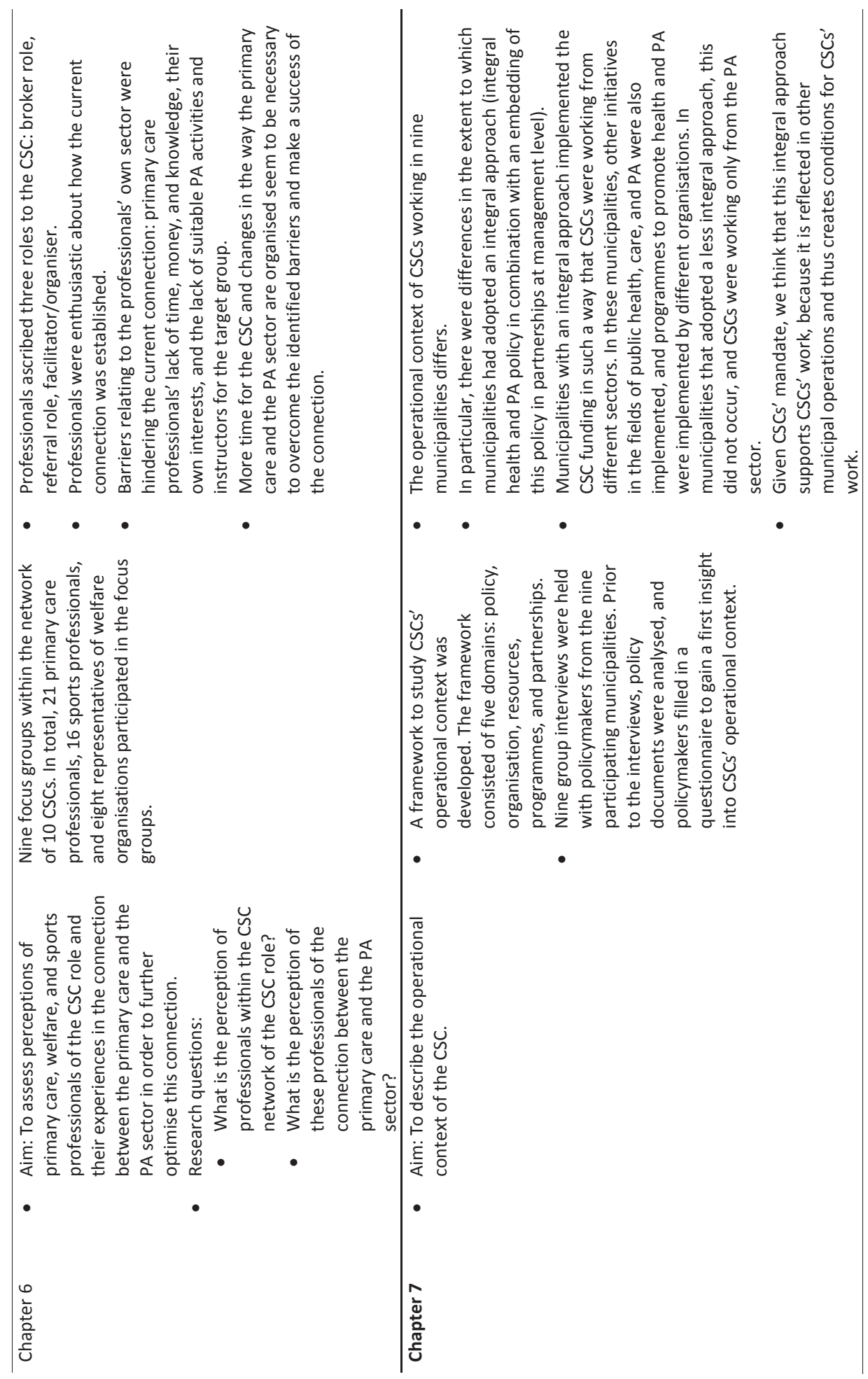




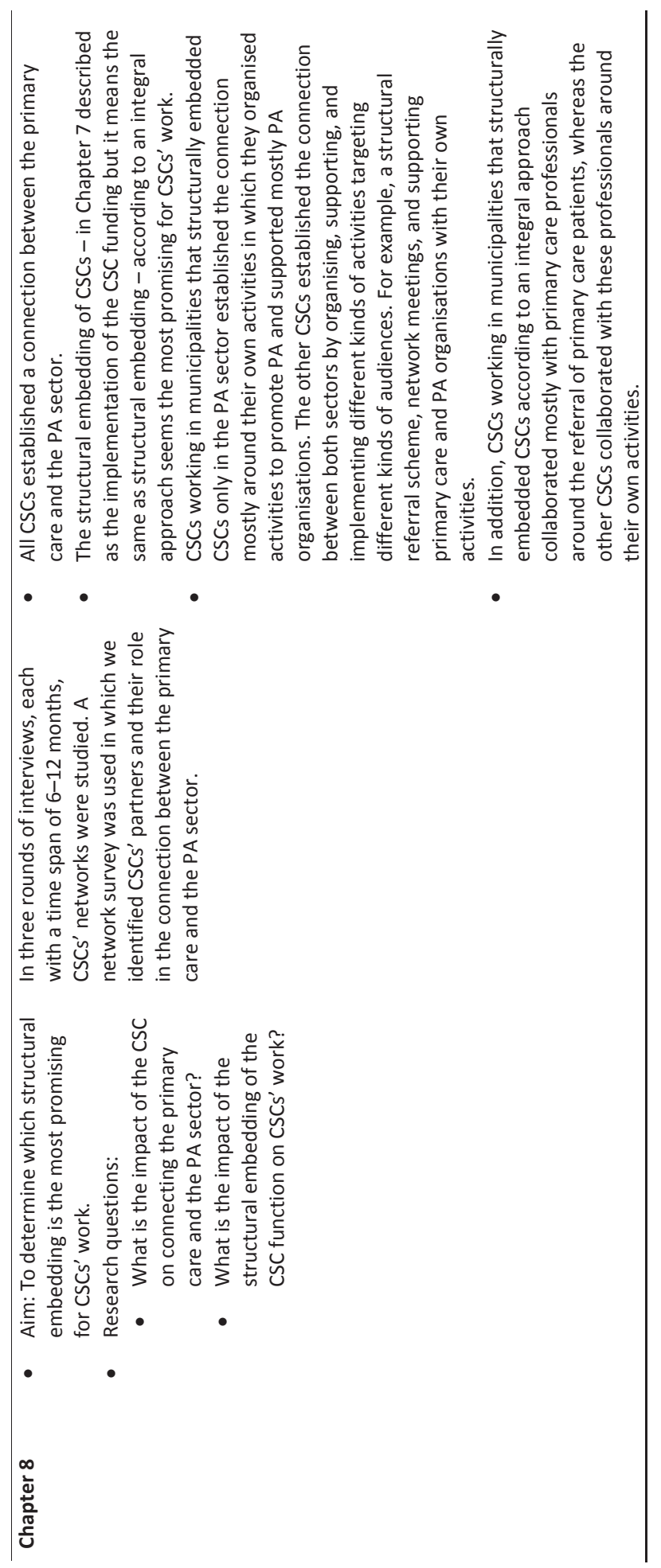




\section{Summary of the main findings}

\section{Q1: Processes that contribute to the connection between the primary care and the PA sector}

Four studies from different perspectives provided insights into: 1) the structure of the connection between the primary care and the PA sector, 2) the role of the CSC in this connection, and 3) perceived barriers and facilitators in this connection.

\section{Structure of the connection between the primary care and the PA sector}

Our review study on initiatives between the primary care and the PA sector (in Chapter 3 formulated as sports sector but reflecting the same definition of the PA sector as in the rest of the thesis) identified two approaches to stimulating PA: 1) PA promotion among the community and 2) referral of primary care patients towards local PA facilities (Chapter 3 ). In these two approaches, four different forms of collaboration between the primary care and the PA sector were identified. In the community approach, one form of collaboration was identified: a network among community partners including the primary care and the PA sector. In the second approach, referral of primary care patients towards local PA facilities, three forms of collaboration were identified: referral scheme, multidisciplinary primary care team with a connection to the PA sector, and a partnership between a community health centre and a PA facility.

The two approaches, PA promotion among the community and referral, as identified in our literature review were also used by CSCs (Chapter 4). CSCs set up two forms of collaboration structures: 1) project basis comparable to the community approach and 2) referral. In the project basis approach, CSCs organised activities in collaboration with professionals. Most often, fitness tests were organised and CSCs guided participants after the fitness test towards local PA facilities. In the referral approach, CSCs collaborated with primary care and welfare professionals. These professionals referred their patients/clients to CSCs, and subsequently CSCs guided these patients towards PA facilities.

\section{The role of the CSC in the connection between the primary care and the PA sector} CSCs ascribed three roles to themselves: 1) broker, 2) referral, and 3) organiser/facilitator. These roles did not change over time and were related to the established collaboration structures by CSCs (Chapters 4 and 5). CSCs fulfilled the broker role, which they described as stimulating collaboration between the primary care and the PA sector, by fulfilling the referral and the organiser role. CSCs differed in how they fulfilled their broker role. Most CSCs connected both sectors around their own activities (referral or organisations of activities) and therefore continued their involvement, whereas other CSCs stated that they withdrew after they had initiated collaboration between both sectors. In the referral role, CSCs guided residents or primary care patients, depending on the recruitment method, towards local PA facilities. In the organiser and facilitator role, CSCs organised PA activities, fitness tests, and supported primary care, PA, and/or welfare organisations with their activities. Primary care, welfare and PA professionals ascribed the same roles to the CSC. They would like to see CSCs stimulating collaboration between both sectors, primary care professionals referring patients to CSCs and CSCs guiding these patients towards PA facilities, CSCs providing primary care and welfare professionals an insight into the PA offer and supporting PA professionals with organising new PA activities (Chapter 6). 


\section{Barriers and facilitators in the connection between the primary care and the PA sector}

Barriers and facilitators in the connection between the primary care and the PA sector were identified in the literature (Chapter 3), in the interviews with CSCs (Chapter 4), and in focus groups with professionals (Chapter 6 ). The insights from these studies resulted in barriers and facilitators on different levels: barriers and facilitators related to the system, to the primary care and the PA sector, and to the collaboration between both sectors. Table 9.2 provides an overview of the identified barriers and facilitators at these different levels. In the connection between the primary care and the PA sector as established by CSCs, professionals perceived barriers related to the system that hindered CSCs from connecting both sectors: a lack of remuneration for preventive work, and municipal health and PA policy (stopped funding for PA activities). In addition, professionals and CSCs perceived both barriers and facilitators related to the primary care and the PA sector that hindered the collaboration between both sectors. Perceived barriers were a lack of knowledge and time on the part of primary care and PA professionals (in chapter 6 formulated as sport professionals but reflected the same group of professionals as in the rest of the thesis), primary care professionals' own interests, a lack of suitable PA activities for the target group (especially those at sport clubs), and a lack of adequate PA instructors. The barriers related to the system probably affect the primary care and the PA sector and can therefore be considered as an explanation for the perceived barriers related to the sector in which professionals are working.

The barriers and facilitators as perceived by professionals and CSCs were similar to the barriers and facilitators identified in our literature review regarding collaborative initiatives in the primary care setting. In these initiatives, barriers related to the system and to the sector in which primary care and PA professionals are working were also identified, like the uncertainty about funding, PA professionals' lack of medical knowledge, and primary care professionals' lack of time. In our literature review, barriers related to the collaboration between both sectors, like differences in cultures and interests, were also identified. However, these kinds of barriers were not perceived by CSCs and professionals in our study. It is worth noting that several barriers, identified in both our literature review and in the interviews and focus groups, are the inverse of the facilitators. So, when there was a lack of funding, this was mentioned as a barrier, whereas the availability of funding was mentioned as facilitator of the connection between the primary care and the PA sector. 


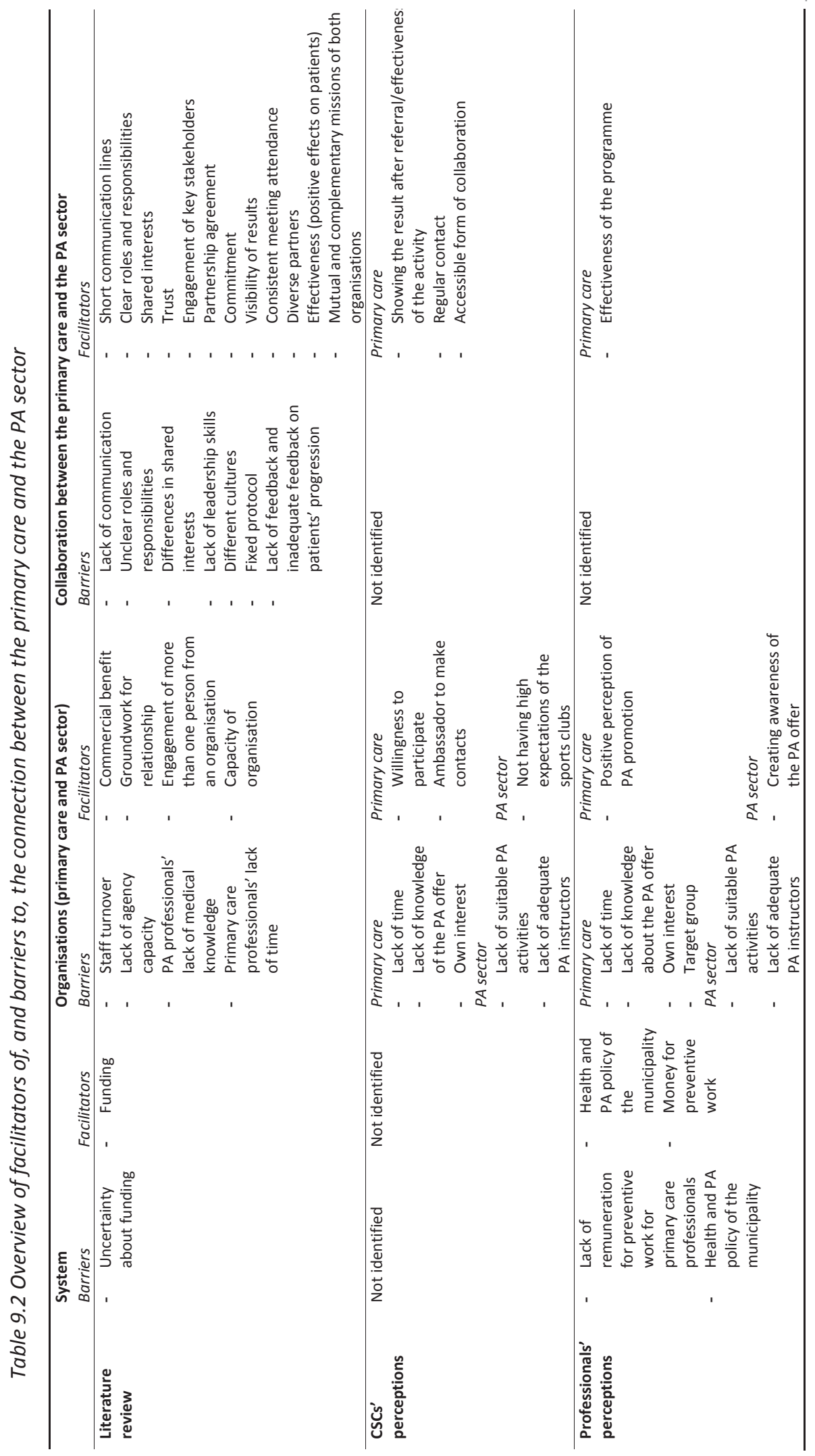




\section{Q2: Conditions at national and local level that facilitate or hinder CSCs}

Conditions at national and local level that facilitate or hinder CSCs in connecting the primary care and the PA sector were identified in different studies. Interviews with CSCs (Chapters 4 and 5) identified conditions at both national and local level, and in the study in which we described CSCs' operational context (Chapter 7), local conditions were identified.

At national level, the continuity of the CSC funding seems to be a prerequisite for the preservation of the connection established between both sectors (Chapter 5). CSCs fulfil an active role in the connection (organisation of activities or referral), and therefore CSCs stated that the funding must be continued. If the funding is continued, the CSC role and therefore also the connection established will be maintained (Chapter 5).

To study conditions at local level that facilitate or hinder CSCs in connecting the primary care and the PA sector, CSCs' operational context was described (Chapter 7). The results showed that the operational context of CSCs differed - in particular, the extent to which municipalities had adopted an integral approach. An integral approach consists of an integral health and PA policy in combination with an embedding of this policy in partnerships between health and the PA sector at management level. More specifically, this integral approach is reflected in the implementation of other municipal operations: the structural embedding of CSCs (in Chapter 7 described as the implementation of the CSC funding but it means the same as structural embedding of CSCs); the implementation of other initiatives in the fields of public health, care, and PA; and the availability of health promotion and PA promotion programmes implemented by different organisations.

Municipalities with an integral approach structurally embedded CSCs in such a way that CSCs were working from different sectors (e.g. care, welfare, PA organisation) or were part of a partnership between primary care, welfare and PA professionals. In these municipalities, other initiatives in the fields of public health, care, and PA were also implemented, and programmes to promote health and PA were implemented by different organisations. In municipalities that adopted a less integral approach, this did not occur, and CSCs were working only from the PA sector. CSCs in these municipalities were mainly responsible for the connection between the primary care and the PA sector. Given the CSC mandate, we think that the integral approach may be more supportive of the CSCs' work than other approaches are, because it is reflected in other operations of the municipalities and thus creates favourable conditions for the CSCs' work. The question of whether this context is more supportive is addressed by research question Q3.

\section{Q3: Impact mediated by CSCs and perceived societal benefits for the municipality, neighbourhood, and local residents}

The impact mediated by CSCs and perceived societal benefits were demonstrated by interviews with CSCs (Chapters 4 and 5), focus groups with professionals within CSC networks (Chapter 6 ), and an analysis of CSC networks over the years (Chapter 8). The results together showed the added value of the CSC for the municipality, neighbourhood, and residents. This was described in terms of: initiating collaboration between both sectors by, for example, organising network meetings, organising activities for the target group, implementing structural referral schemes and guiding primary care patients towards local PA facilities after referral, and supporting PA professionals with their activities (Chapter 4). In addition, CSCs were seen by primary care, welfare, and PA professionals as an important link in the connection between the primary care and the PA sector (Chapter 6). 
CSCs' networks in 2014, 2015, and 2016 were analysed to explore CSCs' impact in connecting the primary care and the PA sector (Chapter 8). All CSCs had organised a network of primary care, welfare, and PA professionals, and had established a connection between both sectors. CSCs organised activities (e.g. fitness test, introduction lessons, PA activities), collaborated with primary care and welfare professionals for the referral of their patients, supported organisations with their activities, and collaborated with organisations that could support them in their work. Over the years, the number of organisations with which CSCs collaborated increased on average from 8.3 organisations in 2014 to 19.8 organisations in 2016. However, we identified differences between the way in which CSCs were structurally embedded and the connection established between both sectors. CSCs who were structurally embedded in the PA sector collaborated mostly with primary care, welfare, and PA professionals to organise activities as a way to stimulate PA among residents. CSCS working in municipalities that structurally embedded the CSC according to an integral approach (see Q2) collaborated mostly with a variety of professionals by supporting their activities and by implementing a structured form of referral. Overall, the structural embedding of the CSC according to an integral approach seems the most promising way to reach the desired outcomes (guide primary care patients towards local PA facilities and connect both sectors).

\section{Reflection on the main findings}

This thesis described a study on the broker role in connecting the primary care and the PA sector. Prior to this study, the connection between these sectors, the performance of their collaborative initiatives, and the use of a broker role to establish this connection were unexplored (Chapter 3). Although some studies have focused on the broker role in the field of health promotion [1-6], to our knowledge this is the first longitudinal study to research this role comprehensively, using different methods and including different perspectives. The results of this thesis contribute three important insights. First, the structure of the connection between the primary care and the PA sector established by CSCs can be characterised as a chain approach. Secondly, barriers related to the sectors are currently hindering this connection. Thirdly, an integral approach to structurally embed CSCs seems to be an important condition to facilitate the connection between both sectors.

\section{The connection between the primary care and the PA sector: a chain approach}

The structure of the connection between the primary care and the PA sector established by CSCs can be characterised as multidisciplinary [7] and can be seen as a chain in which CSCs guide the target group towards PA facilities after referral by primary care and welfare professionals or after CSCs' own recruitment. CSCs who found it hard to involve professionals in these referral schemes organised activities - mostly fitness tests - in collaboration with primary care, welfare, and PA professionals to recruit the general population and guide them towards PA facilities.

In this chain approach, CSCs fulfilled their role as broker mostly by means of their activities (referral or organiser role). Given primary care professionals' lack of time, knowledge, and money to fulfil a role in PA promotion for their patients, and the mostly voluntary-based PA sector and lack of suitable PA activities for the target group, it seems that someone is needed to initiate, organise, and facilitate a connection between both sectors. By organising this chain approach, CSCs fill the gap that exists between these sectors. In addition, 
according to both CSCs and professionals, the target group is apprehensive of PA, hard to stimulate, and difficult to motivate to become physically active (study II, as described in Chapter 2, provides more insight into the target group and what this mean for PA promotion). Therefore, the CSC role, e.g. implementing a referral scheme, guiding the target group towards PA activities, organising PA activities, and supporting existing PA activities, seems to be appropriate and necessary for the connection between both sectors.

The way CSCs fulfilled their broker role seems to be in line with Burt's description [8]: a broker needs to reach across a structural hole. A structural hole manifests itself between two actors who are non-redundant: that is, between two actors who themselves are not connected [8]. In addition, the way CSCs fulfilled their broker role is in line with other studies exploring the broker role in stimulating intersectoral collaboration in the public health setting. In those studies, it appeared that brokers were positioned between the different actors (Figure 9.1.1) and connected these different actors by facilitating and/or organising services or programmes to stimulate a healthy lifestyle among the general population or specific target groups [4-6]. In studies that explored the broker role in other settings (corporate, public-private partnerships), it appeared that brokers were positioned within a network of different actors (Figure 9.1.2) to facilitate and manage the network of different actors to stimulate collaboration and achieve a common goal (e.g. ensuring that activities and goals are met and implemented, managing the network's time schedules and conflicts and criticism within the network) [9-13]. Therefore, it seems that fulfilling the broker role in a public health setting focuses mostly on organising services and programmes to generate benefits for a third party (e.g. promotion of inhabitants' health), instead of on facilitating and managing networks of actors to collaborate and achieve a common goal. This is a relevant insight because it determines which competences a broker needs in a particular setting

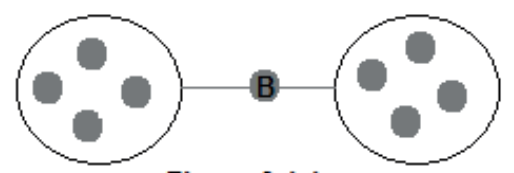

Figure 9.1.1

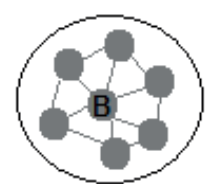

Figure 9.1.2

Figure 9.1 The position of the broker

\section{Barriers at system and sector level hinder the established connection}

In the connection between the primary care and the PA sector, CSCs (Chapter 4) and primary care, welfare, and PA professionals (Chapter 6 ) mostly identified barriers relating to the system and the sectors in which professionals are working. With regard to primary care, a lack of knowledge of PA activities (sector) and a lack of money and time for preventive work (system) were perceived as barriers for the connection between both sectors. These barriers have also been identified in other studies on initiatives aimed at PA promotion in a primary care setting: a lack of time [14-17], lack of remuneration [14,17-19], lack of priority [16-17, 20-22], and lack of knowledge about the PA offer [15, 22-25]. With regard to the PA sector, a lack of suitable activities (sector) and a lack of adequate instructors (sector) were perceived as barriers. Other studies on initiatives aimed at PA promotion among primary 
care patients also identified a lack of suitable PA activities for the target group [26-27] and a lack of adequate instructors [26, 28-20].

It is worth noting that, despite the introduction of the CSC, and especially because this study's population consisted of professionals who were enthusiastic and willing to participate in this connection, the perceived barriers relating to the primary care setting and the PA sector remained the same as identified in other studies [14-28]. It is possible that, over time, the CSC will manage to overcome these barriers, especially because the CSC is a relatively new function and building collaboration structures takes time [27, 31-32]. However, the question remains as to whether the CSC is single-handedly capable of, and responsible for, overcoming these barriers, especially as some of the barriers find their origin at the system level, i.e. a lack of remuneration to primary care professionals for preventive work and a PA sector based mostly on volunteers. Changes are therefore needed the system level.

Prior to the study, it was expected that cultural differences and different sectoral interests would hinder collaboration. This was supported by our review (Chapter 3 ). However, these barriers were not identified in our empirical study (Chapter 6 ). This probably results from the way in which the professionals are collaborating. Because of the multidisciplinary character [7] of the connection between both sectors, professionals work independently on different aspects of the connection. Therefore, barriers relating to their own sector were identified rather than barriers relating to the collaboration between both sectors.

\section{The importance of an integral approach for CSCs and the connection between both sectors}

An integral approach to structurally embed CSCs seemed to influence CSCs' work and subsequently their impact. Table 9.3 provides an overview of the combined results of the studies in which we explored CSCs' operational context (Chapter 7), CSCs' role (Chapters 4 and 5), and CSCs' impact (Chapter 8), for each municipality.

Differences in how CSCs fulfilled the broker role (connected both sector around their own activities or connected both sectors but then withdrew from the connection) cannot be explained by differences in the structural embedding of CSCs (Table 9.3). Nevertheless, the way CSCs were structurally embedded seems to influence which role was mostly fulfilled. Municipalities where CSCs were structurally embedded in the PA sector connected the primary care and the PA sector mostly by jointly organising activities. These CSCs found it hard to involve primary care professionals in referring their patients. Therefore, they fulfilled mostly the organiser role and organised fitness tests to recruit the target group and to guide them towards local PA facilities (Chapter 4). CSCs working in municipalities that adopted an integral approach to structurally embed CSCs (Table 9.3: numbers 5-9) connected both sectors by a variety of activities targeting different audiences, and primary care professionals fulfilled mostly a role in the referral of their patients. Primary care professionals' role in the connection is important because they are in an ideal position to motivate a group of patients who could benefit from PA [33-34].

An integral approach to structurally embed CSCS is therefore likely to create a greater impact: first because of the variety of activities targeting different audiences, which may lead to additional spin-off effects to a broader range of actions and a wider population; secondly because of the referral role fulfilled by primary care professionals, which may result in reaching a target group who could benefit from PA. Whether this integral approach in reality has more impact should be revealed by other studies, part of the larger project, which 
are still ongoing. Preliminary results of a study on CSCs' impact on the individual level have already shown that residents who were referred by primary care and welfare professionals towards CSCs scored significantly worse on different health outcomes than residents reached by CSCs themselves [35].

The differences in type of structural embedding and impact can be understood by the operational context in which CSCS are working. Municipalities that adopted an integral health and PA policy and embedded this policy in partnerships at management level also used an integral approach to structurally embed the CSC (Chapter 7). This was reflected not only in the structural embedding of the CSC but also in other municipal operations, such as other initiatives to connect the primary care and the PA sector and the implementation of health and PA promotion programmes by different organisations. 


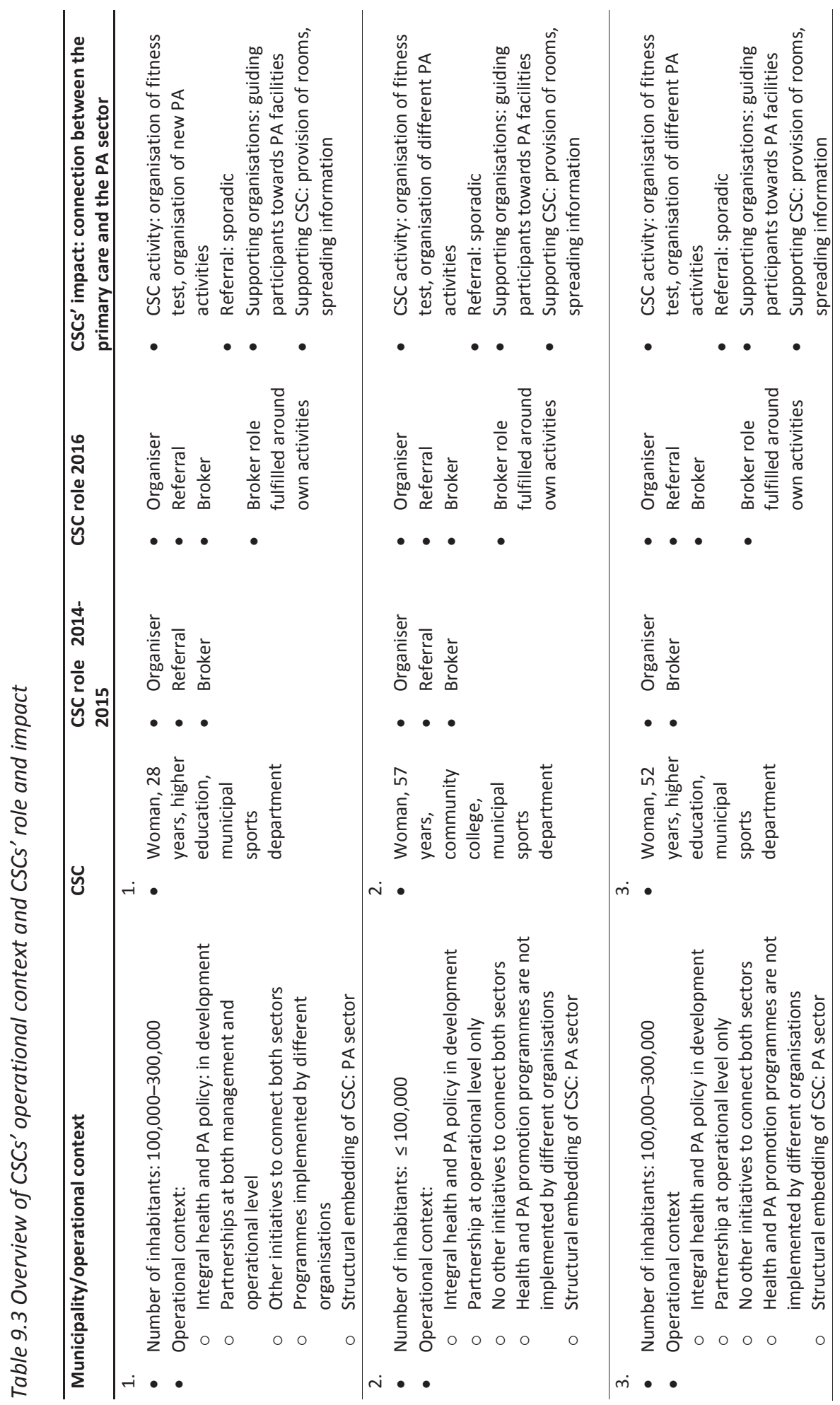




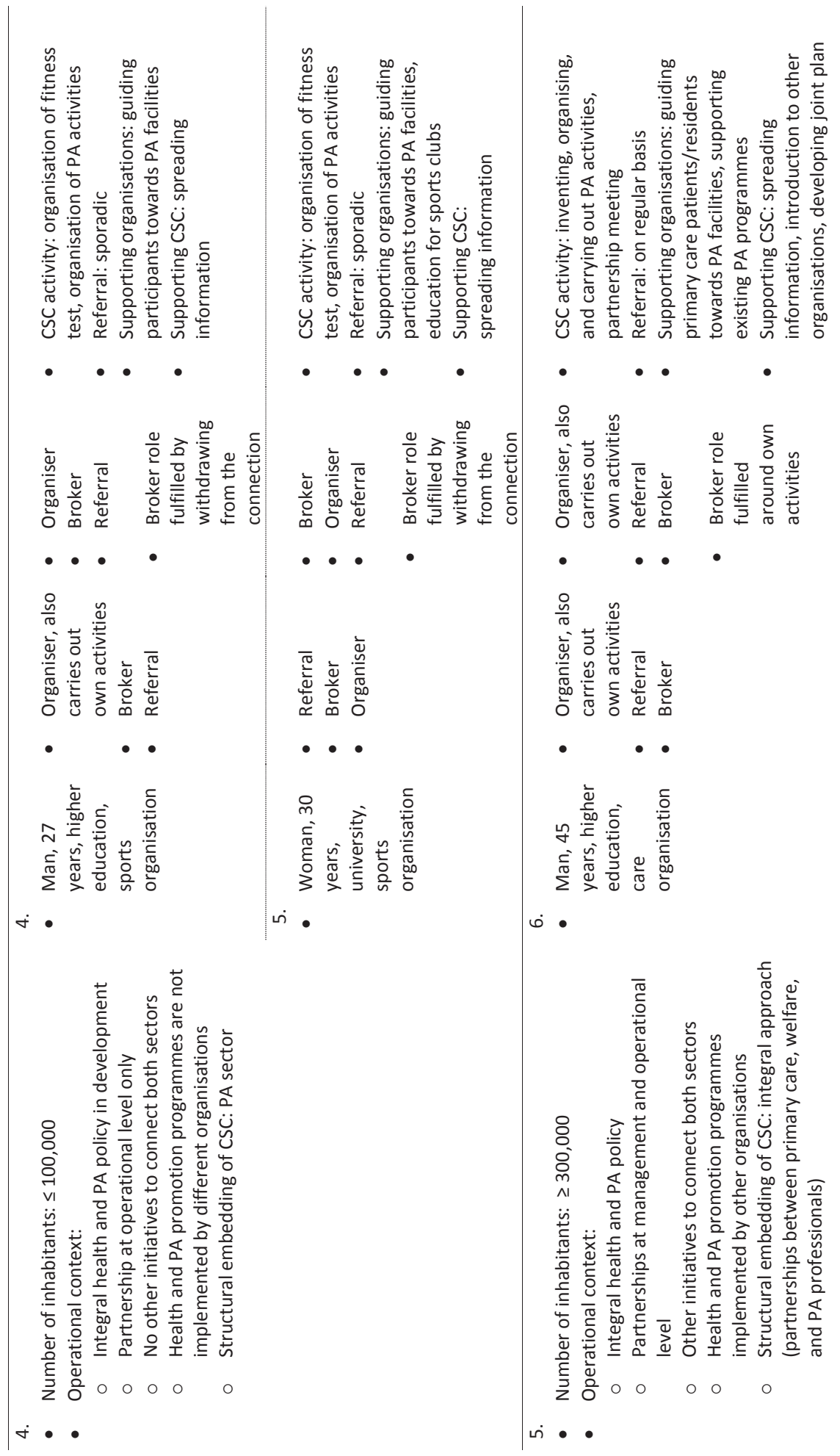



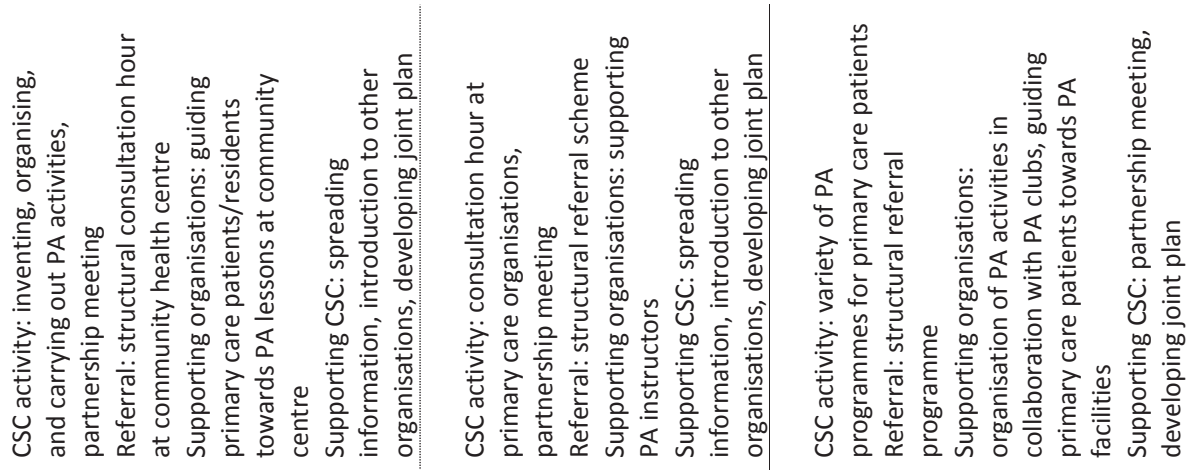

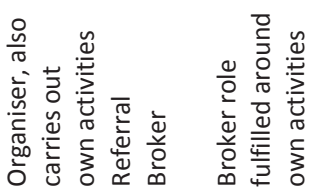
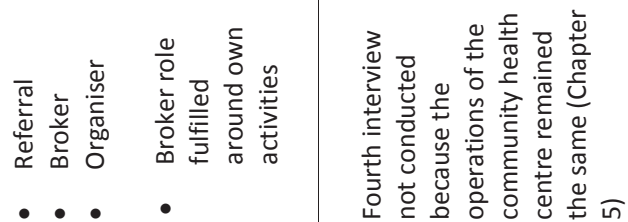

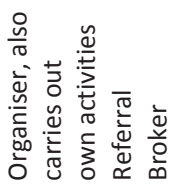

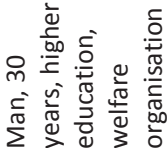

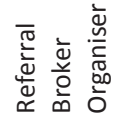

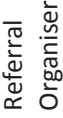

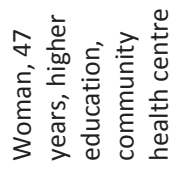

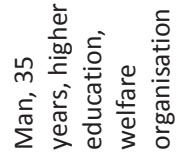

$\infty$.

बं •

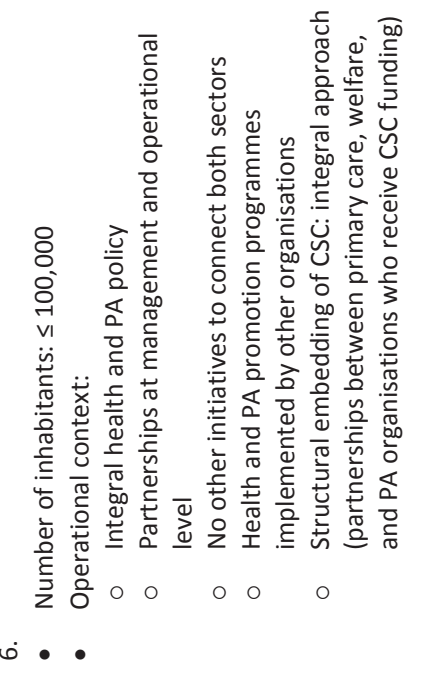




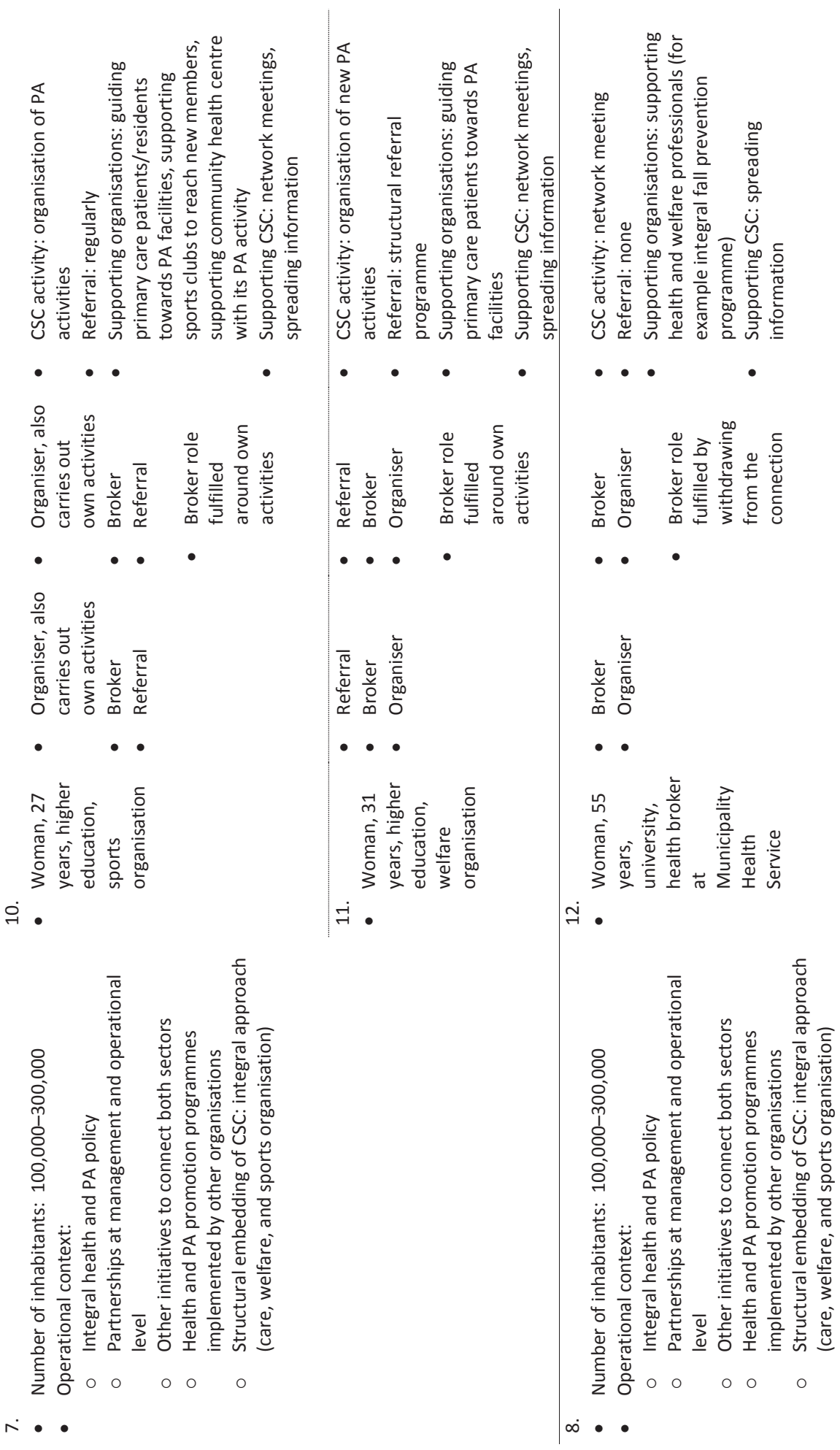




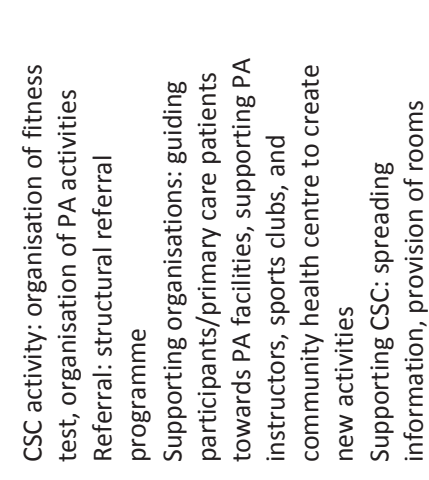

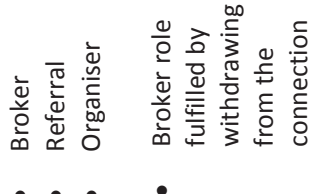

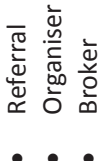

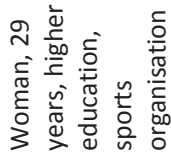

实.

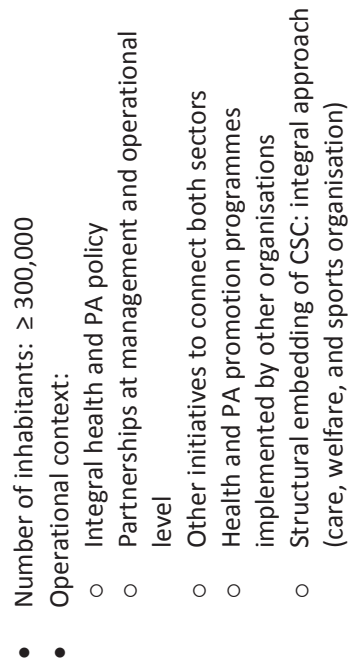




\section{Limitations and strengths of this thesis}

The limitations of this study relate to its qualitative nature and to the challenge of monitoring and evaluating a real-world setting - especially one in which a new function without a blueprint had been recently introduced.

First, to explore CSCs' role and impact, we employed qualitative research methods. Conducting a qualitative study is a limitation in its own right, as qualitative research as a whole has been constantly critiqued for a lack of consensus on assessing its quality and robustness [36]. In addition, it limits the generalisability of this study's results. However, given the lack of knowledge on how CSCs were structurally embedded and how they fulfil their role, a qualitative study was the most appropriate method. The reliability of this study was ensured by using different data collection methods (data triangulation), being consistent in performing the data collection and analysis, and monitoring and documenting changes in methods used [36].

Secondly, no random selection procedures could be applied to select the municipalities and CSCs for this study. When municipalities were being selected, the funding for the NSCs had just become available, CSCs are part of this funding, and no information was available on how this funding was implemented (e.g. target group, sector) in each municipality. It was necessary to enrol the help of project partners' contacts to select municipalities in which CSCs focused on the target group, adults. It is therefore possible that the selected municipalities in our study were working more actively on the connection between the primary care and the PA sector and were more involved and engaged in CSCs than municipalities not participating in this study. However, it is precisely insights from municipalities that are actively working on the connection between both sectors that are useful for improving practice and helping other municipalities that are not yet active. Thirdly, in this study, the fact that we were dependent on data reported by participants themselves could influence internal validity. CSCs were asked during the interviews to elaborate on their network partners and their role. It is possible that the CSCs did not give a complete overview of their network or that they were overly optimistic about their established connection and the role of the organisations in this connection. To describe CSCs' operational context, we were dependent on how information was monitored by policymakers. Unfortunately, not all policymakers monitor their activities and therefore it was not always possible to gain a complete overview of their operations. To limit possible bias, information was checked with CSCs and policymakers, and after the interviews they could provide additional information.

And finally, to include professionals in this study, we were dependent on the professionals who participated in CSCs' networks. It is possible that this study's population consisted of professionals with a more positive attitude towards the CSC role and the connection between both sectors. This could have resulted in more positive perceptions towards the CSC role and CSCs' added value. Nevertheless, professionals critically discussed the CSC role and the established connection. In addition, as part of the larger project, a Delphi study was conducted among relevant stakeholders who were not yet collaborating with a CSC. Professionals who participated in the Delphi study ascribed the same roles to CSCs and mentioned the same barriers in the connection between both sectors [37] as those identified in this study.

Although this study has some limitations, our approach to exploring CSCs' role and impact in the connection between the primary care and the PA sector is also characterised by several strengths: 1) a longitudinal multiple case study, 2) municipalities of different sizes and 
different types of CSCs, and 3) different methods of data collection.

First, our longitudinal multiple case study provides us with an excellent opportunity to gain an in-depth insight into CSCs' role and their impact on connecting both sectors in a real-life setting. To our knowledge, a longitudinal study to explore the impact of a broker role on stimulating intersectoral collaboration between the primary care and the PA sector has not previously been carried out. This study started with 15 CSCs. Two CSCs ceased participating because they resigned their function. Although the number of included CSCs must seem to be a relatively small number, the longitudinal character of the study allowed us to follow these CSCs closely in their work and enabled us to gain an in-depth and comprehensive insight into the CSC role, into the processes that contribute to the connection between both sectors, and into conditions at national and local level that could facilitate or hinder CSCs. This insight is relevant for policymakers, municipalities, organisations, and CSCs to improve and make a success of the connection between the primary care and the PA sector.

Secondly, a strength of this study is the selection of municipalities of different sizes and the selection of different types of CSCs. At the time that municipalities were being selected, as stated in the section on limitations, the funding for the NSCS (CSCs are part of this funding) had just become available, and there was no information on how this funding was being implemented (e.g. target group, sector). Therefore, convenience sampling was used to select municipalities who structurally embedded CSCs with a focus on the target group, adults. Taking into account the region, the size of the municipality, and the way the CSC funding was structurally embedded in the municipality increases the generalisability of the results. In addition, because of this diverse population, a comprehensive picture could be presented of CSCs' role and impact in which we could compare different contexts. This is especially interesting because a blueprint for the CSC funding was not provided. It should be noted that, in this study, we provided an insight into the CSC function only. Other types of NSCS were not part of this study, and therefore the connection between the PA sector and other sectors like education were not studied. The results of this study are therefore only relevant specifically for CSC funding and the connection between the primary care and the PA sector. A third strength of this study is the use of data triangulation, whereby we employed different data collection methods and involved relevant actors in the connection between the primary care and the PA sector. Interviews with CSCs, focus groups with professional within CSCs' networks, analysis of policy documents, a questionnaire and group interviews among policymakers, and a network survey among CSCs were used to study CSCs' role and impact in connecting both sectors. By taking into account relevant stakeholders' perspectives and combining the findings of the different data collection methods, we were able to gain a comprehensive insight into processes that contribute to a connection between both sectors, the CSC role, conditions that facilitate or hinder CSCs, and CSCs' impact. 


\section{Lessons learned for health promotion theory}

Insights from this thesis contribute to advancing health promotion theory. This section reflects on the theory, frameworks, and tools that were intended to be used and that were actually used, and learned lessons for health promotion theory are formulated.

\section{Reflections on theory used in studies I and II}

The idea behind the CSC is that, by connecting the primary care and the PA sector, the target group is stimulated to become more physically active. Therefore, to study CSCs' role and impact in connecting both sectors and on PA promotion, the project as a whole consisted of two studies. The study as described in this thesis focused on CSCs' role and impact in connecting both sectors (study I), and the other study (study II) focused on CSCs' role and impact in stimulating PA among the target group (Chapter 2). In both studies, we adopted the ecological perspective - which emphasises the environmental and policy context of behaviour, while incorporating social and physiological influences [38-40]. The overall project was further based on the Theory of Triadic Influences (TTI) [41] and the Expanded Chronic Care Model (ECCM) [42].

Both TTI and ECCM take the ecological perspective into account and seem to be relevant for studying CSCs' impact on stimulating PA among the target group (study II). TTI and ECCM both focus, like most health promotion theories, on the impact of a programme on the behavioural outcome at the individual level, and therefore both TTI and ECCM offered partial guidance for studying CSCs' role and impact in connecting the primary care and the PA sector (study I).

TTI identifies three streams of influences on behaviours: 1) personal, 2) social, and 3) environmental [41]. By studying CSCs' impact on connecting the primary care and the PA sector an insight was gained in these environmental influences. CSCs influences this environmental stream by connecting the primary care and the PA sector, organising activities and guiding patients towards local PA facilities. CSCs create thus a more supportive environment for patients and the general population to become physically active. Whether the behaviour of the target groups reached by CSCs actually has changed is still being studied (study II). But insights of this thesis showed that conditions at public policy and community level seem to facilitate or hinder CSCs' work (Figure 9.2). For example, at the local policy level, an integral health and PA policy seem to create a supportive environment for CSCs to establish a connection between both sectors and reach the desired target group. Knowledge of these conditions informs what must be done at what level to further improve CSCs' work on connecting the primary care and the PA sector and subsequently on stimulating PA among the target group. 


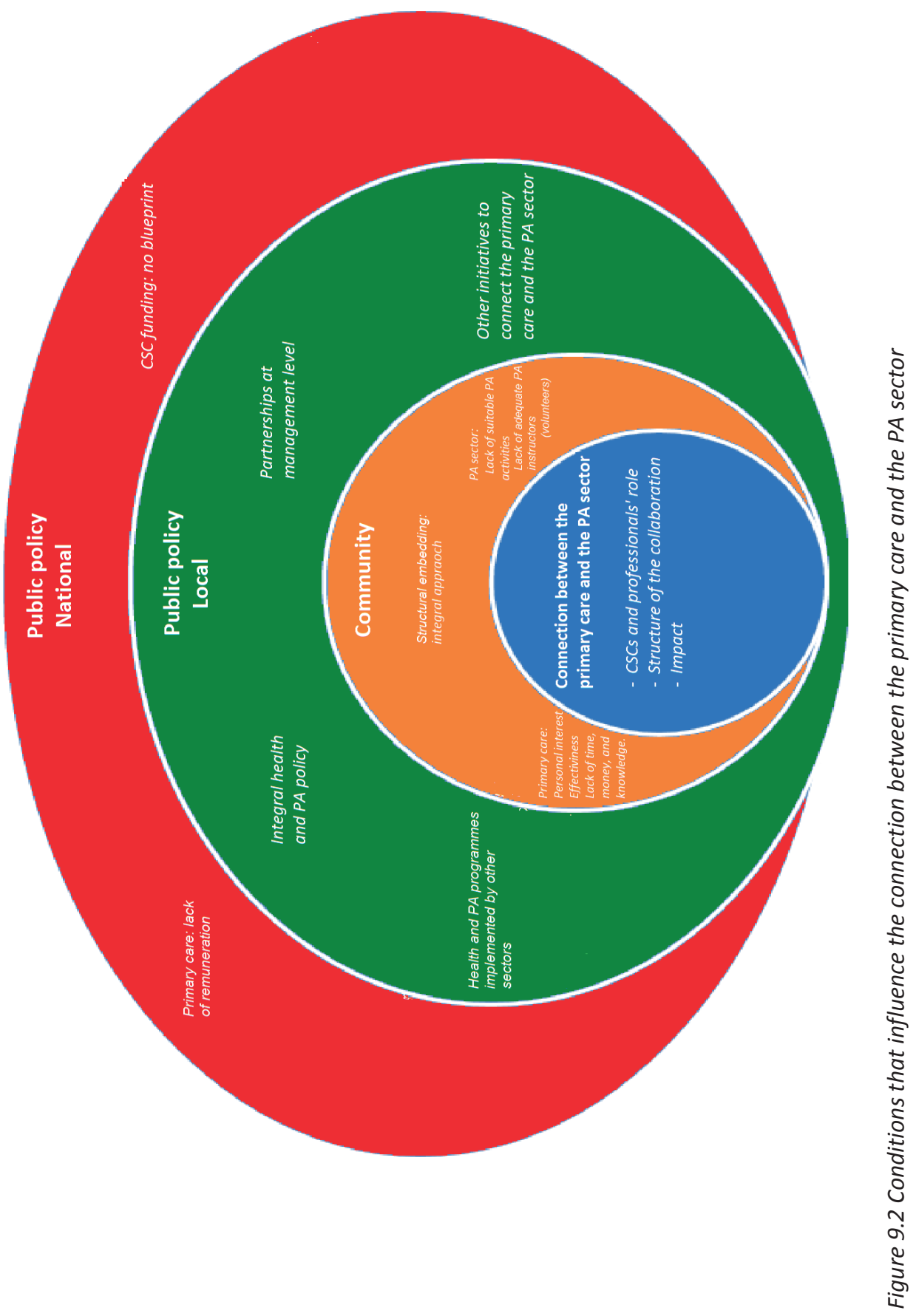


The ECCM was helpful for visualising the position of the CSC function between the health system and the community. CSCs are the link between the community and the health system in which they facilitate a connection between the primary care (health system) and the PA sector (community) by organising PA activities for the target group and guiding primary care patients towards these activities (Figure 9.3). In this way, CSCs bridge the gap that exists between these sectors.

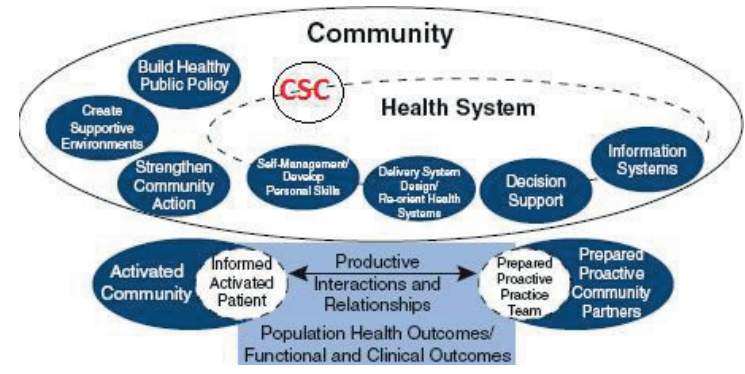

Figure 9.3 CSCs' position in the Expanded Chronic Care Model

\section{Reflections on frameworks and tools used in study I}

In our study, we used different frameworks and tools to address the first three research questions (Table 9.4).

First, to study CSCs' role in connecting the primary care and the PA sector and to identify processes that contribute to this collaboration, we initially intended to use Koelen et al.'s HALL framework [43]. The framework identifies three groups of factors of relevance for intersectoral collaboration, i.e. institutional, personal, and organisation of the alliance. However, during the study it appeared that not all groups of factors in the HALL framework were relevant. Institutional (municipal policy, factors relating to the primary care and PA sector) and personal factors (attitudes and beliefs towards PA promotion) do seem to influence the CSC role in connecting these sectors. However, because of the lack of structured collaboration in CSCs' networks (Chapter 4) and the finding that intersectoral collaboration in our study was organised according to a chain approach, the factors relating to the organisation of the alliance were not applicable in this study and adaptions had to be made. Instead of focusing on factors like communication structure, shared mission, and flexible timeframe, the focus changed to forms of collaboration (coordination of services and programmes for the target group), roles and responsibilities in these forms of collaboration, and communication towards the target group.

Also, because of the lack of structured collaboration, the intended tools [44-45] that facilitate and evaluate intersectoral collaboration in partnerships could not be used in the focus groups. For these focus groups, a new topic list was developed based on the results of interviews with CSCs (Chapter 6), with an emphasis on how the connection between both sectors was established, the different roles stakeholders could fulfil, and the facilitators and barriers in this connection.

Secondly, to study conditions at national and local level, we initially intended to use the ADEPT model [46], which aims to explain and influence policy development and policy impact implementation with four determinants: goals, obligations, resources, and 
opportunities. However, this model focuses only on municipal policy, and CSCs work in a broader system consisting of the health system and the community, hence the broader system needed to be studied. Public health capacity mapping was therefore used as a starting point, and existing frameworks and tools to map public health capacity [47-49] were used to develop a framework to study the operational context of the CSC (Chapter 7). The resulting framework consists of five domains: policy, organisation, resources, programmes, and partnerships (Chapter 7) and is now called the Health Professionals Operational Context framework (Figure 9.4). This framework might, with some adaptations, be useful for other health promotion researchers to study the operational context of professionals working in the field of health promotion, because when the impact of an intervention, programme, and policy is being studied, contextual factors need to be taken into consideration - especially because context-related factors might influence the success of an intervention, programme, or policy [50-51]. In addition, the framework provides insight for policymakers into creating a supportive environment for professionals.

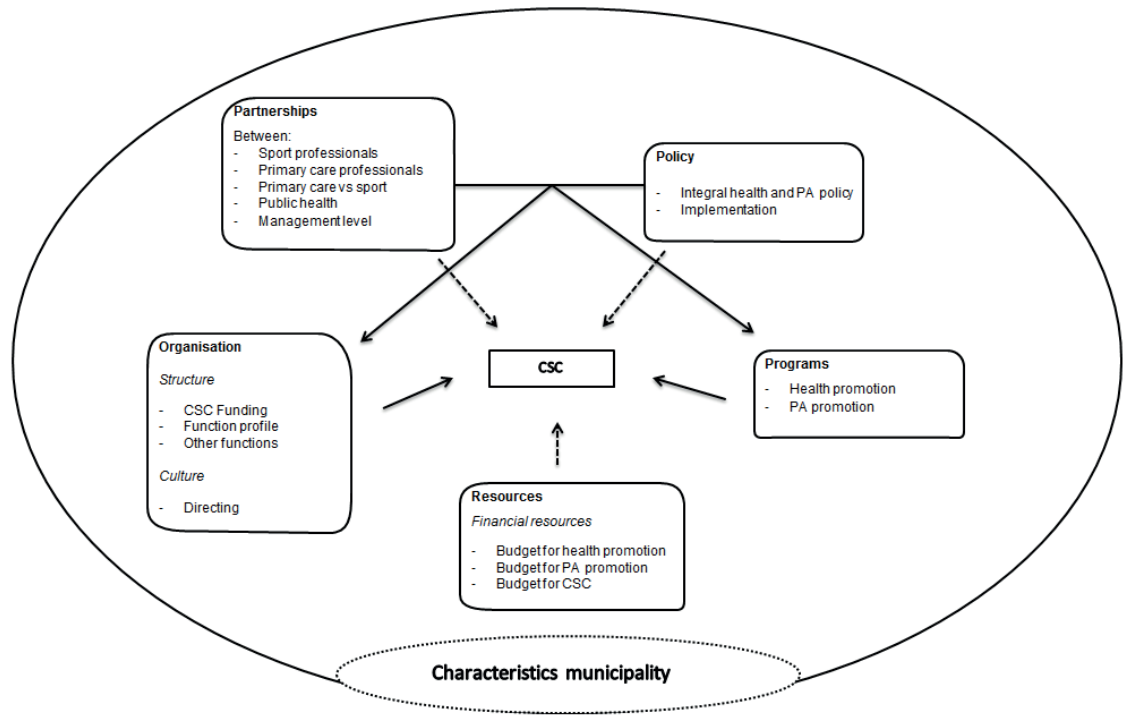

Figure 9.4 Health Professionals Operational Context framework

Thirdly, to study CSCs' impact on connecting the primary care and the PA sector, we analysed CSCs' network using Frey et al.'s Levels of Collaboration Survey [52] and Zaalmink et al.'s network analysis tool [45]. Both tools appeared to be suitable and useful for gaining insight into CSCs' networks. Frey et al.'s tool [52] appeared to be especially relevant for gaining a comprehensive insight into CSCs' networks, the structure of the connection, and the different roles of the organisations in each network.

Finally, at the start of the study we knew little about how CSCs would fulfil their role, and therefore it was hard to select beforehand a suitable framework to study CSCs' impact. During the study it appeared that an adapted RE-AIM framework [53] might be suitable for studying CSCs' impact on connecting both sectors. Although normally this framework is used 
to evaluate intervention impact on individual behaviour change, it seemed that the RE-AIM framework was suitable and useful for analysing the data from the Levels of Collaboration Survey and for studying an intervention's impact on intersectoral collaboration. Other studies have experienced the same potential of the RE-AIM framework to move beyond evaluation of single interventions or settings and to study the impact of multi-faceted reallife initiatives that incorporate multiple interventions targeted at a variety of audiences [5455]. 
Table 9.4 Planned frameworks, methods, and tools versus used frameworks, methods, and tools

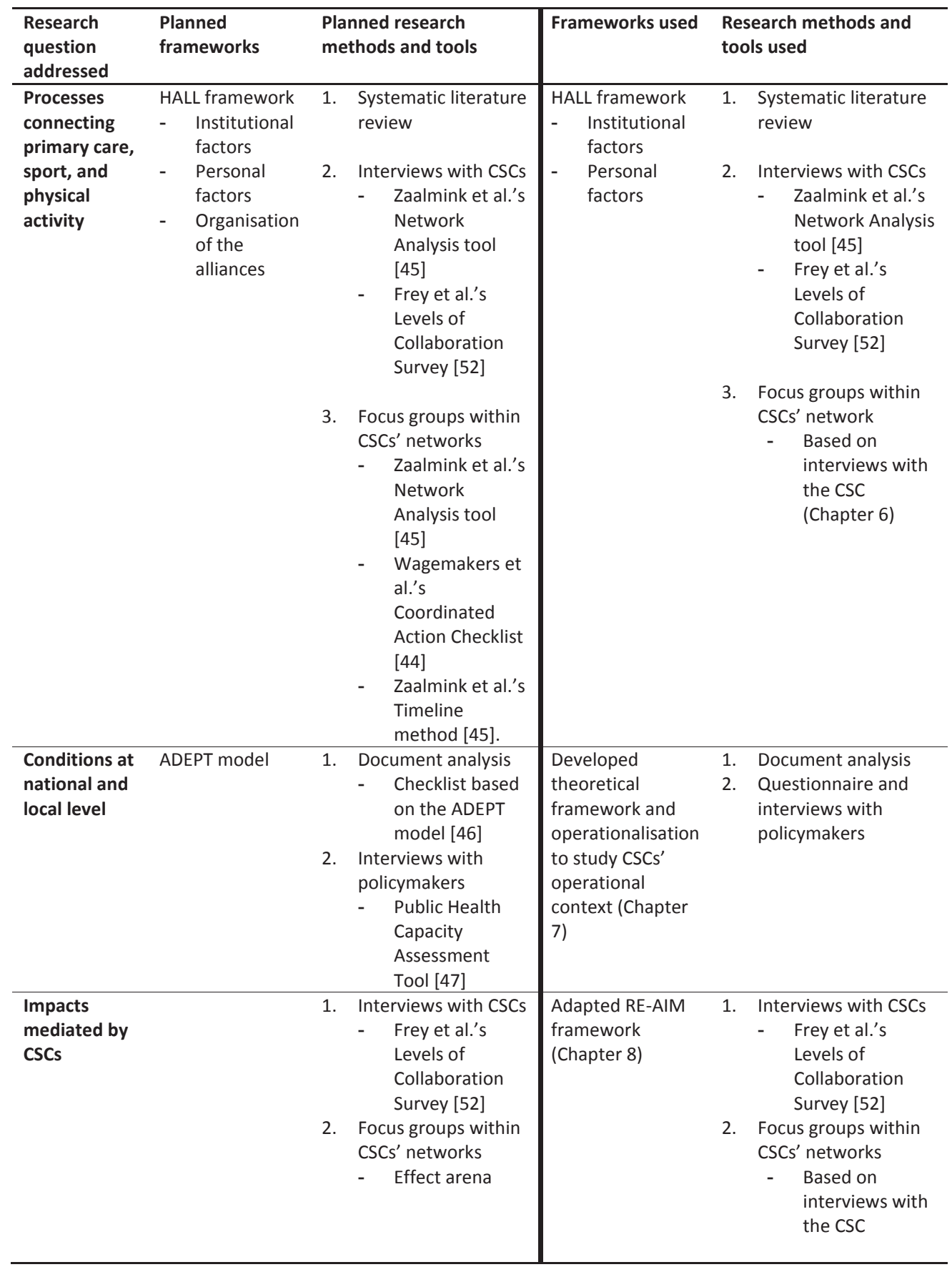




\section{Lessons learned for health promotion theory}

The use of theory, frameworks, and tools led to various lessons for health promotion theory. First, using theories from other scientific areas could be useful for evaluating health promotion programmes targeting outcomes other than those relating to health behavioural outcomes. Although many health promotion models and frameworks (e.g. coherent set of concepts and relationships posited about some phenomena) are focused on contextual factors influencing health, health promotion theories (e.g. 'an ordered set of assertions about a generic behaviour or structure assumed to hold throughout a significantly broad range of specific instances' [56]) provide guidance mostly on the evaluation of a programme on its behavioural outcome. In our study, these health promotion frameworks and models were therefore useful for studying CSCs' role in stimulating intersectoral collaboration, but, due to its focus on behavioural outcomes, our chosen theory was of limited use. Given CSCs' task to stimulate PA, choosing a health promotion theory that takes environmental influences into account to frame this project seems legitimate. In hindsight, we may wonder whether TTI was the best suited theory for study I, especially because the results of this study showed that a broker role relates to a broad range of theoretical concepts (e.g. public policy, intersectoral collaboration, broker, health promotion, capacity) that find their origin in other scientific areas (e.g. policy and administration, organisational studies). Therefore, insights from this study, like CSCs' role in improving intersectoral collaboration and the importance of integral policy, could be further explored with the use of theories from scientific areas other than health promotion. This could be interesting, because according to de Leeuw [57] innovation in health systems and policy can be systematically advanced by conscious theoretical interdisciplinary cross-fertilisation.

To further explore CSCs' role as a broker in improving intersectoral collaboration, organisational theories like Burt's structural holes theory [8] and Evan's Interorganizational Relations Theory [58] could be useful. These theories - based on quantitative outcome measures like density, centrality, and betweenness centrality - study mostly structures, interactions, and relations in collaborative networks. Such theories could be interesting to provide a further insight into CSCs' position in their networks, the relations between the actors, and the development of these networks over a longer period of time. Furthermore, theories on policy agenda setting and implementation, like multiple streams theory [59] and the advocacy coalition framework [60], could be used to study how policy change (towards an integral policy) has occurred and the prerequisites necessary for this policy change. In addition, concepts such as public health capacity [47] and governance for health [61] are interesting concepts to further explore the importance of an integral policy for professionals working in the field of health promotion.

Secondly, with regard to the use of frameworks and tools to evaluate a programme in a realworld setting, one lesson learned is that one must take a critical look at the suitability of existing tools and frameworks, especially when not much is known about the programme and how it is being implemented in the local context. In our study, after the first interview round with CSCs, it appeared that the form of collaboration was different than expected, and therefore not all initially planned frameworks and tools were relevant and suitable for this study. Consequently, a flexible study protocol seems to be important to make required changes if needed after a first insight is gained. In addition, having a flexible study protocol enabled researchers to develop new frameworks more suitable for the research, as we for example developed a framework to study CSCs' operational context. At the same time, to ensure the credibility and dependability of the research process and thus also the quality of 
a qualitative study ([62], it is important that changes in methods used are monitored, documented, and communicated, as we did in our study.

Thirdly, this thesis contributes to insights regarding existing frameworks in the field of health promotion and the development of a new framework relevant for health promotion theory (Health Professionals Operational Context framework). With regard to Koelen et al.'s HALL framework [43], we made suggestions in which the domain 'factors related to the alliances' could be applied to intersectoral collaboration structured as a chain approach. With regard to Glasgow's et al.'s RE-AIM framework [53], we showed, just as other studies [54-55] did, that the RE-AIM framework is also suitable for studying the impact of multi-faceted real-life initiatives that incorporate multiple interventions targeted at a variety of audiences. In addition, the newly developed Health Professionals Operational Context framework was useful for studying the context of professionals working in the field of health promotion. This framework is therefore also relevant for other researchers, because it provides insights into relevant contextual factors influencing the impact of health promotion professionals working to promote health among the population.

The final lesson learned is that approaches in the field of health promotion to guide the development of health promotion programmes should take contextual factors into account. The results of this thesis showed that how CSCs were structurally embedded and the context in which CSCs were operating seemed to influence CSCs' impact. It is therefore important that professionals do not just implement programmes to promote the health of individuals, but also facilitate contextual change at the strategic and operational level, especially because the context is key to effective design and implementation of interventions [63]. For health promotion professionals and policymakers, an insight into general principles of the programme together with an understanding of context-specific factors, which will allow adaptation to suit different situations, is more relevant than just an insight into effective programmes [64]. Mitchie et al.'s behavioural change wheel [63] is a framework that allows users to design and select interventions and policies according to an analysis of the nature of the behaviour, the mechanisms that need to be changed in order to bring about behaviour change, and the interventions and policies required to change those mechanisms. This will help health professionals to take contextual factors into account.

\section{Lessons learned for health promotion practice}

This thesis aimed to explore $\mathrm{CSC}^{\prime}$ role and impact in connecting the primary care and the PA sector. Facilitating and hindering factors identified at public policy (national and local) and community level seemed to influence this connection (Figure 9.2). Therefore lessons could be learned for health promotion practice. This section reflects on implications for practice on these different levels and concerning the relevant stakeholders for the connection between both sectors. Box 9.1 summarises the implications for practice.

\section{National policy \\ Continue the CSC funding}

The Ministry of Health, Welfare, and Sport should continue the CSC funding. Although it appeared during our study that, despite the introduction of the CSC, perceived barriers remained the same, CSCs bridge the existing gap between the primary care and the PA sector. The roles that CSCs perceived for themselves seem to be directed at eliminating some of the existing barriers, and professionals were in general positive about the CSC role. 
Because CSCs have just started their function and because building collaboration structures take time [27, 32], time must be given to CSCs. Continuing the CSC funding will give time to CSCs to further improve the established connection between both sectors. The CSC funding is important for the preservation of the connection.

\section{Advocate and support an integral approach for the structural embedding of the CSC funding}

The Ministry of Health, Welfare, and Sport should advocate and support an integral approach to the structural embedding of the CSC, by adding this integral approach as a condition for the allocation of the CSC funding. In addition, organisations involved with the implementation of the CSC funding should support municipalities in adopting the integral approach.

At this juncture, a blueprint for funding is deliberately not provided, allowing municipalities to deploy this funding according to local needs and context. This has resulted in differences in the way municipalities have structurally embedded CSCs. Based on this study, it may be necessary to advocate and support municipalities to structurally embed CSCs according to an integral approach (e.g. structurally embed CSCs at different organisations or in a partnership of primary care, welfare, and PA professionals) in order to successfully connect both sectors and to reach the desired outcomes, especially because in this way support is created among relevant stakeholders.

\section{Advocate and support the implementation of a specific function profile for CSCs}

The Ministry of Health, Welfare, and Sports should advocate a specific function profile for the deployment of the CSC function and support municipalities with the deployment of CSCS based on this function profile.

CSCs are part of the NSC funding. However, they are different from these coaches. Whereas the vast majority of NSCs are working in the field of education and the PA sector (75\%) [65], CSCs focus specifically on the connection between the primary care and the PA sector. The results from this thesis showed that CSCs focus on various types of tasks (stimulating collaboration, referral, organisation of activities) aimed at different target groups (professionals and primary care patients), whereas NCSs perform particularly executive tasks, like organising PA activities for youth and giving physical education classes in elementary schools [66]. CSCs will therefore have different requirements, and need different skills and competences, than NSCs, for whom a physical education degree is often suitable. Although supporting organisations have already developed a function profile for the different types of NSCs (e.g. PA education, PA care, PA and disabilities) [67], other research has shown that more than half of NSCs are still working on the basis of an outdated function profile based on the function profile defined for the PA promotion programme Impuls School, Sports, and Culture [66]. The question is thus whether policymakers actually appoint neighbourhood sports coaches according to these different function profiles. Therefore, the elaboration of a specific CSC function profile should be advocated, and policymakers should be more supported with the deployment of the funding according to this new function profile.

\section{Reimburse primary care professionals for preventive work}

Reimbursing primary care professionals for preventive work seems a necessary condition for eliminating existing perceived barriers and stimulating primary care professionals to 
participate in health promotion activities. Primary care professionals are in an ideal position to reach a target group that could benefit from PA [33-34]. However, primary care professionals in this study mentioned a lack of time and money as barriers to fulfilling a role in the connection between both sectors. These barriers relate to the system in which primary care professionals are working and are also identified in other studies on PA promotion by primary care professionals [14-25]. The current insurance system in the Netherlands reimburses primary care professionals only for their curative treatments. In addition, uncertainties about funding, and changing policies and programmes regarding prevention, hinder the participation of professionals in projects aimed at health promotion [68] Therefore, healthcare insurance organisations and the government should invest more in a long-term prevention policy and reimbursement of primary care professionals for their preventive work.

Although the results of this thesis suggest that primary care professionals should be reimbursed for their preventive work, from an economic perspective this is not a desirable recommendation, especially given the struggle to control the increasing healthcare costs in the Netherlands [69]. Other financing methods for primary care professionals' preventive work should be organised and implemented, in which healthcare insurance companies, the primary care sector, and municipalities should collaborate more closely.

\section{Local policy \\ Develop an integral health and PA policy and embed this policy in partnerships at management level}

An important implication for local policy is to develop an integral health and PA policy and to embed this policy in partnerships at management level, especially because such policy is reflected in other municipalities operations, like health and PA promotion programmes implemented by different organisations, other initiatives in the field of public health, care, and PA, and an integral approach to structurally embed the CSC. In addition, it creates a supportive context for both CSCs and organisations in the connection between the primary care and the PA sector.

Besides an integral approach seeming to be supportive for CSCs' work and impact, working towards an integral approach seems also to be relevant for municipalities given current developments in the public health system. For example, the decentralisation whereby the Dutch national government has delegated tasks in the field of public health to the municipalities requires a change in the method of care, in which integrated community care with a focus on prevention and health is central [70]. Decentralisation enables municipalities to take charge and provides opportunities for the further development of integrated (health) policies in which bridges are built between key policy sectors [71]. The development of an integral policy and the embedding of this policy in partnerships at management level seem to be relevant for decentralisation and therefore also supportive for other professionals working in the field of public health.

\section{Community level}

\section{Stimulate a health promotion mind-set among primary care professionals}

An implication relevant for umbrella organisations for primary care professionals is the stimulation of a more health promotion mind-set among primary care professionals. CSCs in our study found it difficult to involve primary care professionals in their work and mentioned a perceived lack of priority regarding PA promotion by these professionals. This is 
remarkable, considering the national guidelines for health promotion as formulated by primary care professionals. For example, the federation of physiotherapists in the Netherlands described prevention, both primary and secondary, as one of the main tasks of physiotherapists' job profile [72]; and the GP federation noted the importance of prevention as a task for GPs in their vision for the future [73] and in 2015 implemented a new lifestyle guideline [74]. A health promotion mind-set should therefore be more stimulated among primary care professionals in practice, especially because primary care professionals' advice can be a strong external cue for health-promoting action [75]. A suggestion to umbrella organisations in relation to supporting primary care professionals in carrying out health promotion guidelines is to offer courses and training for health promotion professionals, with an emphasis on the implementation of current guidelines in practice and in regular training programmes.

\section{Focus on existing accessible PA activities rather than on sports clubs}

CSCs and policymakers should focus on already existing accessible PA activities, often taking place at community centres and welfare organisations, instead of on sports clubs. An important implication for PA professionals working on these accessible PA activities is that they should present themselves as a suitable partner.

Most municipal PA promotion policy in the Netherlands focuses on the stimulation of PA participation at sports clubs [76]. However, primary care professionals, welfare professionals, and CSCs in this study perceived that PA activities, especially activities at sports clubs, were not suitable for the target group, and that instructors were not adequately equipped to work with this target group. Although some sports clubs have proved able to offer PA activities to other groups, the majority of sports clubs (84\%) focus only on their core business [77]. In addition, sports clubs do not have enough volunteers (61\%) and have concerns about their financial situation (89\%) [77]. The question is therefore whether sports clubs in the Netherlands are capable of being a suitable partner in the connection between the primary care and the PA sector. Although offering health-enhancing PA activities could be attractive for sports clubs (e.g. increase in members and consequently an increase in financial resources and in potential volunteers), we think that existing accessible PA activities are a more suitable partner for the connection between the primary care and the PA sector, especially because these activities are in general more focused on the target group and instructors are often equipped to work with the target group. However, these activities are not sufficiently known by primary care professionals. PA professionals should present themselves more as a suitable partner in the connection and should generate more publicity for their activities. CSCs should have a facilitating role in generating more publicity for these activities and in creating added value for these kinds of activities in the connection between both sectors, for example by referral of primary care patients towards these activities.

\section{CSCs as a means of eliminating existing barriers}

CSCs in our study ascribed three roles to themselves. These roles correspond with the function profile formulated over time by organisations supporting the NSC funding [67]. To strengthen and expand the established connection between the primary care and the PA sector, CSCs should continue to fulfil this function profile, especially because the roles that CSCs fulfil are directed at eliminating some of the existing barriers in the connection between the two sectors. 
First, as part of their broker role, CSCs should further strengthen the established connection between both sectors by intensifying the existing collaboration and should expand this connection by including more organisations in the connection. This will stimulate an integral approach at the operational level. Secondly, as part of their referral role, CSCs should eliminate existing barriers that hinder primary care professionals from participating in existing referral schemes or from referring their patients towards local PA facilities. CSCs should clarify their role in these referral schemes and inform primary care professionals about existing accessible PA activities for the target group. Thirdly, CSCs as part of their organiser role should have a facilitating role in generating more publicity for existing accessible PA activities and create added value for these kinds of activities in the connection between both sectors by connecting these activities to primary care and welfare professionals.

Box 9.1: Implications for practice

\section{National policy}

- $\quad$ Continue the CSC funding

- Advocate and support an integral approach for the structural embedding of the CSC funding

- Advocate and support the elaboration of a specific function profile for CSCS

- $\quad$ Reimburse primary care professionals for their preventive work

Local policy (municipal policy)

- Develop an integral health and PA policy and embed this policy in partnerships at management level

Community level (professionals and CSCs)

- Stimulate a health promotion mind-set among primary care professionals

- Focus on already existing accessible PA activities instead of on sports clubs

- $\quad$ CSCs as a means of eliminating existing barriers

\section{Implications for further research}

From the results of this study, several avenues for further research can be signposted. First, it would be interesting for further research to study CSCs' role and the connection between both sectors over a longer period of time. Although at this juncture no changes in their roles have been identified, it is possible that the CSC role will change over a longer period of time when the connection between both sectors is further realised. In addition, it would be interesting to know how the connection between both sectors evolves over a longer period of time and how the structural embedding of CSCs influences the established connection. It is possible that CSCs structurally embedded in only the PA sector will need more time to establish a more promising connection than CSCs structurally embedded according to an integral approach, especially because they operate in a context in which an integral approach for health promotion is less present. These CSCs could be a catalyst for change, but it also means that they need more time than CSCs working in a more supportive 
context. In addition, given the decentralisation of public health tasks from national level to municipalities, the context in which CSCs are operating is still changing. It would therefore be interesting to repeat this research in a few years.

Secondly, besides elucidating the CSC role and impact, this thesis also provides an insight into perceived barriers and facilitators for the connection between both sectors. Further research is necessary to identify strategies to overcome current barriers hindering the collaboration between the primary care and the PA sector, especially because most of the barriers remain, despite the introduction of different PA promotion programmes. A specific focus could be placed on alternative financing models for primary care professionals' preventive work.

Thirdly, more research is necessary on the operational context of professionals working in the public health field. CSCs' operational context was studied using a newly developed Health Professionals Operational Context framework. This framework seems useful for describing the operational context of professionals working in the public health field. Although the results showed that an integral health and PA policy and an embedding of this policy in partnership at management level were important conditions for a supportive context, it is not clear how the different domains of the theoretical framework influence one another. Other studies should reveal whether and how these domains influence one another and the operational context. In addition, whether this framework is, after some changes, applicable to other professionals working in the field of public health should be explored. Finally, other studies that are part of the larger project (Chapter 2) should reveal CSCs' impact on stimulating PA among the target group and what type of structural embedding of CSCs is the most promising for this. In addition, study II will provide an insight into the type of PA activities implemented by CSCs, the target group reached, and strategies that are effective in increasing the participation, self-management, and transfer of primary care patients.

\section{General conclusion}

This thesis explored CSCs' role and impact in connecting the primary care and the PA sector. CSCs in our study perceived three roles for themselves - broker, referral, and organiser - in which the broker role was fulfilled by fulfilling the referral and organiser role. These roles themselves did not change over time. The roles relate to the structure of the connection between both sectors, which can be characterised as a chain in which CSCs guide the target group towards PA facilities after referral by primary care professionals or their own recruitment.

All CSCs established a connection between both sectors. The way in which municipalities structurally embedded the CSCs influences CSCs' work. CSCs structurally embedded according to the integral approach connected both sectors by different activities targeting different audiences. These CSCs could also give more meaning to their referral role because primary care professionals were involved in the referral of their patients. CSCs who were structurally embedded in only the PA sector established the connection between both sectors mostly around their own activities and found it hard to involve primary care professionals with regard to the referral of their patients. These CSCs fulfilled therefore mostly the organiser role. CSCs who are structurally embedded according to an integral approach are more likely to create a greater impact and reach a target group that could benefit from PA than CSCs structurally embedded in the PA sector only. An integral approach 
seems therefore the most promising for $\mathrm{CSCs}^{\prime}$ work.

This thesis also provides an insight into processes and conditions that facilitate or hinder the connection between the primary care and the PA sector. Barriers relating to the primary care sector (lack of time, money, and knowledge) and to the PA sector (lack of suitable PA activities and adequate instructors) are currently hindering the connection between both sectors. The roles that CSCs perceived for themselves seem to be directed at mitigating or eliminating some of the perceived barriers, but, to make a success of the connection between the two sectors, changes are needed at both the policy and the community level. For example, local policy should adopt a more integral approach, and a health-promotion mind set should be promoted among primary care professionals. Further research should focus on CSCs' impact on stimulating PA among primary care patients and on the development of the CSC role and the connection between both sectors over time. 


\section{References}

1. Harting J, Kunst AE, Kwan A, and Stronks K. A 'health broker' role as a catalyst of change to promote health: An experiment in deprived Dutch neighbourhoods. Health Promotion International, 2010, 26, 65-81

2. Langeveld K, Stronks K, and Harting J. Use of a knowledge broker to establish healthy public policies in a city district: A developmental evaluation. BMC Public Health, 2016, 16, 271.

3. Hagen S, Helgesen M, Torp S, and Fosse E. Health in all policies: A cross-sectional study of the public health coordinators' role in Norwegian municipalities. Scandinavian Journal of Public Health. 2015, 43(6), 597-605.

4. Nissen LB. Boundary spanners revisited: A qualitative inquiry into cross-system reform through the experience of youth service professionals. Qualitative Social Work, 2010. 9(3), 365-384.

5. McKenna B, Fernbacher S, Furness T, and Hannon M. "Cultural brokerage" and beyond: piloting the role of an urban Aboriginal Mental Health Liaison Officer. BMC Public Health, 2015, 15(1), 881.

6. Hogan A, and Stylianou M. School-based sports development and the role of NSOs as 'boundary spanners': benefits, disbenefits and unintended consequences of the Sporting Schools policy initiative. Sport, Education and Society, 2016, 1-14.

7. Choi BC, and Pak AW. Multidisciplinarity, interdisciplinarity and transdisciplinarity in health research, services, education and policy: 1 . Definitions, objectives, and evidence of effectiveness. Clinical \& Investigative Medicine 2006;29(6):351-364.

8. Burt RS. Structural Holes: The Social Structure of Competition. Cambridge MA: Harvard University Press; 1992.

9. Bevc CA, Markiewicz ML, Hegle J, Horney JA, MacDonald PD. Assessing the Roles of Brokerage: An Evaluation of a Hospital-Based Public Health Epidemiologist . in North Carolina. Journal of Public Health Management Practice, 2012, 18(6), 577-584

10. Hanna $\mathrm{V}$, and Walsh $\mathrm{K}$. Interfirm cooperation among small manufacturing firms. International Small business Journal, 2008, 26(3), 299-321.

11. Jones R, and Noble G. Managing the implementation of public-private partnerships. Public Money and Management, 2008, 28(2), 109-114.

12. Stadtler L, and Probst G. How broker organizations can facilitate public-private partnerships for development. European Management Journal, 2012, 30(1), 32-46.

13. Williams P. The competent boundary spanner. Public administration, 2002, 80(1), $103-$ 124.

14. Bize R, Cornuz J, Martin B. Opinions and attitudes of a sample of Swiss physicians about physical activity promotion in a primary care setting. Schweiz Z Sportmed Sporttraumatol 2007;55(3):97-100.

15. Crisford $\mathrm{P}$, Winzenberg $\mathrm{T}$, Venn $\mathrm{A}$, et al. Understanding the physical activity promotion behaviours of podiatrists: a qualitative study. Journal of Foot and Ankle Research,2013;6(1).

16. Douglas F, van Teijlingen E, Torrance N, et al. Promoting physical activity in primary care settings: health visitors' and practice nurses' views and experiences. Journal of Advanced Nursing, 2006;55(2):159-168.

17. Graham RC, Dugdill L, Cable NT. Health professionals' perspectives in exercise referral: implications for the referral process. Ergonomics, 2005;48(11-14):1411-1422. 
18. Haas R, Maloney S, Pausenberger E, et al. Clinical decision making in exercise prescription for fall prevention. Physyical Therapy,2012;92(5):666-679. doi: 10.2522/ptj.20110130

19. Huijg JM, van der Zouwe N, Crone MR, et al. Factors influencing the introduction of physical activity interventions in primary health care: a qualitative study. International Journal of Behavioural Medicine, 2015;22(3):404-414.

20. Din NU, Moore GF, Murphy S. Health professionals' perspectives on exercise referral and physical activity promotion in primary care: findings from a process evaluation of the National Exercise Referral Scheme in Wales. Health Education Journal, 2014

21. Presseau J, Sniehotta FF, Francis JJ, Cambell, NC. Multiple goals and time constraints: perceived impact on physicians' performance of evidence-based behaviours. Implemention Science, 2009;4(1).

22. Ribera AP, Mckenna J, Riddoch C. Attitudes and practices of physicians and nurses regarding physical activity promotion in the Catalan primary health-care system. European Journal of Public Health, 2005;15(6):569-575.

23. Dillman C J, Shields CA, Fowles JR, et al. Including physical activity and exercise in diabetes management: diabetes educators' perceptions of their own abilities and the abilities of their patients. Canadian Journal of Diabetes, 2010;34(3):218-226.

24. Goodman C, Davies SL, Dinan S, et al. Activity promotion for community dwelling older people: a survey of the contribution of primary care nurses. British Journal of Community Nursing, 2011;16(1):12-17.

25. Hong Y, Ory MG, Lee $C$, et al. Walking and neighborhood environments for obese and overweight patients: perspectives from family physicians. Family Medicine, 2012;44(5):336-341.

26. Ooms L, Veenhof C, Schipper-van Veldhoven N, et al. Sporting programs for inactive population groups: factors influencing implementation in the organized sports setting. BMC Sports Science, Medicine, Rehablitation, 2015;7:12

27. Den Hartog F, Wagemakers A, Vaandrager L, van Dijk, $M$ and Koelen, MA Alliances in the Dutch Beweegkuur lifestyle intervention. Health Education Journal, 2014;73, 576-587.

28. Cashman SB, Flanagan P, Silva MA, Candib LM: Partnering for health: collaborative leadership between a community health center and the YWCA central Massachusetts. Journal of public health management and practice : JPHMP 2012, 18(3):279-287.

29. Foley M, Frey M, McPherson G, and Reid G. Healthy public policy: A policy paradox within local government. Managing Leisure, 2000, 5, 77-90.

30. Wiles R, Demain S, Robinson J, Kileff J, Ellis-Hill C, and McPherson K. Exercise on prescription schemes for stroke patients post-discharge from physiotherapy. Disability Rehability, 2008, 30, 1966-1975.

31. Baker EA, Wilkerson R, Brennan LK: Identifying the role of community partnerships in creating change to support active living. American journal of preventive medicine 2012, 43(5 Suppl 4):S290-299.

32. Casey MM, Payne WR, Eime RM: Partnership and capacity-building strategies in community sports and recreation programs. Managing Leisure, 2009,14(3):167-176.

33. Estabrooks PA, and Glasgow RE. Translating effective clinic-based physical activity interventions into practice. American Journal of Preventive Medicine, 2006, 31(4 Suppl): p.S45-56

34. Vuori IM, Lavie CJ, Blair SN: Physical activity promotion in the health care system. Mayo Clinic proceedings 2013, 88(12):1446-1461. 
35. Smit E, Leenaars KEF, Wagemakers A, Molleman GRM, van der Velden K. Abstract: Invloed van wervingstrategieën op bereikte doelgroep van de buurtsportcoach. Dag van het Sportonderzoek. Groningen 10 november 2016.

36. Leung L. Validity, reliability, and generalizability in qualitative research. Research and Audit, 2015, 4(3), 324-327.

37. Smit E, Leenaars KEF, Wagemakers A, Molleman GRM. Beweeg- en sportstimulering door professionals in de wijk. Rapportage van de resultaten van een Delphi studie. Radboudumc en Wageningen Universiteit; 2016.

38. Sallis JF, Cervero RB, Ascher W, Henderson KA, Kraft MK, Kerr J. An ecological approach to creating active living communities. Annual Reviews Public Health, 2006, 27:297-322. Doi: 0.1146/annurev.publhealth.27.021405.102100

39. Mutrie N, and Woods CB. How can we get people to become more active? A problem waiting to be solved. 2003. In McKenna J, and Riddoch C. (Eds.) Perspectives on Health and Exercise (1st ed., pp. 129-152). Basingstoke, Uk: Palgrave Macmillan.

40. McLeroy KR, Bibeau D, Steckler A, Glanz K. An Ecological Perspective on Health Promotion Programs. Health Education and Behaviour, 1988. doi:10.1177/109019818801500401.

41. Flay BR, Snyder F, Petraitis J. The theory of triadic influence. In: DiClemente RJ, Crosby RA, Kegler MC, editors. Emerging theories in health promotion practice and research. 2nd ed. San Francisco: Jossey-Bass; 2009.

42. Barr VJ, Robinson S, Marin-Link B, Underhill L, Dotts A, Ravensdale D et al. The expanded Chronic Care Model: an integration of concepts and strategies from population health promotion and the Chronic Care Model. Hospital Quarterly. 2003;7(1):73-82.

43. Koelen MA, Vaandrager L, and Wagemakers A. The healthy alliances (HALL) framework: Prerequisites for success. Family Pracitce, 2012, 29 (SUPPL.1), 132-138.

44. Wagemakers A. Community health promotion. Facilitating and evaluating coordinated action to create supportive social environments. Wageningen: Wageningen University; 2010.

45. Zaalmink W, Wielinga E, Bergevoet R, Geerling-Eiff F, Holster H, Hoogerwerf L. et al. Networks with Free Actors. Wageningen University, 2008 Zaalmink 2010

46. Rütten A, Gelius P, Abu-Omar K. Policy development and implementation in health promotionfrom theory to practice: the ADEPT model. Health Promot International, 2011; doi:10.1093/heapro/daq080.

47. Aluttis C, Van den Broucke S, Chiotan C, Costongs C, Michelsen K, and Brand H. Review of Public Health Capacity in the EU: Final Report. Luxembourg: European Commission Directorate General for Health and Consumers, 2013. http://ec.europa.eu/ health/social_determinants/docs/report_ph_capacity_2013_en.pdf (last accessed 15 May 2016).

48. Meyer AM, Davis M, and Mays GP. Defining organizational capacity for public health services and systems research. Journal of Public Health Management and Practice, 2012, 18(6), 535-544.

49. Bagley $P$, and Lin V. The development and pilot testing of a rapid assessment tool to improve local public health system capacity in Australia. BMC Public Health, 2009, 9(1), 413.

50. Ndumbe-Eyouh S, and Moffat $\mathrm{H}$. Intersectoral action for health equity: A rapid systematic review. BMC Public Health, 2013,13,1056. 
51. Glasgow RE, Green LW, Taylor MV, and Stange KC. An evidence integration triangle for aligning science with policy and practice. American Journal of Preventive Medicine, 2012, 42(6), 646-654.

52. Frey BB, Lohmeier JH, Lee SW, Tollefson N. Measuring collaboration among grand partners. American Journal of Evaluation. 2006;27:383-92.

53. Glasgow RE, Vogt, TM, Boles, SM: Evaluating the Public Health Impact of Health Promotion Interventions: The RE-AIM Framework. American Journal of Public Health, 1999, 89(9), 1322-1327.

54. Finch CF, Donaldson A: A sports setting matrix for understanding the implementation context for community sport. British Journal of Sports Medicine, 2010, 44:973-978.

55. Sweet SH, Martin Ginis KA, Estabrooks PA, Latimer-Cheung AE: Operationalizing the REAIM framework to evaluate the impact of multi-sector partnerships. Implementation Science, 2014, 9:74

56. Sutherland JW. Systems: Analysis, Administration and Architecture, New York, Van Nostrand; 1975.

57. De Leeuw E. Theory and Policy Innovation for Health: where has the creativity and fun gone?. Health Promotion International, 2011, 26 (1): 1-3. doi: 10.1093/heapro/dar001

58. Evan WM. Toward A Theory of Inter-Organizational Relationships. Management Science, 1965, 11; B-217-B-230.

59. Kingdon JW. Agendas, alternatives, and public policies (2nd ed.). New York, Longman; 1995.

60. Sabatier P. An Advocacy Coalition Framework of Policy Change and the Role of PolicyOriented Learning Therein. Policy Sciences, 1988, 21(2-3): 129-68

61. Kickbusch I, Gleicher D. Governance for health in the 21st century. Copenhagen, WHO; 2012.

62. Lincoln YS, and Guba EG. Paradigmatic controversies, contradictions, and emerging confluences. In N. K. Denzin \& Y. S. Lincoln (Eds.), The handbook of qualitative research (2nd ed., pp. 163-188). Beverly Hills, CA, Sage; 2000.

63. Michie S, van Stralen MM, West R. The behavior change wheel: A new method for characterising and designing behavior change interventions. Implementation Science, 2011;6:42.

64. Green J. The role of theory in evidence-based health promotion practice. Health Education Research, 2000,15(2):125-129. doi: 10.1093/her/15.2.125

65. van Lindert C, Pulles I, van der Poel H. Voortgangsrapportage Monitor Sport en Bewegen in de buurt 2016. Utrecht, Mulier Instituut; 2016.

66. van Ginneken Z, van Lindert C. van der Poel H. Verdiepingsonderzoek buurtsportcoaches 2016: tabellenrapportage. Utrecht, Mulier Instituut; 2016.

67. Sport in de Buurt. Function Profile NCSs. Retrieved from: http://www.sportindebuurt.nl/kwaliteitsimpuls-buurtsportcoaches/profielen-encompetenties Last accessed February 10, 2017.

68. Koopmans B, Korevaar J, Nielen M, Verhaak P, de Jong J. Preventie kan effectiever! Deelnamebereidheid en deelnametrouw aan preventieprogramma's in de zorg. Utrecht, Nivel; 2012.

69. CPB. Health care costs in the Netherlands. Retrieved from: https://www.cpb.nl/persbericht/3211095/zorguitgaven-blijven-stijgen Last accessed February 20, 2017. 
70. Ministerie van Binnenlandse Zaken en Koninkrijksrelaties. Decentralisatiebrief kabinet. Den-Haag, Ministerie BZK; 2013.

71. Storm I. Towards a HiAP cycle: Health in All Policies as a practice-based improvement process. Amsterdam, Free University; 2016.

72. de Vries C, Hagenaars L, Kiers H, Schmitt M. Beroepsprofiel Fysiotherapeut. Amersfoort, KNGF; 2014.

73. NHG-LHV. Toekomstvisie Huisartsenzorg. Utrecht, NHG-LHV; 2012.

74. Nederlandse Huisarts Genootschap. NHG-Zorgmodules Leefstijl. Utrecht, NHG; 2015.

75. Whitlock EP, Orleans CT, Pender N, Allan J. Evaluating primary care behavioral counseling interventions: an evidence-based approach. American Journal of Preventive Medicine, 2002, 22 :267-284.

76. Hoekman R, and van den Dool R. Gemeentelijke uitgaven aan sport. Een overzicht van de ontwikkelingen (2010-2015). Utrecht, Mulier Instituut; 2015.

77. Hulsebos L, Knaapen T, Jentink I. Sportaanbiedersmonitor 2015. Arnhem, NOC*NSF; 2015. 


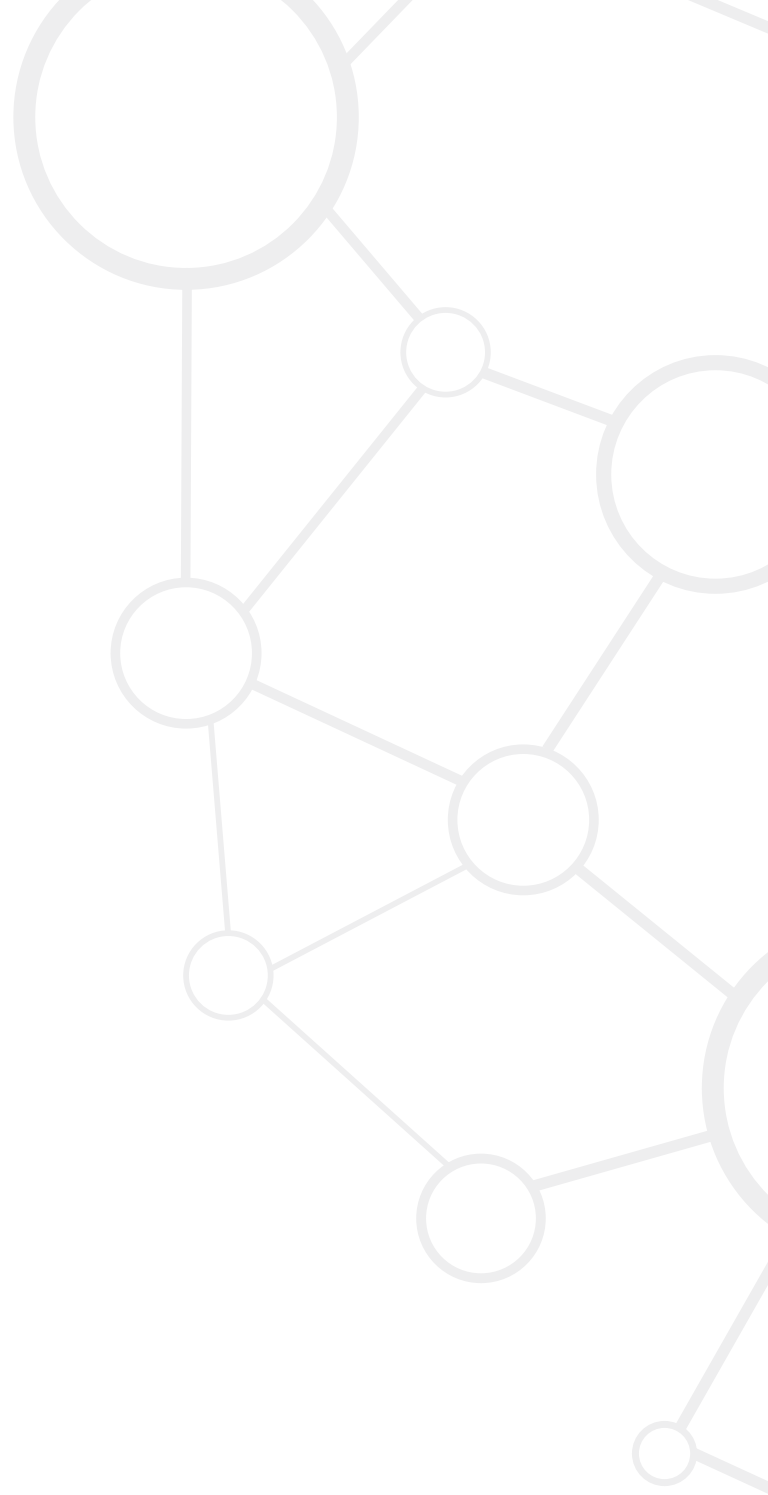



To stimulate physical activity (PA), the Dutch Ministery of Health, Welfare and Sports introduced Care Sport Connectors (CSCs) in 2012. This function is $40 \%$ funded by the state, with the remaining $60 \%$ funded by the municipality or other local organisations. CSCs are employed specifically to connect the primary care sector and the PA sector in order to guide primary care patients towards local sport facilities. The defined outcome of CSCs is an increased number of residents participating in local PA facilities and being physically active in their neighbourhood. This new CSC function is challenging because previous studies have shown that differences between the primary care and the PA sector can hinder their mutual collaboration.

A broker, like the CSC, seems promising for improving intersectoral collaboration. However, to our knowledge the work, significance and challenges of brokers has not been studied often. Most studies focus on a brokers' position and its impact on a network performance measured with quantitative outcome measures. The case of the CSC enables us to explore the broker role in connecting the primary care and the PA sector in order to stimulate PA. This insight is necessary firstly because the CSC function is new and unique and therefore the latest Dutch policy and its accountability need to be evaluated. Secondly, because intersectoral collaboration between the primary care and the PA sector is challenging, insight in CSCs' role and impact seem to be relevant to further improve this connection. Thirdly, because the role and impact of a broker in establishing intersectoral collaboration is not studied often and therefore an insight helped us to advance health promotion theory and practice.

The case of the CSC enables us to explore the role and impact of a broker on stimulating intersectoral collaboration. To explore CSCs' role and impact in connecting the primary care and the PA sector four research questions were studied in different chapters:

1. What are the processes that contribute to the connection between primary care, and PA sector?

2. What are the conditions at national and local level that facilitate or hinder CSCs in connecting the primary care and the PA sector

3. Which impacts are mediated by CSCs and what are the perceived societal benefits for the municipality, neighbourhood, and local residents?

4. What lessons can be learned to advance health promotion theory and practice?

This thesis employed a multiple case study design in which 15 CSCs of nine municipalities spread over the Netherlands were followed in their work from 2014 to the end of 2016. In line with a multiple case-study design, perspectives of different stakeholders (policymakers, professionals, CSCs) in the connection between both sectors on different levels (policy, and community level) were taken into account in which different data collection methods were used (literature review, interview, focus group, document analysis, and questionnaires). Including different perspectives and using a mixed methods approach enabled us to provide a comprehensive insight in the connection between both sectors established by CSCs. In addition, cross-case synthesis helped us to draw general conclusions concerning the connection between the primary care and the PA sector when different cases share some similarities. As CSCs have the task to connect the primary care and the PA sector, and to stimulate PA among the target group, another study - not part of this thesis - is carried out as well, which aims to explore CSCs' impact on promoting PA among the target group.

Chapter $\mathbf{2}$ provided more detailed information on the design and the methods used in this study. 
Chapter 3 describes our systematic literature review which was conducted to gain an insight in collaborative initiatives between the primary care and the sport sector and to identify barriers and facilitators in these initiatives. 28 different initiatives between the both sectors were identified. In these initiatives two approaches to promote PA were distinguished. In the approach to refer primary care patients towards local PA facilities three forms of collaboration were identified: referral scheme, multidisciplinary primary care team with a connection to the sport sector, and a partnership between a community health centre and a sports facility. In the approach to promote PA among the community one form of collaboration was identified: a network among community partners including the primary care and the sport sector. The identified facilitators and barriers differed in the two approaches to promote PA. In the referral of patients, sport professionals' lack of medical knowledge, and health professionals' lack of time, were seen as barriers. In networks to organise activities to promote PA among the community, different shared interests and different cultures were seen as barriers.

The role of the CSC in connecting the primary care and the PA sector (in Chapter 3 formulated as sports sector but reflecting the same definition of the PA sector as in the rest of the thesis) was explored in Chapter 4. Three rounds of interview with CSCs in the course of one year were conducted to identify how CSCs perceived their role in connecting the primary care and the PA sector, how they establish a connection between the primary care and the PA sector, and what factors were perceived as barriers and facilitators in this connection. CSCs perceived themselves three roles: 1) broker, 2) referral, and 3) organiser and set up two forms of collaboration structures: 1) project basis, and 2) referral. In their work to connect both sectors, CSCs perceived the following barriers: primary care professionals' lack of knowledge and time, primary care professionals' own interests, lack of suitable PA activities for the target group, and a lack of adequate PA instructors. Results of this study showed that the way municipalities implement the CSC funding seems to influence the ease with which the CSC could establish collaboration structures. CSCs working for a care or a welfare organisation had easier access to primary care professionals than CSCs working for a sports organisation or the municipal sport department, and could therefore better fulfil the referral function and guide primary care patients towards local PA facilitates. CSCs with a lack of involvement fulfilled mostly the organiser role rather than the referral function.

In chapter 5, we followed up on how CSCs fulfilled their role over time and gained a more indepth insight into how CSCs fulfilled specifically their role as broker to establish the connection between both sectors. In the course of two years, 13 CSCs were interviewed in multiple interview rounds. During the years, all CSCs mentioned that they performed the broker role. However, differences could be distinguished in how the broker role was fulfilled in order to connect the primary care and the PA sector: 1) fulfilling the broker role by connecting both sectors with their own activities (referral or organisations of activities), and 2 ) initiating collaboration between both sectors but the CSCs recede themselves of this connection.

The study described in chapter 6 assessed perceptions of primary care, welfare, and PA professionals towards the CSC role and their experiences in the connection between the primary care and the PA sector. In total, 9 focus groups with professionals within CSCs networks were held. Primary care, welfare and PA professionals ascribed three roles to the 
CSC: 1) broker role, 2) referral, 3) facilitator. No major differences were identified between the different professionals in their perceptions on the CSC role. Professionals found the CSC role and the current established connection promising. However, factors relating to their own sector were currently perceived to hinder this connection, like primary care professionals' lack of time, money and knowledge, and the lack of suitable PA activities and instructors for the target group.

In chapter 7 we described CSCs' operational context of nine municipalities. In order to describe CSCs' operational context a new theoretical framework was developed. The CSC function is a new function, and a framework specific to the context in which CSCs are working was not yet available. On the basis of a literature search, in-depth interviews with experts in the field of public health, and a workshop at the Dutch conference for Public Health, a framework which consisted of five domains: policy, organisation, resources, programs, and partnerships was developed. Based on a document analysis of current policy documents, a questionnaire, and interviews with policymakers of the nine municipalities, information was collected regarding the five domains of the theoretical framework. The results of this study showed the extent to which municipalities had adopted an integral approach seems to be different. An integral approach consists of an integral health and PA policy in combination with an embedding of this policy in partnerships between health and the PA sector at management level. Municipalities with an integral approach structurally embedded CSCs in such a way that CSCs were working form different sectors or within a partnership of primary care, welfare and PA professionals. In these municipalities, other initiatives in the fields of public health, care and PA were also implemented, and programs to promote health and PA were implemented by different organisations. In municipalities that adopted a less integral approach, this was hardly present, and CSCs were structurally embedded only at the PA sector. Given CSCs' mandate, we argue that the integral approach may be supportive for ' CSCs' work, because it is reflected in other operations of the municipality and thus creates conditions for the CSCs' work. Whether this integral approach is actually supporting CSCs in their work needs to be further studied. .

The study in chapter 8 explored CSCs impact on connecting the primary care and PA sector and aimed to explore which structural embedding was the most promising in reaching the desired outcomes. A network survey was used to provide an insight in the CSCs network and professionals' role in the collaboration between both sectors. During three rounds of interview with 13 CSCs, each with a time span of approximately 6-12 months between them, this network survey was completed. Results of this study showed that all CSCs had organised a similar looking network of primary care, welfare and PA professionals and established a connection between both sectors. However, differences were found between the structural embedding and the way the connection between both sector was established. CSCs working in municipalities who structural embedded CSCs according to an integral approach (e.g. care, welfare and sports organistions, or within a partnership between primary care, welfare and PA professionals) collaborated mostly with the professionals by supporting their activities and implemented a structured form of referral. The other CSCs who were working from the PA sector collaborated mostly with professionals around their own activities as a way to stimulate PA among the residents. Therefore, results of this study showed that a structural embedding according an integral approach seems the most promising in reaching the desired outcomes. 
The main findings are summarised and reflected on in Chapter 9. In addition, we reflected on used theory, models and tools used in this study and formulated lessons for both health promotion theory as practice.

This thesis aimed to explore CSCs' role and impact in connecting the primary care and the PA sector. The results of this thesis contribute to three important insights. First, the structure of the connection between the primary care and the PA sector established by CSCs can be characterised as a chain approach. Secondly, barriers related to the sectors are currently hindering this connection. Thirdly, an integral approach to structurally embed CSCs seems to be an important condition to facilitate the connection between the both sectors.

The results all together showed that the CSC function seemed to be promising in connecting the primary care and the PA sector. However, to make a success of the connection between both sectors changes at both the policy as community level are needed. For example local policy should adopt a more integral approach, and a health-promotion mind set should be promoted among primary care professionals. Further research should focus on CSCs' impact on stimulate PA among primary care patients, and the development of CSC' role and the connection between both sectors in course of time. 


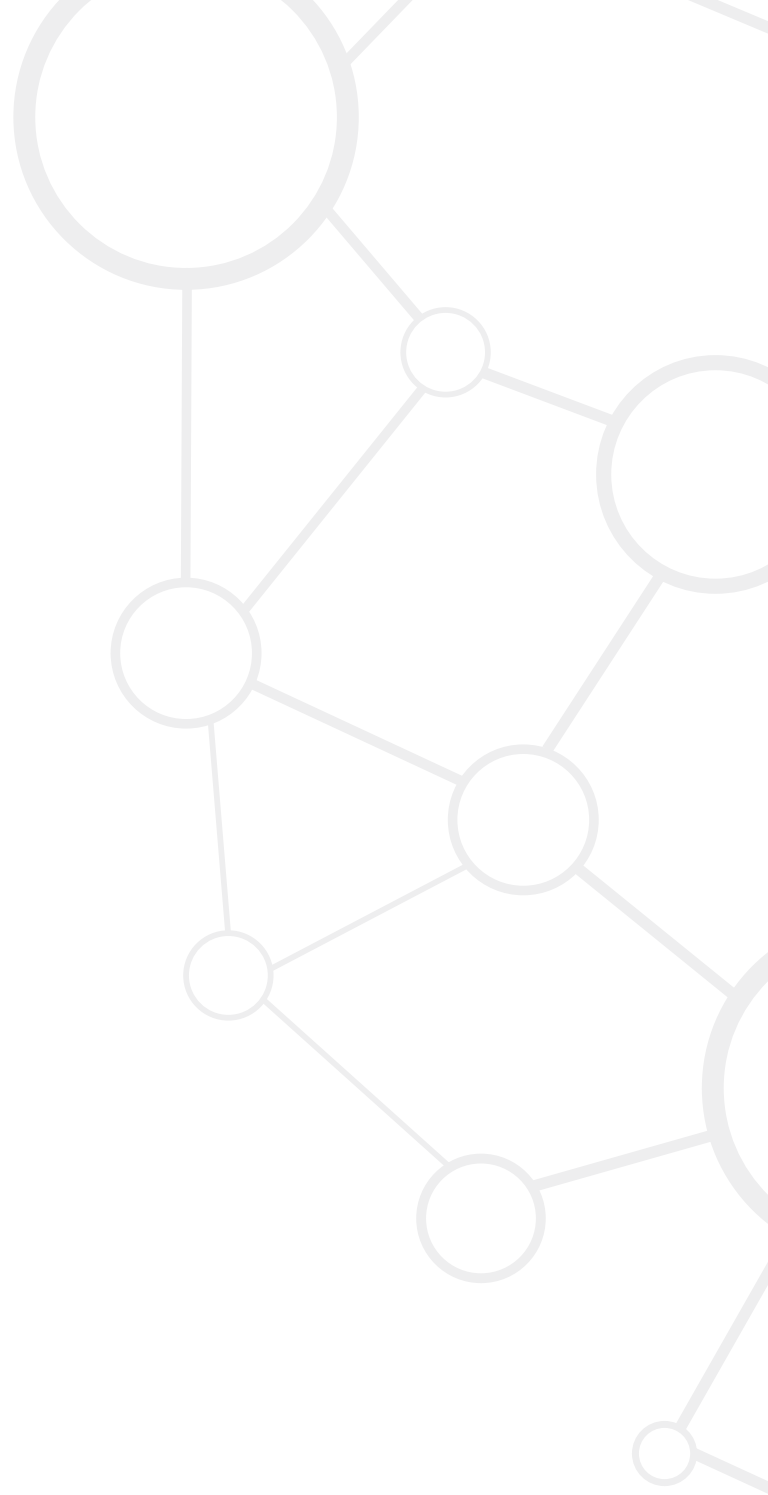


Samenvatting 
In 2012 zijn door het Ministerie van Volksgezondheid, Welzijn en Sport buurtsportcoaches (BSC'es) geïntroduceerd. Deze BSC'es hebben als doel mensen te stimuleren meer te gaan bewegen. Deze functie wordt voor $40 \%$ gesubsidieerd door de overheid, de overige $60 \%$ wordt betaald door de gemeente of andere lokale organisaties. Sommige van deze BSC'es zijn specifiek aangesteld om de verbinding te maken tussen de eerstelijnszorg en de sporten beweegsector met als doel patiënten uit de eerstelijnszorg te begeleiden naar lokale sport- en beweegactiviteiten. De gewenste uitkomst is een toename van het aantal mensen dat sport en beweegt bij activiteiten in de buurt. Deze nieuwe functie is een uitdaging, omdat eerdere onderzoeken hebben laten zien dat verschillen tussen de eerstelijnszorg en de sport- en beweegsector de samenwerking tussen deze sectoren kan belemmeren. Een makelaar, zoals de BSC, lijkt veelbelovend in het bevorderen van intersectorale samenwerking. Maar naar ons weten zijn de werkzaamheden, de meerwaarde en uitdagingen van het werk van een makelaar nog maar weinig onderzocht. Veel onderzoeken richten zich op de positie van een makelaar in het netwerk en de impact van deze makelaar op de prestatie van het netwerk. Dit wordt vaak gemeten aan de hand van kwantitatieve uitkomstmaten. Het doel van deze thesis was om de makelaars rol van de BSC in het verbinden van de eerstelijnszorg en de sport- en beweegsector te exploreren. Een dergelijk inzicht is noodzakelijk, ten eerste omdat de buurtsportcoach functie nieuw en uniek is en daarom moet onderzocht worden of dit een geschikte beleidsstrategie is. Ten tweede, omdat intersectorale samenwerking tussen de eerstelijnszorg en de sport- en beweegsector een uitdaging is, zijn inzichten in de rol van de BSC en zijn impact relevant om deze verbinding te kunnen optimaliseren. Ten derde, draagt dit onderzoek bij aan het bevorderen van de theorie en praktijk rondom gezondheidsbevordering. Om de rol van de BSC en de impact van de BSC in het verbinden van de eerstelijnszorg met de sport- en beweegsector te exploreren zijn vier onderzoeksvragen geformuleerd:

1. Wat zijn de processen die bijdragen aan de verbinding tussen de eerstelijnszorg en de sport- en beweegsector?

2. Wat zijn de condities op nationaal en lokaal niveau die de BSC ondersteunen of belemmeren in het verbinden van de eerstelijnszorg met de sport- en beweegsector?

3. Wat is de impact van de BSC en wat is het gepercipieerde maatschappelijk rendement voor de gemeente, wijk en inwoners?

4. Welke lessen kunnen geleerd worden om de theorie en praktijk rondom gezondheidsbevordering te bevorderen?

Dit proefschrift beschrijft een meervoudig case studie design waarin 15 BSC'es uit negen gemeenten verspreidt over Nederland van 2014 tot het einde van 2016 zijn gevolgd in hun werkzaamheden. Overeenkomstig dit design, zijn perspectieven van verschillende stakeholders (beleidsmedewerkers, professionals, BSC'es) op verschillende niveaus (beleid en gemeente/wijk) door middel van verschillende methoden van dataverzameling (literatuuronderzoek, interviews, focusgroep gesprekken, document analyse, en vragenlijsten) onderzocht. Het betrekken van deze verschillende perspectieven en het gebruik maken van verschillende methoden van dataverzameling zorgt ervoor dat we een zo volledig mogelijk inzicht in de verbinding tussen de eerstelijnszorg en de sport- en beweegsector konden verkrijgen. Daarnaast hielp cross-case synthese, waarbij casussen met elkaar vergeleken worden, om te komen tot algemene conclusies ten aanzien van de verbinding tussen de eerstelijnszorg en de sport- en beweegsector. Aangezien BSC'es ook de taak hebben om beweging te stimuleren onder de doelgroep, wordt er ook een andere 
studie - die geen deel uit maakt van dit proefschrift - uitgevoerd. Deze studie exploreert de impact van de BSC op het stimuleren van beweging onder de doelgroep. Hoofdstuk 2 geeft meer gedetailleerde informatie over het ontwerp van deze studie en de methoden die zijn gebruikt.

Hoofdstuk 3 beschrijft ons systematisch literatuuronderzoek dat is uitgevoerd om een inzicht te krijgen in samenwerkingsinitiatieven tussen de eerstelijnszorg en de sport sector. Daarnaast had dit literatuuronderzoek ook als doel om belemmerende en bevorderende factoren te identificeren in deze initiatieven. Achtentwintig verschillende initiatieven tussen de eerstelijnszorg en sportsector zijn geïdentificeerd. In deze initiatieven werden twee aanpakken om sport en bewegen te stimuleren onderscheiden. Ten eerste, in de aanpak om patiënten uit de eerstelijnszorg te verwijzen naar lokale sport- en beweegfaciliteiten, werden drie vormen van samenwerking geïdentificeerd: doorverwijsschema, een multidisciplinair team van professionals uit de eerstelijnszorg met een connectie naar de sportsector, en een samenwerkingsverband tussen een gezondheidscentra en een beweegaanbieder. Ten tweede, in de aanpak om sporten- en bewegen te stimuleren in een wijk of gemeente, werd één vorm van samenwerking geïdentificeerd: een netwerk van verschillende partijen uit de gemeente/wijk met onder andere professionals uit de eerstelijnszorg en sportsector. De belemmerende en bevorderende factoren verschillende in de twee aanpakken om sport- en bewegen te bevorderen. In het doorverwijzen van patiënten naar sport- en beweegaanbod werden het gebrek aan medische kennis van sportprofessionals en het gebrek aan tijd van eerstelijnszorg professionals gezien als belemmerende factoren. In de netwerken die activiteiten organiseren om zo sport en bewegen te bevorderen onder de gemeenschap werden verschillende interesses en verschillende culturen gezien als belemmerende factoren.

De rol van de buurtsportcoach in het verbinden van de eerstelijnszorg met de sport- en beweegsector is onderzocht in hoofdstuk 4. De BSC'es zijn gedurende één jaar in drie interviewrondes geïnterviewd. Deze interviews hadden als doel om te identificeren hoe de BSC tegen hun rol in het verbinden van de eerstelijnszorg en sport- en beweegsector aan kijken, op welke wijze zij de verbinding tussen deze twee sectoren realiseren, en welke factoren zij als belemmerend of bevorderend ervaren in deze verbinding. De BSC kenden zichzelf drie rollen toe: 1) makelaar, 2) doorverwijzer, 3) organisator. Zij realiseerden twee vormen van samenwerking: 1) project basis en 2) doorverwijsschema. In hun werk in het verbinden van de beide sectoren ervaarden de BSC'es de volgende belemmerende factoren: gebrek aan tijd en kennis van professionals uit de eerstelijnszorg, eigen belang van professionals uit de eerstelijnszorg, gebrek aan geschikt sport- en beweegactiviteiten voor de doelgroep en gebrek aan geschikte sport professionals om te werken met deze doelgroep. Resultaten uit dit onderzoek laten zien dat de wijze waarop gemeente de BSC regeling hebben geïmplementeerd van invloed lijkt te zijn op het gemak waarmee de BSC samenwerking kan realiseren. BSC'es werkzaam voor een zorg of welzijn organisatie betrokken makkelijker professionals uit de eerstelijnszorg dan BSC'es werkzaam voor een sport organisatie of de sportafdeling van de gemeente. Daardoor konden zij meer invulling geven aan de doorverwijsrol en het begeleiden van patiënten uit de eerstelijnszorg naar sport- en beweegaanbod in de buurt. BSC'es met minder betrokkenheid van professionals uit de eerstelijnszorg vervulden vooral de rol als organisator in plaats van de doorverwijs rol. 
In hoofdstuk 5, zijn we nagegaan op welke wijze de BSC invulling geeft aan zijn rol in verloop van tijd. Daarnaast hebben we meer inzicht gekregen in de wijze waarop de BSC zijn rol als makelaar invult om zo een verbinding tussen beide sector te realiseren. Gedurende twee jaar zijn 13 BSC'es in meerdere interviewrondes geïnterviewd. Gedurende de jaren gaven alle BSC'es aan dat zij de makelaarsrol vervulden. Verschillen konden echter worden onderscheiden in de wijze waarop de BSC invulling gaf aan de makelaarsrol om de verbinding tussen de eerstelijnszorg en sport- en beweegsector te verbinden: 1)invulling geven aan de makelaarsrol door het verbinden van beide sectoren rondom de eigen activiteiten (doorverwijzen of het organiseren van activiteiten) en 2) het initiëren van samenwerking tussen beide sectoren waarna de BSC zich terug trekt uit de verbinding.

Het onderzoek dat wordt beschreven in hoofdstuk 6 bracht de percepties van eerstelijnszorg-, welzijn- en sportprofessionals ten aanzien van de rol van de BSC en hun ervaringen ten aanzien van de verbinding tussen de eerstelijnszorg en sport- en beweegsector in kaart. In totaal werden 9 focusgroep gesprekken met professionals uit het netwerk van de BSC uitgevoerd. Eerstelijnszorg-, welzijn en sport- en beweegprofessionals schreven drie rollen toe aan de BSC: 1) makelaarsrol, 2) doorverwijsrol, 3) facilitator. Geen grote verschillen konden ontdekt worden tussen de verschillende professionals en hun percepties ten aanzien van de rol van de BSC. De professionals vonden de rol van de BSC en de huidige verbinding tussen beide sectoren veelbelovend. Maar professionals ervaren factoren gerelateerd aan de eigen sector als belemmerend in de verbinding tussen beide sectoren. Zoals het gebrek aan tijd, kennis en geld van professionals uit de eerstelijnszorg en het gebrek aan geschikt sport- en beweegaanbod en instructeurs voor de doelgroep.

In hoofdstuk 7 hebben we de operationele context van de BSC uit 9 gemeenten beschreven. Om deze operationele context te kunnen beschrijven hebben we een nieuw theoretisch raamwerk ontwikkeld. De BSC is een nieuwe functie en een raamwerk die geschikt was voor het bestuderen van de context van de BSC was nog niet beschikbaar. Aan de hand van een literatuuronderzoek, diepte-interviews met professionals werkzaam op het terrein van publieke gezondheid, en een workshop tijdens het Nederlands Congres voor Volksgezondheid is het raamwerk ontwikkeld. Dit raamwerk bestaat uit vijf domeinen: beleid, organisatie, middelen, programma's en samenwerkingsverbanden. Informatie met betrekking tot deze vijf domeinen van het raamwerk werd verzameld aan de hand van een document analyse van huidige beleidsdocumenten, een vragenlijst en interviews met beleidsmedewerkers uit de negen gemeenten. De resultaten van dit onderzoek laten zien dat de mate waarin gemeenten werken volgens een integrale aanpak verschilt. Een integrale aanpak bestaat uit een integraal gezondheid- en sportbeleid in combinatie met de inbedding van dit beleid in samenwerkingsverbanden met zorg- en sportorganisaties op management niveau. Gemeenten met deze integrale aanpak hebben de BSC'es op een zodanige manier ingebed dat BSC'es werkzaam waren vanuit verschillende sectoren of onderdeel uit maakten van een samenwerkingsverband tussen professionals uit de eerstelijnszorg, welzijn en sporten beweegsector. In deze gemeenten werden ook andere initiatieven op het gebied van publieke gezondheid, zorg en sport en bewegen geïmplementeerd en voerden verschillende organisaties gezondheidsbevorderende- of sportstimuleringsprogramma's uit. In gemeenten die minder volgens deze integrale aanpak werkzaam zijn, was dit alles nauwelijks aanwezig en zijn BSC'es uit die gemeenten enkel ingebed in de sport- en beweegsector. Gezien de opdracht van de BSC denken wij dat deze integrale aanpak ondersteunend is voor het werk 
van de BSC, omdat het zichtbaar is in andere activiteiten van de gemeenten en dus ondersteunende condities creëert voor het werk van de BSC. Of deze integrale aanpak daadwerkelijk ondersteunend is aan het werk van de BSC moet verder onderzocht worden.

De studie in hoofdstuk 8 exploreerde de impact van de BSC in het verbinden van de eerstelijnszorg en de sport- en beweegsector. Daarnaast had deze studie ook als doel om te exploreren welke structurele inbedding van de BSC het meest kansrijk is in het bereiken van de gewenste uitkomsten. Een netwerkvragenlijst was gebruikt om inzicht te krijgen in het netwerk van de BSC en de rol van de professionals in de samenwerking tussen beide sectoren. In drie interview rondes, elk met een tijdspan van 6-12 maanden, werden deze netwerkvragenlijsten ingevuld. Resultaten van deze studie laten zien dat alle BSC'es een vergelijkbaar netwerk van professionals uit de eerstelijnszorg, welzijn en sport- en beweegsector hebben. Ook hebben zij allemaal een verbinding tussen beide sectoren gerealiseerd. Echter konden wel verschillende gevonden worden tussen de wijze waarop de BSC structureel ingebed was en de wijze waarop de verbinding werd vormgegeven. BSC'es werkzaam in gemeenten die de BSC'es structureel ingebed hadden op een integrale wijze (bij zowel zorg, welzijn als sportorganisaties, of in een samenwerkingsverband van zorg, sport en welzijnsprofessionals), werkten met name samen met professionals door professionals te ondersteunen met hun activiteiten en door een structureel doorverwijsschema te implementeren in de eerstelijnszorg. BSC'es werkzaam in gemeenten die de BSC'es structureel ingebed hebben in enkel de sport- en beweegsector, werkten vooral samen met professionals rondom eigen activiteiten als een manier om beweging te stimuleren onder de inwoners. Resultaten van deze studie laten daarom zien dat BSC'es structureel inbedden op een integrale wijze het meest kansrijk lijkt te zijn voor het bereiken van de gewenste uitkomsten.

In hoofdstuk 9 zijn de belangrijkste bevindingen samengevat en is hierop gereflecteerd. Daarnaast hebben we gereflecteerd op de gebruikte theorie, modellen en tools in deze studie en zijn er lessen geformuleerd voor zowel de theorie als de praktijk rondom gezondheidsbevordering.

Het doel van dit proefschrift was om de rol van de BSC en zijn impact in het verbinden van de eerstelijnszorg en sport- en beweegsector te exploreren. De resultaten van dit proefschrift resulteren in drie belangrijke inzichten. Ten eerste, de structuur van de verbinding tussen de eerstelijnszorg en de sport- en beweegsector gerealiseerd door de BSC kan gekarakteriseerd worden als een ketenaanpak. Ten tweede, factoren gerelateerd aan de beide sectoren belemmeren op dit moment de verbinding. Ten derde, de BSC structureel inbedden op een integrale wijze blijkt een belangrijke ondersteunende voorwaarde te zijn voor een verbinding tussen de eerstelijnszorg en sport- en beweegsector.

De resultaten tezamen laten zien dat de BSC functie veelbelovend is in het verbinden van de eerstelijnszorg en de sport- en beweegsector. Echter, om een succes te maken van de verbinding tussen beide sectoren zijn veranderingen op zowel beleids- als gemeente/ wijkniveau noodzakelijk. Bijvoorbeeld lokaal beleid zou een meer integrale aanpak moeten aannemen en een gezondheidsbevorderende blik zou meer gestimuleerd moeten worden onder professionals uit de eerstelijnszorg. Toekomstig onderzoek moet zich richten op de impact van de BSC op het stimuleren van beweging bij patiënten uit de eerstelijnszorg en de ontwikkeling van de rol van BSC in het verbinden van beide sectoren in verloop van tijd. 


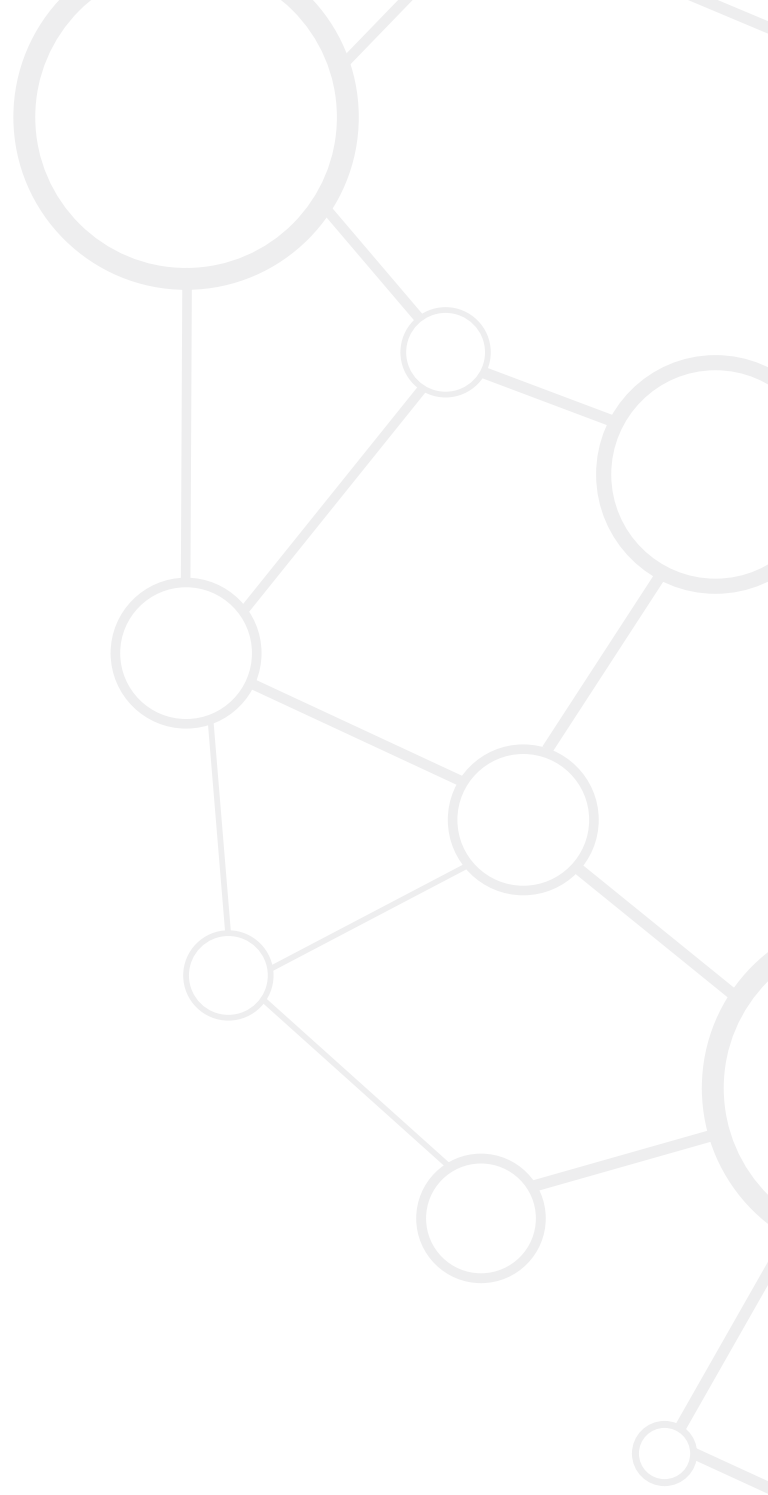


Dankwoord 
Aangezien het dankwoord een van de meest gelezen hoofdstukken van het proefschrift is, zou het goed zijn hier nogmaals de belangrijkste onderzoeksresultaten te bespreken. Maar na 257 pagina's heb ik volgens mij wel genoeg gezegd over de buurtsportcoach en het verbinden van de eerstelijnszorg en de sport- en beweegsector. Met het schrijven van dit dankwoord komt er dan ook een einde aan mijn promotieonderzoek. Een onderzoek van 4 jaar waar nogal wat mensen aan hebben meegewerkt. Het bedanken van die mensen is dan ook wel op zijn plaats.

Allereerst wil ik graag de buurtsportcoaches, die we gedurende drie jaar gevolgd hebben in hun werkzaamheden, voor hun inzet en betrokkenheid bij dit onderzoek bedanken. Ik vind het leuk dat ik drie jaar lang een kijkje in jullie keuken mocht nemen. Het uitvoeren van al die interviews door de jaren heen was een van de leukste onderdelen van dit onderzoek. Jullie zijn allemaal goed op weg om de eerstelijnszorg en sport- en beweegsector met elkaar te verbinden. Veel succes en ik ben benieuwd hoe de verbinding er over een aantal jaar uit ziet!

Ook dank aan de betrokken beleidsmedewerkers uit de gemeenten Den Bosch, Nijmegen, Utrecht, Den Haag, Franeker, Emmen, Heusden, Hoogeveen en Zwolle. Bedankt dat wij het onderzoek in jullie gemeenten mochten uitvoeren en dank voor jullie bijdrage aan dit onderzoek.

Daarnaast wil ik ook graag mijn begeleiders bedanken voor de begeleiding gedurende dit onderzoek. Maria bedankt voor het vertrouwen dat je altijd hebt gehad in de wijze waarop ik mijn onderzoek wilde vormgeven. Dat werkt heel prettig. Daarnaast natuurlijk ook bedankt voor alle nuttige feedback, opmerkingen en vragen. Annemarie, bedankt dat je altijd de tijd hebt genomen om al mijn stukken te lezen en van feedback te voorzien. Ik heb veel geleerd over het schrijven en structureren van artikelen. Gerard, bedankt voor o.a. al de praktische kennis die jij mee nam in dit onderzoek. Heel interessant om te horen, maar ook heel bruikbaar om de resultaten in een breder perspectief te kunnen plaatsen.

Ook natuurlijk dank aan Eva. Samen zijn we in 2013 begonnen aan dit grote project. Ik vond het prettig om met je samen te werken en het maakte de reisjes naar al die gemeenten en bijeenkomsten een stuk gezelliger. Succes met de afronding van jouw onderzoek!

Bij dit project waren ook KNGF, ROS, VSG en Kenniscentrum Sport betrokken. Sjoerd, Henk, Marjon en Liesbeth bedankt voor jullie bijdrage aan dit onderzoek. Jullie zorgen ervoor dat de resultaten van dit onderzoek ook vertaald worden naar bruikbare informatie en tools voor de buurtsportcoach en andere betrokkenen. Een belangrijke taak dus! Daarnaast natuurlijk ook bedankt voor het meedenken tijdens het gehele project.

Tijdens dit onderzoek heb ik het geluk gehad 4 studenten van de opleiding Health and Society te mogen begeleiden met hun master thesis. Karlijn, Annemiek, Eline en Noor, ontzettend bedankt voor jullie harde werk, frisse en kritische blik en de gezelligheid tijdens het reizen naar alle locaties voor de interviews en focusgroep gesprekken. Al jullie harde werk heeft een plekje in dit proefschrift gekregen.

Dank aan mijn opponenten Edith Feskens, Janneke Harting, Mariken Leurs en Hugo van der Poel voor het zitting nemen in de leescommissie. 
Graag wil ik ook mijn collega's van de afdeling Health and Society bedanken. Bedankt voor jullie interesse in het onderzoek, de nuttige suggesties, maar ook voor de gezellige lunchwandelingen. Speciale dank aan Sabina en Niels. Vier jaar lang zijn we elkaars kamergenoten geweest. Eerst in kamer 2053, later in horrorkamer 2068. Heel fijn om met jullie te kunnen sparren over het doen van onderzoek, maar vooral ook het kletsen over van alles en nog wat. Heel veel succes met de afronding van jullie projecten!

Ook dank aan mijn collega's van het Centrum voor Gezond Leven voor de belangstelling in mijn promotietraject.

Als laatste wil ik graag mijn familie en vrienden bedanken. Bedankt voor de nuchtere kijk op het onderzoek, alle "goede" suggesties voor de kaft en stellingen en jullie luisterend oor als het even iets minder liep. Maar vooral bedankt voor alle gezelligheid buiten dit promotieonderzoek om. Speciale dank voor mama en papa, omdat jullie altijd voor ons klaar staan. Papa, jammer dat het journalclubje niet van de grond is gekomen!

Ilse en Maaike, super leuk dat jullie als paranimfen samen met mij op het podium staan! Ik kan mij geen betere paranimfen wensen en ik hoop dat de afkorting $\operatorname{Dr}(\mathrm{rrrr})$ geen problemen gaat opleveren ;-)

Harmen, de verminderde reistijd was natuurlijk een goede bonus maar ik ben vooral blij dat we het zo leuk hebben met elkaar. Dank dat je altijd luistert als ik weer eens zichtbare of onzichtbare Canadese beren op de weg zie. 


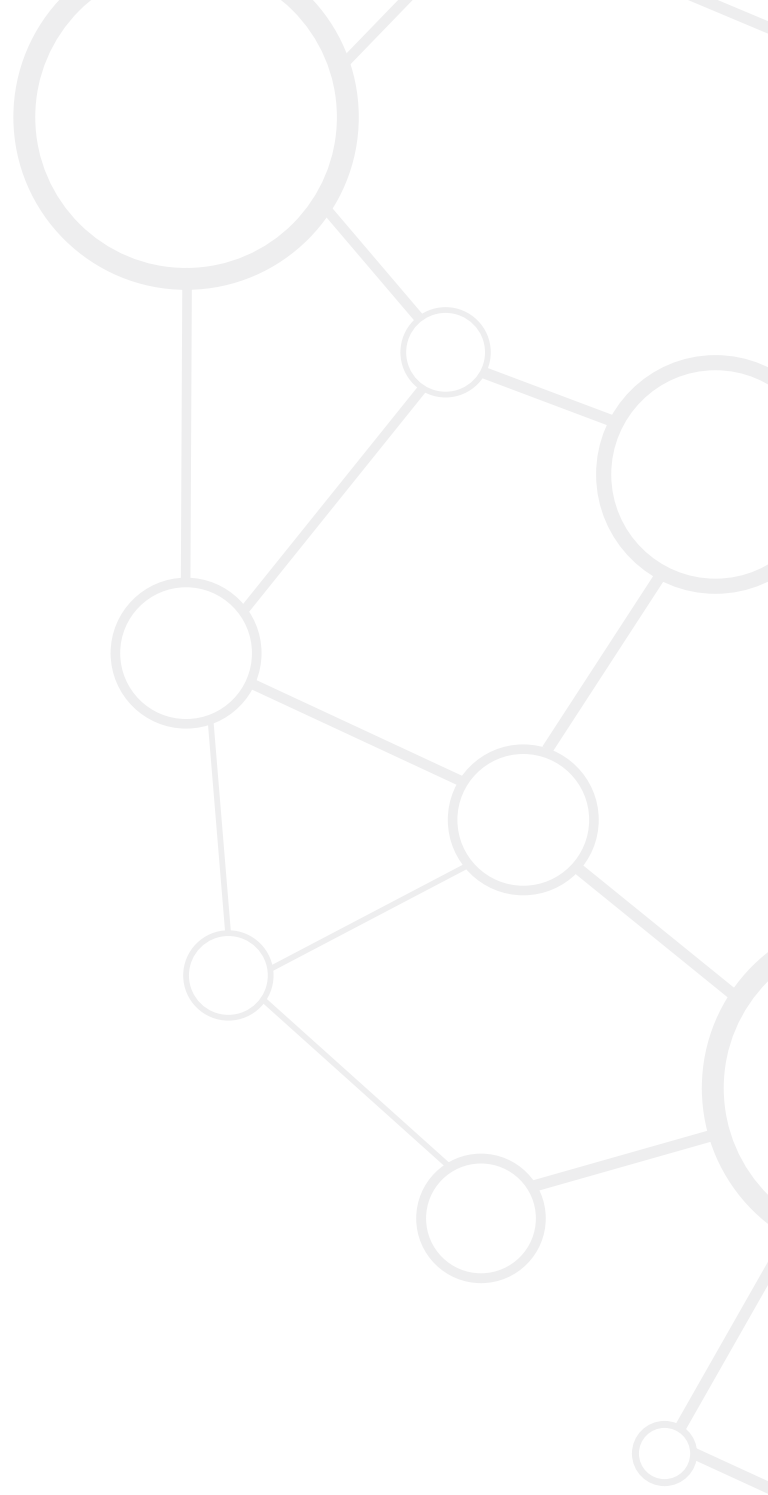


About the author 
Karlijn Leenaars (Tilburg, The Netherlands, June 30th 1988) obtained in 2009 a bachelor degree in health promotion at the HAN University of Applied Science. From 2009 till 2012 she obtained her bachelor' and master' degree in Health Sciences (specialised in Prevention and Public Health) at the VU University in Amsterdam. From 2012 till 2013 she worked as a junior researcher at the Department of Public Health of the Academic Medical Centre in Amsterdam. In September 2013, she started to work on her PhD thesis at Wageningen University, department Health and Society, which resulted in this thesis. Currently, she is working as an advisor at Centre of Healthy Living at The Dutch National Institute for Public Health and the Environment (RIVM). 
Karlijn Leenaars

Wageningen School of Social Sciences (WASS)

Completed Training and Supervision Plan

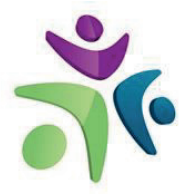

Wageningen School

of Social Sciences

\begin{tabular}{l} 
Name of the learning activity \\
\hline A) Project related competences \\
ETC-PHHP Summer School Health Promotion \\
'The Care Sport Connector in the Netherlands \\
'Verbinden zorg, sport en bewegen'.
\end{tabular}

Department/Institute

Year

ECTS*

'Randvoorwaarden voor inzet en ondersteuning van de buurtsportcoach in landelijk en gemeentelijk beleid: een beleidsanalyse'.

'Het in kaart brengen van gemeentelijke capaciteit voor publieke gezondheid in Nederland'.

'Verbinden zorg, sport en bewegen'

ETC Summer Courses

2014

Tafisha, Enschede

Knowledge day 'Sport and

2013

Exercise in the Neighbourhood'.

NCVGZ, Rotterdam

2013

2014

2015

Workshop, NCVGZ, Rotterdam

Knowledge day 'Sport and

Exercise in the Neighbourhood', Kenniscentrum Sport and Radboudumc

'Verbinden van de eerstelijnszorg en sportsector'

Workshop, Network meetings for CSCs (VSG, Kenniscentrum Sport, NOC*NSF, Radboudumc)

Workshop, NCVGZ, Rotterdam

'Verbinden zorg, sport en bewegen' in collaboration withRadboudumc.

'Professionals' perceptions towards the role of the

HEPA, Belfast

Care Sport Connector and the connection

between the primary care and the PA sector in the Netherlands'

'De impact van de buurtsportcoach in het verbinden van zorg, sport en bewegen'

'Verbinden zorg, sport en bewegen'

'Verbinden zorg, sport en bewegen'

\section{B) General research related competences}

Introduction course

2013

University of Geneva

2016

WASS

2016

WASS

2014

Keynote presentation, DSO

The power of sport, Hogeschool

Masterclass on the conceptual foundations of public governance

Governance theories and governance

\section{C) Career related competences/personal development}

Education and supervision, lecture Health

Wageningen University, HSO

supervision of Bsc and Msc students

Wageningen into Languages

2015 2

\begin{tabular}{ll}
\hline Total (30 - 45 ECTS) & 2015 \\
\hline
\end{tabular}

*One credit according to ECTS is on average equivalent to 28 hours of study load 
The research described in this thesis was financially supported by ZonMw, the Netherlands Organisation for Health Research and Development (project number: 525001002). Financial support from Wageningen University for printing this thesis is gratefully acknowledged.

Cover design: Proefschriftmaken.nl || Uitgeverij BOXPress

Printed and Lay out by: Proefschriftmaken.nl || UitgeverijBOXPress

Published by: Uitgeverij BOXPress, Vianen. 

<smiles>CCC1OC2OOC2C1C</smiles> 


\section{Propositions}

1. The Care Sport Connector is indispensable for the connection between the primary care and the physical activity sector, and therefore the Care Sport Connectors' funding should be continued.

(this thesis)

2. In the connection between the primary care and the physical activity sector, sport clubs are an unfit partner.

(this thesis)

3. Health promotion theory is inadequate studying health promotion programs targeting more than only behavioural outcomes.

4. The value of qualitative research is still underestimated.

5. The program 'Sport en Bewegen in de Buurt' is the best ever physical activity promotion program implemented in the Netherlands.

6. Scientific journals should adopt a uniform format for submitting a manuscript.

Propositions belonging to the this, entitled

'The Care Sport Connector in the Netherlands'

Karlijn Leenaars

Wageningen, 22 September 2017. 